\title{
ESTUDO DE FISSURAÇÃO EM CONCRETO ARMADO COM FIBRAS E ARMADURA CONVENCIONAL
}

\author{
Ewang Bruce Ekane
}

\begin{abstract}
Dissertação apresentada à Escola de Engenharia de São Carlos da Universidade de São Paulo, como parte dos requisitos para obtenção do título de Mestre em Engenharia de Estruturas
\end{abstract}

ORIENTADOR: Prof. Dr. Mounir Khalil EI Debs 


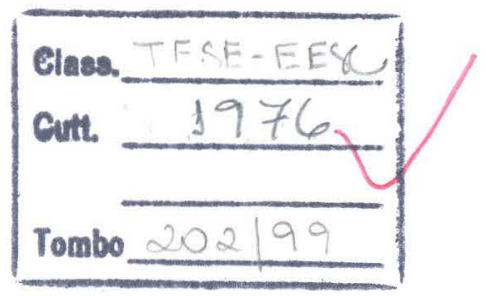

Ficha catalográfica preparada pela Seção de Tratamento da Informação do Serviço de Biblioteca - EESC/USP

Ewang, Bruce Ekane

Estudo de fissuração em concreto armado com fibras e armadura convencional / Ewang Bruce Ekane. -- São Carlos, 1999.

Dissertação (Mestrado) - Escola de Engenharia de São Carlos-Universidade de São Paulo, 1999.

Área: Engenharia de Estruturas.

orientador: Prof. Dr. Mounir Khalil El Debs.

1. Abertura de fissura. 2. Fissuração (fratura).

3. Concreto armado com fibras. 4. Espaçamento de fissura.

5. Modelo micro-mecânico. 6. Modelo macro-mecânica.

7. Relação tensão-abertura de fissura. 8. Ensaios de tração. 9. Micro-mecanismo. I. Ekane, Ewang Bruce. II. Título. 


\section{FOLHA DE APROVACÃO}

Candidato: Engenheiro EWANG BRUCE EKANE

Dissertação defendida e aprovada em 30-04-1999

pela Comissão Julgadora:

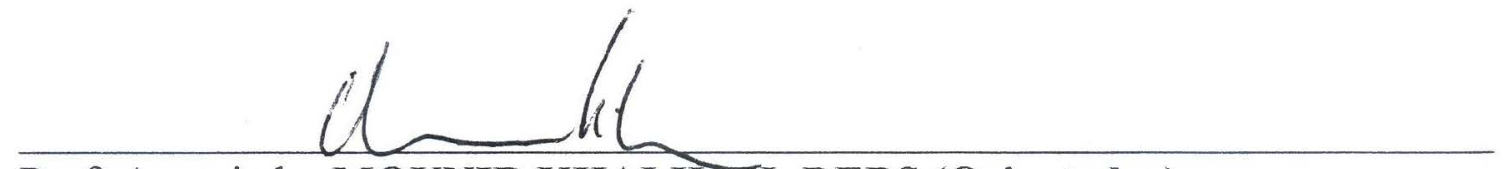

Prof. Associado MOUNIR KHALIL EL DEBS (Orientador)

(Escola de Engenharia de São Carlos - Universidade de São Paulo)

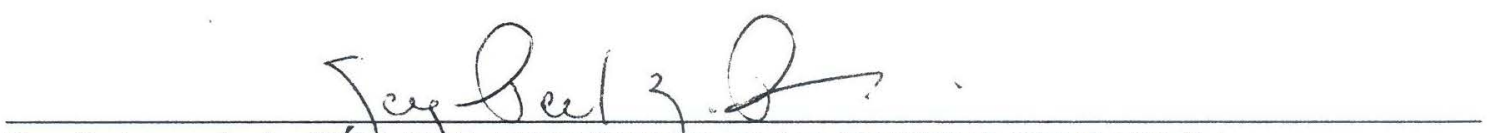

Prof. Associado SÉRGIO PERSIVAL BARONCINI PROENÇA

(Escola de Engenharia de São Carlos - Universidade de São Paulo)
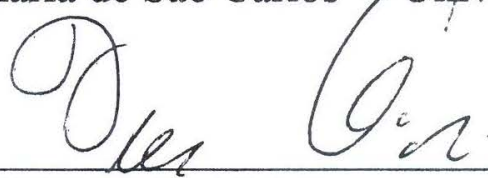

Prof. Doutor WALTER LIBARDI

(Universidade Federal de São Carlos - UFSCar)

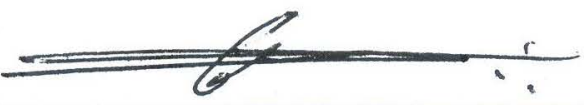

Prof. Titular CARLITO CALIL JUNIOR

Coordenador da Área de Engenharia de Estruturas

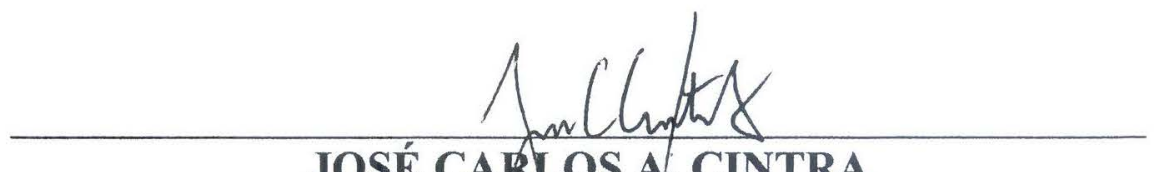

JOSÉ CARLOS A. CINTRA

Presidente da Comissâe de Pós-Graduação da EESC 
"A razão pode sonhar o que sonhos não podem raciocinar"

Aos meus Pais e Avós, que não viveram suficiente para ver este trabalho. Para Ekane Senze e Randhy McEkane, filhos eternos. 


\section{Agradecimentos}

Ao Professor Mournir Khalil El Debs, pela sua paciência, e dedicação dentro e fora da amplitude de orientação, e pela maneira com que orientou esta pesquisa, tornando-o agradável, e despertou em me as chamas do gosto pelo tema.

Aos meus pais pelo esforços na minha criação, pelo carinho e amor, e pelo belo mundo.

À minha tia, pela contribuição na minha educação $e$ formação da minha personalidade, à qual agradeço também aos meus irmãos.

Aos meus amigos no Brasil e no exterior que foram meus aliados durante todos estes anos, e dos quais aprendi muitos das minhas lições de vida.

Aos meus professores no Brasil e no exterior, que minuciosamente me forneceram as ferramentas corretas com as quais venci as grandes batalhas mundanas.

À Dna. Therezinha Horta de Jesus e sua família, que me acolheu se tornou minha familia brasileira. 
LISTA DE FIGURAS

$\begin{array}{ll}\text { LISTA DE TABELAS vi } & \text { vi }\end{array}$

LISTA DE ABREVIAÇÕES E SIGLAS vii

$\begin{array}{lll}\text { RESUMO viii } & \text { vil }\end{array}$

$\begin{array}{ll}\text { ABSTRACT } & \text { ix }\end{array}$

CAPÍTULO 1: INTRODUÇÃO 1

1.1 GENERALIDADES 1

1.2 FORMULAÇÃO DA SITUAÇÃO-PROBLEMA 3

$\begin{array}{lll}1.3 & \text { OBJETIVOS }\end{array}$

1.4 LIMITAÇÃO DE ABORDAGEM DO PROBLEMA 7

1.5 IMPORTÂNCIA E JUSTIFICATIVAS DO ESTUDO 8

1.6 REFERENCIAL TEÓRICO-CONCEITUAL 12

$\begin{array}{lll}1.7 & \text { METODOLOGIA } & 13\end{array}$ 
Sumário

1.8 APRESENTAÇÃO DA DISSERTAÇÃO

CAPÍTULO 2: COMPORTAMENTO DO CONCRETO SIMPLES E CAF NA TRAÇÃO

$\begin{array}{lll}2.1 & 17\end{array}$

2.2 CURVAS DE TENSÃO-DESLOCAMENTO 23

2.2.1 Materiais Cimentíceos 23

2.2.2 Compósitos Cimentíceos Armados com Fibras 30

2.3 A CURVA TENSÃO-ABERTURA DE FISSURA EM CAF 35

2.3.1 Amolecimento de Tensão 35

2.3.2 Processos de Fratura e Mecanismos de Tenacidade em CAF 39

2.3.3 Modelagem Analítica da Fratura 42

2.3.4 Fatores que Influenciam a Curva Tensão-Abertura de Fissura 44

\section{CAPÍTULO 3: MODELAGEM DE CONCRETO ARMADO} COM FIBRAS $\quad 52$

3.1 PRELIMINARES 52

3.2 MÉTODO DE MATERIAL COMPÓSITO 53

3.2.1 Comportamento de Compósitos de Baixas Taxas de Fibras 54

3.2.1.1 Fase elástica 54

3.2.1.2 Fase pós-fissuração $\quad 57$

3.2.2 Limitação do Modelo ACK e Taxa Crítica de Fibras 59

3.3 MECÂNICA DE FRATURA 64

3.3.1 Caracterização Micro-Mecânica de Concreto Armado com Fibras

3.3.2 Caracterização Analítica da Matriz ou Efeito de Travejamento do Agregado

3.3.3. Contribuição das fibras 67

3.3.3.1 Modelo de travejamento das fibras. $\quad 68$

3.3.3.2 Efeito de orientação das fibras

3.3.3.3 Efeito do módulo de elasticidade da fibra 75

3.3.3.4 Consideração de esmagamento do concreto 78

3.3.3.5 Consideração da ruptura da fibra.

3.3.3.6 Modelo de travejamento do compósito 87 
Sumário

3.3.4 Interação Fibra-Matriz 93

3.3.4.1 Efeito Cook-Gordon 99

3.3.5 Efeito da Pré-tração 102

CAPÍTULO 4: PREVISÃO DE ABERTURA E ESPAÇAMENTO DE FISSURA EM CONCRETO ARMADO COM FIBRAS E ARMADURA CONVENCIONAL

4.1 PRELIMINARES

105

4.2 TEORIA CLÁSSICA DE FISSURAÇÃO 106

4.2.1 Considerações Básicas da Teoria de Fissuração 106

4.2.2 Previsão das Deformações $\quad 115$

4.2.3 Desenvolvimento dos Procedimentos da Norma Brasileira 116

4.3 MODELO DE AL-TAAN E AL-FEEL 119

4.3.1 Modelo Geométrico 119

4.3.2 Modelo Mecânico 122

4.3.2.1 Aderência CAF/armadura $\quad 125$

4.3.2.2 Interação fibra/matriz 126

4.3.2.3 Deformação do concreto $\quad 127$

4.3.3 Abertura Máxima de Fissura 131

$\begin{array}{lll}4.4 & \text { MODELO DE STANG } & 131\end{array}$

4.4.1 Modelo Geométrico 131

4.4.2 Modelo Analítico 134

4.4.2.1 Soluções 136

4.4.3 Calibração do Modelo 140

4.4.4 Otimização do Modelo 141

4.4.5 Implementação do modelo de Stang e Aarre 142

CAPÍTULO 5: PROGRAMA EXPERIMENTAL E RESULTADOS OBTIDOS

$\begin{array}{lll}5.1 & \text { PRELIMINARES } & 144\end{array}$

$\begin{array}{lll} & 145\end{array}$

5.2.1 Variáveis Experimentais 145

5.2.2 Geometria de Corpo de Prova 146

5.2.3 Materiais 147 
Sumário

$\begin{array}{lll}\text { 5.3 PREPARO DAS PLACAS } & 147\end{array}$

5.3.1 Preparo e Montagem das Armaduras 147

5.3.2 Mistura 149

5.3.3 Moldagem, Adensamento e Cura 151

5.3.4 Ensaio das Placas 154

5.3.5 Resultados Obtidos 156

5.3.5.1 Efeitos da taxa de fibra sobre abertura de fissura 157

5.3.5.2 Efeito de fibras sobre o tipo de armadura 159

5.3.6 Modo de Fissuração 160

5.4 ANALISE TEÓRICA DOS RESULTADOS 162

5.4.1 Espaçamento de Fissura 163

5.4.2 Carga de Fissuração 164

5.4.3 Curvas Força-Abertura de Fissura 164

CAPÍTULO 6: CONSIDERAÇÕES FINAIS E CONCLUSÕES 166

CAPÍTULO 7: APÊNDICE

APÊNDICE I: DEDUÇÃO DA RELAÇÃO TENSÃO-ABERTURA DE FISSURA PRÉ-PICO DO COMPÓSITO 171

APÊNDICE Ir: DEDUÇÃO DA RELAÇÃO TENSÃO-ABERTURA DE FISSURA PÓS-PICO DO COMPÓSITO 175

APÊNDICE Iı: DEDUÇÃO DA RELAÇÃO TENSÃO-ABERTURA DE FISSURA SEM CONSIDERAÇÃO DA RUPTURA DAS FIBRAS 


\section{LISTA DE FIGURAS}

Figura. 1.1-Aplicações de fibras em matrizes cimentícias

Figura. 1.2-Aberturas de fissura calculadas empregando várias normas para uma laje

Figura. 2.1-Modo de ruptura em (a) materiais elastoplásticos, e (b) compósitos cimentíceos

Figura. 2.2-Aspectos principais que distinguem a fratura em (a) material elástico linear, (b) material dúctil, e (c) material quase-frágil. L se refere a região elástico linear, $\mathrm{N}$ à zona não linear, e F à zona de processo de fratura (Segundo ACI Report 446.1 R.91 apud KARIHALOO, 1995)

Figura. 2.3—Representação esquemática do desenvolvimento da zona de processo de fratura: (a) microfissuração na vizinhança do agregado devido à presença de uma macrofissura, (b) perda de aderência e microfissuração, (c) coalescência da fissuração proveniente da perda de aderência com a macrofissura, e (d) travejamento de fissura, perda de aderência, desvio de fissura, e microfissuração (Segundo KARIHALOO, 1995)

Figura. 2.4-A curva esquemática tensão-deslocamento, $\sigma-\delta$, de um material cimentíceo (Segundo KARIHALOO, 1995).

Figura. 2.5-Componentes dos deslocamentos para a transformação da curva tensão-deslocamento, $\sigma-\delta$, para a curva tensão-abertura de fissura, $\sigma-\delta_{t}$

Figura. 2.6-Curva esquemática de tensão-deslocamento, $\sigma-\delta$, de um compósito Tipo I que exibe a fissuração múltipla (Segundo COTTERELL E MAI, 1996).

Figura. 2.7-Zona de Processo (ZPF) e de Travejamento (ZTF) de fratura em um elemento entalhado de um compósito Tipo II (Segundo COTTERELL E MAI, 1996) 
Figura. 2.8 - Curva esquemática de tensão-deslocamento, de um compósito Tipo IIA armado com fibras compridas (Segundo COTTERELL E MAI, 1996).

Figura. 2.9-Curva esquemática de tensão-deslocamento, $\sigma-\delta$, de um compósito Tipo IIB com fibras curtas (Segundo COTTERELL E MAI, 1996).

Figura. 2.10-Curva tensão de travejamento-abertura de fissura $\sigma-\delta_{t}$, (Segundo LI ET AL., 1994).

Figura. 2.11-Modelo de fissura para compósitos CCAF mostrando (a) zona de fratura, e (b) possível distribuição de tensão (Segundo VIASALVANICH E NAAMAN, 1983)

Figura. 2.12-Possíveis mecanismos de tenacidade num CAF (Segundo LI E MAALEJ, 1996)

Figura. 2.13 — Deslocamentos na zona de processo onde ocorrem instabilidade (Segundo HILLERBORG, 1989)

Figura. 2.14 - Influência da insuficiência da rigidez por rotação do aparelho de ensaio (Segundo HILLERBORG, 1989)

Figura. 3.1-Elemento de compósito submetido à tensão de tração (Segundo LIM ET AL., 1987)

Figura. 3.2-Condição de fissuração múltipla para compósitos de fibra dúctil/matriz (Segundo LI E WU, 1992 apud Aveston et al., 1971)

Figura. 3.3-Esquema de perda de aderência, escorregamento e arrancamento.

(a) Modelo cilíndrico AxIsimétrico, (b) Tensões axiais na fibra e matriz e a tensão de cisalhamento na interface (Segundo BAO E SONG, 1993).

Figura. 3.4-Esquema de perda de aderência (a) e arrancamento (b) para o cálculo da tensão de travejamento (Segundo LIN E LI, 1997) 70

Figura. 3.5-Uma fibra atravessando a fissura (Segundo LI ET AL., 1991) 73

Figura. 3.6-Arrancamento de uma fibra com orientação $\Phi$ (Segundo LI ET AL., 1991) 
Figura. 3.7-Arrancamento de fibra com: (a) comprimento livre da fibra e portanto fibra Inicialmente fletida; (b) fibra inicialmente reta (Segundo LEUNG E YBANEZ, 1997)

Figura. 3.8 - Deformação da fibra durante o arrancamento: (a) e (b) para uma fibra inicialmente fletida; (c) e (d) para uma fibra inicialmente reta (Segundo LEUNG E YBANEZ, 1997)

Figura. 3.9-Definição dos parâmetros para o novo modelo de arrancamento da fibra (Segundo LEUNG E YBANEZ, 1997)

Figura. 3.10 — Espaço de ruptura da fibra (Segundo MAALEJ ET AL., 1995)

Figura. 3.11 - O mecanismo de Cook-Gordon num compósito com interface fraca: o campo de tensão a frente da ponta de uma fissura (Segundo BENTUR E MINDESS 1990 apud COOK E GORDON, 1964)

Figura. 3.12-O Efeito Cook-Gordon (a) induz a separação da fibra-matriz devido a tensão de tração na direção horizontal associada com o campo elástico da ponta de fissura de uma fissura que se aproxima, e (b) resulta em uma abertura adicional devido à deformação elástica de um segmento da fibra mais associado à perda de aderência na interface (Segundo LI ET AL., 1993)

Figura. 4.1—As condições na superfície de um elemento de concreto armado tracionado durante o desenvolvimento da fissuração (Segundo BEEBY, 1979)

Figura. 4.2-Mecanismo de fissuração, "sem escorregamento": relação entre o cobrimento, c, e $\mathrm{s}_{\mathrm{o}}$ (Segundo BEEBY, 1979)

Figura. 4.3 - Componentes de abertura de fissura (Segundo BEEBY, 1979).

Figura. 4.4—Elemento de compósito sob tração (Segundo AL-TAAN E AL-FEEL, 1989)

Figura. 4.5-Modelo geométrico mostrando as tensões nas seções 1-1 e 2-2 e a distribuição de aderência (Segundo AL-TAAN E

AL-FEEL, 1989)

Figura. 4.6-Suposta distribuição de tensão para um elemento tracionado (Segundo AL-TAAN E AL-FEEL, 1989) 
Figura. 4.7-Modelo geométrico empregado no modelo de fissura estrutural (Segundo STANG ET AL., 1995)

Figura. 4.8-Elemento de Volume Representativo (EVR)

Figura. 5.1—Geometria do corpo de prova e disposição da armadura

Figura. 5.2-Esquema da geometria e preparo da armadura de fio (a) visão geral, note que os pontos de fixação foram defasados entre si para evitar um plano preferencial de fissuração, e (b) detalhamento da extremidade alargada

Figura. 5.3 - Esquema de montagem das armaduras na forma (a) forma com armadura de fio montada, e (b) forma com armadura de tela soldada

Figura. 5.4—Processos de mistura: (a) mistura de fibras na argamassa, (b) verificação da consistência da mistura

Figura. 5.5—Preenchimento e vibração da forma

Figura. 5.6-Moldagem dos corpos de prova: (a) preenchimento da forma, (b) compactação

Figura. 5.7 - Moldagem dos corpos de prova: (a) acabamento do corpo do prova (b) visãogeral dos corpos de prova moldados

Figura. 5.8 - Montagem do sistema garra/placa: (a) divisão da placa em regiões e colocação de entalhe, (b) colocação de massa colante de epóxi, e (c) montagem da garra

Figura. 5.9-Esquema de ensaio: (a) Montagem do sistema garra/placa no pórtico e instrumentação, e (b) ensaio de placa, mostrando sistema hidráulico

Figura. 5.10 - Esquema de acompanhamento da fissuração: (a) Detalhe de uma fissura característica marcada $\mathrm{X}$ em tinta preta na região designada 2A. O número 2 representa o lado 2, e a letra $\mathrm{A}$, a região. Note que ocorreu uma ruptura no entalhe, e (b) Visão geral de uma peça rompida mostrando as fissuras características e as três regiões.

Figura. 5.11 - Curvas de tenção-abertura média de fissura

Figura. 5.12-Curva de taxa de fibra-abertura média de fissura 
Figura. 5.13—Modo de fissuração da série N-T; P0,5-T; e P1-T 160

Figura. 5.14—Modo de fissuração da série N-T; A1-T; A2-T; e A2-I 160

Figura. 5.15- Modo de fissuração da série N-T; P0,5-T; e P1-T; A1-T; e A2-T 161

Figura. 5.16 — Modo de fissuração da série A2-I; e A1-I 161

Figura. 5.17-Curvas de força-abertura de fissura teóricas e experimentais 165 


\section{LISTA DE TABELAS}

TABELA 4.1-Valores de $\mathrm{K}_{1}$ e $\mathrm{K}_{2}$ (Segundo BEEBY, 1979) 114

$\begin{array}{ll}\text { TABELA 5.1—Variáveis experimentais } & 146\end{array}$

TABELA 5.2—Características geométricas e mecânicas das armaduras 147

$\begin{array}{ll}\text { TABELA 5.3—Propriedades físicas e mecânicas das fibras } & 147\end{array}$

$\begin{array}{ll}\text { TABELA 5.4—Composição das misturas } & 151\end{array}$

TABELA 5.5—Resistência à compressão simples do compósito 153

TABELA 5.6—Parâmetros micromecânicos 163

TABELA 5.7-Espaçamento de fissura prevista pelo modelo e resultados experimentais $(\mathrm{em} \mathrm{cm})$

TABELA 5.8 - Carga de fissuração prevista pelo modelo e resultados experimentais $(\mathrm{em} \mathrm{kN})$ 


\section{LISTA DE ABREVIAÇÕES E SIGLAS}

CAR — Concreto de Alta Resistência

CAF-Concreto Armado com Fibras

ZPF-Zona de Processo de Fratura

ZTF-Zona de Travejamento de Fissura

ASTM—American Society for Testing Material

LVDT_Linear-Variable Differencial Transducer

CTOD_Crack-Tip Opening Displacement

COD—Crack Opening Displacement

BS-British Standard

ABNT_Associação Brasileira de Normas Técnicas

NBR-Norma Brasileira

MDC—Mecânica de Dano do Contínuo

EVR-Elemento de Volume Representativo

TDC_Teoria de Defasagem de Cisalhamento

ACK—Aveston, Cooper, e Kelly

CEB - Comité Européenne du Béton

FIP_Federation International de la Précontrainte

PVA—Polivinylalcool

PP_Polipropileno

IBTS - Instituto Brasileiro de Tela Soldada 


\section{RESUMO}

Devido à fragilidade do concreto, o controle e combate da fissuração são de importância fundamental em estruturas de concreto armado. Uma maneira de melhorar as propriedades do concreto à tração é pelo emprego de fibras. A presente pesquisa é uma tentativa de fornecer diretrizes para o dimensionamento de estruturas de concreto armado com fibras, e armadura convencional sob condições de serviço. Apresenta-se inicialmente, um estudo do comportamento do material à tração. Um modelo probabilístico/micro-mecânico fundamentado na mecânica de fratura, e capaz de prever o comportamento pós-fissuração do compósito é apresentado. O modelo prevê a relação tensão-abertura de fissura do compósito levando em conta os seguintes micro-mecanismos: travejamento de agregado e fibras, a ruptura das fibras, os efeitos de: atrito local (snubbing effect), esmagamento da matriz, Cook-Gordon, e da pré-tração das fibras. Em nível estrutural, dois modelos macro-mecânicos são apresentados. O primeiro modelo tem premissa na teoria clássica de fissura, e o segundo na mecânica de dado. O primeiro modelo é ajustado para aplicação na previsão de espaçamento e aberturas de fissura em estruturas de concreto armado com fibras discretas e aleatoriamente dispostas. É demostrado que o modelo micro-mecânico pode alimentar perfeitamente o modelo macro-mecânico. Ensaios de tração com elementos de placas de argamassa com fibras armada com tela ou fios foram realizados. Os resultados teóricos previstos pelo modelo foram comparados com os obtidos do programa experimental, e mostram uma boa concordância, comprovando a validade do modelo apresentado.

Palavras chave: Abertura de fissura, fissuração (fratura), concreto armado com fibras, espaçamento de fissura, modelo micro-mecânico, modelo macro-mecânico, relação tensão-abertura de fissura, ensaios de tração, micro-mecanismos. 


\begin{abstract}
Due to the brittleness of concrete, the control and prevention of cracking in reinforced concrete structures are of prime importance. One way of improving the tensile properties of concrete is by the addition of fibres. The present research is a trial to provide guidelines for the design of fibre reinforced concrete structures under service loads. First of all, a study of the tensile behaviour of the composite material is presented. A probabilistic/fracture mechanics based micromechanical model, capable of predicting the poscracking behaviour of the material is presented. The model predicts the tensile stress-crack width relationship, accounting for the following micromechanisms: fibre and aggregate bridging, fibre rupture, local snubbing, matrix spalling, the Cook-Gordon interface effect, and fibre prestressing. At the structural level, two macromechanical models are presented. One is founded on the classical theory of cracking, while the other, a shear lag model, is founded on the continuum damage mechanics. The first model is adjusted for application to the prevision of crack width and crack spacing in fibre reinforced concrete structures with short discrete and randomly dispersed fibres. It is shown that the micromechanical model fits very well in the macrostructural model. Tensile tests with mortar specimens reinforced with continuous steel wires or meshes and PVA or polypropylene fibres were carried out. The theoretical results predicted by the model were compared with results obtained from the experimental program, and show very good agreement, confirming the validity of the theoretical model.
\end{abstract}

Keywords: Crack width, cracking (fracturing), fibre reinforced concrete, model, crack spacing, micromecanical model, macromechanical model; tensile stress-crack width relationship, tensile tests, micromechanisms. 
Nesse mesmo dia, o Faraó deu ordem aos capatazes e inspetores dizendo:

"Não dêem ao povo palha para fazer tijolos, como vocês faziam antes. Que eles próprios providenciem a palha". 


\section{INTRODUÇÃO}

\subsection{GENERALIDADES}

As matrizes cimentícias de concreto e argamassa são os materiais mais empregados na industria de construção civil. Todavia, essas matrizes possuem duas desvantagens do ponto de vista estrutural: o problema da fissuração e a baixa tenacidade.

Por ser intimamente ligada à durabilidade e ao desempenho da estrutura, a fissuração em concretos e argamassa tem sido, durante muitas décadas, um assunto de ampla pesquisa (BEEBY, 1972; BEEBY ET AL., 1972; BEEBY, 1979; MIANOWSKI, K. M., 1992; BALÁZS, 1993), e as normas internacionais estipulam aberturas máximas em função da agressividade do ambiente.

Do ponto de vista estrutural, o problema de fissuração pode ser tratado em uma das três maneiras discutidas a seguir, dependendo do tipo de fissura envolvido. As fissuras podem ser: (a) evitadas, (b) induzidas a ocorrer em pontos pré-determinados onde seus efeitos podem ser melhor acomodados, ou (c) podem ser permitidas a se formar aleatoriamente e a armadura detalhada de tal forma que resulte aberturas limitadas. As cláusulas de normas para a previsão da fissuração, entretanto, tratam da 
primeira (concreto protendido) e da terceira maneira da resolução do problema da fissuração. Na presente pesquisa, será tratado apenas o terceiro problema de fissuração.

Em conseqüência da fragilidade das matrizes cimentícias, e as altas taxas de armadura empregadas para o controle da fissuração, há uma necessidade crescente de materiais alternativos com melhor desempenho à tração nas condições de serviço. Uma maneira de melhorar as propriedades de concretos é pelo emprego de fibras.

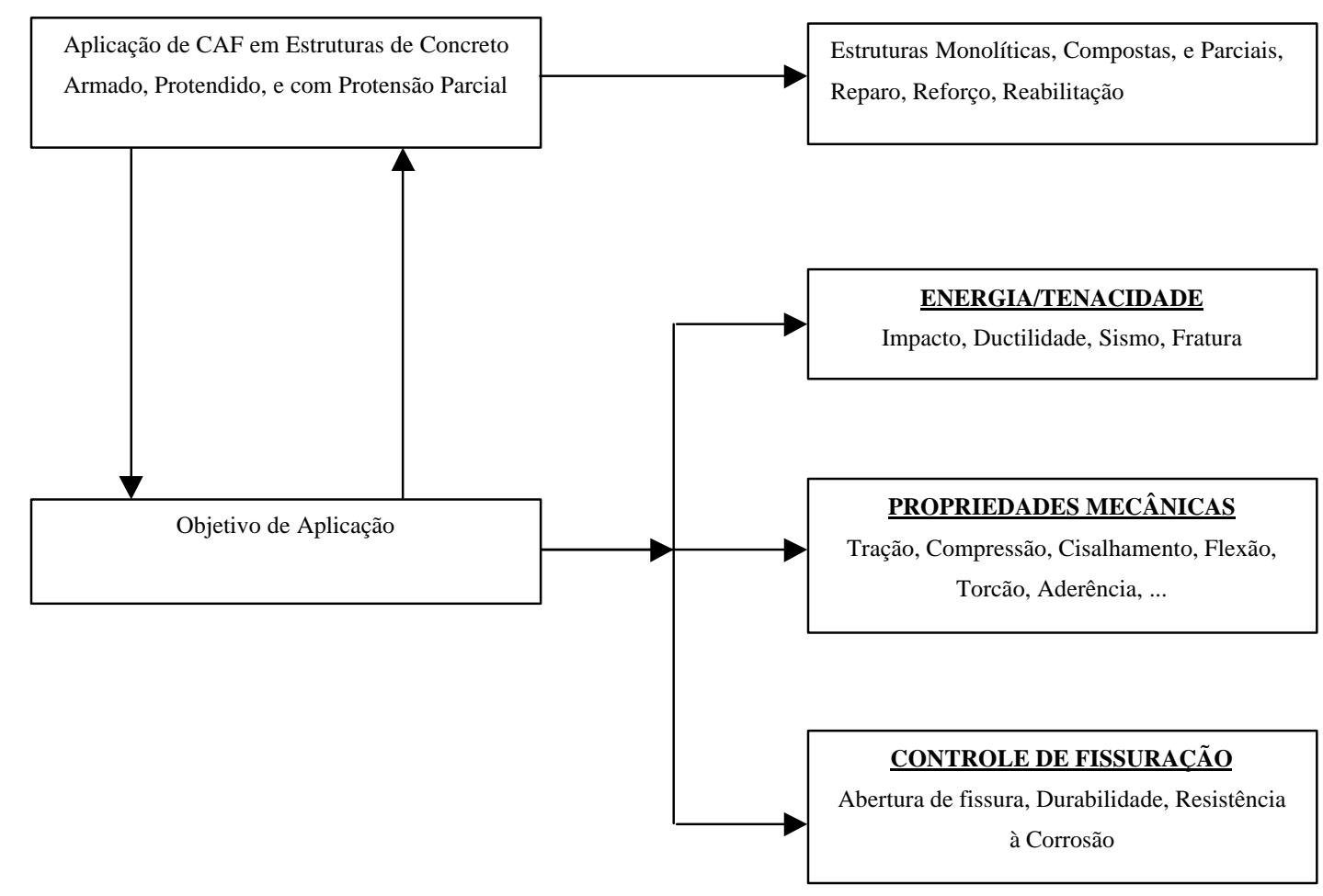

Fig. 1.1: Aplicações de fibras em matrizes cimentícias

A viabilidade do emprego de fibras para melhorar as propriedades de matrizes cimentícias tem sido reconhecida desde a antigüidade. Na bíblia, já comenta do uso de palhas na fabricação de tijolos (Êxodo ${ }^{1}$ ). Desde então a evolução no uso de fibras tem acompanhado os avanços tecnológicos da engenharia de materiais. $O$ concreto armado com fibras (CAF) apresenta uma grande diversidade quanto: (a) ao tipo de fibras; contínuas ou discreta, e (b) à taxa de fibra; menor ou maior que a crítica, e as aplicações para as quais o compósito está destinado estão intimamente ligadas a

1 Êxodo 5: 6-7; Bíblia Sagrada 
esses fatores. Hoje, o CAF tem uma grande gama de aplicação em estruturas de concreto armado ou protendido nas quais desempenha diversos fins, estruturais ou não estruturais, como mostra a figura 1.1 .

Embora a mais antiga aplicação de fibras tenha sido em matriz cerâmica, atualmente, pesquisas realizadas em vários países do mundo comprovam a viabilidade do uso de fibras para melhorar as propriedades de matrizes cimentícias à tração. Esses estudos, direcionados para vários campos do comportamento estrutural; tração (LIM ET AL., 1988; LI E BACKER, 1990; EL DEBS E EKANE, 1998), compressão (SOROUSHIAN ET AL., 1992; TAERWE E VAN GYSEL, 1996), e flexão (LIM ET AL., 1988; SOROUSHIAN ET AL., 1992; BAYASI E ZENG, 1993; EL DEBS E NAAMAN, 1993), mostram que a adição de baixas taxas de fibras curtas e aleatoriamente distribuídas (menores que 5\%) proporciona às matrizes cimentícias armadas com fibras a potencialidade de redução de aberturas de fissuras, alta absorção de energia, alta ductilidade, e alta resistência; sendo os dois últimos possíveis apenas quando os parâmetros que controlam o comportamento do compósito forem adequadamente engenhados (LI E WU, 1992; LI E LEUNG, 1992). Com essas vantagens, o concreto armado com fibras e armadura convencional tem sido empregado (principalmente no exterior) em obras civis quando for necessário a diminuição da abertura de fissura, ou onde a presença das fissuras for indesejável.

O principal fenômeno por trás do melhor comportamento do concreto armado com fibras tem sido atribuído ao efeito de grampeamento das fissuras, o atrito e aderência durante o arrancamento das fibras (BENTUR E MINDESS, 1990). Por conseguinte, o concreto armado com fibras e armadura convencional é projetado de tal modo que a armadura atenda às necessidades da capacidade resistente, enquanto as fibras servem para reduzir e controlar a abertura de fissura e absorção de energia.

\subsection{FORMULAÇÃO DA SITUAÇÃO-PROBLEMA}

Apesar das melhorias no desempenho estrutural proveniente do uso das fibras, o potencial do concreto armado com fibras para fins estruturais não tem sido melhor aproveitado, devido, principalmente, à falta do conhecimento do meio técnico com respeito ao comportamento de materiais compósitos. No caso de concreto com fibras, 
essa falta de conhecimento pode ser atribuída a dois conceitos principais: (a) a previsão da abertura de fissura e (b) a contribuição das fibras. No caso especifico de concreto armado com fibras e armaduras convencionais, além dos conceitos acima citados, há uma falta de ferramenta analítica que permite a consideração do efeito adicional das fibras no cálculo estrutural.

Em muitos países, desde a entrada em vigor das normas de dimensionamento de estruturas de concreto armados, pouco se fez para rever ou reformular os conceitos de fissuração aí propostos. De fato as pesquisas sobre o fenômeno de fissuração estão praticamente estagnadas. Esse comportamento por parte dos pesquisadores vis-à-vis a fissuração, cria duas impressões. Em primeiro lugar, pode-se pensar que o fenômeno de fissuração é totalmente do conhecimento do meio técnico, ou, pode-se pensar que, o fenômeno de fissuração é extremamente complexo que, até então não é conhecido na sua totalidade, e foi apenas relegado para a última instância por outros motivos. De fato a segunda situação é a verdade. O fenômeno de fissuração está longe de ser integralmente conhecido. Contudo, a falta de atenção dirigida para estudo desse fenômeno pode ser atribuído principalmente ao fato de que, o estado limite de utilização não expõe uma estrutura ao mesmo perigo como o estado limite último. Além do mais, o atendimento das exigência do estado limite de utilização pode inviabilizar economicamente a construção.

Sem restrição, a atual situação, especialmente com 0 aparecimento de compósitos cimentícios de alto desempenho, e cujo comportamento depende de um grande número de parâmetros, exige que os conceitos de fissuração vigentes sejam revistos. De fato, os atuais conceitos da fissuração e as deduções deles derivadas são muito limitados, demostrando grandes divergências nos métodos de cálculo para a previsão da abertura de fissuração. Isso pode ser facilmente descritas por um trabalho realizado por BEEBY (1979). BEEBY (1979), num cálculo da abertura de fissura em uma laje típica de concreto armado, comparou dez normas internacionais. Os resultados obtidos por BEEBY (1979), e o obtido empregando a Norma Brasileira para o mesmo problema são mostrados na figura 1.2. 


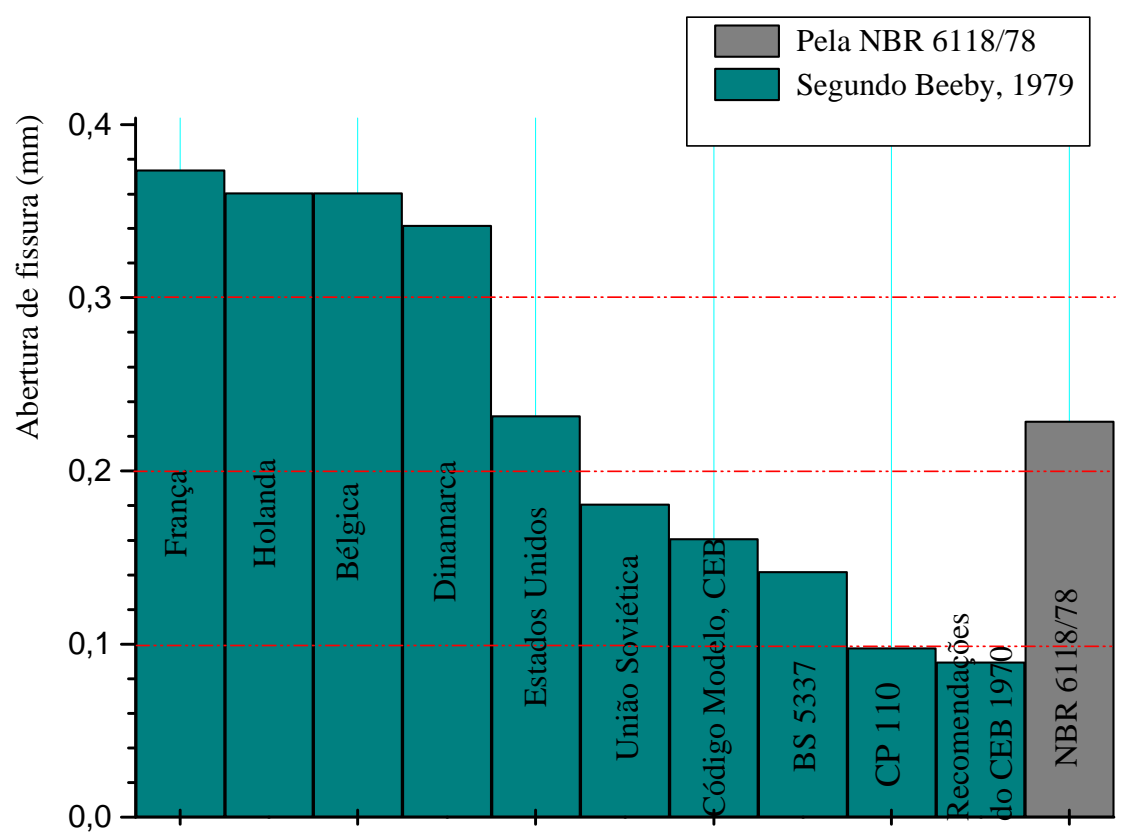

Fig. 1.2: Aberturas de fissura calculadas empregando várias normas para uma laje

Da figura 1.2 pode-se concluir que, a laje em questão seria considerada inadequada em qualquer ambiente agressivo por quatro normas, adequado para ambientes fracos por duas normas (incluindo a Norma Brasileira), adequada para ambientes moderadas por três normas, e adequada para todos os ambientes por duas normas. É portanto de difícil compreensão por que uma grande diferença possa ocorrer no dimensionamento de um elemento estrutural dito "normal', para um fenômeno que o meio técnico desprezando.

Segundo BEEBY (1979), as diferenças não são devido ao fato de que as várias teorias e equações resultantes para a previsão da abertura de fissura estejam totalmente incompatíveis, mas sim, por ser as mesmas na maioria dos casos, apenas descrições parciais do fenômeno da fissuração (da teoria clássica de fissuração de Saliger). A partir disso, conclui-se que, é preciso em primeiro lugar, uma teoria geral para o fenômeno de fissuração.

Entretanto, apesar da discrepância, as formulações propostas em normas, geralmente formulações semi-empíricas, possuem uma vantagem: o fato de que a 
abertura de fissuração pode ser normalmente expressa como uma função da tensão de serviço nas armaduras e um parâmetro geométrico que descreve o tamanho das barras e a taxa geométrico efetivo da armadura de tração considerada. É portanto, característica desse tipo de fórmula que tenha uma grande extensão de aplicabilidade, pois os únicos parâmetros de entrada são a tensão na armadura e algum parâmetro geométrico que pode ser definido para uma grande gama de estruturas. A única desvantagem de tais formulações, entretanto, é o fato de que, é praticamente impossível estender o uso dessas formulações a tipos de concreto não convencionais como CAF ou a tipos de armaduras não convencionais como fios de carbono, devido à natureza empírica das formulas.

Em segundo lugar, a contribuição das fibras no comportamento global do compósito é difícil de ser considerada. Tal contribuição depende de vários parâmetros cuja atuação simultânea, quando considerada, resulta em um problema altamente complexo e difícil de ser resolvido analiticamente.

Conclui-se portanto que, é necessário estabelecer uma teoria geral de fissuração de concreto armado em geral e CAF em particular. No entanto, no caso da previsão de abertura de fissura em concreto armado com fibra e armadura convencional, tal formulação deve ter a mesma generalidade geométrica, i.e., que seja possível a sua aplicação a uma grande gama de estruturas, e ao mesmo tempo, que seja possível a incorporação de forma clara e fácil de determinar em laboratório, de todos os parâmetros que influenciam o comportamento global do material.

\subsection{OBJETIVOS}

Esta pesquisa tem como objetivo precípuo, fornecer diretrizes para 0 dimensionamento de estruturas de concreto armado com fibras (CAF) e armaduras convencionais (CAFAC) em condições de serviço. Com este objetivo em mente, pretende-se contribuir na avaliação de abertura e espaçamento de fissura em elementos de concreto e argamassa armados com fibras e armadura convencional.

Para atingir este objetivo, pretende-se contribuir de forma analítica-experimental na previsão do comportamento do concreto armado com fibras 
em elementos de concreto e argamassa armados com fibras e armadura convencional sob condições de serviço.

Além disso, pretende-se como objetivos secundários, realizar ensaios de protótipos submetidos à tração, e finalmente comparar os resultados experimentais com alguns modelos teórico-analíticos propostos em literatura, indicar ou ajustar os modelos existentes para o casos particulares de concreto e argamassa armado armados com fibras e armadura convencional.

\subsection{LIMITAÇÃO DE ABORDAGEM DO PROBLEMA}

O comportamento do concreto armado com fibras depende de vários parâmetros relacionados com as propriedades mecânicas da matriz, geometria e propriedades mecânicas das fibras e a interação fibra/matriz. Várias pesquisa mostram que para certos valores desses parâmetros, há até uma mudança na reologia do material. A implicação desse efeito é que o comportamento do "novo" material, apesar de ser um concreto armado com fibras, não pode ser previsto pelo modelo analítico apresentado nesta pesquisa. É portanto, antes de qualquer modelagem analítica, limitar o problema de fissuração a ser tratado nesta pesquisa com respeito a certos parâmetros.

\section{Taxa de Fibras}

O parâmetro mais importante no comportamento é a taxa de fibras. Segundo STANG (1991) ${ }^{\mathrm{a}}$, os concretos armados podem ser classificados em dois grupos: CAF com localização de deformação e CAF sem localização de deformação. O limite da taxa de fibras que separa os dois materiais é conhecido como a taxa crítica de fibras. A taxa de fibra portanto, define o tipo de concreto com fibras e por conseguinte a viabilidade da tecnologia de processamento do material resultante. A presente pesquisa está limitada aos concretos armados com fibras com baixas taxas de fibras (taxas menores que crítica). 


\section{Tipo de Fibras}

Quando uma fibra está submetida a um carregamento crescente, ela pode atingir a sua capacidade e romper. Entretanto, o nível de carregamento que leva à ruptura da fibra depende da sua capacidade de deformação ou a ductilidade. Certas fibras como de carbono (fibras frágeis) rompem antes mesmo de atingir a sua capacidade máxima de ruptura. O tipo de fibra (dúctil ou frágil) é de grande importância na avaliação da tensão de travejamento do compósito. Os modelos analíticos a serem apresentados são aplicáveis às fibras dúcteis, descontínuas e aleatoriamente dispostas.

\section{Tipo de Matriz e Armadura}

Como foi mencionado, serão empregados dois modelos de fissuração. $O$ método de AL-TAAN E AL-FEEL (1989) é aplicável apenas para matrizes de concretos e argamassa e armadura convencional de barras e fios. Entretanto, além de matrizes de concreto e argamassa e armaduras convencionais, o método de STANG E AARRE (1992) é aplicável à outras matrizes frágeis como cerâmica e armaduras não convencionais como fios e barras de carbono.

Deve-se neste ponto salientar que embora os modelos analítico sejam aplicáveis para qualquer taxa de fibras menor que a crítica, não se garante a viabilidade de processamento do material pois este aspecto é puramente tecnológico.

\subsection{IMPORTÂNCIA E JUSTIFICATIVAS DO ESTUDO}

A abertura de fissuras define um dos estados limite de utilização da estrutura e, está intimamente ligada à estética e à durabilidade e desempenho da estrutura. Pela sua importância, as normas de dimensionamento de estruturas de concreto exigem obrigatoriamente a verificação de aberturas de fissuras que deve estar dentro de certos limites impostas. Neste item a importância da verificação do estado limite de utilização não será mais enfatizada e portanto, não se pretende justificar aqui esta rotina. Entretanto, a importância do emprego de fibras pode ser vista de diferentes ângulos, e cada vantagem ou desvantagem pode ser um ponto subjetivo. Pretende-se portanto, 
justificar apenas o emprego das fibras em matrizes cimentícias de concreto e argamassa armados. Isto será feito considerando algumas de suas aplicações.

\section{Concreto de alta resistência}

As aplicações de concreto de alta resistência são um fator importante no avanço tecnológico da construção civil de hoje. Pode-se mostrar por exemplo que o concreto de alta resistência (CAR) tem permitido a construção de edifícios de múltiplo pavimentos resultando em uma tremenda economia nessas construções tanto no Brasil como o exterior, devido principalmente à redução do custo da fundação proveniente da redução das seções transversais dos elementos estruturais, e do peso total do edifício. As vantagens e economia de CAR têm motivados esforços consideráveis no melhoramento de suas propriedades mecânicas. Hoje, é possível atingir resistências da ordem de 80-100MPa (LI E MAALEJ, 1996) empregando técnicas e procedimento normais de processamento e de cura.

Infelizmente, apesar dos avanços significativos no processamento, vários fatores ainda limitam a confiança do consumidor final desse material e portanto, a limitação da ampla aplicação do CAR. Primeiramente, segundo Li et al., o CAR é mais frágil e sensível ao entalhe do que o concreto convencional de modo que uma armadura adicional ou encamisamento são necessários para evitar a ruptura frágil. Além disso, literaturas sobre a tecnologia de concreto revelam que existem poucos dados sobre a tenacidade à fratura de concretos de resistência à compressão maior que $60 \mathrm{MPa}$ (LI ET AL., 1996). Portanto, desenvolvimentos no emprego de CAR e na previsão do desempenho mecânico de componentes estruturais exigem técnicas sofisticados de ensaio para determinar as propriedades de fratura ligadas ao cálculo estrutural para evitar a ruptura brusca. Um emprego de CAR pode ser viabilizado quando uma metodologia de ensaio baseado na mecânica de fratura (MF) for estabelecido, que por si, deve ser baseada numa fundação teórica em conjunto com um desenvolvimento de simulações de métodos numéricos (LI ET AL., 1996).

Uma maneira de superar a fragilidade do concreto de alta resistência pode ser pela introdução de fibras na matriz. Tem sido mostrado que pode-se obter um melhoramento significativo de tenacidade com a adição de fibras no concreto 
convencional. Este principio é também aplicável ao CAR, e portanto pode viabilizar o seu uso efetivo em estruturas de concreto armado.

\section{Argamassa armada}

Desde a sua utilização por Nevi até a produção massiva das fabricas de escolas no Rio de Janeiro, São Paulo e Salvador, e os CAICS, a argamassa foi sofrendo adaptações com o avanço da tecnologia de concreto. De Nevi até a sua introdução no Brasil por Martinelli e Schiel (na Escola de Engenharia de São Carlos da USP), a argamassa passou por grandes transformações estruturais com a incorporação de telas de aço (de maiores aberturas) e, assim sendo, destacando-se como um material estrutural confiável.

As possibilidades demonstradas pela argamassa armada são enormes, sendo de fato, segundo a FIP, o material indicado para elementos delgados, principalmente para pré-moldados leves.

Entretanto, por se tratar de peças de pequenas espessuras, as taxas de armadura são muito elevadas. Segundo HANAI (1996), para-se conseguir uma argamassa de alto desempenho, é necessário um consumo de aço superior a $300 \mathrm{~kg} / \mathrm{m}^{3}$ (normalmente tela de pequena abertura ). Entretanto, uma argamassa com essas características tem custos elevados e sua aplicação na construção civil é, de modo geral, inviável economicamente (HANAI, 1996 ). Além dos altos custos, as altas taxas de armadura podem criar sérios problemas do ponto de vista construtivo, que, consequentemente, podem comprometer a durabilidade e desempenho da estrutura.

Uma maneira de viabilizar o emprego da argamassa armada e ao mesmo tempo evitar os problemas relacionados, é o uso de fibras discreta e aleatoriamente dispostas e tela de grande abertura ou fios (EL DEBS E NAAMAN, 1995; EL DEBS E EKANE 1998).

\section{Concreto armado}

Em alguns projetos de concreto armado convencional, a maior parte da armadura serve apenas para combater ou controlar a abertura de fissura no estado limite de utilização. Isto é o caso típico das estruturas como reservatórios e outras 
estruturas de armazenamento onde a estanqueidade é um fator crítico. Do ponto de vista do cálculo estrutural, uma das duas soluções é normalmente adotadas para solucionar um problema de fissuração: (a) aumentar as dimensões transversais do elemento, ou (b) alocar uma armadura adicional para controlar a fissuração.

A primeira solução nem sempre é viável do ponto de vista estética. Além do mais, o aumento da espessura do elemento pode resultar num desvio das hipóteses da teoria sobre a qual o problema a ser resolvido está baseado. Como exemplo, cita-se o cálculo de reservatórios em concreto armado. De um primeiro instante, o cálculo de reservatórios é baseado na teoria de cascas que são por hipótese, elementos delgados. Para satisfazer este critério a relação espessura/raio, do elemento deve estar num intervalo. Portanto, qualquer aumento da espessura pode criar uma fuga das hipóteses nas quais a teoria de cascas está baseada.

A segunda solução é a mais empregada na pratica de cálculo estrutural. Entretanto, esta solução acarreta sérios problemas do ponto de vista de execução. Isto é devido ao fato de que, a armadura destinada ao controle da fissuração, dependendo do tipo de estrutura, pode ser muito difícil de executar, consequentemente, encarecendo a construção. Além disso, é sempre muito difícil de lançar e vibrar o concreto entorno dessas armaduras, sob o risco de vibrá-las e portanto acarretando sérios problemas patológicos que podem comprometer a durabilidade e o desempenho da estrutura.

Também, várias estruturas de concreto armado estão submetidas a carregamento repetido. As literaturas citam várias estruturas (principalmente as pontes, e bases de maquinas) que entraram em colapso devido a fadiga. Como no caso de fissuração, uma solução para combater a fadiga é aumentar a armadura resultando às mesmas inconveniências de problemas de execução. Em razão do mencionado, surgise a necessidade de reduzir ou eliminar as armaduras destinadas ao controle de fissuração ou à fadiga. Tem sido mostrado que a adição de fibras em concreto armado proporciona excelentes propriedades de absorção de energia e controle de fissuração. Pode-se portanto, dimensionar as estruturas de concreto armado com fibras e armadura convencional tal que as fibras fornecem a capacidade de absorção de energia (controle da fadiga) e/ou controle da fissuração, enquanto a armadura é destinada para fornecer a capacidade resistente da estrutura. 


\subsection{REFERENCIAL TEÓRICO-CONCEITUAL}

Existem várias maneiras de abordar o problema de fissuração em elementos de concreto armado. Os procedimentos atualmente empregados são basicamente fundamentados na teoria clássica de fissuração de Saliger, e normalmente são aplicadas e aplicáveis a nível de elemento estrutural. Essa abordagem é conhecida como uma abordagem macro-mecânica. Mesmo desprezando as limitações nos procedimentos atualmente empregados, os atuais métodos, normalmente baseados na resistência à tração do concreto (métodos de tensões), não são apropriados para descrever a fissuração em matrizes cimentícias.

Para uma aplicação correta dos modelos de fissuração normalmente empregados para concreto e seus compósitos, é necessário fazer uma distinção entre o elemento estrutural e o material do qual é feito. Embora sejam apenas descrições parciais da teoria de fissuração, segundo afirma BEEBY (1979), dentro de suas limitações, os atuais modelos de previsão de abertura e espaçamento de fissura são adequados. Todavia, a resistência à tração do concreto, por ser o principal parâmetro de entrada nesses modelos compromete a precisão de tais modelos, e dificulta a previsão do real comportamento do material, pois é impossível prever o comportamento de matrizes cimentícias pela relação tensão-deformação.

Vários estudos mostram que o parâmetro mais importante para definir o comportamento mecânico de materiais cimentícios é a energia de fratura (COTTERELL E MAI, 1995). HILLERBORG ET AL. (1976), originalmente no seu trabalho pioneiro e clássico amarraram este parâmetro à chamada relação tensão-deslocamento, $\sigma-\delta$. Os mesmos sugeriram o emprego da relação $\sigma-\delta$ para caracterizar mecanicamente as fissuras. O emprego da relação $\sigma-\delta$ em vez da relação tensão-deformação, como empregado nos atuais modelos, é que, o dano difuso em um dado material cimentício está localizado numa pequena faixa (ou plano numa escala contínua), chamada zona de processo de fratura, ZPF, devido à concentração de tensão associada com a não homogeneidade do material e a geometria estrutural como entalhes, resultando em micro-fissuração do material. Como conseqüência disso, a relação tensão-abertura de fissura é o parâmetro que caracteriza a zona de processo de fratura, e portanto o comportamento pós-fissuração de materiais cimentícios. 
Diante do exposto, conclui-se que, qualquer modelo macro-mecânico que pretende prever o comportamento pós-fissuração em geral e abertura e espaçamento de fissura em particular deve obrigatoriamente incorporar a relação tensão-abertura de fissura como entrada no modelo. Tais modelos são conhecidos como modelos micro-mecânicos. De fato, os usos mais importantes da modelagem micro-mecânico são: (a) fornecer um conhecimento profundo sobre como as propriedades do compósito são controladas pela micro-estrutura do material, e (b) fornecer um guia para uma receita ótima para o dimensionamento.

A abordagem proposta na presente pesquisa é a modelagem micro-mecânica do material. Em vez de uma relação tensão-deformação, modelos micro-mecânicos fundamentados na mecânica de fratura serão empregados como parâmetros de entrada em um modelo macro-mecânico fundamentado na teoria clássica de fissuração, e um modelo macro-mecânico fundamentado na mecânica de dano.

\subsection{METODOLOGIA}

Existem vários modelos empíricos (LIM ET AL.,1986; NAAMAN E PARAMASIVAM, 1987; STANG, LI ET AL., 1993) e resultados experimentais (EL DEBS E NAAMAN, 1995; EL DEBS E EKANE, 1998) nas literaturas para prever o comportamento de matrizes cimentícias e especialmente os concretos e argamassas armados com fibras e armadura convencional. Entretanto, como foi mencionado anteriormente, existe uma carência de modelos analíticos para a previsão de aberturas e espaçamentos de fissuras em elementos de argamassa e concreto armado com fibras e armadura convencional sob condições de serviço. Na pressente pesquisa duas metodologias são empregadas em conjunto para este fim: métodos teórico-analíticos e métodos experimentais.

Considerando a importância do comportamento mecânico do concreto e seus compósitos sob tração na avaliação da fissuração em elementos de concretos armados com fibras e armadura convencional, os métodos teóricos-analíticos serão divididos em duas partes para fins específicos: (a) modelos analíticos para a previsão do comportamento mecânico do concreto armado com fibras e (b) modelos analíticos para 
a determinação da fissuração em concretos armados com fibras e armadura convencional.

O modelo analítico para a previsão do comportamento do CAF submetido a tração que será abordado nesta pesquisa foi originalmente proposto por Li (1991) a , posteriormente modificado por LI ET AL. (1993) e finalmente posteriormente melhorado por STANG ET AL. (1995). Este método é um método micro-mecânico baseado na mecânica não-linear de fratura e tem como sua principal vantagem a possibilidade de considerar a otimização do material. Basicamente, o método tem como premissa uma caracterização mecânica do material do ponto de vista analítico empregando equações constitutivas do material e uma caracterização experimental para determinar os parâmetros essenciais do material a serem incorporados nas equações analíticas.

Para a previsão de abertura de fissura em elementos de CAFAC, dois modelos analíticos serão empregados. O primeiro é um modelo proposto por AL-TAAN E AL-FEEL (1989), e consiste basicamente na analise de equilíbrio do corpo rígido de um elemento fissurado. Este método tem a grande vantagem da sua simplicidade e por se identificar com os modelos normalmente propostos em normas como da ABNT. O segundo método é um modelo inicialmente proposto por STANG (1991) adaptando-se o modelo de STANG (1991) a para aplicação estrutural. Posteriormente, o modelo de STANG $(1991)^{b}$ foi melhorado por STANG E AARRE (1992) considerando a defasagem de cisalhamento, e depois por STANG ET AL. (1995) para sua aplicação para sistemas híbridos. O modelo se enquadra nos chamados modelos de defasagem de cisalhamento, e tem como base a análise do campo de deformação na região da fissura, com a aderência entre a armadura e a matriz prevista da teoria de defasagem de cisalhamento.

A metodologia experimental é constituída de ensaios a serem realizados em laboratório. Basicamente, foram ensaiados uma série de corpos de prova de argamassa armada com fibras e armadura convencional em forma de placas de pequena espessura submetidas à tração para a obtenção de aberturas e espaçamentos de fissuras. O objetivo principal desses ensaios é obter resultados para o efeito de comparação com as previsões dos modelos analíticos. 


\subsection{APRESENTAÇÃO DA DISSERTAÇÃO}

Esta dissertação está dividida em seis capítulos. Todos os capítulos, salvo o primeiro e o último iniciam com uma breve introdução que embasa os conceitos fundamentais do problema a ser tratado no capítulo.

O capítulo dois apresenta as características gerais do concreto e concreto armado com fibras baseadas na mecânica de fratura. Esses capítulo serve como uma introdução à modelagem micro-mecânica a ser vista no próximo capítulo. Apresenta-se a relação-abertura de fissura como controlador do comportamento de concretos e concretos armados com fibras. O capítulo encerra apresentando os principais processos e mecanismos de fratura, e como os mesmos influenciam na modelagem analítica do material.

No capítulo três apresenta-se a mecânica de concretos armados com fibras. De fato, esse capítulo faz a diferença entre a abordagem aqui proposta, e as empregadas em normas para a previsão de abertura e espaçamento de fissura. Dois modelos micro-mecânicos são apresentados. O primeiro é baseado na teoria de material compósito. O segundo é um modelo micro-mecânico/estatístico baseado na mecânica de fratura, com premissa básica na "teoria de fissura transversal" (Through-crack model) de LI ET AL. (1991), ao contrario da "teoria de fissuração múltipla" (Multiple-crack model) de LANGE-KORNABAK E KARIHALOO (1997), e capaz de simular a seqüência dos eventos durante $o$ arrancamento das fibras.

O capítulo quatro trata dos modelos macro-mecânicos empregados para a previsão de abertura e espaçamento de fissura em elementos de concreto armado com fibras e armadura convencional de barras ou fios. Neste capítulo, mostra-se como os modelos micro-mecânicos anteriormente deduzidos podem servir como parâmetros de entrada nos modelos macro-mecânicos. Dois modelos são discutidos. O primeiro, o modelo de AL-TAAN E AL-FEEL (1989), está fundamentado na teoria clássica de fissuração de Saliger, e o segundo, o modelo de STANG E AARRE (1992), foi primeiramente embasado por STANG $(1991)^{\mathrm{b}}$ e posteriormente melhorado por STANG ET AL. (1995), enquadra se nos chamados modelos de defasagem de cisalhamento, e está fundamentado na mecânica de dano.

O capítulo cinco apresenta o programa experimental empregado no presente estudo para verificar e aferir os modelos macro-mecânicos tratados na pesquisa. 
Também é apresentado uma comparação dos resultados experimentais e analíticos de abertura e espaçamento de fissura previstos pelo modelo de AL-TAAN E AL-FEEL (1989).

Finalmente, o capítulo seis traz considerações finais e as conclusões do estudo. Os resultados obtidos são discutidos e a validade do modelo é justificada. O capítulo seis encerra com a apresentação de algumas recomendações de futuras pesquisas na área de compósitos cimentícios armados com fibras. 


\section{CAPÍTULO \\ DOIS}

\section{COMPORTAMENTO DO CONCRETO SIMPLES E CAF NA TRAÇÃO}

\subsection{PRELIMINARES}

Para qualquer análise de fissuração em concreto e/ou seus compósitos, é imprescindível o conhecimento do comportamento mecânico do material à tração. No dimensionamento 'convencional' de estruturas de concreto, as propriedades do concreto são geralmente especificadas apenas pela resistência à compressão simples. Propriedades mecânicas como a resistência à tração e o módulo de elasticidade são empiricamente deduzidas da resistência à compressão.

Atualmente, existem várias técnicas que fornecem informação sobre as características do concreto à tração. Um ensaio de flexão ou de compressão diametral são comuns. No entanto, a técnica mais empregada na determinação das características do concreto é a flexão por 'carregamento nos terços'. A tensão teórica de tração na face inferior da viga na ruptura, denominada módulo de ruptura, é determinada com base na teoria da técnica de flexão, supondo que o comportamento do concreto é elástico até a ruptura. Segundo WELCH (1966), esta suposição não é correta. NEVILLE (1997) e MEHTA E MONTEIRO (1985) também confirmam a opinião 
do WELCH (1966). Segundo esses pesquisadores, o módulo de ruptura superestima a resistência à tração do concreto. Além do mais, quando uma viga submetida à flexão é considerada, é evidente que apenas uma pequena região imediatamente abaixo do ponto de carregamento, que está sujeita às tensões críticas (AARRE, 1992). A probabilidade de um elemento fraco, ou um dano, estar presente no local crítico é portanto muito menor no ensaio de flexão que em outros tipos de ensaios (AARRE, 1992; NEVILLE, 1997).

A determinação da resistência à tração a partir do ensaio de compressão diametral também apresenta limitações, pois esta também depende da suposição do comportamento linear do concreto até a fratura na tração ou na compressão (AARRE, 1992; NEVILLE, 1997; MEHTA E MONTEIRO, 1985). Segundo HANNANT (1972), há evidência de que a tração por compressão diametral subestima a resistência à tração de argamassa e concreto leve, e superestima a do concreto simples. Subseqüentemente, é evidente que o tamanho do corpo de prova afeta o módulo de ruptura e a resistência à tração obtidos do ensaio de compressão diametral. Este efeito de escala foi confirmado por NEVILLE ${ }^{1}$ (1997) e WARD ET AL (1989).

Com respeito a determinação da resistência à tração a partir da resistência à compressão simples, AARRE (1992) afirma que a relação entre a resistência à compressão simples e à tração não é única. BENAICHE ET AL. (1989) divulgaram que a relação água/cimento tem apenas um efeito marginal sobre a resistência a tração. Ao contrário, aumentos maiores da resistência à tração são obtidos pelo uso de aditivos ou adições e, em particular, o emprego de microsílica. Além do efeito de adições, NEVILLE (1997) e MEHTA E MONTEIRO (1985) afirmam que há um efeito do tamanho e forma de agregado sobre a resistência à compressão.

Diante desses fatos, pode-se concluir que não há uma relação única entre os resultados de ensaio de tração e os resultados como de flexão, compressão diametral, ou compressão simples. Portanto, não é obvio a obtenção com precisão dos parâmetros de ensaio de tração de qualquer outro ensaio a não ser do ensaio de tração direta propriamente dita.

Embora em muitos casos os métodos atuais de dimensionamento de estruturas de concreto não levam em conta, de forma explicita, a resistência à tração do concreto,

\footnotetext{
${ }^{1}$ Esta referência representa apenas uma edição recente. O efeito de escala é um fenômeno bem antigo.
} 
uma apreciação da mesma permite uma melhor compreensão do comportamento do material. Segundo NEVILLE (1997), a aplicação direta da força de tração livre de excentricidade é difícil, e além do mais, é complicado pela presença de tensões secundárias induzidas pelas garras do aparelho de ensaio.

Uma alternativa de determinar a resistência à tração do concreto é pela relação tensão2deslocamento do concreto na tração direta. De fato, a curva tensãodeslocamento do concreto tem a vantagem de que, é o único ensaio do qual pode-se conhecer as tensões e deslocamentos precisos e, além do mais, não depende da suposição da elasticidade ou plasticidade (AARRE, 1992). Os resultados de um ensaio de tração são portanto fáceis de analisar, porém experimentalmente, é difícil pois consome muito tempo (AARRE, 1992).

Embora a resistência à tração do concreto não é levada em conta no dimensionamento convencional de estruturas de concreto, a importância do conhecimento da curva tensão2deslocamento, incluindo a parte descendente da mesma, está se tornado muito obvia. O emprego de modelos baseados na mecânica de fratura em conjunto com a crescente importância de elementos finitos na modelagem numérica requerem, não apenas a resistência à tração direta do concreto, como também a energia de fratura, como dados ou parâmetros de entrada.

Também, o recente desenvolvimento e o emprego crescente de concreto de alta resistência e o concreto armado com fibras exigem a necessidade de considerar outras propriedades do concreto além da resistência à compressão simples. Em primeiro lugar, o CAR demostra um modo de fratura diferente do concreto simples. $A$ superfície de fratura em CAR passa através dos agregados, resultando em uma superfície de fratura lisa. Ao contrario, em concreto normal, a fratura se dá pelo arrancamento dos agregados, resultando em uma superfície de fratura rugosa. O modo de fratura de CAR pode alterar significantemente o desempenho estrutural em muitas aplicações. Segundo AARRE (1992), a superfície alterada em CAR é melhor caracterizada pelo comportamento pós-pico do material.

O concreto armado com fibras, quando definido como na presente pesquisa (taxa de fibra menor que a crítica), é um material cujos parâmetros convencionais, como a resistência e o módulo de elasticidade, são muito semelhantes aos parâmetros do concreto simples. Contudo, o CAF possui uma resistência à formação e 
desenvolvimento de fissuras discretas mais alta que o concreto. Se portanto o efeito positivo das fibras sobre a resistência à fratura do concreto é considerado, é muito importante conhecer o comportamento do concreto na fase pós-pico da curva de tensão2deslocamento.

Como foi mencionado no parágrafo anterior, há uma semelhança entre os parâmetros convencionais do CAF e o concreto simples. Isto implica que o comportamento dos dois materiais sob tração são semelhante, porem, esses parâmetros são quantitativamente diferentes. Sob a ótica dessa semelhança, para uma fácil compreensão das características de fratura por tração do CAF, serão apresentadas primeiramente as características de fratura por tração do concreto, e se referir especificamente ao CAF quando necessário.

O concreto e seus compósitos são materiais sem escoamento. A fratura de tais materiais pode ser comparada com o desenvolvimento de um estrangulamento em materiais com escoamento. Entretanto, segundo AARRE (1992), há uma diferença. O desenvolvimento de um estrangulamento em materiais com escoamento é acompanhado com o estreitamento da seção transversal na zona de estrangulamento (figura 2.1a), perpendicular à direção das tensões de tração. Portanto, a diferença entre o estado plano de tensões e de deformações na zona de estrangulamento é muito mais pronunciada (AARRE, 1992).

(a)

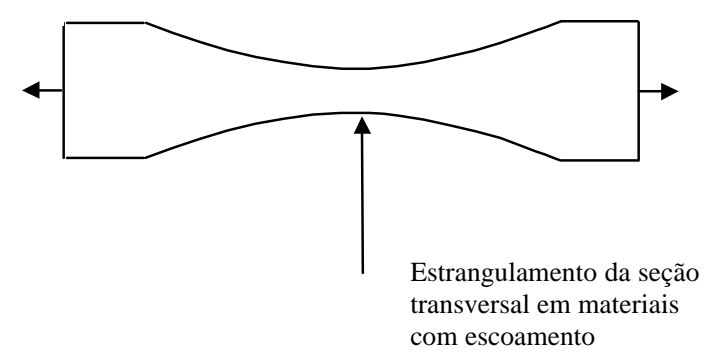

(b)

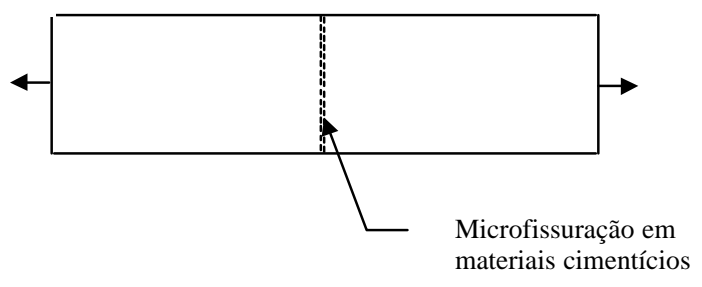

Fig. 2.1: Modo de ruptura em (a) materiais elastoplásticos, e (b) compósitos cimentíceos

Como conseqüência, os resultados de ensaios de tração de materiais com escoamento dependem do tamanho da seção transversal (efeito de escala) do corpo de prova. Ao contrário, a fratura do concreto e seus compósitos sob tração direta é 
proveniente da formação de microfissuras, numa pequena região chamada zona de processo de fratura (ZPF), sem qualquer deformação transversal (figura 2.1b). Em corpos de prova de matizes cimentíceos simples sob tração, a ZPF se desenvolve numa região atravessando a seção do corpo de prova. A mesma também se desenvolve na frente de uma macrofissura pré-existente, ou entalhe em corpos de prova entalhados.
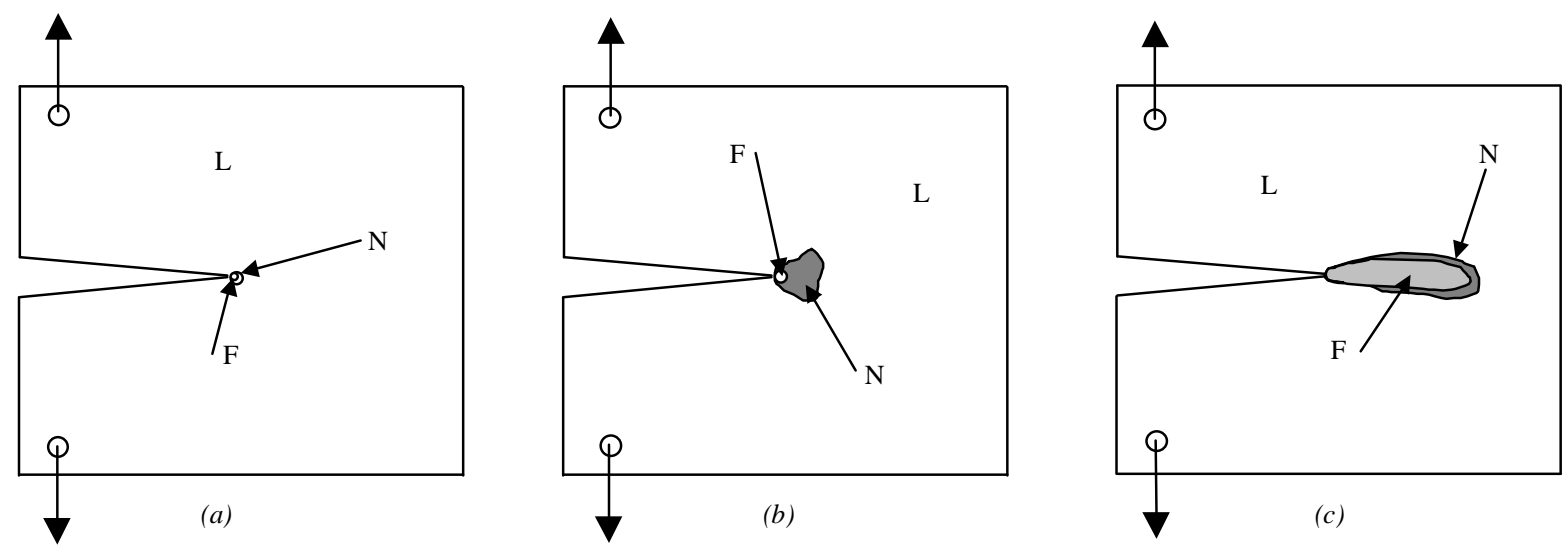

Fig. 2.2: Aspectos principais que distinguem a fratura em (a) material elástico linear, (b) material dúctil, $e$ (c) material quase-frágil. L se refere a região elástico linear, $N$ à zona não linear, e $F$ à zona de processo de fratura (Segundo ACI Report 446.1 R.91 apud KARIHALOO, 1995).

De fato a presença ou não da zona de processo de fratura, e seu tamanho são o principais aspectos que distinguem os materiais dúcteis, como os metais, dos materiais quase-frágeis, como o concreto, rocha e cerâmico e materiais frágeis. Essa diferença é devido principalmente ao fato de que, em materiais dúcteis a zona de processo de fratura, embora pequena, é envolvida por uma relativamente grande zona plástica não linear (figura 2.2b). Ao contrário, em materiais quase-frágeis, a zona de processo de fratura ocupa praticamente toda zona de deformação não linear (figura 2.2c). Também contrário aos dois últimos materiais, a zona de deformação não linear é praticamente ausente em materiais puramente frágeis (figura 2.2a)

A existência da própria ZPF tem sido um tema de amplo debate entre os pesquisadores da área de mecânica de fratura. Segundo KARIHALOO (1995), há razões muito fortes em se pensar que uma ZPF extensa se desenvolve com a fratura (fissura) de materiais cimentíceos. Isso pode ser sustentado baseando-se tanto na 
micro estrutura heterogênea do material, como em resultados de ensaios. No entanto, segundo aponta KARIHALOO (1995), a controvérsia sobre a existência ou não de uma ZPF é proveniente da definição da mesma, muitas vezes ditada pelos métodos da sua medição. O mesmo pesquisador fornece uma definição universalmente aceita da ZPF como, um zona que se refere a região total na frente ou no início de uma fissura livre de tração, onde o material demostra um comportamento de amolecimento de tensão. $A$ mesma poderia até ser envolvida por uma (pequena) zona de material com comportamento não linear devido à microfissuração, mas que não ainda está amolecido. A figura 2.3 é uma representação esquemática do desenvolvimento da zona de processo de fratura em materiais cimentíceos.
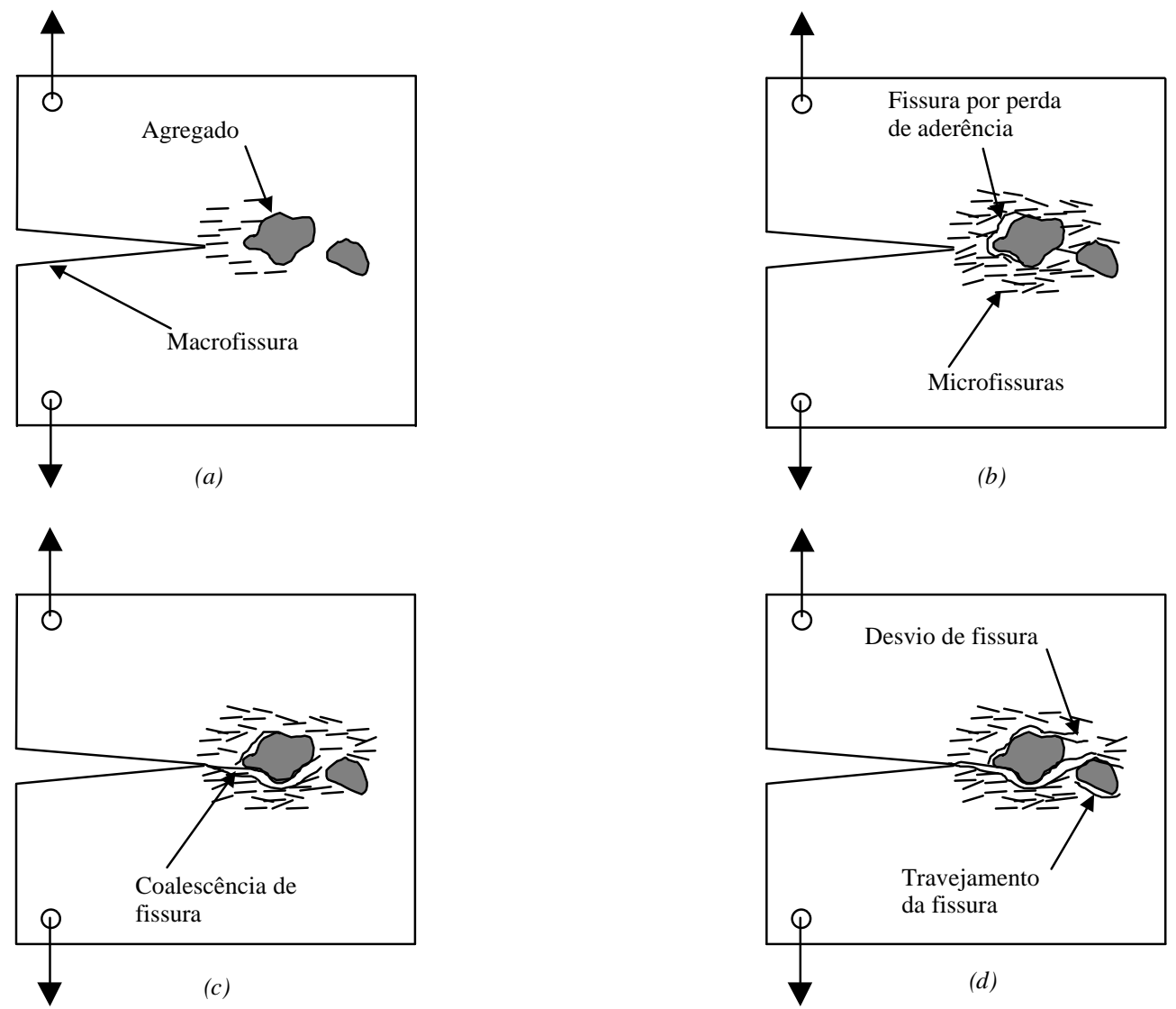

Fig. 2.3: Representação esquemática do desenvolvimento da zona de processo de fratura: (a) microfissuração na vizinhança do agregado devido à presença de uma macrofissura, (b) perda de aderência e microfissuração, (c) coalescência da fissura proveniente da perda de aderência com a macrofissura, e (d) travejamento de fissura, perda de aderência, desvio de fissura, e microfissuração. (Segundo KARIHALOO, 1995). 
Baseando-se em argumentos micro-mecânicos, é de conhecimento geral que a introdução de uma fratura (fissura) em concreto pode inicia pequenas fissuras (microfissuras) em defeitos (tais como vazios e pequenas fissuras normalmente presente em concreto normal, antes mesmo da aplicação de um defeito externo como macrofissura ou carregamento) mais próximos e em partículas da segunda fase (i.e., agregado miúdo e graúdo), ocasionando a perda de aderência destes da pasta de cimento que os envolve. Sob um carregamento externo, as microfissuras se coalescem uma com outra ou com fissuras na interface agregado/pasta (figura 2.3c), para formar fissuras maiores que podem até se encontrar com a macrofissura externa se não houver nenhum obstáculo como vazios e/ou partículas que impedem este acontecimento. Os vazios são em particular obstáculos muito importantes, pois são livres de tensão e portanto, atraem microfissuras que "procuram" um caminho de menor resistência. Segundo KARIHALOO (1995), isso explica porque se espera o concreto celular apresentar um queda mais gradativa da capacidade resistente na tração após pico que o concreto de alta resistência.

No que diz respeito às partículas da segunda fase numa matriz de cimento, estes têm a capacidade de capturar o avanço de uma fissura que se desenvolve. Isso implica a necessidade de trabalho externa adicional para sustentar a propagação da fissura. A fissura pode ser obrigada portanto, a se desenvolver em volta do agregado deixando-o grampear as faces da fissura.

\subsection{CURVAS DE TENSÃO2DESLOCAMENTO}

\subsubsection{Materiais Cimenticeos}

$\mathrm{Na}$ seção anterior, foi destacado que a fratura de materiais cimentíceos é caracterizada pela formação de uma zona de processo de fratura extensiva na frente de uma macrofissura pré-existente ou entalhe, devido aos defeitos como vazios e microfissuras. Devido a tais defeitos, o material na zona de processo de fratura exibe um comportamento de amolecimento de tensão, fazendo com que materiais a base de cimento, embora tradicionalmente considerados como materiais frágeis, na realidade 
demostrassem um comportamento diferente. Esses materiais apresentam um comportamento de moderado endurecimento de deformação antes de atingir sua capacidade última na tração (carregamento de pico), parecido com materiais metálicos de alta resistência. No entanto, ao contrário de materiais metálicos, conforme foi exposto na seção anterior, os materiais a base de cimento são caracterizados por um aumento de deslocamento com uma queda da capacidade resistente na tração. Tal resposta é conhecida como amolecimento de tensão. Segundo KARIHALOO (1995), materiais que apresentam um endurecimento de deformação antes de atingir a sua capacidade resistente na tração, seguido por um amolecimento de tensão após o carregamento de pico, são chamados materiais quase-frágeis.

Pode-se notar também que, em materiais quase-frágeis como o concreto, a zona de processo de fratura, apesar de análoga à escoamento plástico em materiais dúcteis, não é afetada pela tensão e é portanto independente da espessura do corpo de prova (COTTERELL E MAI, 1996; DUDA E KÖNIG, 1992). Como conseqüência disso, a diferença entre o estado plano de tensão e de deformação na zona de processo de fratura é desprezível para os concretos e seus compósitos (AARRE, 1992; COTTERELL E MAI, 1996). Assim, os resultados de ensaios de tração direta devem ser independentes da seção transversal do corpo de prova, e consequentemente, segundo HILLERBORG (1983), podem ser considerados como parâmetro do material.

A figura 2.4 é uma ilustração esquemática do comportamento de um corpo de prova de concreto entalhado submetido a tração. Como foi visto, o comportamento é definido pela relação tensão2deslocamento. A suposição básica da existência da curva $\sigma-\delta$ é que, o dano difuso em um dado material cimentíceo está localizado numa pequena faixa (ou plano, numa escala contínua) devido à concentração de tensões associado com a não homogeneidade do material, e a geometria estrutural (como entalhe). A correspondência entre os vários pontos da figura 2.4 tem objetivo apenas de mostrar um retrato qualitativo da zona de processo de fratura. Porém esta figura é apropriada para destacar algumas propriedades importantes. A curva pode ser dividida em quatro regiões principais. 


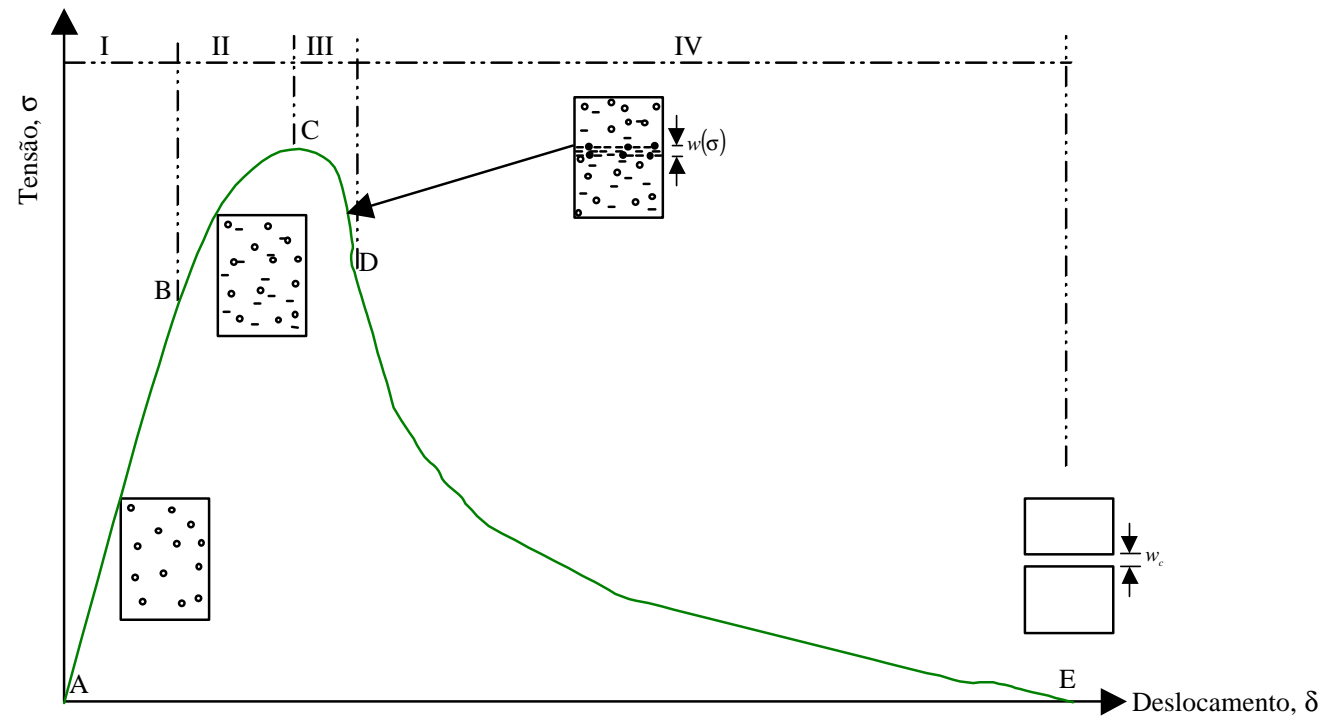

Fig. 2.4: A Curva esquemática tensão2deslocamento, $\sigma-\delta$, de um material cimentíceo (Segundo KARIHALOO, 1995).

O concreto contem vazios e microfissuras mesmo no seu estado virgem e não solicitado. Sob baixos níveis de solicitação na tração, até $60 \%$ da resistência última, $\sigma_{c m}$, segundo COTTERELL E MAI (1996), a influência desses defeitos internos sobre a resposta mecânica é desprezível. Isso resulta portanto, em um comportamento elástico linear da barra de concreto. No entanto, KARIHALOO (1995) afirma que mesma se este efeito fosse considerável, qualquer pequeno efeito que os defeitos possam ter sobre a resposta média da relação tensão2deformação já é levado em conta nas constantes elásticas, módulos de elasticidade e coeficiente de Poisson. $\mathrm{O}$ comportamento elástico é representado pela região I (curva $A B$ na figura 2.4). Nesta etapa de carregamento, o comportamento do concreto pode ser melhor descrita tanto por uma relação tensão2deformação (AARRE, 1992), como por uma relação tensão2deslocamento. Com o aumento de carregamento, região II (curva $\mathrm{BC}$ ), há uma formação de microfissuras nas interfaces argamassa/agregado graúdo, resultando numa não linearidade pré-pico (i.e., antes da resistência última à tração). Essas microfissuras interfaciais se desenvolvem primeiramente entre a argamassa e os agregados de maior dimensão. Segundo aponta KARIHALOO (1995), a transição de um comportamento linear para não linear (ponto $B$ na figura 2.4) é governado principalmente pela extensão das interfaces disponíveis, ou seja, a fração das 
partículas segunda fase dura (agregado graúdo) na matriz. Com o aumento da tensão de tração a partir do ponto $B$, as microfissuras não apenas se propagam estavelmente como também mais microfissuras são progressivamente formadas na interface entre a argamassa e os agregados menores. Como o concreto normalmente contem agregados dentro de uma faixa de tamanhos, o processo da propagação estável da microfissura e formação de novas microfissuras continue sob o aumento de tensão de tração, resultando numa resposta não linear pré-pico (curva BC na figura 2.4). Embora exista uma curvatura na relação tensão2deslocamento até a tensão máxima, COTTERLL E MAI (1996) sugerem que o deslocamento até este ponto pode ser suposto elástico e uniforme.

Quando a tensão atinge o valor crítico ou tensão de pico (ponto C na figura 2.4), o dano (ou melhor, microfissuras) no material cimentíceo se localiza formando uma zona de processo de fratura (AARRE, 1992; COTTERELL E MAI, 1996; MAI, 1992; KARIHALOO, 1995). O colapso ou ruptura eventual do material após o carregamento de pico ocorre ao longo dessa zona de dano localizada, formando um macrodefeito dominante com toda deformação nesta fase não linear limitada nela (região II). A formação desse macrodefeito é acompanhada pela perda de rigidez do elemento. Segundo KARIHALOO (1995), as microfissuras difusas em qualquer outro ponto não têm nenhum papel importante na determinação da resposta mecânica do material. Este papel pertence apenas ao macrodefeito localizado. Após a tenção de pico, o comportamento do elemento é caracterizado pelo aumento de deslocamento (ou deformação) com a queda da capacidade resistente à tração do elemento (curva CDE na figura 2.2). Segundo afirma MAI (1992) e COTTERELL E MAI (1996), há uma recuperação elástica no elemento ao longo de todo trecho CDE. No entanto, na região III em particular, esta recuperação elástica é devido a contribuição elástica da ZPF com a queda de tensão até $\sigma_{c t}$, e pode ser considerada paralela á rigidez inicial. Os mesmos pesquisadores acrescentam que, normalmente 0 deslocamento correspondente à recuperação elástica na região III é muito pequena $\left(\delta_{m}<<w_{c}\right)$ tal que a mesma pode ser desprezada. Está consideração implica que, pode-se considerar o comportamento pós-pico representado pela curva DE (na figura 2.2) pois $\sigma_{c m} \approx \sigma_{c t}$. 
Após a recuperação elástica, há um amolecimento progressivo da tensão. Uma macrofratura (fissura) é logo formada com o arrancamento e/ou fratura do agregado, que se torna bem visível quando o deslocamento local na ZPF, $\delta_{t}$ atinge um valor crítico, $w_{c}$. É fácil perceber da figura 2.4 que a não linearidade pré-pico (BC) e a região de amolecimento de tensão pós-pico (CD) são resultado principal da microfissuração. De destaque é a grande extensão da curva de amolecimento (DE) onde as pontes (agregados) que travejam a macrofratura estão sendo arrancados sob atrito ou fraturados.

Em materiais frágeis, o macrodefeito levaria a uma fratura frágil. No entanto, em concreto, seu avanço catastrófico é impedido tanto pela microfissuração, como outros mecanismos que não foram responsáveis para a não linearidade pré-pico (KARIHALOO, 1995). Entre esses mecanismos, o mais importante é o chamado mecanismo de travejamento de agregado, que interrompe a continuidade de uma macrofissura dominante, de tal forma que os segmentos descontínuos não podem crescer instavelmente. O travejamento é proveniente do embricamento entre as partículas da fase dura, a capacidade de endurecimento de deformação de pontes não rompidas entre os segmentos da macrofissura e pelos vazios, que atraem e capturam a macrofissura. Em materiais quase2frágeis armados com fibras, um travejamento significante adicional é fornecido pela armadura (fibra/partícula) externa.

Uma conseqüência do micro dano progressivo no regime de amolecimento de tensão acima discutido, é o consumo de energia significante. Isso resulta no aumento da tenacidade intrínseca (energia de fratura) do material quase2frágil. Para quantificar essa contribuição, é necessário descrever o comportamento de amolecimento de tensão empregando-se técnicas de modelagem micro-mecânica. Uma dessa será considerada no capítulo 3. Segundo COTTERELL E MAI (1996), o parâmetro do material mais importante para a determinação do tamanho da zona de processo de fratura é a relação tensão2deslocamento da zona de processo de fratura. Os mesmos pesquisadores afirmam que, salvo em corpos de prova muito pequenos, esta zona de processo de fratura é relativamente constante, e a relação tensão2deslocamento da mesma processo é quase uma propriedade do material, independente da geometria, e escala. Isso confirma portanto, o proposto de HILLERBORG (1983). 
Para a análise do comportamento pós-fissuração do concreto, é prudente dividir a curva tensão-deslocamento em duas partes distintas. Uma parte crescente que representa a fase pré fissuração representada pela curva ABC (regiões I e II), que pode ser descrita por uma relação tensão-deformação, $\sigma-\varepsilon$ (após consideração da curva BC como linear, segundo simplificação proposta por COTTERELL E MAI, 1996), e uma parte decrescente, curva DE, que representa o comportamento pós-fissuração do compósito (após desprezar a recuperação elástica conforme a simplificação proposta por COTTERELL E MAI, 1996 ). A curva pós-pico, descreve a relação constitutiva ao longo da fissura (LI ET AL., 1987; WANG ET AL.,1990; MAALEJ ET AL., 1991; LI ET AL., 1991) e portanto é considerado um parâmetro do material do qual a estrutura é composta (LEUNG E LI, 1995), e a partir da qual pode-se prever as propriedades meso-mecânicas da estrutura. Isto implica que, um tratamento analítico da fissuração em concreto e/ou seus compósitos exige obrigatoriamente uma modelagem analítica baseada na mecânica de fratura, da zona de processo de fratura.

Visto que os deslocamentos da parte decrescente da curva não são linearmente distribuídos ao longo do comprimento da barra, não é prudente o emprego do deslocamento total da barra como medida do comportamento do material. A fase pós-fissuração é portanto melhor descrita por uma relação tensão2abertura de fissuração, $\sigma-w$. Segundo LI E LIANG (1986), o emprego de uma curva $\sigma-w$ em vez de $\sigma-\varepsilon$ para descrever a deformação não elástica na zona de processo está relacionado ao comportamento frágil da matriz que resulta em microfissuração, e aos efeitos de travejamento da fissura pelos agregados (no caso de concreto) e fibras (no caso de CAF).

Para transformar a curva tensão-deslocamento do elemento para uma curva tensão-abertura de fissura (tensão-deslocamento da ZPF), deve-se subtrai o deslocamento elástico da região I e região $\mathrm{II}, \delta_{e}$ (após consideração da curva $\mathrm{BC}$ como linear, segundo simplificação proposta por COTTERELL E MAI, 1996), do deslocamento total. Segundo AARRE (1992), quando se transforma a curva $\sigma-\delta$ nas curvas $\sigma-\varepsilon$ e $\sigma-w$, é suposto que a abertura de fissura é zero antes de atingir a resistência à tração do compósito. Além do mais, supõe-se que o material fora da zona de processo se descarrega com um módulo (de elasticidade) de descarregamento correspondente ao módulo tangente inicial como mostra a figura 2.5. 


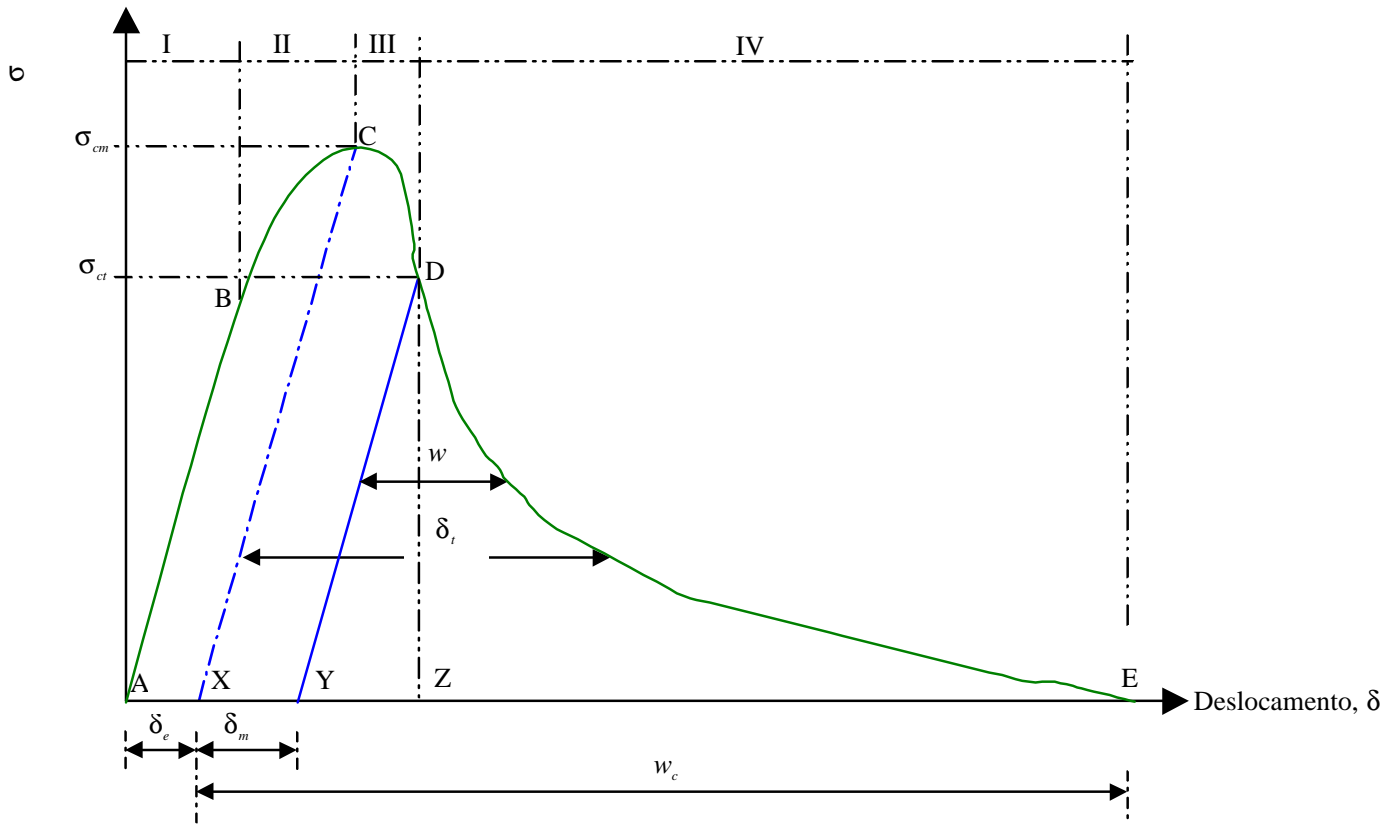

Fig. 2.5: Componentes dos deslocamentos para a transformação da curva tensão2deslocamento, $\sigma-\delta$, para tensão2abertura de fissura, $\sigma-\delta_{t}$.

A curva tensão2deslocamento da zona de processo, também chamada tensão2abertura de fissura (curva $\mathrm{B}-\mathrm{C}$ ), é de importância particular no estudo do comportamento pós-fissuração do concreto e seus compósitos. Esta parte da curva pode ser facilmente obtida da curva $\sigma-\delta$ subtraindo-se o deslocamento elástico da região pré fissuração (regiões I e II) do deslocamento total. É de se pensar que o comportamento da curva de amolecimento depende do mecanismos de travejamento que proporcionam a resistência contra a propagação da fissura. Esta opinião é sustentada por LI E LIANG (1986) e WANG ET AL. (1991). LI E LIANG (1986), também afirmam que, baseado sobre os processos físicos de fratura, a curva $\sigma-w$ deve refletir a dissipação de energia dos mecanismos de absorção de energia. 


\subsubsection{Compósitos Cimentíceos Armados com Fibras}

A adição de fibras, sejam elas contínuas ou discretas em uma matriz frágil de um material cimentíceo, melhora a sua tenacidade à fratura e a resistência. AVESTON ET AL. (1971) apud BENTUR E MINDESS (1990) mostraram que, para uma dada taxa de fibras maior que a crítica, as fibras são capazes de sustentar uma tensão maior que aquela necessária para causar a fissuração da matriz. Para esta classe de compósitos armados com fibras (Tipo I, segundo a denominação de COTTERELL E MAI (1996)), a matriz fissura em um número de fissuras paralelas (fissuração múltipla).

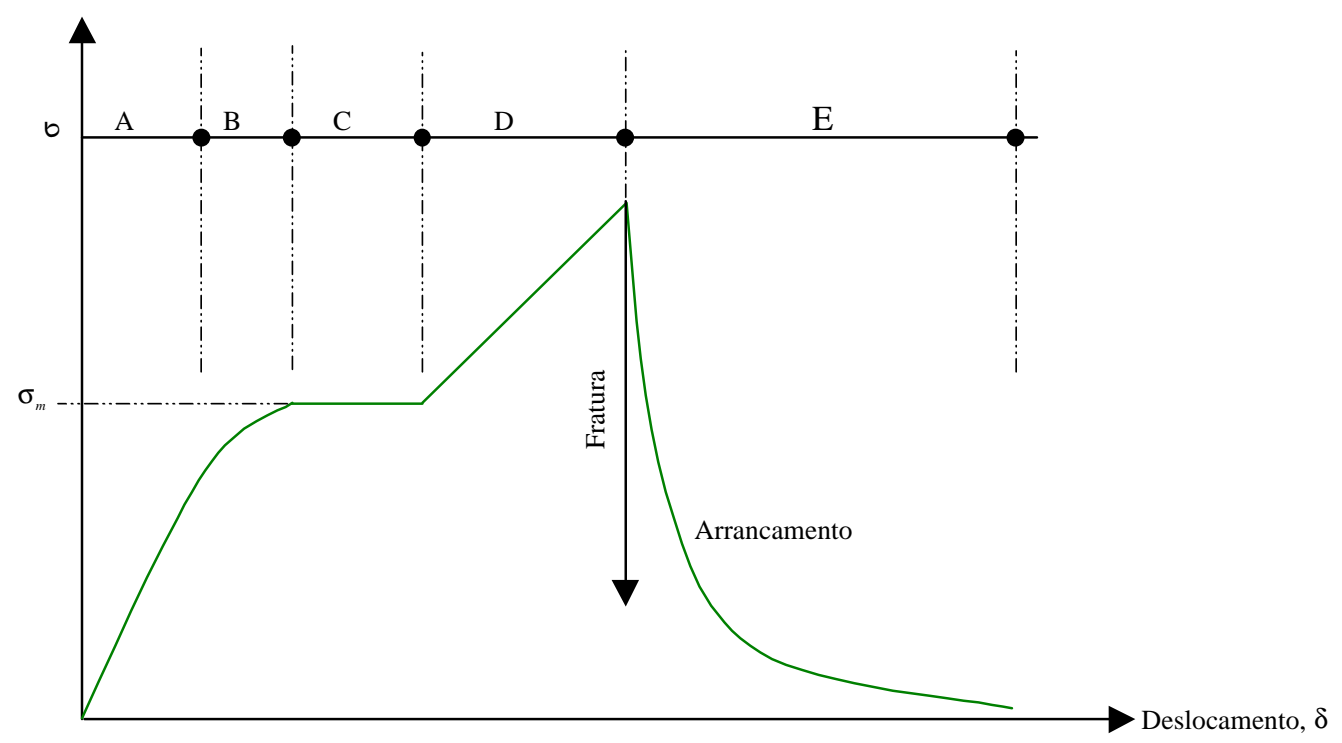

Fig. 2.6: Curva esquemática tensão-deslocamento, $\sigma-\delta$, de um compósito Tipo I que exibe a fissuração múltipla (Segundo COTTERELL E MAI, 1996).

A figura 2.6 ilustra uma curva esquemática da relação tensão2deslocamento de um compósito Tipo I. Na Região A, o comportamento é essencialmente elástico-linear, embora exista uma micro2fissuração difusa. Na Região B, forma-se uma ZPF bem definida, causando a não linearidade na curva tensão2deslocamento. Atingido uma tensão crítica do compósito, $\sigma_{m}$, a matriz se fissura e uma fissura contínua da matriz se forma na zona de processo de fratura. Como a taxa de fibras é maior que a crítica, a tensão sustentada pelas fibras que travejam a fissura aumenta com a 
deformação, o que resulta no chamado, fissuração múltipla na Região C. Isto procede até que o espaçamento de fissura atinge um valor mínimo que depende da aderência fibra/matriz. Na Região D, o aumento da deformação resulta em um aumento de tensão quase linear, mas com menor inclinação que na Região $A$. A Região D termina com a ruptura das fibras, ou, se o comprimento das mesmas for menor que a crítica necessário para a fratura das fibras, as fibras são gradativamente arrancadas, mobilizando o atrito interfacial fibra/matriz (Região E).

Pode-se observar da figura 2.6 que, o comportamento de compósitos de Tipo I é semelhante em diversas maneiras ao dos materiais elasto2plástico. Isto implica que a mecânica de fratura não é necessária para descrever o comportamento de estruturas feitas desse material (COTTERELL E MAI, 1996).

Se a taxa de fibras for menor que a taxa crítica, há uma queda na tensão sustentada pelo compósito ora, quando a matriz se fissura, ou, se houver uma perda estável de aderência fibra/matriz, imediatamente após a fissuração da matriz. Este tipo de compósito, segundo COTTERELL E MAI (1996), é denominado compósito Tipo II. Na prática, a maioria de compósitos Tipo II são armados com fibras discretas (não contínuas) que normalmente são arrancadas em vez de fraturar. (A condição sob a qual as fibras são arrancadas ou rompidas será vista no capítulo 3). Compósitos de Tipo II não apresentam o fenômeno de fissuração múltipla, e a sua fratura sob tração ocorre essencialmente numa única ZPF estreita. A principal diferencia entre compósitos Tipo I e Tipo II é o fato de que, além da formação de uma zona de processo de fratura, uma zona chamada zona de travejamento de fratura (fissura), ZTF também se desenvolve. Este fenômeno se manifesta particularmente em corpos de prova entalhados. Com o aumento de carregamento, a abertura da ponta da fissura atinge um valor critico da matriz, $w_{c}$, além do qual a zona de travejamento da fratura começa a se desenvolver. Quando a ZTF é totalmente desenvolvida, começa o arrancamento e/ou fratura das fibras. A figura 2.7 é uma ilustração esquemática da ZPF e ZTF. 


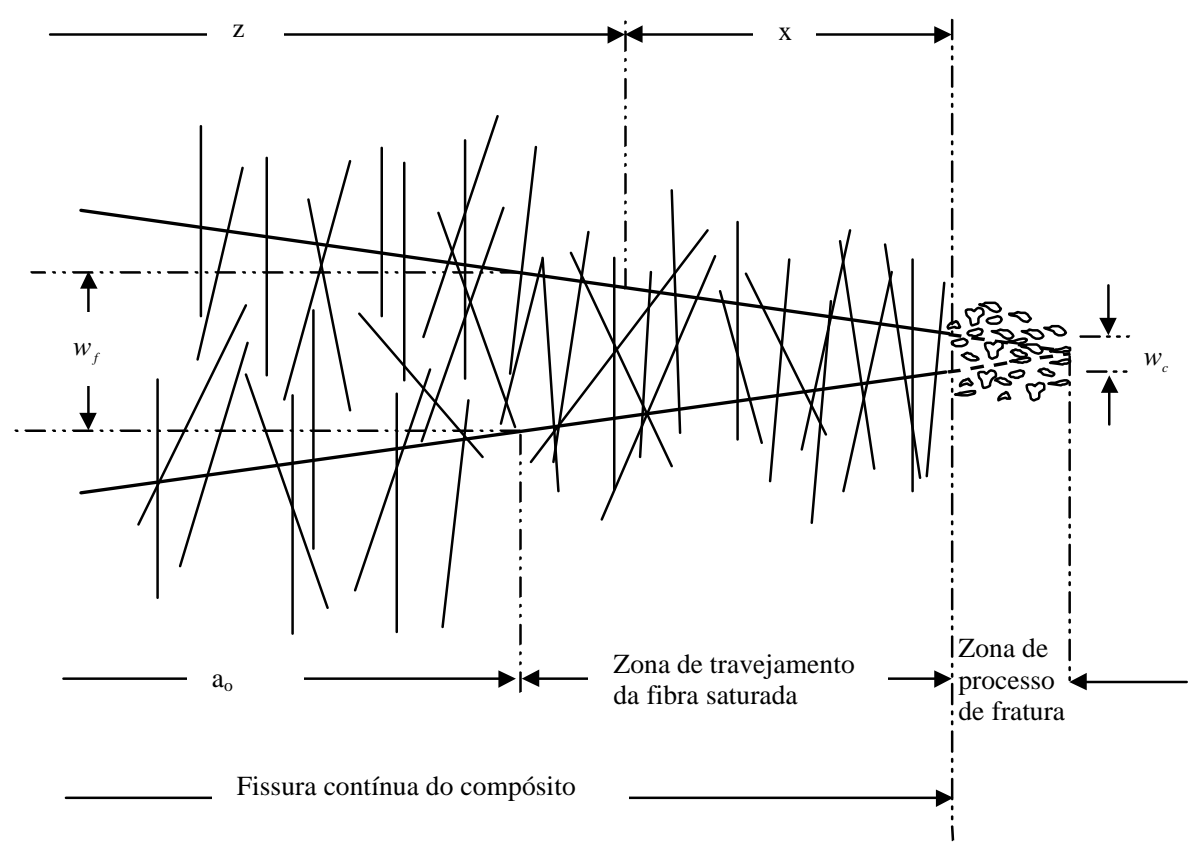

Fig. 2.7: A Zona de Processo (ZPF) e de Travejamento (ZTF) de Fratura em um elemento entalhado de um Compósito Tipo II (Segundo COTTERELL E MAI, 1996).

Embora seja muito simples, a figura 2.7 mostra claramente a diferença entre as duas zonas principais de uma fratura. Como pode-se ver desta figura, a divisão entre as duas zonas é a ponta da fratura da matriz que, segundo COTTERELL E MAI (1996), é difícil de ser localizada com exatidão. Segundo os mesmo pesquisadores, em geral, o tamanho da ZTF em compósitos cimentíceos depende da razão do aspecto (aspect ratio) das fibras, da geometria, e tamanho (efeito de escala) do elemento e da configuração de carregamento. Seu tamanho também varia de compósito a compósito.

O comportamento dos compósitos Tipo II pode melhor ser descrito em termos de uma curva tensão2deslocamento, onde o deslocamento elástico total antes das fissuração é separado do deslocamento na zona de processo de fratura ou na zona de travejamento de fissura. Existem dois tipos de compósito Tipo II; os compósitos Tipo IIA e Tipo IIB. Em compósitos Tipo IIA as fibras são compridas e a tensão de arrancamento é praticamente constante para altos valores de CODs (crack opening displacements). A figura 2.8 ilustra uma curva esquemática de tensão2deslocamento de um compósito Tipo IIA. 


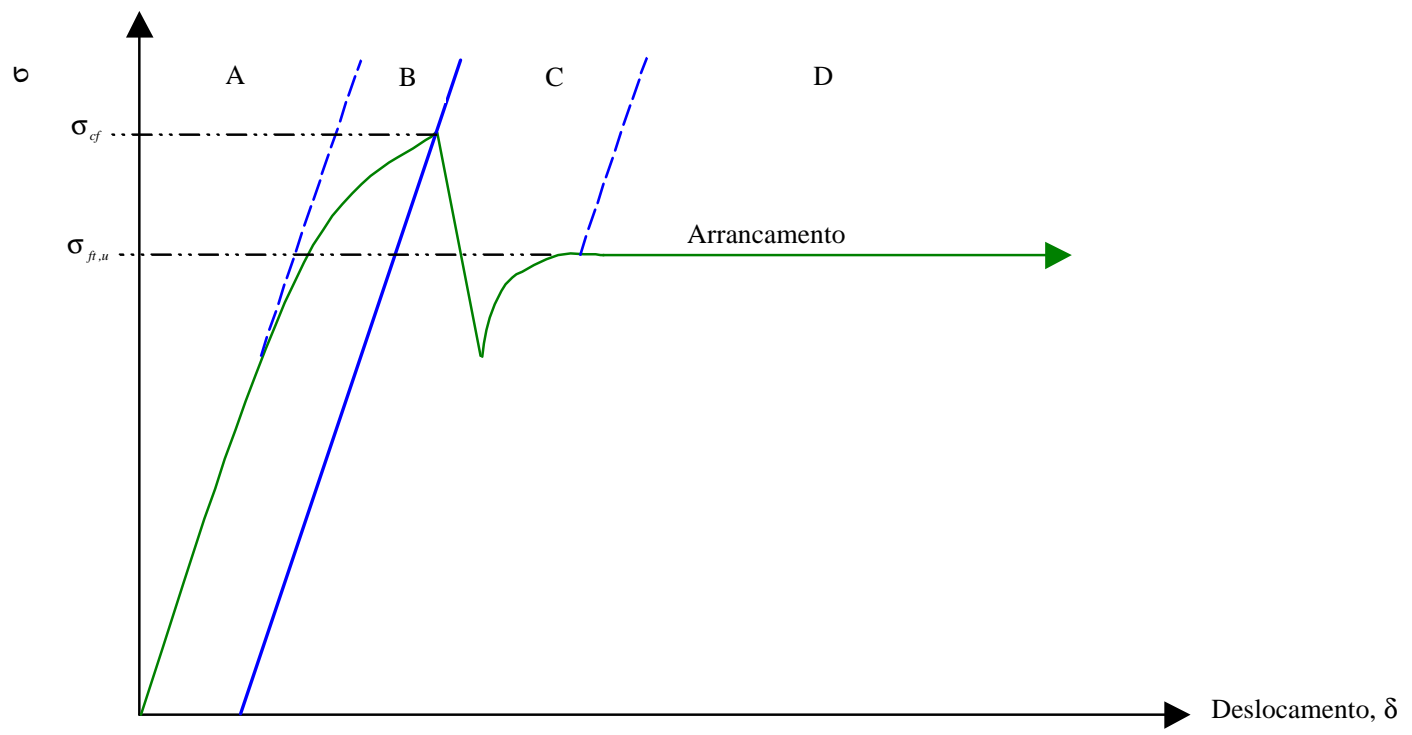

Fig. 2.8: Curva esquemática tensão 2 deslocamento, $\sigma-\delta$, de um compósito Tipo IIA armado com fibras compridas (Segundo COTTERELL E MAI, 1996).

O comportamento inicial é elástico linear (Região A). Com o aumento da tensão, há uma não linearidade na curva tensão2deslocamento (Região B) devido principalmente à microfissuração na zona de processo de fissura. COTTERELL E MAI (1996) afirmam que há uma estabilização parcial da microfissuração pelas fibras, e como conseqüência, o compósito atinge uma deformação máxima antes da localização da ZPF ser maior que a deformação correspondente à da matriz não armada. Atingida a resistência à fratura, do compósito, $\sigma_{c f}$, a tensão cai com a mobilização do atrito. Pode haver uma pequena recuperação de carga na Região $C$ devido à deformação elástica das fibras na vizinhança da fissura antes que as mesmas sejam arrancadas sob atrito. Se as fibras são compridas, a tensão permanece constante $\sigma_{f t, u}$ (Região D).

Os compósitos Tipo IIB são compostos de fibras curtas, e são o tipos de compósitos tratados nesta pesquisa. Ao contrário de compósitos Tipo IIB onde as fibras são preferencialmente alinhadas, as fibras curtas e discretas empregadas em CAF são aleatoriamente dispostas. Esta orientação tem a vantagem de cumprir uma dupla exigência tecnológica: o alinhamento de fibras curtas (quando estes forem a opção mais adequada) é extremamente difícil, exigindo uma tecnologia sofisticada. A disposição aleatória tem um grande benefício do ponto de vista do processamento do 
compósito, embora isso quase sempre é obtido ao custo de melhor desempenho proveniente de alinhamento. Este benefício é proveniente exatamente do fato de que, para a disposição aleatória, as fibras curta são simplesmente misturadas com outros componentes da mistura como se fossem agregados. Além do mais, a disposição aleatória tem uma vantagem do ponto de vista do desempenho sob tração comparado ao das fibra curtas e alinhadas. Este desempenho vem do fato de que, durante o arrancamento, as fibras aleatórias (e portanto inclinadas) consomem maior energia devido à plastificação da mesma na região do plano da fissura. Essa plastificação é provida pela restrição causada pelo atrito, formado uma rótula plástica. Este fenômeno será abordado em detalhe no capítulo 3.

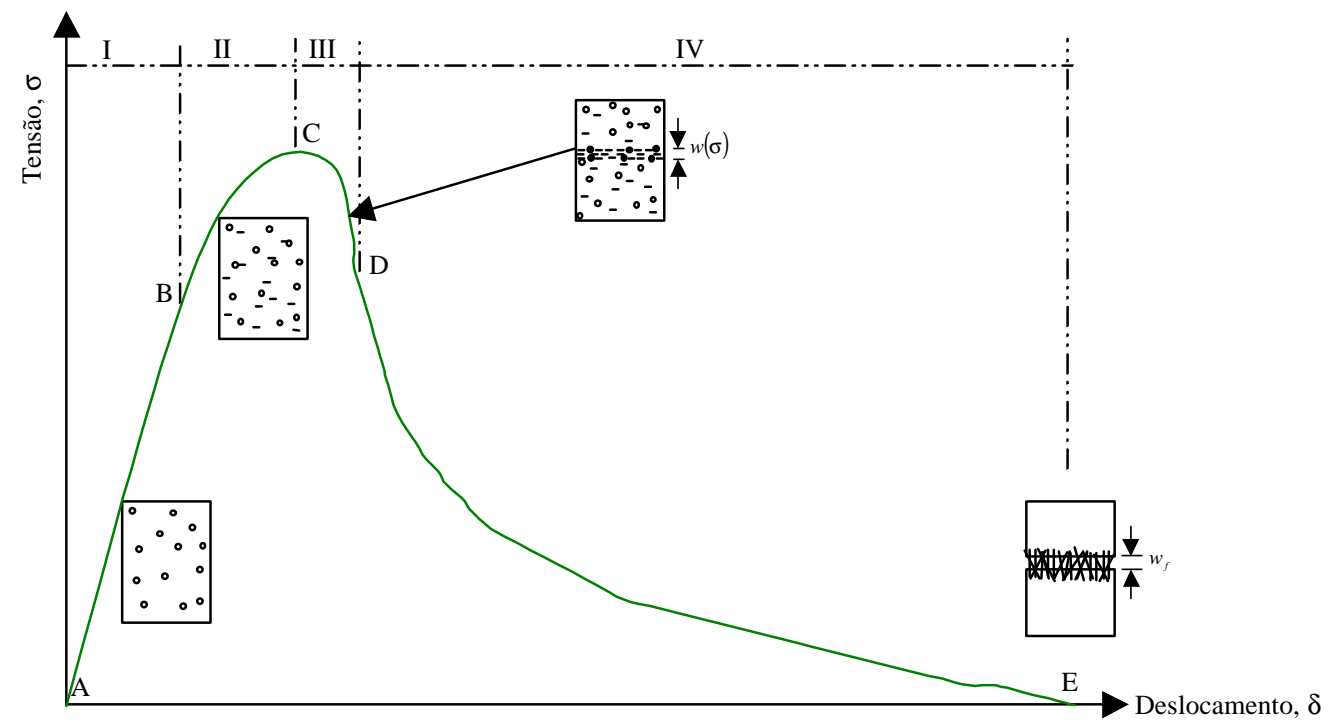

Fig. 2.9: Curva esquemática tensão2deslocamento, $\sigma-\delta$, de um compósito Tipo IIB armado com fibras curtas (Segundo COTTERELL E MAI, 1996).

A figura 2.9 é uma ilustração do comportamento de compósitos Tipo IIB armados com fibras curtas, discretas e aleatoriamente dispostas. Pode-se ver que esses compósitos apresentam uma queda de tensão após pico, ao contrário dos Tipo IIA. Isso é devido principalmente ao efeito do comprimento da fibras. Enquanto as fibras Tipo IIA são arrancadas sob tensão, em compósitos de Tipo IIB, a tensão de arrancamento deve cai pois cada fibra arrancada deixa de contribuir na capacidade pósfissuração do compósito. Também é importante perceber, como anteriormente 
apontado na seção 2.1 que, o comportamento dos compósitos Tipo IIA é semelhante ao correspondente matriz cimentícia não armada com fibra. Na região I o compósito exibe um comportamento elástico linear, passando para não linear antes de atingir do pico, devido à formação de microfissuras (região II). Há uma não linearidade pós-pico e uma conseqüente perda de rigidez na região III, e uma recuperação elástica paralela à rigidez inicial devido à perda de aderência. Nesta região, um macrodefeito já se estabelece, e na região IV o compósito demonstra um amolecimento progressivo de tensão devido ao arrancamento e/ou fratura das pontes. No entanto, ao contrário dos materiais cimentíceos não armados com fibras nos quais a abertura crítica de fissura, $w_{c}$ (COD), é da ordem de 0,1mm (COTTERELL E MAI, 1996), em compósitos Tipo IIB este valor é igual a metade do comprimento da fibra $\left(w_{f}=l_{f} / 2\right)$.

\subsection{A CURVA TENSÃO2ABERTURA DE FISSURA EM CAF}

\subsubsection{Amolecimento de Tensão}

No item 2.2, a importância da relação tensão2deslocamento como parâmetro mais importante na descrição do comportamento de compósitos cimentíceos foi apresentada, destacado-se o comportamento pós2fissuração. Na mesma seção alguns dos vários mecanismos mobilizados no início ou na propagação de uma fratura em materiais cimentíceos foram mencionados. Na seção 2.2.2, esses mecanismos foram revistos no que diz respeito a materiais cimentíceos armados com fibras, dando maior ênfase nos CAF Tipo IIB. Além do mais, foi menciona que o comportamento de CAF Tipo IIB é qualitativamente semelhante ao matriz cimentícia não armado embora devido à adição das fibras, os parâmetros dos dois compósitos são diferentes. Este ponto foi bem sustentado e explicado na seção 2.2.2 apresentando-se a zona de travejamento de fissura em compósitos cimentíceos armados com fibras que se superpõe sobre a zona de processo de fissura em compósitos não armado.

Segundo LI E LIANG (1986), o comportamento pós2fissuração de um concreto armado com fibras descontínuas e aleatoriamente distribuídas pode ser previsto por uma relação tensão2abertura de fissura. Segundo esses pesquisadores, o emprego de 
uma curva tensão2abertura de fissura em vez de tensão2deformação, para descrever a deformação inelástica na zona de processo de fissura está relacionado ao comportamento frágil da matriz que resulta em microfissuras, e aos efeitos de travejamento através da fissura pelo agregado e fibras. Portanto, o desenvolvimento da zona de processo de fratura é caracterizado pela relação tensão2abertura de fissura, $\sigma-\delta_{t}$, que reflete os mecanismos de tenacidade na zona de processo de fratura (LI E MAALEJ, 1994; LI ET AL., 1994; WANG ET AL., 1991). Segundo LI E LIANG (1986), esses mecanismos controlam a forma da curva $\sigma-\delta_{t}$ que por sua vez influencia 0 comportamento pós2fissuração de um elemento de concreto ou concreto armado com fibras e portanto, é um parâmetro do material. Este fato tem uma implicação sérias do ponto de vista de dimensionamento e análise de estruturas de compósitos a base de cimento. A implicação é que, a curva $\sigma-\delta_{t}$ é um parâmetro geral do material, não afetada pelo efeito de escala conforme discutido na seção 2.1. Isso tem a grande vantagem de que, o dimensionamento e/ou a análise da estrutura pode ser feito antes mesmo do conhecimento das dimensões e carregamentos estruturais.

É de fácil aceitação que após fissuração, o elemento fissurado pode ser dividido em dois trecho distintos: um trecho na região das fissuras, e um segundo trecho entre as fissuras. O trecho que constitui uma pequena faixa na região das fissuras, na realidade é a zona de processo, e demostra um comportamento inelástico (curva CE da figura 2.10). Ao contrário, o trecho entre fissuras, por não estar fissurado, exibe um comportamento elástico linear como do elemento antes da fissuração. Diante disso, o comportamento pós2fissuração em geral, e o estudo da fissuração de um compósito cimentíceo em particular, é uma superposição de um comportamento elástico linear entre as fissura e um comportamento inelástico na ZPF. O estudo da fissuração em concreto e seus compósitos portanto exige o estudo e modelagem do comportamento dos dois trechos. O comportamento elástico do compósito e sua contribuição, chamado endurecimento de tensão (tension stiffening) na abertura de fissura e a sua modelagem serão vista no capítulo 3. Neste capítulo a atenção está dirigida ao comportamento do compósito na ZPF e/ou ZTF (curva de amolecimento, $\sigma-\delta_{t}$ ).

Para o efeito de estudo da fissuração, a curva de amolecimento é de extrema importância, pois somente após da sua modelagem, seja ela analítica ou experimental, que somos capazes de levar em conta todos os mecanismos que resistem 0 
desenvolvimento ou propagação de uma fissura, e portanto, será possível a determinação dos vários parâmetros da fissuração como, a abertura e consequentemente o espaçamento de fissura. Alguns desses mecanismos já foram apresentados no decorrer das seções anteriores, e um retrato claro dos mesmos será visto mais a diante neste capítulo para uma melhor clareza. A obtenção dessa curva a partir da curva tensão-deslocamento, $\sigma-\delta$, já foi discutida na seção 2.2.1 para o caso de compósitos não armados. Sob a ótica da semelhança entre materiais cimentíceos não armados e CAF Tipo IIB, está reproduzida, na figura 2.10, a parte pós-pico da curva tensão2deslocamento da figura 2.5, após ter subtraído o deslocamento elástico, $\delta_{e}$. Isso significa que, para a curva tensão-abertura de fissura da figura 2.5, a ordenada passa pelo ponto X conforme mostra a figura 2.10 (linha tracejada). A descrição dos vários pontos e trechos da curva segue como anteriormente discutido para materiais não armados, mudando-se apenas a simbologia dos parâmetros para destacar as diferencia quantitativa dos parâmetros conforme já mencionado.

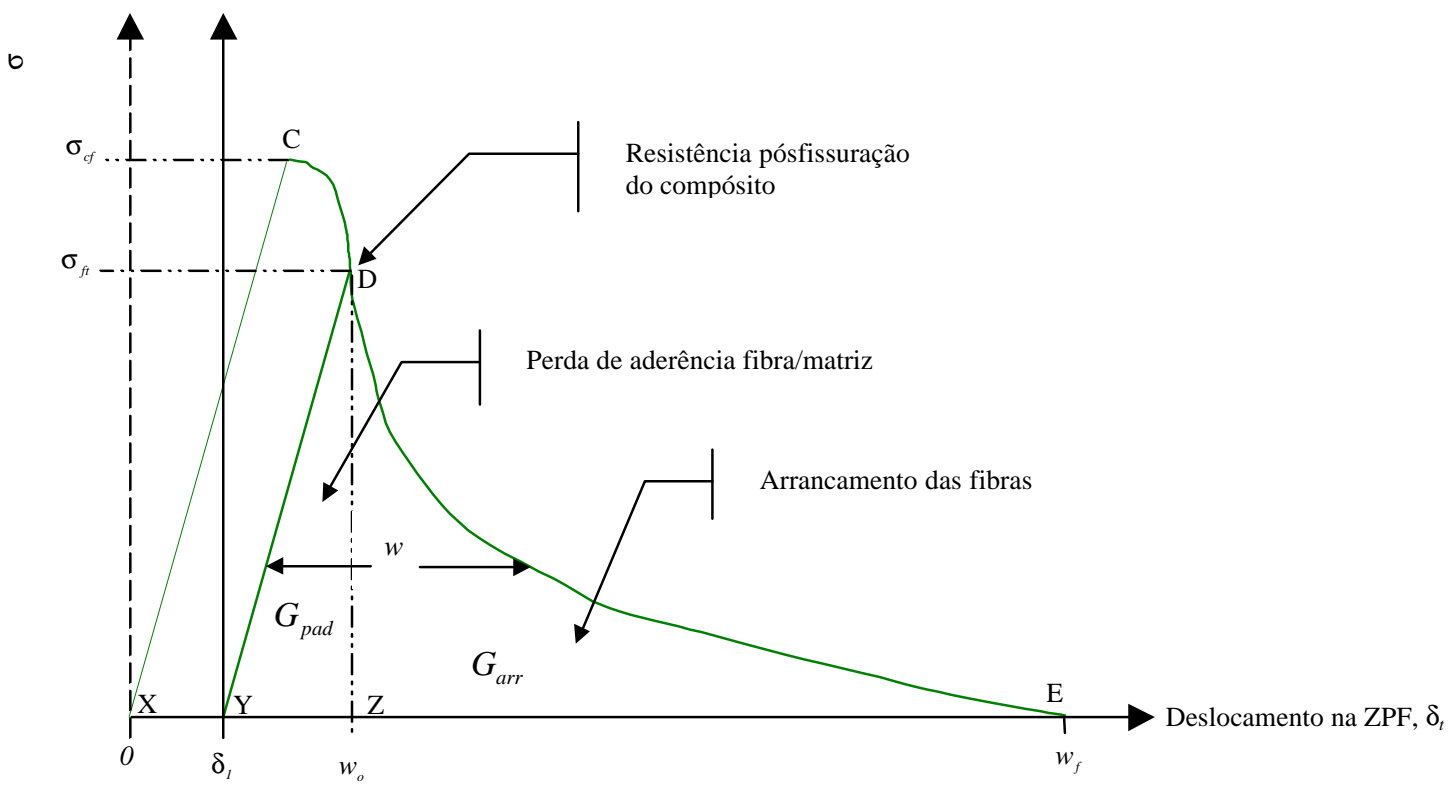

Fig. 2.10: Curva esquemática tensão de travejamento2abertura de fissura, $\sigma-\delta_{t}$. (Segundo LI ET AL., 1994).

A curva tensão2abertura de fissura, $\sigma-\delta_{t}$, (XCDE na figura 2.10) é composta de duas partes; uma parte crescente até um pico, XC, chamada curva pré2pico, e uma 
parte decrescente, CE, chamada curva pós2pico. Segundo afirma LI E LIANG (1986), a curva pré2pico é proveniente de presença de deformação entre os suportes do LVDT em ensaios de tração direta. Ela pode portanto ser interpretada como a soma da deformação elástica e o dano distribuído antes da localização inelástica sobre a zona de processo de fratura, e portanto, não deve ser considerada como parte da relação $\sigma-\delta_{t}$. Da mesma maneira como o comportamento pré2fissuração do elemento, a curva pré2pico pode ser prevista da relação tensão2deformação $\sigma-\varepsilon$ (BENTUR E MINDESS, 1990; LEUNG E LI, 1995). Esta curva é uma propriedade fundamental do material e deve governar a tensão de fissuração do compósito e a presença ou não da fissuração múltipla (LI E LEUNG, 1992).

Na figura 2.10 o ponto $w_{o}$ representa a abertura de fissura correspondente à tenacidade da ponta da fratura. Como foi anteriormente discutido, este ponto representa o início de arrancamento e/ou fratura das pontes, e portanto a fissura física visível. Este valor da tenacidade define o ponto $\left(w_{o}, \sigma_{f t}\right)$ na curva $\sigma-\delta_{t}$ pelo qual uma reta paralela à inclinação da curva inicial $\sigma-\delta$ pode ser traçada. A parte da curva $\sigma-\delta_{t}$ a direita desta reta representa a curva verdadeira $\sigma-\delta_{t}$. Isto significa a translação do eixo ordena de $\delta_{1}$ (linha cheia na figura 2.10). Segundo um tratamento numérico realizado por LI ET AL. (1994), a curva de tensão-abertura de fissura verdadeira, $\sigma-w$, pode ser deduzida numericamente da curva $\sigma-\delta_{t}$ corrigindo-se a abertura de fissura da zona de processo devido ao deslocamento elástico $\delta_{l}$. LI ET AL.(1994), propõem que abertura de fissura real devido ao deslocamento na zona de processo é dada por:

$$
w=\delta_{t}-\left[\delta_{1}+\frac{w_{o}-\delta_{1}}{\sigma_{f t}} \sigma\left(\delta_{t}\right)\right], \text { para } \delta_{t} \geq w_{o}
$$

onde os parâmetro na equação (2- 1) são ilustrado na figura 2.10 e são dados por: $w$-deslocamento real na ZPF, igual a abertura de fissura; $\delta_{t}$ - deslocamento total medido no LVDT; $\delta_{1}$ - a recuperação elástica na ZPF devido à deformação elástica das pontes; 
$w_{o}$-deslocamento da abertura da ponta da fissura (CTOD) correspondente à tenacidade da ponta da fissura;

$\sigma_{f t}$ —esistência pós-fissuração do compósito;

$\sigma\left(\delta_{t}\right)$ —ensão de travejamento pós-pico.

\subsubsection{Processos de Fratura e Mecanismos de Tenacidade em CAF}

É de aceitação geral que a propagação de uma fissura em matrizes cimentícias e seus compósitos é controlada pela formação de uma zona de travejamento de fissura atrás da ponta da fissura. Conforme visto na seção 2.2.2, além da formação da ZPF, nos ensaios de peças de compósitos cimentíceos armados com fibras, Tipo II, uma zona de travejamento de fissura (ZTF) é formada devido ao travejamento das fibras.

A formação e propagação de uma fratura em um material cimentíceo é um fenômeno que absorve energia. A energia total de fratura de compósitos cimentíceos armados com fibras de Tipo II é proveniente de vários mecanismos, alguns dos quais já foram falados no decorrer das seções anteriores. Esses mecanismos são conhecidos como mecanismos de tenacidade, pois tem o efeito de aumentar a resistência à fratura (tenacidade) do material. É evidente portanto, que o modo de fratura esteja intimamente ligada ao tipo preponderante dos mecanismos mobilizados. Há portanto razões muito fortes em se pensar que o comportamento da curva de amolecimento depende do mecanismos de travejamento que proporcionam a resistência contra a propagação da fissura. Esta opinião é sustentada por LI E LIANG (1986) e WANG ET AL. (1991). LI E LIANG (1986), também afirmam que, baseado nos processos físicos de fratura, a curva $\sigma-w$ deve refletir a dissipação de energia dos mecanismos de absorção de energia. Portanto, o conhecimento desses micromecanismos e dos parâmetros que os controlam é de extrema importância, pois somente este conhecimento pode viabilizar o dimensionamento de compósitos cimentíceos armados com fibras de alta resistência e/ou tenacidade.

Os mecanismos de fratura são por si, restritos a serem mobilizados dentro de processos de fratura específicos. Esses processos pode ser classificados segundo zonas na fratura chamadas zonas de fratura, nas quais os vários mecanismos que os 
compõem são mobilizados. Segundo VISALVANICH E NAAMAN (1983), para uma fratura bem desenvolvida, os mecanismos de tenacidade podem ser descritos segundo três zonas: a zona livre de tensão (zona I), a zona pseudoplástica (zona II), e a zona de processo de fratura (zona III). A figura 2.11 ilustra as várias zonas de uma fratura (fissura) onde os mecanismo físicos de tenacidade responsáveis pelo consumo de energia durante a fratura, são mobilizados.

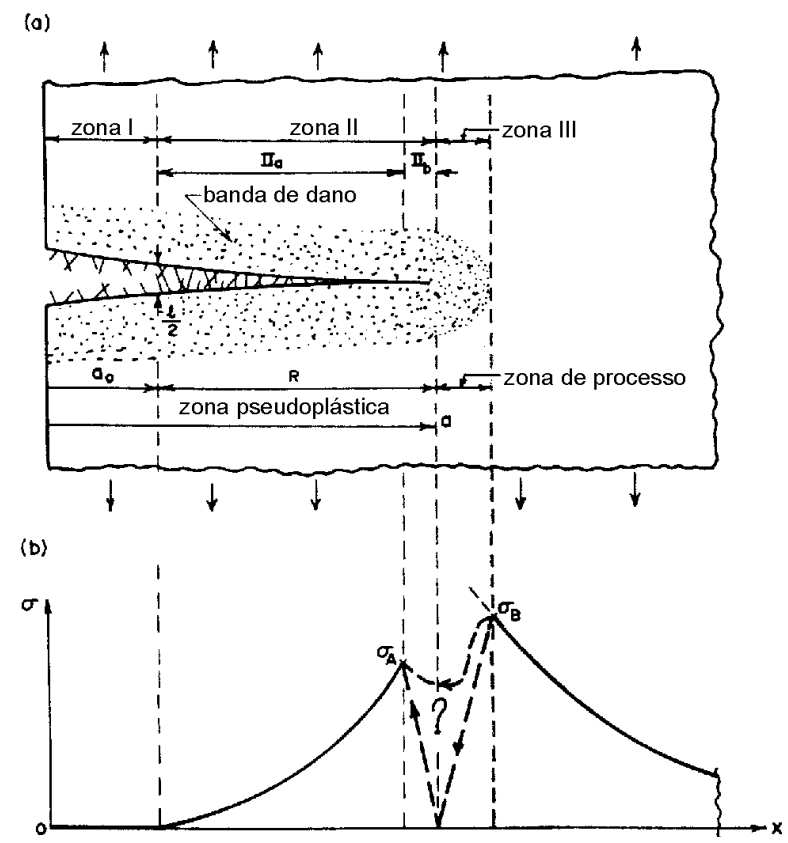

Fig. 2.11: Modelo de fissura para compósitos CCAF mostrando (a) zona de fratura, e (b) possível distribuição de tensão (Segundo VISALVANICH E NAAMAN, 1983)

Zona I: Esta zona representa a fissura real no compósito, ao longo da qual as superfícies da fissura estão sob tensão nula devido ao arrancamento e/ou ruptura das pontes de sustentação.

Zona II: A zona pseudoplástica, análoga à zona plástica em materiais dúcteis, é aquela onde a matriz está fissurada mas as fibras ainda fornecem uma resistência ao arrancamento ou deformação. Segundo VISALVANICH E NAAMAN (1983), esta zona pode ser dividida em duas: zona IIa, onde todas as fibras estão efetivas, e zona IIb, onde a abertura de fissura é muito pequena para induzir o arrancamento das pontes.

Zona III: É a zona de microfissuração ou zona de processo de fissura (ZPF). 
Existem três famílias principais de processos de fratura responsáveis pela tenacidade em concretos armados com fibras (LI E MAALEJ, 1996; ): (a) Processos frontais ("Frontal processes), (b) Processos da ponta da fissura ("Crack-tip processes"), e (c) Processo no rasto da fissura ("Crack wake processes"). Cada um desses processos está localizado em uma das zonas de fratura onde são mobilizados mecanismos específicos do processo, sendo que, do ponto de vista de energia, cada mecanismo é responsável pelo consumo de um certo quihão de energia de fratura. $A$ figura 2.12 demostra os mecanismos de tenacidade que compõem os três principais processos de fratura.

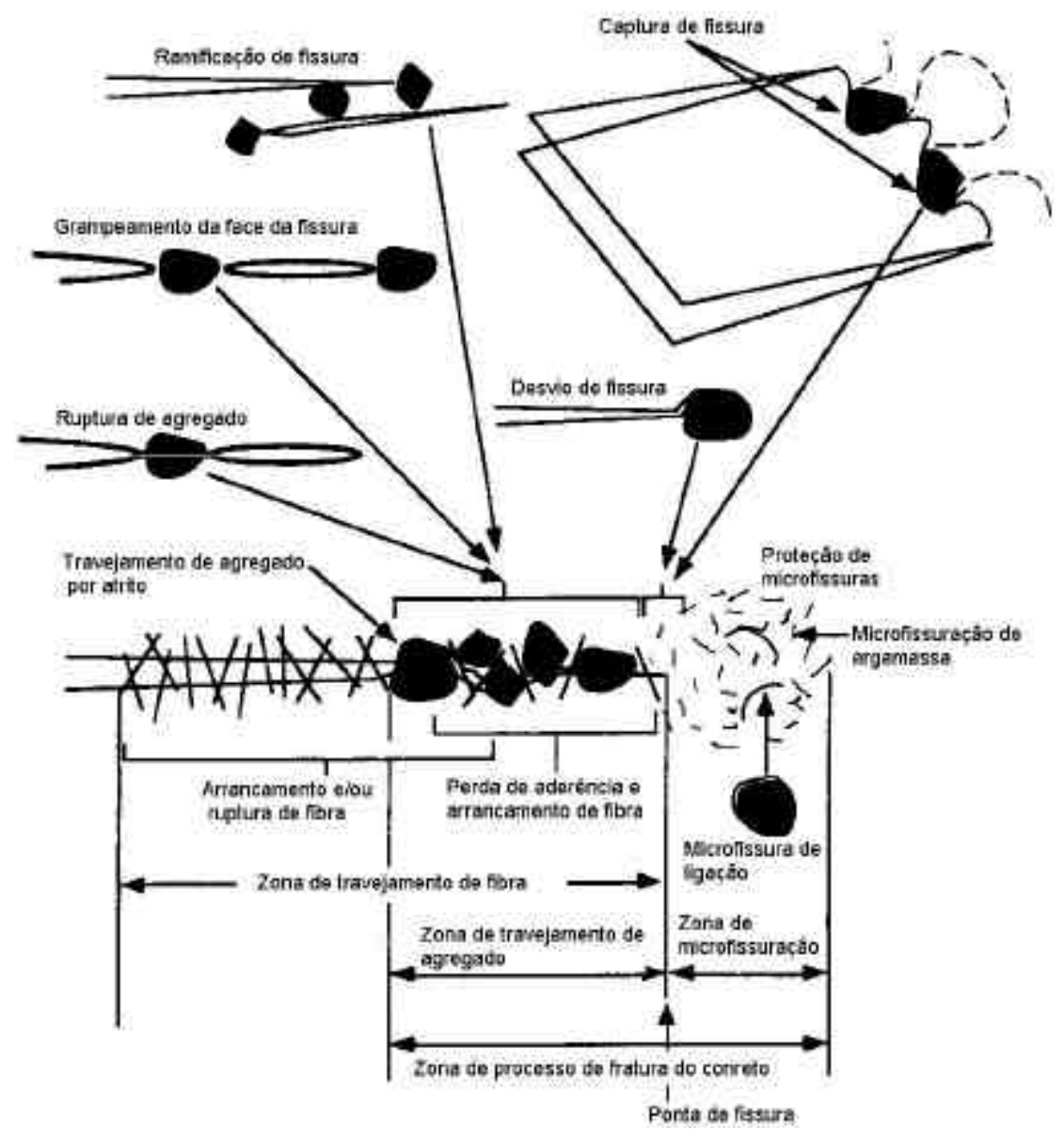

Fig. 2.12: Possíveis mecanismos de tenacidade num CAF (Segundo LI E MAALEJ, 1996)

1) Processos Frontais ("Frontal Processes")

Estes processos são compostos principalmente do mecanismos conhecidos como mecanismo de proteção da fratura pelas microfissuras ("microcrack shielding") 
presente na zona III da figura 2.11. Na figura 2.12, esta zona é representada pela região após a ponta da fissura.

2) Processos de Ponta da Fissura ("Crack Tip Processes")

São processos que se manifestam na da ponta da fissura. A zona de fratura correspondente é a zona IIb onde a abertura a muito pequena a ser vista (figura 2.11). $\mathrm{Na}$ figura 2.12, esta zona corresponde a uma pequena faixa imediatamente antes da ZPF. Os processos de ponta da fissura são compostos dos seguintes mecanismos:

- mecanismo de apreensão ou captura da frente da fissura ("crack front trapping"), e

- mecanismo de desvio de fissura ("crack deflection").

3) Processos no Rasto da Fissura ("Crack Wake Processes")

Esses processos se manifestam na região da fissura real que estende entre as zonas I e IIa. Os mecanismos que compõem os processos de rasto da fissura são:

- mecanismo de alfinetamento ou grampeamento da face da fissura ("crack face pinning") na zona IIa.

- mecanismo de travejamento agregado/ligamento ("aggregate/ligament bridging") na zona IIa,

- mecanismo de perda de aderência e arrancamento das fibras a zona IIa,

- mecanismo de arrancamento e/ou ruptura das pontes (fibras e/ou agregados) na zona I.

\subsubsection{Modelagem Analitica da Fratura}

Qualquer modelo analítico, para ser eficaz em descrever a fissuração em concreto e seus compósitos, deve obrigatoriamente, levar em conta os vários mecanismos de tenacidade que ocorrem na zona de processo e de travejamento da fratura. A quantificação da contribuição desses mecanismos na tenacidade total do compósito é extremamente importante na formulação analítica pois, somente a partir disso que, se pode claramente justificar qualquer simplificação.

Segundo LI E MAALEJ (1996), a variação da tensão ao longo da linha da fissura em um CAF, devido ao presença de agregados e fibras, pode ser considerada 
como uma combinação dos efeitos de singularidade da ponta da fissura, amolecimento de tensão do agregado e o travejamento das fibras. Do ponto de vista da modelagem analítica, isso implica a modelagem de cada uma das três parcela se a fissura deve ser analisada.

Considerando portanto, o concreto armado com fibras como a superposição de concreto simples e fibras, dois modelos independentes podem ser superpostos para descrever completamente a variação da tensão ao longo da fissura: o Modelo de Fissura Coesiva de Barenblatt e Dugdale, e o Modelo de Fissura Travejada de Cox e Marshall (LI E MAALEJ, 1996). Os dois modelos são importantes para prever as duas famílias de processos; os processos frontais "frontal processes" e processos no rastro da fissura "wake processes", que absorvem energia e portanto são associados ao desenvolvimento da fissura. Segundo LI E MAALEJ (1996), a natureza localizada dos processos de rastro usualmente implica que tais processos governam a parte de amolecimento da curva de tensão2deslocamento num ensaio de tração. Essa afirmação implica simplesmente que, o consumo de energia de fratura nos processos frontais e de ponta pode ser considerado desprezível.

Se portanto esses processos podem ser caracterizados por uma relação tensão2abertura de fissura, a energia de fratura pode ser facilmente determinada como:

$$
G=\int_{0}^{\ell} \sigma(x) \frac{\partial \delta_{t}(x)}{\partial x}=\int_{0}^{w_{f}} \sigma\left(\delta_{t}\right) d \delta_{t}
$$

onde a primeira integral na equação (2- 2) é baseada na chamada integral J, e o segunda integral representa a área sob a curva $\sigma-\delta_{t}$.

Pode-se ver portanto que a relação tensão-abertura de fissura, $\sigma-w$, está amarrada a um parâmetro básico de fratura, a energia de fratura. A expressão (2- 2) é uma representação mais apurada do fenômeno de fissuração, pois leva em conta os principais mecanismos de tenacidade. Portanto, ela pode ser considerada exata, e representa a premissa básica do estudo analítico da fissuração. A área sob a curva $\sigma-w$ é uma medida da energia de fratura ou tenacidade do material. Isso está 
ilustrado na figura 2.10, onde a área YDZ representa a energia de perda de aderência, e a área DEZ representa a energia de arrancamento e/ou fratura das pontes.

Segundo LI E MAALEJ (1996), o Modelo de Fissura Coesiva é apropriado para descrever a fissuração em concreto pois modela os mecanismos físicos de avanço de uma fissura (ou os processos de dano controladores do avanço de uma zona coesiva), enquanto o Modelo de Fissura Travejada modela os mecanismos de travejamento devidos às fibras (aumento de tenacidade devido às fibras). Esses dois modelos serão empregados no capítulo 3 na modelagem micromecânica do concreto armado com fibras, para uma modelagem analítica posterior da abertura física de uma fissura.

\subsubsection{Fatores que Influenciam a Curva Tensão-Abertura de Fissura}

Conforme foi descrito nas seções 2.3 e 2.4 , a curva tensão-abertura de fissura na tração é uma propriedade do material. Isto entretanto exige que as exigências do material submetido à tração sejam cumpridas. Em outras palavras, a curva tensão-deslocamento global obtida de um corpo de prova ensaiado na tração direta apenas representa a propriedade verdadeira do material caso as deformações são uniformemente distribuídas ao longo de toda zona de processo de fratura, a partir do instante em que a primeira fissura se inicia, até o instante em que nenhum carregamento pode ser transferido através da zona de processo. A implicação do mencionado é que, a reprodução da curva tensão-deslocamento em laboratório exige alguns requisitos.

\section{Rigidez do equipamento de ensaio}

Em primeiro lugar, o equipamento de ensaio deve ser muito rígido se quiser reproduzir a curva tensão-deslocamento. Se a rigidez do equipamento não for suficiente, ocorrerão problemas de instabilidade (AARRE, 1992; HILLERBORG, 1989; VAN MIER E SCHLANGEN, 1989; COTTERELL E MAI, 1996). Este tipo de instabilidade ocorre tipicamente na parte descendente da curva de tensão-deslocamento (curva de amolecimento), pois a parte ascendente da curva não 
representa um comportamento real do material. HILLERBORG (1989) estudou o problema da rigidez do equipamento de ensaio. Segundo este pesquisador, as propriedade elásticas do equipamento podem ser expressas como:

$$
\delta=\varsigma_{o}-\frac{F}{k_{s}}
$$

onde:

$\delta$-deslocamento transferido ao corpo de prova,

$\varsigma_{o}$-deslocamento produzido pelo equipamento,

$F=A_{s} \sigma(w)$ força aplicada, e

$k_{s}$ —rigidez do equipamento.

HILLERBORG (1989) demostrou que para se obter uma fratura estável, o seguinte critério de estabilidade deve ser satisfeito: a reta representada pela equação (2.3) não deve tangenciar a curva $\sigma-w$. Isto pode ser formalmente expressa como:

$$
k_{s}>-A_{e f} \frac{d \sigma(w)}{d w}
$$

onde

$$
\begin{aligned}
& \frac{d \sigma(w)}{d w} \text {-inclinação da curva } \sigma-w, \mathrm{e} \\
& A_{e f} \text {-área da seção transversal do corpo de prova. }
\end{aligned}
$$

No entanto, este tipo de problema de instabilidade é bem conhecido e relativamente simples de resolver empregando-se um equipamento hidráulica servo controlado (VAN MIER E SCHLANGER, 1989; AARRE, 1992) e equipado com um sistema para ensaio em ciclo fechado (closed2loop system).

Além da rigidez global do equipamento na direção de tração, é preciso também considerar a rigidez por rotação do equipamento. Se a rigidez por rotação do sistema não for adequada, ocorrerá uma instabilidade por rotação. Instabilidade por rotação significa que as duas partes do corpo de prova em cada lado a zona de processo 
giram, uma com respeito à outra (figura 2.13), e por conseguinte, o deslocamento dentro da zona coesiva (ZPF) não é uniformemente distribuído.
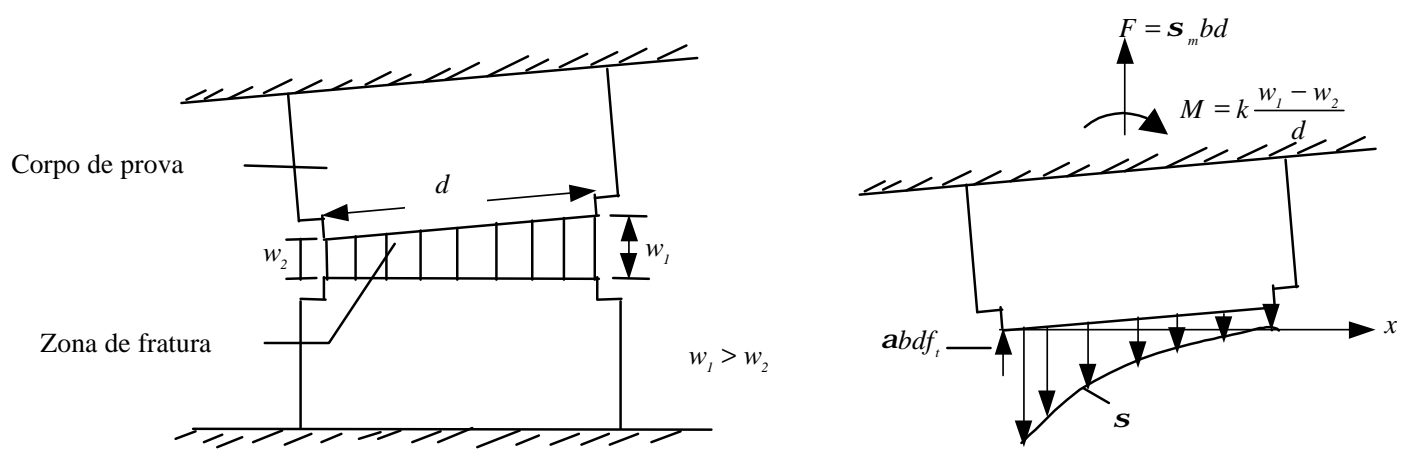

Fig. 2.13: Deslocamentos na zona de processo onde ocorrem instabilidade (Segundo HILLERBORG, 1989).

Segundo AARRE (1992), este fenômeno envolve um maior risco de resultados incertos e, ao contrário da instabilidade devida à rigidez inadequada do equipamento, a instabilidade por rotação pode ocorrer sem seja percebida.
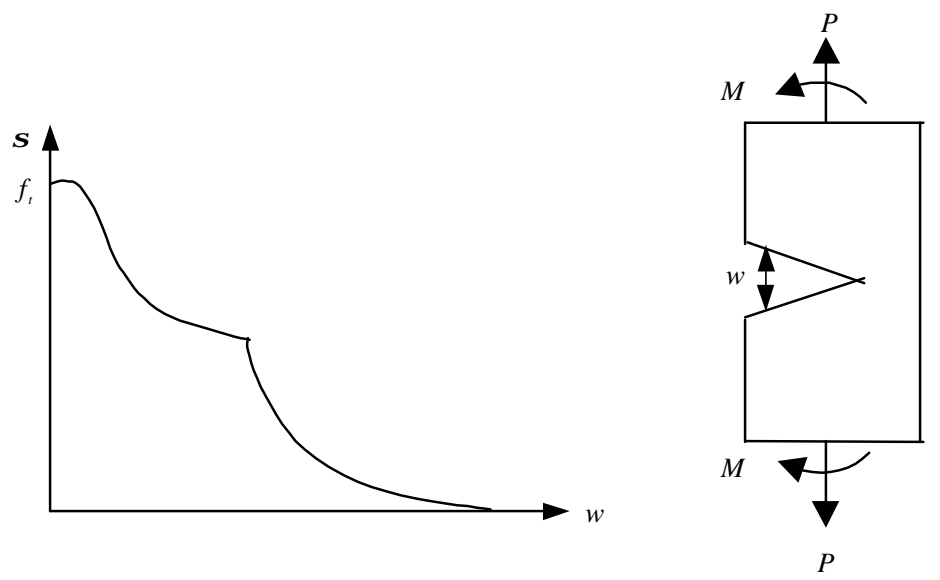

Fig. 2.14: Influência da insuficiência da rigidez por rotação do aparelho de ensaio (Segundo HILLERBORG, 1989)

A instabilidade por rotação tem sido profundamente estudada por HILLERBORG (1989) e VAN MIER E SCHLANGER (1989). No seu trabalho, Hillerborg observou que se a rigidez por rotação for insuficiente, um patamar pronunciada é formado na curva de amolecimento (figura 2.14). Segundo HILLERBORG (1989), este 
patamar está relacionada ao momento estabilizante proveniente da crescente excentricidade do sistema corpo de prova/equipamento de ensaio, quando o corpo de prova começa a fletir.

HILLERBORG (1989) também afirmou que se a rigidez à rotação aproxima a zero, situação que corresponde a vinculação do corpo de prova por rótulas, a curva tensão-deslocamento é muito próxima à curva verdadeira. Segundo AARRE (1992), embora o uso de vínculos rotulados possa fornecer resultados razoáveis, deve-se lembrar que a zona de processo é influenciada, não apenas pelas tensões normais, mas sim, também pelas tensões tangenciais, e por conseguinte, as condições de carregamento deixam ser de tração simples.

Segundo HILLERBORG (1989), pode-se evitar a instabilidade por rotação se a rigidez do equipamento de ensaio e a parte fora da zona de processo $K_{s}$ satisfazem a seguinte condição:

$$
K_{s}>I\left(-\frac{d \sigma(w)}{d w}\right)
$$

onde:

$K_{s}$ —rigidez à rotação do equipamento

$I$-momento de inércia da seção transversal do corpo de prova.

$\frac{d \sigma(w)}{d w}$-inclinação máxima da curva $\sigma-w$.

Resultados experimentais divulgados por VAN MIER E SCHLANGER (1989), também mostram a presença de um patamar na curva de amolecimento por falta de uma rigidez à rotação. Além disso VAN MIER E SCHLANGER (1989) observaram que, com a permissão da livre rotação do corpo de prova, uma curva de tensão-abertura de fissura próxima à verdadeira pode ser obtida. 


\section{Comprimento do corpo de prova e trecho de medida}

Como foi acima apontado, a rigidez do equipamento é de importância fundamental se um ensaio estável com deslocamentos controláveis for obtido. No entanto, é também de importância fundamental, a consideração da rigidez do corpo de prova.

Segundo AARRE (1992), se o corpo de prova é muito comprido, ocorrerá uma instabilidade pois a baixa rigidez do corpo de prova reduz a rigidez global do sistema. HILLERBORG (1976) afirma que mesmo se o equipamento possui uma rigidez infinita, o comprimento do corpo de prova deve ser menor que um comprimento característico, $l_{c h}$. O comprimento característico pode ser definido como:

$$
l_{c h}=\frac{E G_{F}}{f_{t}^{2}}
$$

onde:

$E$-módulo de elasticidade,

$G_{F}$ energia de fratura definida como a área sob a curva $\sigma-w, \mathrm{e}$

$f_{t}$-resistência à tração.

Segundo PETERSSOS ${ }^{2}$ apud AARRE (1992) para evitar a instabilidade num equipamento de ensaio com rigidez infinita, o comprimento do corpo de prova deve satisfazer a seguinte condição:

$$
l_{s}<-\frac{E}{\left(\frac{d \sigma(w)}{d w}\right)_{\text {máx }}}
$$

onde $(d(w) / d w)_{\text {máx }}$ corresponde a inclinação máxima da curva $\sigma-w$.

\footnotetext{
${ }^{2}$ Petersson, P. -E.;(1981). "Crack Growth and Development of Frature Zones in Plain Concrete and Similar Materials", Report TVBM-1006, thesis, university of Lund, Sweden, 1981, p. 185
} 
Segundo AARRE (1992), para evitar um colapso instável na curva de amolecimento, deve-se considerar também o comprimento $l_{g}$ do aparelho medidor de deslocamento no ensaio de tração simples. Supondo que o material fora da zona de fratura tem comportamento elástico, o deslocamento, $\delta_{e}$, coberto pelo aparelho medidor de deslocamento (LVDT), excluindo o deslocamento da zona de fratura, $w$, pode ser expresso como:

$$
\delta_{e}=\frac{\sigma}{E} l_{g}
$$

Segundo STANG E AARRE (1992), o deslocamento da zona de fratura é dado por:

$$
\frac{\sigma}{f_{t}}=\frac{1}{\left(1+\frac{w}{w_{o}}\right)}
$$

onde

$f_{t}$ é resistência à tração, e

$w_{o}$ é a abertura de fissura correspondente a redução da capacidade de carga em $50 \%$ da carga de fissuração.

A partir disso, AARRE (1992) indica que, para evitar um colapso instável, o deslocamento total $\delta_{\text {tot }}$ coberto pelo aparelho medidor de deslocamento deve sempre ser positivo, expresso como:

$$
\delta_{\text {tot }}=\delta_{e}+w \geq 0
$$

Portanto, o comprimento mínimo $l_{g}$ de (2.8) a (2.10) é dado por:

$$
l_{g} \leq \frac{E w_{o}}{f_{t}}
$$




\section{Tensões iniciais}

Segundo AARRE (1992), a presença de tensões iniciais internas também pode influenciar a curva tensão2deslocamento. Essas tensões podem ser causadas por exemplo, se o corpo de prova não for corretamente centralizado, por retração por secagem, por gradientes de umidade, ou excentricidades provenientes do desalinhamento do aparelho que aplica o carregamento. Segundo AARRE (1992), até que ponto tais tensões iniciais afetarão os resultados dependem do tamanho do corpo de prova e da tenacidade do material. Quanto menor o tamanho do corpo de prova e maior a tenacidade, menor a importância da diferença entre a curva $\sigma-w$ obtida no ensaio de tração e a curva verdadeira com a presença de tensões iniciais não desejadas. Ao contrário, se o corpo de prova for muito pequeno, o mesmo deixa de ser representativo do material, e por conseguinte, há uma maior dispersão nos resultados experimentais. O código da ASTM (C192-76) prescreve que a relação entre as dimensões mínimas do corpo de prova e o tamanho máximo do agregado deve ser maior a 3 (COTTERELL E MAI, 1996; KARIHALOO, 1995)

\section{Forma e geometria do corpo de prova}

O efeito da forma e geometria do corpo de prova foi estudado por AARRE, (1992). Quando se deseja obter a curva de amolecimento, normalmente se emprega corpos de prova com entalhe. No entanto, é importante estar informado da influencia do uso de corpos de prova entalhados.

AARRE (1992) realizou vários ensaios de tração com corpos de prova entalhados e não entalhado. Os resultados experimentais demostram claramente que o entalhe tem uma influência pronunciada sobre o módulo de elasticidade e a deformação última. O módulo de elasticidade de corpos de prova não entalhados é cerca de três vezes do medido em corpos de prova entalhados, e a deformação máxima de corpos de prova entalhados é cerca de 4 a 7 vezes maior que medida em corpos de prova não entalhado. LUB E PADMOES (1989) também observaram um aumento na não linearidade pré2pico e módulo de elasticidade reduzido nos ensaios de corpos de prova entalhados. 
Segundo AARRE (1992), uma explicação possível do módulo de elasticidade reduzido e aumento da não linearidade pré2pico é que, a presença de entalhes causa um campo de tensões não uniforme na seção do entalhe.

AARRE (1992) também observou que a magnitude da influência é levemente dependente de, se o concreto é armado com fibras ou não. Para um concreto não armado com fibras, praticamente nenhuma diferença na tensão máxima foi observada entre corpos de prova entalhados e não entalhados. Ao contrário, para CAF, a tensão máxima observada em corpos de prova entalhados chega a $9 \%$ maior que em corpos de prova não entalhados. Além do mais, a deformação máxima é cerca de $50 \%$ maior para CAF que para concreto não armado com fibras, enquanto não há nenhuma diferença entre corpos de prova não entalhado.

Segundo AARRE (1992), um explicação para esse fenômeno é que, quando corpos de prova não entalhados são ensaiados, há uma falha nos ensaios se as deformações se localizam fora da região coberta pelo medidor de deslocamentos. Para o CAF observa-se que o carregamento aumenta mesmo após a localização da microfissuração. 


\section{CApirituo \\ TRÊS}

\section{MODELAGEM DE CONCRETO ARMADO COM FIBRAS}

\subsection{PRELIMINARES}

No capítulo 2 um embasamento teórico/conceitual do comportamento dos compósitos cimentícios sob tração foi apresentado. A curva tensão-deslocamento, e em particular, a relação tensão-abertura de fissura como parâmetros mais importantes na caracterização da zona de processo, foram apresentadas. Além do mais, no item 2.3.3, foi mostrada que a relação tensão-deslocamento está intimamente amarrada à energia de fratura, fundamentando, portanto, a premissa da modelagem analítica do comportamento CAF.

Por ser um parâmetro baseado na micro-estrutura do material, a relação $\sigma-\delta$ é normalmente conhecida como um parâmetro micro-mecânico. A descrição do comportamento de um material cimentício baseada numa modelagem micro-mecânica foi profundamente estudada por BARENBLATT (1995). De fato, a modelagem micro-mecânica tem duas funções importantes: fornecer um conhecimento profundo sobre como as propriedades do compósito são controladas pela micro-estrutura do 
material e, fornecer um guia para uma receita ótima para o dimensionamento. No presente trabalho, apenas a primeira função é discutida.

Vários modelos analíticos baseados no modelo micro-mecânico dos concretos armados com fibras têm sido propostos. Segundo STANG (1995), essencialmente, existem dois modelos micro-mecânicos que definem o comportamento dos concretos armados com fibras. O primeiro, proposto por Aveston, Cooper, e Kelly, e conhecido como a teoria ACK ou lei de material compósito, é baseado em princípio na lei de mistura. Pela teoria de material compósito, as propriedades ou parâmetros micro-mecânicos do compósito podem ser previstos pela soma das propriedades dos vários componentes na mistura, cada um contribuindo no comportamento global em relação ao seu volume parcial (ou taxa volumétrico). Entretanto, a teoria ACK, embora simples, é incapaz de prever o real comportamento de amolecimento pós-fissuração do compósito, pois ela não leva em conta a seqüência dos eventos durante o arrancamento das fibras. Esta teoria é portanto válida apenas na previsão do comportamento elástico do material, sendo que os parâmetros pós-fissuração deduzidos da mesma representam desvios da realidade. A outra maneira de prever os parâmetros micro-mecânicos do compósito é pela mecânica de fratura, empregandose relação tensão-abertura (STANG, 1995). Baseado nisso, os parâmetros podem ser deduzidos de um modelo simples de arrancamento das fibras.

Embora no presente capítulo a maior ênfase será dada na obtenção dos parâmetros micro-mecânicos via a relação tensão-abertura de fissura, a previsão dos mesmos pela teoria ACK também será abordada. É importante destacar que a modelagem feita neste capítulo é válida somente para compósitos Tipo IIB com fibras aleatoriamente distribuídas.

\subsection{MÉTODO DE MATERIAL COMPÓSITO}

O método de material compósito é usualmente baseado na lei de mistura. Para as propriedades mecânicas tais como a resistência e o módulo de elasticidade, o conceito da lei de mistura é válido apenas se os dois componentes tiverem comportamento elástico linear, e se a ligação entre as mesmas for perfeita. Ela deve ser portanto, aplicada na fase elástica pré-fissurada do compósito, e mesmo nesta 
fase deve ser considerada como limite superior, pois na prática a ligação não é perfeita (BENTUR E MINDESS, 1990).

\subsubsection{Comportamento de Compósitos de Baixas Taxas de Fibras}

Para compósitos de baixa taxa de fibra, $\left(V_{f}<V_{f, c r i t}\right)$, LIM ET AL. (1987) baseando-se na lei de material compósito, deduziram um modelo analítico para prever o comportamento pré-fissuração de um compósito cimentício armado com fibras descontínuas e aleatoriamente distribuídas, levando em conta o efeito da orientação das fibras. Este modelo tem sido empregado por vários pesquisadores (BENTUR E MINDESS, 1990; TJIPTOBROTO E HANSEN, 1993) para prever o comportamento pré-fissuração do compósito. Para o comportamento pós-fissuração, LIM ET AL. (1987) propuseram um modelo analítico simples tendo como premissa básica, o método de aderência-deslocamento a partir do qual pode-se avaliar os parâmetros essenciais do compósito. Segundo LIM ET AL. (1987), o comportamento pós-fissuração é descrito como uma combinação da deformação elástica na zona não fissurada e a abertura da fissura

\subsubsection{Fase elástica}

Considere-se um elemento de um compósito cimentício armado com fibra (figura 3.1). Segundo LIM ET AL. (1987) a tensão do compósito, $\sigma_{c}$, deduzida da teoria de material compósito é dada por:

$$
\sigma_{c}=\sigma_{m} V_{m}+\eta_{\ell} \sum_{i=1}^{n} V_{f i} \sigma_{f i} \cos ^{2} \Phi_{i} \cos ^{2} \rho_{i}
$$

onde:

$\sigma_{c}$ tensão do compósito armado com fibras;

$\sigma_{m}$ - tensão da matriz não armada com fibras;

$V_{m}$-taxa volumétrica da matriz;

$\eta_{\ell}$ fator de eficiência de comprimento da fibra; 
$V_{f i}$ taxa de fibra i;

$\sigma_{f i}$ tensão na fibra;

$n$ —número total de fibras na seção transversal.

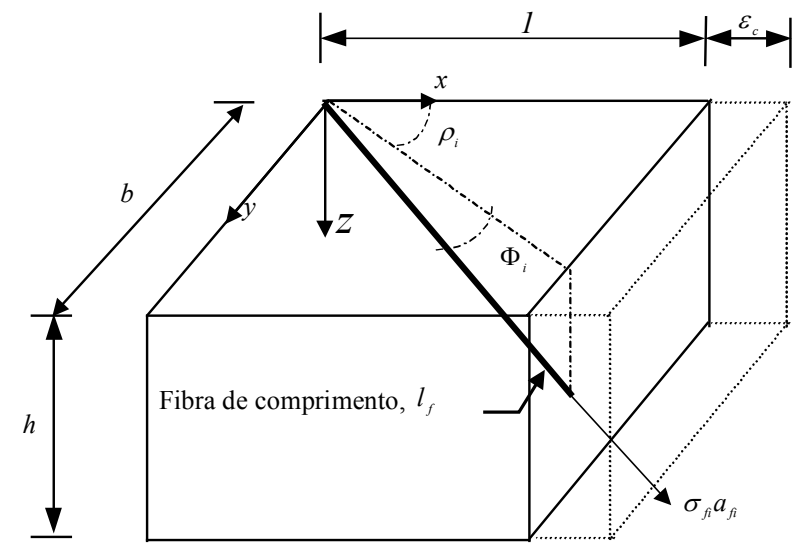

$\sigma_{c}$

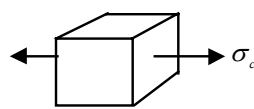

Fig. 3.1: Elemento de compósito submetido à tensão de tração (Segundo LIM ET AL., 1987)

Considerando válida a teoria de pequenas deformações, a deformação, $\varepsilon_{f i}$, é uma função da orientação. Portanto tem-se:

$$
\varepsilon_{f i}=\varepsilon_{c} \cos ^{2} \Phi_{i} \cos ^{2} \rho_{i}
$$

onde:

$$
\begin{aligned}
& \varepsilon_{f i} \text { - deformação da fibra i; } \\
& \varepsilon_{c} \text {-deformação do compósito. }
\end{aligned}
$$

substituindo (3- 2) em (3- 1) tem-se:

$$
\sigma_{c}=\sigma_{m} V_{m}+\eta_{\ell} \sum_{i=1}^{n} V_{f i} E_{f} \varepsilon_{c} \cos ^{2} \Phi_{i} \cos ^{2} \rho_{i}
$$

Empregando a lei de Hooke e considerando os valores médios a equação (3- 3) pode ser escrita como: 


$$
\sigma_{c}=\sigma_{m} V_{m}+\eta_{\ell} \eta_{\Phi} \sigma_{f} V_{f}
$$

e

$$
E_{c t}=E_{m} V_{m}+\eta_{\ell} \eta_{\Phi} E_{f} V_{f}
$$

com,

$$
\eta_{\Phi}=\frac{\int_{0}^{\bar{\rho}} \int_{0}^{\bar{\Phi}} \cos ^{4} \Phi \cos ^{4} \rho d \Phi d \rho}{\int_{0}^{\bar{\rho}} \int_{0}^{\bar{\Phi}} d \Phi d \rho}
$$

onde:

$E$ —módulo de elasticidade e os subscrito $c t, m$, e $f$ representam o compósito, matriz e fibra respectivamente.

A deformação de fissuração é dada pela expressão proposta por NATHAN ET AL. (1977) apud LIM ET AL. (1987):

$$
\begin{aligned}
& \varepsilon_{c r}=\eta_{\ell} \eta_{\Phi}^{\prime} V_{f}\left(\varepsilon_{f p}-\varepsilon_{m p}\right)+\varepsilon_{m p} \\
& \eta_{\Phi}^{\prime}=\frac{\int_{0}^{\rho} \int_{0}^{\bar{\Phi}} \cos \Phi \cos \rho d \Phi d \rho}{\int_{0}^{\rho} \int_{0}^{\bar{\Phi}} d \Phi d \rho}=\frac{\operatorname{sen} \bar{\Phi} \operatorname{sen} \bar{\rho}}{\bar{\Phi} \rho}
\end{aligned}
$$

onde:

$\varepsilon_{c r}$ - deformação do compósito na primeira fissura;

$\varepsilon_{f p}$ —deformação da fibra no limite de proporcionalidade;

$\varepsilon_{m p}$ — deformação da matriz no limite de proporcionalidade;

$\eta_{\Phi}^{\prime}$-fator de eficiência de orientação pós-fissuração da fibra.

As expressões dos fatores de orientação pré e pós-fissuração dadas por (3-6) e (3- 8) são simplificações grosseiras. SOROUSHIAN E LEE (1990), baseando-se numa modelagem estatística, mostraram que os valores dos fatores de eficiência de 
orientação são dependentes da espessura do elemento, das condições de contorno, e do tipo de adensamento.

A curva força-deslocamento teórica pode ser prevista como:

$$
\Delta L=\frac{P L}{A_{e f} E_{c t}}
$$

onde:

$L$-comprimento do elemento;

$A_{e f}$-seção transversal;

$\Delta L$ - deslocamento;

$P$ força aplicada.

Supõe-se que a fase elástica termina quando a deformação do compósito atinge a deformação de fissuração, $\varepsilon_{c r}$. Neste ponto o deslocamento, $\Delta L_{c r}$, e a força de fissuração, $P_{c r}$, são dados por:

$$
\begin{aligned}
& \Delta L_{c r}=\varepsilon_{c r} L \\
& P_{c r}=A_{e f} E_{c t} \varepsilon_{c r}
\end{aligned}
$$

\subsubsection{Fase pós-fissuração}

Idealizando o compósito como um sistema isotrópico equivalente, LIM ET AL. (1987) modelaram o comportamento pós-fissuração supondo uma fissura teórica de abertura nula. A formulação analítica essencial que descreve o comportamento pós-fissuração do compósito, segundo LIM ET AL. (1987) é dada por:

$$
w=\frac{2 r k_{1}}{k}\left(\sigma_{f}^{*}-2 \xi^{2}\right)\left[\cot g h\left(\frac{k_{1} l_{f}}{2}\right)-\operatorname{cosech}\left(\frac{k_{l} l_{f}}{2}\right)\right] \text {, para } \tau(x)<\tau_{u} \mathrm{e}
$$




$$
\begin{aligned}
w & =\frac{2 l_{o}}{E_{f}}\left(\sigma_{f}^{*}-\frac{1}{2 r} \tau_{u} l_{o}\right)+\frac{2}{k}\left\{\tau_{u}-r k_{l}\left[\left(\sigma_{f}^{*}-\frac{1}{r} \tau_{u} l_{o}-\xi^{2}\right) \operatorname{cosech} k_{l}\left(\frac{l_{f}}{2}-l_{o}\right)+\right.\right. \\
& \left.\left.+\xi^{2}{\cot g h k_{l}}_{(}\left(\frac{l_{f}}{2}-l_{o}\right)\right]\right\}, \text { para } \tau\left(l_{o}\right)=\tau_{u}
\end{aligned}
$$

onde:

$w$-abertura de fissura;

$k$-módulo de escorregamento;

$r$-relação entre a área e o perímetro da fibra;

$\sigma_{f}^{*}$ - tenção na fibra quando ocorre a primeira fissura;

$k_{1}$ e $\xi$-funções do material e parâmetros da mistura;

$k_{l}^{2}=\frac{k}{r}\left(\frac{1}{E_{f}}+\frac{\eta_{\ell} \eta_{\Phi}^{\prime} V_{f}}{E_{m t} V_{m}}\right), k_{2}^{2}=\frac{k}{r}\left(\frac{\sigma_{f}^{\prime} \eta_{\ell} \eta_{\Phi}^{\prime} V_{f}}{E_{m t} V_{m}}\right)$ e $\xi=\frac{k_{2}}{k_{l}}$

Além do modelo do comportamento pós-fissuração proposto por LIM ET AL. (1987), pode-se facilmente deduzir um modelo analítico simples do comportamento pós-fissuração de um compósito armado com fibras baseado na lei de material compósito. Pela lei, após ter sido atingida a tensão de fissuração, a tensão e módulo de elasticidade do compósito são deduzidos das equações (3- 4) (3- 5) como:

$$
\begin{aligned}
& \sigma_{c u}=\sigma_{m u}^{\prime} V_{m}+\eta_{\Phi}^{\prime} \eta_{\ell} \sigma_{f}^{\prime} V_{f} \\
& E_{c t}=E_{m} V_{m}+\eta_{\Phi}^{\prime} \eta_{\ell} E_{f} V_{f}
\end{aligned}
$$

onde:

$\sigma_{f}^{\prime}$ é a tensão na fibra para a deformação de fissuração, e $\sigma_{m u}^{\prime}$ é a resistência da matriz à tração na ausência das fibras. 


\subsubsection{Limitação do Modelo ACK e Taxa Critica de Fibras}

Como foi apontado anteriormente, a lei de material compósito definida pelas equações (3- 4), (3- 5) (3-14) e (3-15) é restrita para compósitos de baixa taxas de fibras (BENTUR E MINDESS 1990). A previsão pós-fissuração do compósito definido por essa lei, e dada pelas equações (3-14) e (3-15) é uma simplificação grosseira, pois é incapaz de levar em contar os vários mecanismo mobilizados durante o arrancamento das fibras. No entanto, a lei de material compósito oferece um meio muito simples de determinar a taxa crítica das fibras.

A principal influência das fibras é após a localização de deformação (SHAH E OUYANG, 1991) onde a contribuição da matriz é pequena ou desprezível devido à fissuração múltipla (BENTUR E MINDESS 1990). Nesta fase o comportamento do compósito é definido pela taxa de fibra. Desprezando a contribuição da matriz, pode-se rescrever as equações (3-14) para o cálculo da tensão do compósito, $\sigma_{c u}$, na fase pós-fissuração como:

$$
\sigma_{c u}=\eta_{l} \eta_{\Phi}^{\prime} \sigma_{f u} V_{f}
$$

Para compósitos de fibras contínuas e alinhadas (teoria ACK) a expressão acima é dada por:

$$
\sigma_{c u}=\sigma_{f u} V_{f}
$$

Segundo BENTUR E MINDESS (1990), as equações (3- 16) são válidas apenas para taxas volumétricas que excedem o valor crítico, $V_{f, c r i t}$. Abaixo desse valor, a capacidade de carga das fibras dada pela tensão nas equações (3- 16), é menor que a tensão de fissuração do compósito dada pelas equações (3- 14). Portanto, deve-se avaliar a taxa de fibras do compósito, $V_{f}>V_{f, c r i t}$ ou $V_{f}<V_{f, c r i t}$, antes de qualquer tentativa de desenvolver formulações gerais para descrever o comportamento do compósito. 


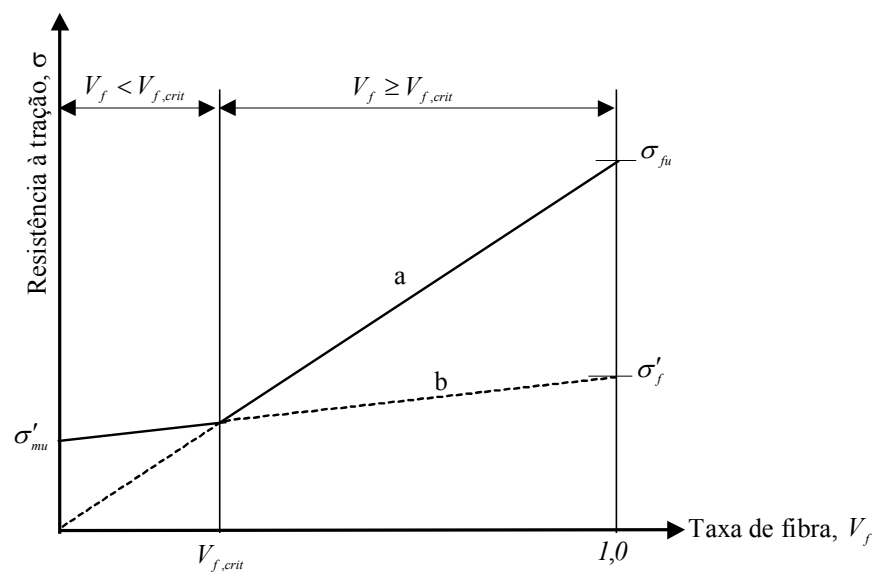

Fig. 3.2: Condição de fissuração múltipla para compósitos de fibra dúctil/matriz (Segundo LI E WU, 1992 apud Aveston et al., 1971)

A figura 3.2 mostra as curvas que representam as expressões (3-14) e (3- 16) traçadas no mesmo sistema de coordenadas. Segundo BENTUR E MINDESS (1990), a interseção das curvas representa o valor da taxa crítica de fibras, e pode ser calculada substituindo as expressões das tensões elásticas; $\sigma_{f}^{\prime}=\varepsilon_{m u} E_{f}$ e $\sigma_{m u}^{\prime}=\varepsilon_{m u} E_{c t}$ em (3-14) e (3- 16).

$$
V_{f, c r i t}=\frac{E_{c t}}{E_{m}} \frac{\sigma_{m u}}{\sigma_{f u}}=\frac{\sigma_{m u}}{\sigma_{f u}+\left(1-\frac{E_{f}}{E_{m}}\right) \sigma_{m u}} \text {, para fibras continuas }
$$

onde $E_{c t}$ é dado pela equação (3- 15). Considerando que em um típico compósito cimentício armado com fibra, $E_{c t}$ não é maior que $E_{m}$ e $\sigma_{m u} \cong \sigma_{m u}^{\prime}$, a equação (3- 15) pode ser aproximada a:

$$
V_{f, c r i t}=\frac{\sigma_{m u}^{\prime}}{\sigma_{f u}}
$$

Uma implicação de (3-18) é que o aumento da taxa de fibras além da crítica pode alterar a natureza da matriz e a capacidade de tensão e deformação da matriz (SHAH E OUYANG, 1991). Para compósitos de $V_{f}>V_{f, c r i t}$, o comportamento após a 
primeira fissura é totalmente diferente da matriz. Baseado na lei de mistura, para compósitos de fibras contínuas e alinhadas, a equação fundamental (3-4) pode ser modificada para a desigualdade:

$$
\sigma_{f} V_{f}>\sigma_{c u}=E_{m} \varepsilon_{m u} V_{m}+E_{f} \varepsilon_{m u} V_{f}
$$

Portanto, após a primeira fissura, um carregamento suficientemente alto é transferido das fibras para a matriz tal que a propagação da microfissuração é estabelecida resultando em uma distribuição homogênea das fissuras conhecida como a fissuração múltipla (BENTUR E MINDESS, 1990; SHAH E OUYANG, 1991; LI E WU, 1992; LI E LEUNG, 1992; LI E HASHID, 1993; WU E LI, 1994).

A capacidade de tensão e deformação de um compósito que apresenta a fissuração múltipla é muitas vezes maior que da matriz (LI E LEUNG, 1992; LI E WU, 1992; WU E LI, 1994). Essa melhoria também conhecida como o pseudo-endurecimento de deformação está intimamente associada ao fenômeno de fissuração múltipla estável (LI E WU, 1992) e pode resultar em uma nova classe de estruturas de concreto armado com fibras (SHAH E OUYANG, 1991), os concretos armados com fibras de alto desempenho, com propriedades de ductilidade muito mais parecidas ao aço do que o concreto (LIN E LI, 1997)

As condições sob as quais um compósito pode exibir o pseudo-endurecimento de deformação têm sido amplamente estudada por AVESTON ET AL. apud BENTUR E MINDESS (1990) (para compósitos com fibras contínuas) e LI E LEUNG, 1992; LI E WU, 1992; WU E LI, 1994 (para compósitos com fibras descontínuas e aleatoriamente distribuídas).Em princípio, a condição necessária para a fissuração múltipla estável é ainda à proposta pela clássica teoria ACK de AVESTON ET AL. (1973) apud BENTUR E MINDESS (1990). Segundo AVESTON ET AL. (1973) apud BENTUR E MINDESS (1990), um compósito exibirá o fenômeno de pseudo-endurecimento de deformação se for satisfeita a igualdade:

$$
V_{f} \geq V_{f, c r i t}
$$

onde $V_{f, c r i t}$ é dado por (3-17)

No entanto, embora a condição necessária para a exibição de pseudo-endurecimento de deformação da teoria clássica ACK dada pela equação (3- 
17) ainda é válida, pode-se perceber facilmente dessa expressão que, a taxa crítica de fibras é uma função apenas da deformação da matriz. Isto portanto, coloca uma restrição sobre a capacidade de deformação da matriz. Entretanto, pesquisas realizadas por LI E HASHIDA (1993) e WU E LI (1994), mostram que todas as matrizes frágeis podem exibir as propriedades de pseudo-endurecimento se as propriedades forem adequadamente engenhadas.

Ao contrário do que estipula a equação (3-17), mesmo no caso de ruptura do compósito devido à propagação de uma única fissura instável, a força de fissuração deve depender da energia de fratura da matriz, o tamanho da fratura, e a tenacidade devido ao travejamento das fibras (LI E WU, 1992; LI E LEUNG,1992; WU E LI, 1994). Segundo esses pesquisadores, a condição necessária para a fissuração múltipla estável é dada por:

$$
V_{f} \geq V_{f, c r i t} \equiv \frac{48 G_{\text {ext. }}}{\left[g \tau d_{f}\left(\frac{l_{f}}{d_{f}}\right)^{2} \delta^{*}\right]}
$$

onde $G_{\text {ext. }}$ - taxa de absorção de energia de fratura pela extremidade de fissura;

$g$-fator de restrição;

$\tau$ —tensão de aderência fibra/matriz;

$d_{f}$ - diâmetro da fibra;

$l_{f}$ - comprimento da fibra;

$$
\delta^{*}=\frac{2 \tau}{(1+\eta) E_{f}}\left(\frac{l_{f}}{d_{f}}\right) ; \text { e } \eta=\frac{V_{f} E_{f}}{V_{m} E_{m}}
$$

Pode-se facilmente perceber que (3-21) reflete a importância dos processos de ponta da fissura, e portanto, a tenacidade da matriz na condição de pseudo endurecimento de deformação. No entanto, embora (3- 21) fornece um valor exato da taxa crítica de fibras, LI E WU (1992) e WU E LI (1994) afirmam que a unicidade de solução para a equação (3- 21) não é garantida. Segundo os mesmos, uma condição necessária para a obtenção de uma solução para a equação (3- 21) é dada por: 


$$
\begin{gathered}
\frac{24\left(1-v^{2}\right) E_{f}(1+\eta) K_{m}^{2} E_{c t}}{E_{m}^{2} d_{f} V_{f}^{\prime} g} \leq \frac{\sigma_{f u}^{3}}{\tau}, \text { para fibras contínuas e alinhadas } \\
\frac{24\left(1-v^{2}\right) E_{f}(1+\eta) K_{m}^{2} E_{c t}}{E_{m}^{2} d_{f} V_{f}^{\prime} g} \leq \tau^{2}\left(\frac{l_{f}}{d_{f}}\right)^{3}, \text { para fibras discretas e aleatórias }
\end{gathered}
$$

onde

$u$-coeficiente de Poisson;

$K_{m}$-tenacidade da matriz; e

$V_{f}^{\prime}$ satisfaz a seguinte condição:

$$
V_{f}^{\prime}\left[E_{c t}\left(E_{f}-E_{m}\right)+(1+\eta) V_{m}^{\prime} E_{m} \frac{\partial E_{c t}}{\partial V_{f}^{\prime}}\right]=(1+\eta) E_{m} E_{c t}\left(1-2 V_{f}^{\prime}\right)
$$

Para compósitos de fibras contínuas, e empregando a lei de mistura para a elasticidade do compósito $E_{c t}$, a equação (3-21) pode ser escrita como:

$$
\frac{\sigma_{f u}^{3}}{\tau} \geq \frac{96 E_{f}^{2} K_{m}^{2}}{E_{m}^{2} d_{f}}
$$

Das equações (3-21) e (3- 22) pode-se perceber que o aumento de $V_{f}$ não garante o pseudo-endurecimento de deformação ao contrario da previsão da teoria ACK, e pode em vez disso, resultar em problemas de moldagem (WU E LI, 1994). Isto foi confirmado por LI E WU (1991), LI (1992) e LI ET AL. (1992) mostrando que, pode-se conseguir o pseudo-endurecimento em compósitos de baixas taxas de fibras (até $2 \%$ ). 


\subsection{MECÂNICA DE FRATURA}

\subsubsection{Caracterização Micro-Mecânica de Concreto Armado com Fibras}

Na seção 2.3.3 vimos que a variação da tensão ao longo do contorno da fissura em um CAF devido ao presença de agregados e fibras pode ser considerada como uma combinação dos efeitos de singularidade da ponta da fissura, amolecimento de tensão do agregado e o travejamento das fibras. Isso implica que o comportamento de CAF pode ser considerado como uma superposição entre os efeitos de agregado e as fibras. Em particular, foi mencionado que os processos de rasto que ocorrem na zona IIa governam o amolecimento de tensão, pois este processos representam, do ponto de vista de consumo de energia, os processos preponderantes durante a fratura do compósito, desprezando portanto, o efeito da singularidade da ponta da fissura.

Do ponto de vista analítica/mecânica de fratura, diante do acima colocado, deve-se modelar os processos de rastro vis-à-vis agregado e as fibras. O efeito de agregado pode ser modelado empregando-se o modelo de fissura coesiva de Barenblatt e Dugdale, enquanto o efeito de travejamento das fibras será modelado pelo modelo de travejamento de Cox e Marshall. Esses dois modelos podem ser portanto, superpostos para produzir um modelo do concreto armado com fibras.

$\mathrm{Na}$ presente seção, consideramos o CAF como um material compósito. Para caracterizar mecanicamente o material, supõe-se que o material é caracterizado por um comportamento elástico-linear até a tensão de fissuração descrito por três parâmetros: o módulo de elasticidade $E_{c a f}$, o coeficiente de Poisson $v_{c a f}$ e a tensão de fissuração $\sigma_{f u}$; e um comportamento não-linear pós-pico definido por uma relação tensão-abertura de fissura, $\sigma-w$, descrito por dois parâmetros. Essencialmente, o modelo de caracterização mecânica pós-fissuração descreve a tensão, $\sigma_{c}$, transferida numa fissura (efeito de amolecimento da tensão no CAF) como função da abertura de fissura.

Considerando-se a superposição dos efeitos de agregado e das fibras, a tensão do compósito pode ser escrita como:

$$
\sigma_{c}(w)=\sigma_{a}(w)+\sigma_{f}(w)+\sigma_{p s}(w)
$$


onde:

$\sigma_{a}(w)$ - tensão no concreto simples e leva em conta o efeito de travejamento do agregado;

$\sigma_{f}(w)$-leva em conta o efeito de travejamento das fibras (efeito de endurecimento de tensão, "tension stiffening effect" das fibras);

$\sigma_{p s}(w)$ —contribuição das fibras na capacidade resistente ou efeito de pré-tração das fibras.

Percebe-se da equação (3- 26) que para uma caracterização completa do CAF, é necessário que o material seja caracterizado visando cada uma das três parcelas e superpondo-os posteriormente.

\subsubsection{Caracterização Analitica da Matriz ou Efeito de Travejamento do Agregado}

Para a caracterização analítica da matriz, supõe-se que o concreto tem um comportamento elástico-linear até a tensão máxima, descrito por três parâmetros: tensão máxima (ou tensão de fissuração), $\sigma_{c t}$, módulo de elasticidade, $E_{m}$; e coeficiente de Poisson, $v_{m}$. Além da tensão de fissuração, aparecem fissuras discretas ou localizadas caracterizadas por uma relação não linear, $\sigma-w$, descrita por dois parâmetros. Um parâmetro representa a abertura característica de fissura, $\widetilde{w}$, enquanto o outro descreve a forma, $p$, da curva $\sigma-w$.

Até este momento, a importância da resposta de amolecimento de tensão pós-pico para o comportamento na fratura de estruturas de concreto ou seus compósitos deve ser obvia, e não pode ser subestimada. Até então, sabe-se tudo que causa o amolecimento de tensão em concreto e CAF. Na seção 2.3.3, foi demostrado que um conhecimento preciso da relação tensão-deslocamento, $\sigma(w)$, no regime pós-fissuração é também de suma necessidade para a determinação do parâmetro básico mais importante no estudo de fartura, a energia de fratura. No entanto, a obtenção experimental da região de amolecimento é dificultada pelo fato de que, esta região, em geral, é descontínua (KARIHALOO, 1995). Isso pode parecer que qualquer tentativa na determinação precisa de $\sigma(w)$ seria frustrada. Entretanto, existem várias 
maneiras de determinar curva de amolecimento. Esses métodos são classificados como diretos ou indiretos. Existem dois métodos diretos (citados a seguir), o segundo dos quais será mencionado na presente pesquisa:

- Relação $\sigma(w)$ obtido de ensaios de tração direta sobre painéis, e

- Relação $\sigma(w)$ obtido de ensaios de tração direta sobre corpos de prova delgados com seção intermediária reduzida.

Desde o trabalho pioneiro de HILLERBORG ET AL. (1976) vários modelos diretos têm sido propostos para prever a curva de amolecimento de tensão devido à contribuição do agregado. Entre esses é o modelo de STANG E AARRE (1992). Esse modelo é baseado nos ensaios de tração direta sobre corpos de provas entalhado realizados num equipamento hidráulico servo controlado (Instron), equipado com um sistema para ensaio em ciclo fechado. Após uma análise de regressão dos deslocamento não elásticos, foi obtido um modelo do qual após comparação com o modelo de fissura coesiva, as constantes essenciais foram determinadas. CORNELISSEN ET AL., (1986) apud KARIHALOO (1995) anteriormente já tinham obtido um modelo baseado na mesma abordagem. Entre os vários modelos baseados nessa abordagem, o modelo de STANG (1991) é mais adequado, pois descreve melhor os dados experimentais (LI E MAALEJ, 1996), e pode ser considerado exato para a previsão de aberturas de fissura entre $0,1 \mathrm{~mm}$ a $0,7 \mathrm{~mm}$, que são aberturas normalmente encontradas em estruturas de concreto. Segundo STANG E AARRE (1992), a tensão de travejamento dos agregados é dada por:

$$
\sigma_{a}(w)=\frac{\sigma_{c t}}{1+\left(\frac{w}{\widetilde{w}}\right)^{p}}
$$

onde:

$\sigma_{c t}$-resistência a tração da matriz;

$\widetilde{w}$-abertura característica de fissura igual à abertura de fissura correspondente a uma redução da capacidade do compósito em $50 \%$; e

$p$ - fator de forma que descrever a forma da curva. 
Segundo LI ET AL. (1993), para pequena taxas de fibras o efeito das fibras sobre o agregado pode ser desprezado e portanto tem-se:

$$
\sigma_{c a f}(w)=\sigma_{a}(w)=\frac{\sigma_{f t}}{1+\left(\frac{w}{\widetilde{w}}\right)^{p}}
$$

onde:

$\sigma_{f t}$ resistência à tração do compósito.

\subsubsection{Contribuição das Fibras}

A contribuição das fibras na tenacidade do compósito é computada considerando todos mecanismos mobilizados desde o carregamento do elemento até a sua ruptura durante o arrancamento das fibras. Evidentemente o resultado depende da abordagem do problema e suposição admitidas. No presente trabalho será tratado um modelo proposto por LI (1991), chamado modelo de fissura transversal (Through-crack model). Nesta abordagem, emprega-se a influência das fibras, representada como uma tração coesiva na fissura (fratura), como uma resistência à fratura crescente com sua propagação da mesma. Esse efeito de tenacidade devido às fibras que travejam a fratura não apenas aumenta a tenacidade do compósito, como também conduz a um fenômeno chamado fratura estável. Neste modelo supõe-se um elemento pré-fissurado com uma fissura de abertura nula. Partindo-se dessa suposição, a contribuição das fibras é computada calculando-se a tensão de travejamento durante o arrancamento de uma única fibra, e depois a contribuição total calculada pelo integral da contribuição de uma fibra na seção transversal do elemento.

Pode-se perceber que o modelo de LI (1991) não é representativo da situação real, pois despreza a contribuição das fibras na fase pré-fissuração ou adesão entre as fibras e matriz que se manifesta na fase pré-fissuração. Além do mais, em compósitos reais, as condições pós-fissuração não são descritas pelo arrancamento de uma única fibra. Contrário ao modelo de LI (1991), o modelo proposto por LANGE-KORNBAK E KARIHALOO (1996), conhecido como o modelo de fissuração múltipla, leva em conta a 
adesão na fase pré-fissuração em conjunto com o modelo de fissura transversal na fase pós-pico, para descrever o comportamento do compósito. Além do mais, o modelo de fissuração múltipla considera a arrancamento de múltiplas fibras ao contrário do arrancamento de uma fibra proposto por LI (1991). Apesar de ser mais representativo, o modelo de fissuração múltipla não será abordado no presente trabalho. Opta-se pelo modelo de fissura transversal devido à sua simplicidade sem qualquer perda de rigor ou generalidade. Isso pode ser sustentado pelo fato de que, segundo vários pesquisadores (LI ET AL., 1991; LI, 1992; LIN E LI, 1997) a parcela devido à adesão é desprezível é muito pequena.

\subsubsection{Modelo de travejamento das fibras.}

Como foi anteriormente mencionado, na sua forma mais simples, o modelo de travejamento tem como premissa básica o arrancamento de uma única fibra de um compósito hipotético considerado pré-fissurado. Isso simula com um maior grão de certeza um ensaio de arrancamento de uma única fibra. Supõe-se que as fibras estão presas na matriz pelo efeito do atrito, com uma aderência elástica desprezível na interface matriz/fibra. Isso significa que a energia devido à perda de aderência é desprezível. Essa afirmação pose ser sustentada considerando-se a figura 2.10, onde $a$ área sob a curva YDZ é normalmente muito menor que a área ZDE.

Desprezando-se portanto a aderência interfacial, fibra/matriz, o carregamento aplicado é resistido apenas por um atrito constante, $\tau_{o}$, na interface fibra/matriz ao longo do comprimento embutido da fibra. Essa fase de arrancamento na qual a fibra está sob atrito constante é conhecida como a fase pré-pico. É fácil perceber que na fase pré-pico, o escorregamento da fibra é ativado. Com o aumento de carregamento, o comprimento da zona de escorregamento ativada onde $\tau_{o}$ está efetiva aumenta. Isso é conhecido como a perda de aderência. Portanto, do grosso modo, a perda de aderência corresponde ao início da mobilização de atrito interfacial fibra/matriz, desprezando-se a perda parcial de aderência que ocorre no intervalo entre a aplicação do carregamento até quando atinge-se a aderência última, no qual os dois efeitos, aderência e atrito, são efetivos. A perda de aderência continua até a extremidade 
embutido da fibra. Nesse instante, o deslocamento total da fibra atinge um valor, $\delta_{o}$. A figura 3.3 mostra o modelo cilíndrico de travejamento com o esquema da perda de aderência (figura 3.3a e figura 3.4a) e o estado de tensões na fibra e matriz (figura $3.3 b)$.
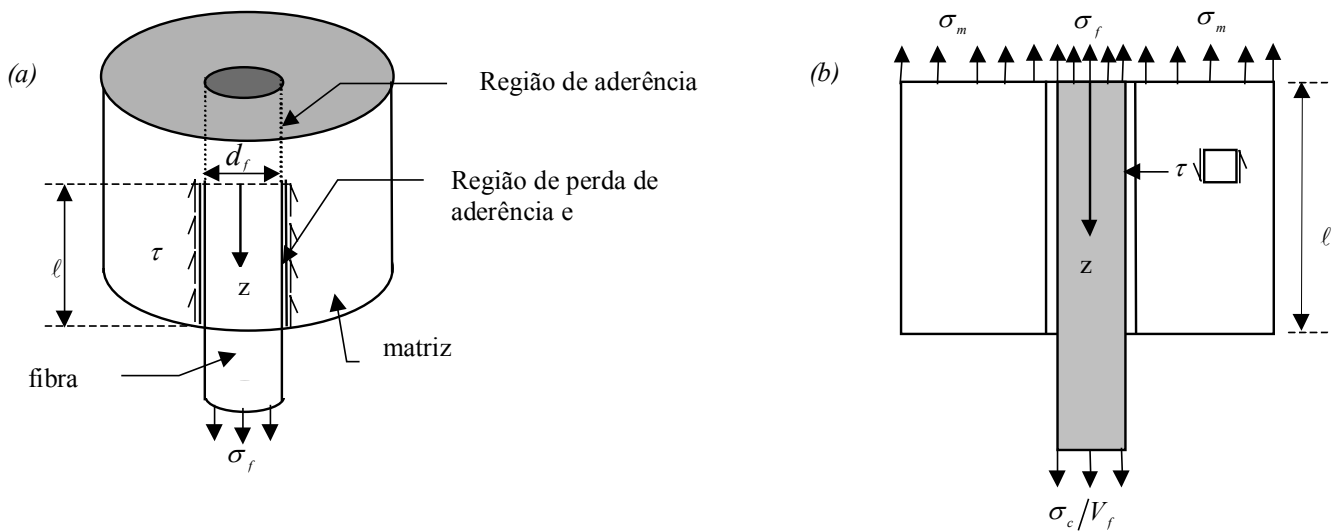

fig. 3.3: Esquema de perda de aderência, escorregamento e arrancamento. (a) Modelo cilíndrico axisimétrico, (b) Tensões axiais na fibra e matriz e a tensão de cisalhamento na interface (Segundo BAO E SONG, 1993).

Quando a perda de aderência atinge a extremidade embutida da fibra, inicia-se o escorregamento da mesma e a força de arrancamento cai com o deslocamento da fibra, $\delta$. Essa fase de carregamento é chamada a fase pós-pico (figura 3.4b). No entanto, além do escorregamento da fibra, há uma deformação elástica da mesma.

Além da suposição feita sobre a perda de aderência, na modelagem também será é suposto que as fibras são suficientemente curtas (ou com atito na interface fibra/matriz suficientemente baixa) que todas as fibras são arrancadas sem nenhuma ruptura das mesmas. 
(a)

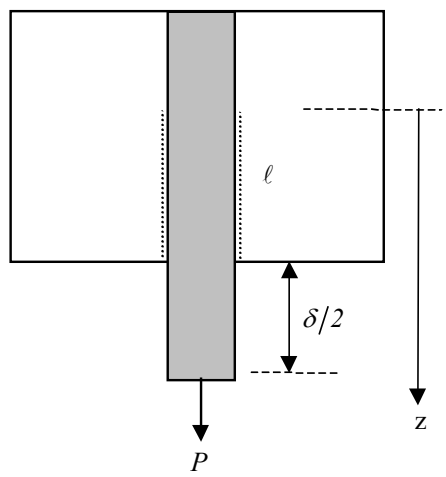

(b)

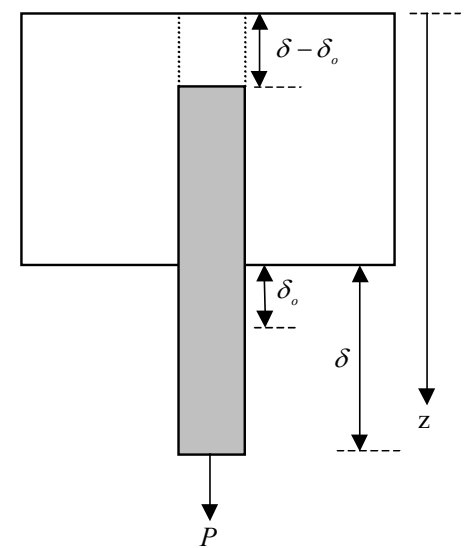

Fig. 3.4: Esquema de perda de aderência (a) e arrancamento (b) para o cálculo da tensão de travejamento(Segundo LIN E LI, 1997).

\subsection{Travejamento pré-pico de uma única fibra}

Considera-se uma única fibra com um comprimento embutido, $\ell$. como mostra a figura 3.4. Na fase pré-pico a relação força de travejamento da fibra, $P$, contra a abertura de fissura, $\delta$, pode ser obtido do equilíbrio por uma análise de defasagem de cisalhamento como:

$$
P=\pi \tau d_{f} \ell(1+\eta)
$$

$\operatorname{com} \frac{A_{f}}{A_{m}}=\frac{V_{f}}{V_{m}} ; \mathrm{e} \frac{E_{f} V_{f}}{E_{m} V_{m}}=\eta$

onde os termos são mostrados na figura 3.3, e

$A$ área;

$V$-taxa volumétrica;

$E$-módulo de elasticidade, e os subscrito $m$, e $f$ representam a matriz e fibra respectivamente.

Considerando-se a deformação da fibra na fase de perda de aderência, a abertura de fissura é função da deformação da fibra. Neste caso tem-se: 


$$
\varepsilon=\frac{\delta}{\ell} \Rightarrow P=\frac{\delta}{\ell} E_{f} \frac{\pi d_{f}^{2}}{4}
$$

de (3- 29) tem-se $\ell=\frac{P_{f}}{\pi \tau d_{f}(1+\eta)}$ de onde substituindo em (3- 30) tem-se:

$$
P(\delta)=\frac{\pi}{2} \sqrt{E_{f} d_{f}^{3} \tau \delta(1+\eta)}, \text { para } \delta \leq \delta_{o}
$$

onde:

$\delta_{o}$-abertura de fissura correspondente à perda completa de aderência.

Obtido a força de travejamento da fibra, pode-se facilmente determinar a tensão de travejamento como a força dividida pela área transversal da fibra. Portanto tem-se que:

$$
\sigma_{d}(\delta)=\frac{P(\delta)}{A_{f}}=\frac{\pi}{2 A_{f}} \sqrt{E_{f} d_{f}^{3} \tau \delta(1+\eta)}
$$

que após transformação é dada por:

$$
\sigma_{d}(\delta)=\left[4(1+\eta) \tau E_{f}\left(\frac{\delta}{d_{f}}\right)^{\frac{1}{2}}\right]=\frac{4 \sigma_{o}}{V_{f}}\left(\frac{\hat{\delta}}{\hat{\delta}^{*}}\right)^{\frac{1}{2}} \text {, para } \delta \leq \delta_{o}
$$

onde $\hat{\delta}=\frac{\delta}{l_{f} / 2} ; \hat{\delta}^{*}=2 \frac{\left(\frac{\tau}{E_{f}}\right)\left(\frac{l_{f}}{d_{f}}\right)}{(1+\eta)} ; \sigma_{o}=\frac{V_{f} \tau l_{f}}{2 d_{f}}$

\subsection{Travejamento pós-pico de uma única fibra}

Quando a força de travejamento atinge o pico, há uma perda completa de aderência na interface fibra/matriz. Isso representa a situação em que a abertura de fissura for maior que $\delta_{o}$. O deslocamento pós-pico pode ser obtido subtraindo-se $\delta_{o}$. Do deslocamento total. Isso resulta em um escorregamento, $\delta-\delta_{o}$, da fibra. Portanto, em qualquer instante após pico, o comprimento embutido deve ser obtido subtraindo o 
escorregamento, $\delta-\delta_{o}$, do comprimento embutido inicial, $\ell$. No entanto, a abertura de fissura só pode atingir um máxima igual ao comprimento embutido inicial da fibra, $\ell$. Portanto, a força de travejamento pós-pico pode ser obtida da equação (3- 29) fazendo-se o comprimento embutido em cada instante após pico igual a $\ell-\left(\delta-\delta_{o}\right)$ e o parâmetro $\eta$ igual a zero, como ilustra a figura 3.4 b. Portanto a equação (3- 29) se reduz a:

$$
P(\delta)=\pi \tau d_{f}\left[\ell-\left(\delta-\delta_{o}\right)\right]=\pi \tau d_{f} \ell\left[1-\frac{\delta-\delta_{o}}{\ell}\right], \text { para } \delta_{o} \leq \delta \leq \ell
$$

Da mesma maneira calcula-se a tensão de travejamento pós-pico da fibra da equação (3-34) como:

$$
\sigma_{p}(\delta)=\frac{P(\delta)}{A_{f}}=\frac{4 \pi \tau d_{f} \ell\left[1-\frac{\delta-\delta_{o}}{\ell}\right]}{\pi d_{f}^{2}}
$$

após transformação a equação (3- 35) pode ser escrita como:

$$
\sigma_{p}(\delta)=\left(\frac{4 \tau}{d_{f}}\right)\left[\ell-\delta+\delta_{o}\right]=\frac{4 \sigma_{o}}{V_{f}}\left(\hat{\ell}+\hat{\ell}^{2} \hat{\delta}^{*}-\hat{\delta}\right), \text { para } \delta_{o} \leq \delta \leq \ell
$$

onde $\hat{\ell}=\frac{\ell}{l_{f} / 2}$

\subsubsection{Efeito de orientação das fibras}

No modelo simples de travejamento da fibra acima proposto, supõe-se que as fibra estão orientadas na direção do carregamento. Entretanto, esta disposição está longe de ser encontrada em compósitos reais. Em matrizes reais as fibras estão dispostas aleatoriamente com orientações variadas em relação à direção do carregamento como mostra a figura 3.5. 


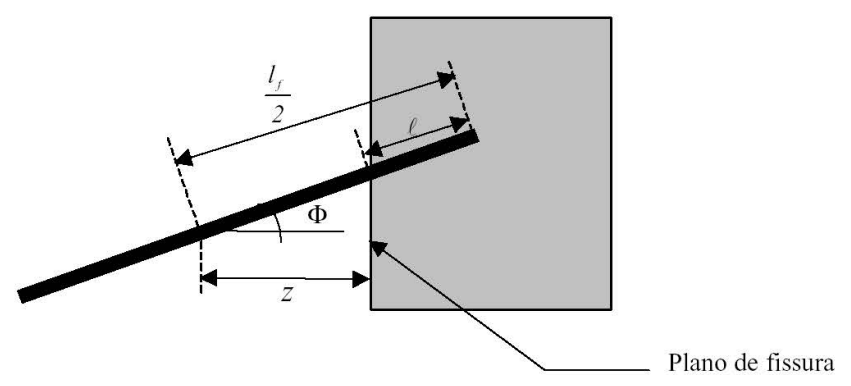

Fig. 3.5: Uma fibra atravessando a fissura (Segundo LI ET AL., 1991)

No entanto, o modelo acima proposto é muito simples, pois a força de arrancamento sempre não está aplica no eixo da fibra. Formulado o modelo de arrancamento de uma fibra alinhado na direção de arrancamento, pode-se modelar o efeito da orientação da fibra, incorporando-o no modelo deduzido na seção anterior.

O efeito de arrancamento de uma fibra numa direção $\Phi$, com relação ao eixo da fibra foi primeiramente estudado por MORTON E GROVES (1974) em compósitos armados com fibras de aço. No seu trabalho pioneiro MORTON E GROVES (1974) atribuíram o aumento da força $P$ constatado ao atrito localizado. Posteriormente, MORTON E GROVES (1976) propuseram um modelo analítico para levar em conta o efeito da orientação.

Baseando-se no modelo simples de MORTON E GROVES, (1976), LI ET AL. (1991), propuseram um modelo micro-mecânico estatístico ("snubbing friction model"), modelando a fibra como uma corda flexível sobre uma polia com atrito. No modelo de LI ET AL. (1991), o atrito localizado entre a fibra e matriz no ponto onde a fibra intersecta o plano de fissura foi levado em conta incorporando-se um coeficiente de restrição por atrito (snubbing coeficient). Este efeito de atrito da "polia" tem como conseqüência aumentar as tensões de travejamento pré-pico e pós-pico dadas pelas equações (3- 33) e (3- 36). A figura 3.6 mostra a configuração da fibra durante o carregamento. Note a mudança brusca de direção que resulta em um nó. 


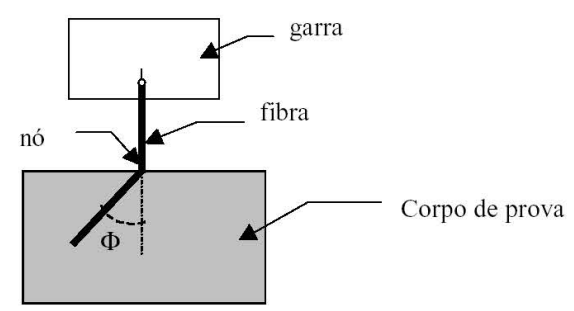

Fig. 3.6: Arrancamento de uma fibra com orientação (LI ET AL., 1991)Ф

Embora o modelo de LI ET AL. (1991) considera apenas a força na direção de arrancamento, $\Phi$, LEUNG E LI (1992) mostraram que a força de travejamento fornecida por uma fibra inclinada (fibra não perpendicular ao plano de fissura) pode ser considerada como uma soma vetorial de duas componentes:

1) uma componente de perda de aderência/arrancamento na direção do eixo da fibra, e

2) uma componente de flexão normal ao eixo da fibra.

Segundo LEUNG E LI (1992), a componente de flexão para fibras flexíveis é desprezivel comparada à componente de perda de aderência que, normalmente é aumentada pelo atrito localizado no ponto onde a fibra sai da matriz. Diante do acima exposto, o modelo de LI ET AL. (1991) é adequado apenas para o arrancamento de fibras flexíveis.

Segundo LI ET AL. (1991), a força máxima de travejamento $P$ para um ângulo $\Phi$ é dada por :

$$
P(\ell, \delta, \Phi)=P(\ell, \delta, \Phi=0) \exp (f \Phi)
$$

onde:

$f$-coeficiente de restrição ("snubbing coeficient").

Pode-se, portanto, substituindo (3- 31) em (3- 37), determinar a tensão de travejamento pré-pico como:

$$
\sigma_{b}(\delta, \Phi, z)=\sigma_{d} e^{f \Phi}
$$


onde $\sigma_{d}$ é dada por (3-34).

Do mesmo modo, a tensão de travejamento pós-pico é dada por:

$$
\sigma_{b}(\delta, \Phi, z)=\sigma_{p} e^{f \Phi}
$$

com

$$
\ell=\left(\frac{l_{f}}{2}\right)-\left(\frac{z}{\cos \Phi}\right)
$$

onde $\sigma_{p}$ é dada por (3-36).

\subsubsection{Efeito do módulo de elasticidade da fibra}

O modelo de restrição proposto por LI ET AL. (1991) é baseado no modelo experimental supondo-se um comprimento livre da fibra como mostra a figura 3.7a. A configuração da fibra dada pela figura 3.7 a no entanto implica que no modelo de restrição, a fibra é suposta inicialmente fletida antes mesmo da aplicação do carregamento. Porem em compósitos reais, as fibras se mantêm retas antes da aplicação do carregamento. Portanto, uma situação mais representativa seria de uma fibra reta como mostra a figura $3.7 \mathrm{~b}$.
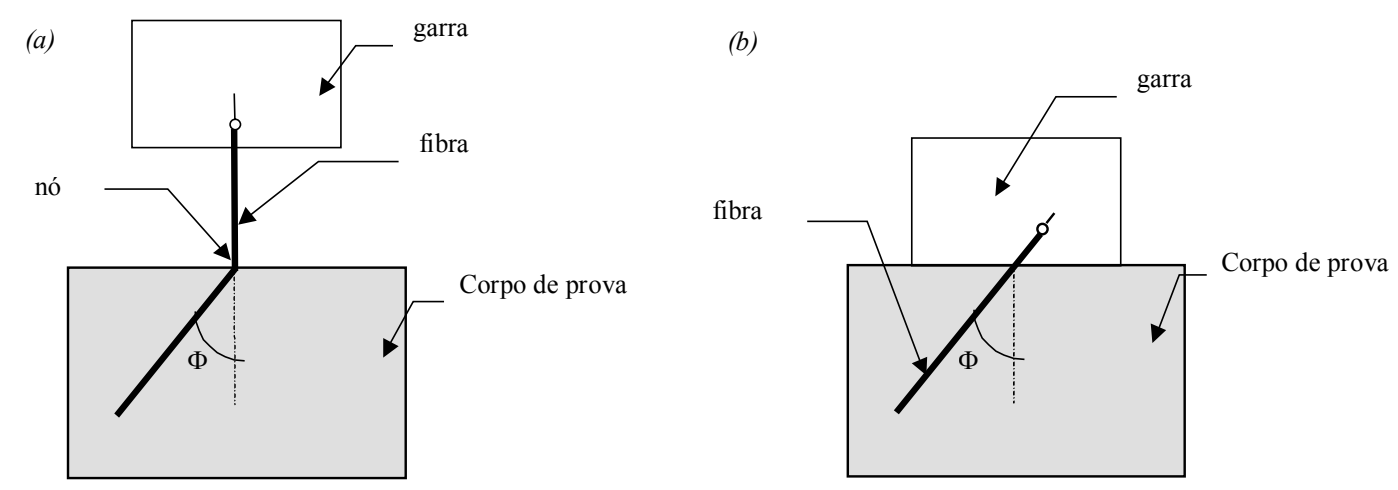

Fig. 3.7: Arrancamento de fibra com: (a) comprimento livre da fibra e portanto fibra inicialmente fletida; (b) fibra inicialmente reta (Segundo LEUNG E YBANEZ, 1997)

De fato, a tensão de travejamento para o arrancamento de uma fibra reta e originalmente inclinada é dependente do modulo de elasticidade (rigidez) da fibra, pois a componente de flexão da fibra, conforme discutido anteriormente, dependendo da 
rigidez da fibra, pode não ser desprezível. Isto é o caso de fibras de alto modulo de elasticidade como as fibra de aço.

(a)

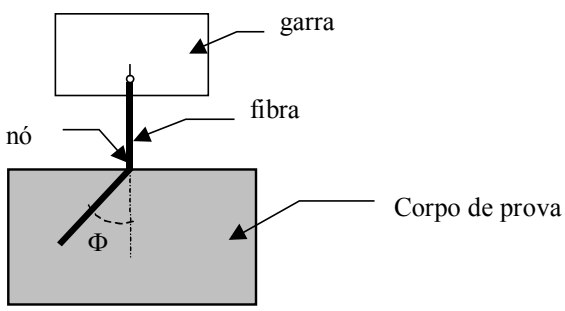

Fibra inicialmente fletida com uma mudança brusca de curvatura

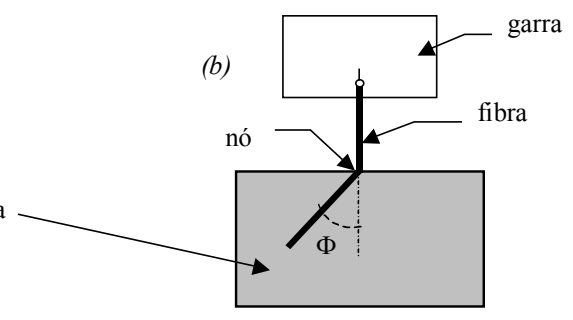

Fibra inicialmente fletida. Sob tração a curvatura se mantém brusca

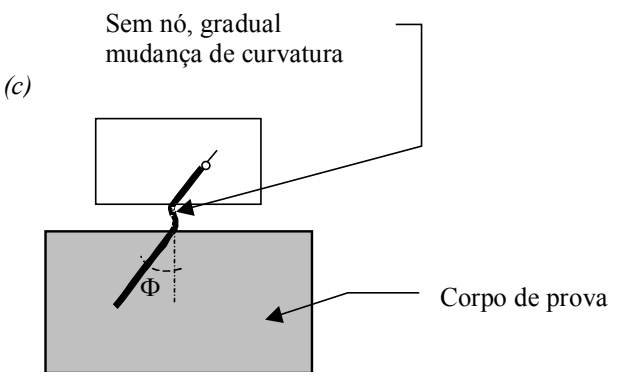

Fibra inicialmente retalcom uma mudança gradual de curvatura com início de tração na fibra)

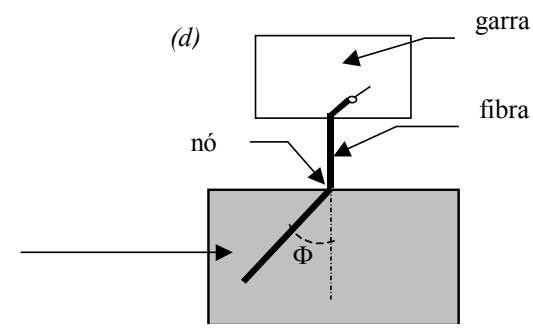

Fibra inicialmente reta atingindo uma configuração de nó após uma tração significativa

Fig. 3.8: Deformação da fibra durante o arrancamento: (a) e (b) para uma fibra inicialmente fletida; (c) e (d) para uma fibra inicialmente reta (Segundo LEUNG E YBANEZ, 1997)

Se a fibra for perfeitamente flexível (rigidez nula), ela se comporta como uma corda e as duas situações 3.7a e 3.7b devem fornecer resultados idênticas. Entretanto, todas as fibras reais possuem uma rigidez finita conforme o seu módulo de elasticidade. Segundo LEUNG E NUMER (1997), mesmo as fibras de polipropileno, a fibra mais flexível empregada na pratica na CAF, a suposição de modelo de "corda" esta longe da realidade. A figura 3.8 mostra as configurações da fibra supondo uma "corda flexível" ou fibra originalmente fletida, figura $3.8 \mathrm{a}$ e $3.8 \mathrm{~b}$, e supondo uma fibra rígida originalmente reta, nos estágios iniciais e avançados de carregamento respectivamente. É portanto evidente a partir da figura 3.8 que, um modelo real da tensão de travejamento da fibra deve considerar a flexão da fibra proveniente da rigidez da mesma nos estágios iniciais do carregamento (fig. $3.8 \mathrm{c}$ ). 
A modelagem da flexão da fibra foi originalmente proposta por MORTON E GROVES (1974) supondo-se a ruptura da matriz e a formação de uma rótula plástica na fibra (modelo de flexão elasto-plástica). Posteriormente, LEUNG E LI, (1992) modelaram a flexão de fibras frágeis em uma matriz frágil como uma viga sobre uma fundação elástica com propriedades da fundação variáveis. A rigidez da fundação foi modelado por elementos finitos, incorporando um critério de esmagamento da matriz.

O mesmo problema da flexão da fibra foi tratado separadamente por LEUNG E CHI (1995) e KATZ E LI (1995), que ampliaram o modelo de LEUNG E LI (1992) para outros tipos de fibras. LEUNG E CHI (1995) abordaram o problema da flexão de fibras dúcteis, baseando-se num modelo de flexão no regime elasto-plástica. Para determinar as propriedades da fundação, o modelo micro-mecânico proposto por LEUG E CHI (1995) incorporou a perda de aderência e o arrancamento sob o atrito no ensaio de arrancamento, considerando a teoria de defasagem de cisalhamento, e a flexão de uma matriz elástica.

Ao contrário do modelo de LEUNG E CHI (1995), KATZ E LI (1995) empregaram o modelo de flexão das fibras para o caso de fibras elásticas. O modelo analítico proposto por KATZ E LI (1995) foi dividido em duas partes. Primeiramente, uma parte da fibra foi modelado como uma viga apoiada sobre uma fundação elástica (modelo de MORTON E GROVES, 1974). Para está parte, KATZ E LI (1995) aplicaram o modelo de LEUNG E CHI (1995) para determinar as propriedades da fundação. A segunda parte foi modelada como uma viga engastada, representando a parte que traveja a fissura.

Além da modelagem de efeito de travejamento da fibra, KATZ (1996) verificou a dependência da flexão da fibras no módulo de elasticidade. O trabalho de KATZ (1996) no entanto, foi direcionado ao estudo experimental. No seu estudo, KATZ (1996) empregando um microscópio eletrónico ("scanning electron microscope"), mapeou a flexão de fibras frágeis e dúcteis. Segundo KATZ (1996), a ruptura por flexão das fibras depende principalmente das propriedades da matriz e da fibra. O mesmo afirma que, o aumento do módulo de elasticidade pode resultar no aumento das tensões por flexão desenvolvidas na fibras, resultando numa ruptura precoce da mesma. 


\subsubsection{Consideração de esmagamento do concreto}

Além da flexão das fibras, outro fenômeno que se manifesta durante o arrancamento de uma fibra é o esmagamento da matriz. O modelo de atrito de restrição (LI ET AL., 1991) não leva em conta os fenômeno de esmagamento observado para orientações maiores $\left(\Phi \geq 60^{\circ}\right)$. No entanto, LEUNG E CHI (1995) e KATZ E LI (1995) modelado numericamente este fenômeno.

Diante do exposto, um modelo físico verdadeiro do arrancamento da fibra deve portanto, considerar tanto a flexão da fibra importante nos estágios iniciais de arrancamento, como a restrição da fibra nos estágios posteriores de arrancamento, para todas as orientações, $\Phi$ das fibras. Tal modelo, LEUNG E NUMER (1997), é muito complexo.

O esmagamento da matriz foi estudado analiticamente por LEUNG E NUMER (1997). Como uma melhoria do modelo de atrito de restrição, LEUNG E NUMER (1997) propuseram um modelo fenomenológico para o arrancamento de fibras flexíveis que leva em conta apenas o efeito do atrito de restrição. Embora se considera apenas o atrito de restrição já considerado por LI ET AL. (1990), o modelo de LEUNG E NUMER (1997) leva em conta o esmagamento da matriz considerando:

(a) $\mathrm{O}$ aumento do atrito interfacial $\tau$ com o deslocamento da fibra durante $\mathrm{O}$ escorregamento da mesma;

(b) aumento do coeficiente de restrição $f$ com o deslocamento da fibra durante o escorregamento, e

(c) esmagamento da matriz nas proximidades do ponto onde a fibra sai da matriz. 
A figura 3.9 mostra o modelo geométrico para a obtenção dos parâmetros micro-mecânicos essenciais devido ao esmagamento da matriz, segundo o modelo analítico de LEUNG E NUMER (1997).

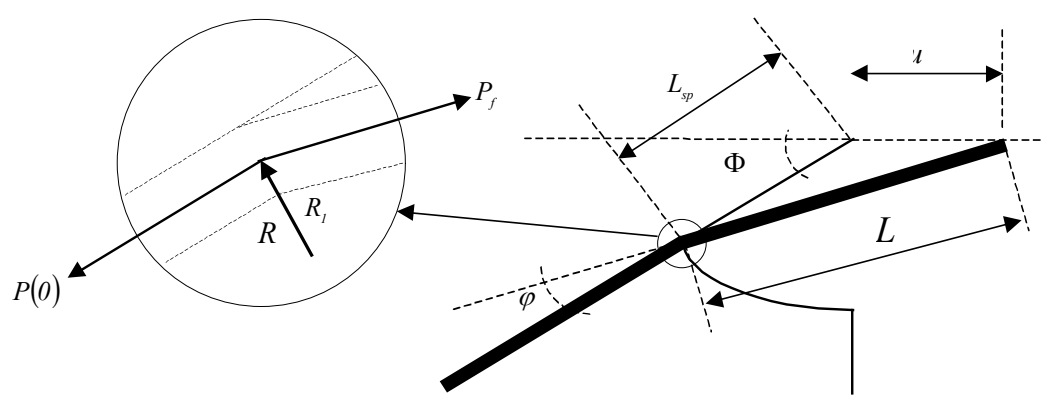

Fig. 3.9: Definição dos parâmetros para o novo modelo de arrancamento da fibra (Segundo LEUNG E YBANEZ, 1997)

Considera-se uma fibra inclinada e uma matriz de comprimento $L_{s p}$ lascada nas proximidades do ponto onde a fibra sai da matriz (figura 3.9). Após o esmagamento, o ângulo entre a parte embutida e a parte livre da fibra diminui de ângulo inicial, $\Phi$, para $\varphi$. A relação entre $\Phi$ e $\varphi$ pode ser facilmente obtida da trigonometria como:

$$
\operatorname{sen} \varphi=\frac{u \cos \Phi}{L}
$$

onde:

$u$ - deslocamento na direção do carregamento correspondente à abertura de fissura;

$\varphi$ —orientação da parte livre da fibra após o esmagamento;

$\Phi$ —orientação inicial da fibra;

$L$ —comprimento livre da fibra após o esmagamento.

Para qualquer abertura de fissura $u$, o comprimento livre da fibra é dado por :

$$
L^{2}=u^{2}+L_{s p}^{2}+2 u L_{s p} \cos \Phi ; \Rightarrow L=\sqrt{u^{2}+L_{s p}^{2}+2 u L_{s p} \cos \Phi}
$$


onde:

$L_{s p}$ —projeção do comprimento livre da fibra na direção $\Phi$.

A força axial na parte livre da fibra $P_{f}$, pode ser determinada empregando-se o modelo de restrição como:

$$
P_{f}=P(0) e^{f \varphi}
$$

Pela geometria, a componente da força de travejamento normal ao plano da fissura, $P(\Phi)$, é dada por:

$$
P(\Phi)=P_{f} \cos (\Phi-\varphi)
$$

Conseqüentemente, o deslocamento, $\delta$, sofrido pela fibra, proveniente da força $P(\Phi)$ é dado pela diferencia entre os comprimento embutido e o comprimento livre. Pode-se portanto escrever:

$$
\delta=L-L_{s p}
$$

Percebe-se da figura 3.9 que antes da perda completa de aderência, a força axial $P(0)$ no ponto onde a fibra intersecta o plano da fissura pode ser calculada do deslocamento total composto de duas parcelas; uma parcela como função comprimento embutido após esmagamento, $\left(l_{f}-L\right)$ e a outra como função do comprimento livre da fibra, $L$. A partir disso tem-se:

$$
\delta=f_{1}\left(l_{f}-L\right)+f_{2}(L)
$$

A primeira parcela da equação (3- 46) pode ser facilmente obtida da equação (3- 31). Dessa expressão pode-se escrever que:

$$
\delta_{1}=\frac{2 P_{f}(0)^{2}}{\pi^{2}(1+\eta) E_{f} \tau d_{f}^{3}}
$$


A segunda parcela pode ser calculada considerando o comportamento elástico do comprimento livre da fibra que consequentemente é dado por:

$$
\delta_{2}=\frac{P_{f} L}{E_{f} A_{f}}
$$

onde $P_{f}$ é dado por (3-43)

Lembrando-se a expressão do modelo de restrição dada por (3- 43), a equação (3- 48) por ser escrita como:

$$
\delta_{2}=\frac{P(0) e^{f \varphi} L}{E_{f} A_{f}}
$$

Das expressões acima, pode-se determinar o deslocamento total dado pela soma de (3- 42) e (3-49). Isso leva a:

$$
\delta=\frac{2 P(0)^{2}}{\pi^{2}(1+\eta) E_{f} \tau d_{f} 3}+\frac{P(0) e^{f \varphi} L}{E_{f} A_{f}}
$$

A equação (3- 50) fornece uma maneira de determinar a força $P(0)$. No entanto, deve-se considerar o estágio de carregamento. Com a perda completa de aderência, a força axial na fibra será dada por:

$$
P_{c d}=\pi \tau d_{f}\left(l_{f}-L_{s p}\right)
$$

É fácil perceber que se $P(0)$ calculada de (3-50) for maior que $P_{c d}$, isto significa que há uma perda completa de aderência e portanto, a fibra está escorregando. Isso significa que há uma perda completa de aderência, e portanto o fenômeno de atrito esta ativo. Neste caso o valor de $P(0)$ será dada por:

$$
P(0)=\pi \tau d_{f}\left(l_{f}-L\right)
$$


onde $\tau$ é o atrito na interface fibra/matriz, e a foça $P(\Phi)$ pode ser determinado de (343) e (3-44) como:

$$
P(\Phi)=P(0) e^{f \varphi} \cos (\Phi-\varphi)
$$

onde:

$$
P(0) \text { é dado por (3-52). }
$$

Determinadas as forças pré-pico (equações 3- 50 e 3- 53) e pós-pico (equações 3- 52 e 3- 53) na fibra, pode-se determinar a tensão de travejamento da fibra devido ao esmagamento da matriz.

\subsubsection{Consideração da ruptura da fibra.}

$\mathrm{Na}$ dedução dos modelos apresentados nas seções 3.3.3.1 até 3.3.3.4, foi suposto que a tensão na fibra carregada não atinge a sua resistência à tração, $\sigma_{f u}$. No entanto, é prudente supor que para certos sistemas de fibras/matriz, há combinações de comprimento embutido de fibra, diâmetro, inclinação da fibra, e atrito interfacial e de restrição (snubbing), tais que as tensões numa fibra carregada ultrapassam a resistência à tração da fibra. Nesse caso, há uma ruptura da fibra. Esta consideração é de suma importância em compósitos armados com fibras, pois otimiza o desempenho do material, atingindo seu estado limite último.

As condições necessárias para levar uma fibra inclinada à ruptura foram primeiramente modeladas por OBLA E LI (1995). Baseando-se no modelo proposto por OBLA E LI (1995), MAALEJ ET AL. (1995) posteriormente estudaram as várias combinação de comprimento e orientação da fibra que leva à ruptura da mesma.

Considera-se um compósito de fibra/matriz no qual pode-se ocorrer uma ruptura potencial da fibra. Supondo que todas as fibras são idênticas, e que a resistência à tração é uniforme ao longo de seu comprimento, quando ocorre a ruptura da fibra, isto se dá no plano da fissura. Para que a fibra rompe, ela deve tem um comprimento 
mínimo igual ao critico necessário para que a tensão na mesma atinja a sua resistência à ruptura. E quando ela rompe, a sua contribuição na tensão de travejamento do compósito não é mais efetiva, e deve ser descontada.

O comprimento crítico embutido $L_{u}$, além do qual ocorre uma ruptura potencial da fibra é determinado fazendo a tensão de travejamento $\sigma_{b}(\delta, \Phi, z)$ obtida na equação (3- 39), igual à resistência à tração da fibra $\sigma_{f u}$. Consequentemente, tem-se;

$$
L_{u}=L_{c} e^{-f \Phi}
$$

onde:

$$
L_{c}=\frac{\sigma_{f u} d_{f}}{4 \tau}
$$

Percebe-se de (3- 54) que, para um coeficiente de restrição, $f=0$, as fibras rompem apenas se seu comprimento embutido for maior que $L_{c}$. Neste caso particular, todas as fibras com comprimento embutido no intervalo $\left[L_{c}, \frac{l_{f}}{2}\right]$ rompem em vez de escorregar. Entretanto, devido ao efeito do atrito (snubbing effect), a equação (3- 55) mostra que todas as fibras para os quais o comprimento embutido e a orientação pertencem ao espaço bidimensional $\left.\{\ell \in] 0, \frac{l_{f}}{2}\right]$; e $\left.\Phi \in\left[0, \frac{\pi}{2}\right]\right\}$ tal que $\ell \geq L_{c} e^{-f \Phi}$ rompem em vez de escorregar. A combinação de comprimento embutido e orientação da fibra para a qual a fibra rompe portanto, define uma espaço bidimensional conhecido como espaço de ruptura das fibras. Baseado na sua definição, o espaço de ruptura das fibras é dado por:

$$
S=\left\{\ell \in\left[L_{c} e^{-f \frac{\pi}{2}}, \frac{l_{f}}{2}\right], \Phi \in\left[0, \frac{\pi}{2}\right] / \ell \geq L_{c} e^{-f \Phi}\right\}
$$


Consequentemente, existe um comprimento crítico mínimo, $L_{r}$, igual a $2 L_{c} e^{-f \frac{\pi}{2}}$, além do qual ocorre a ruptura da fibra.

(a)

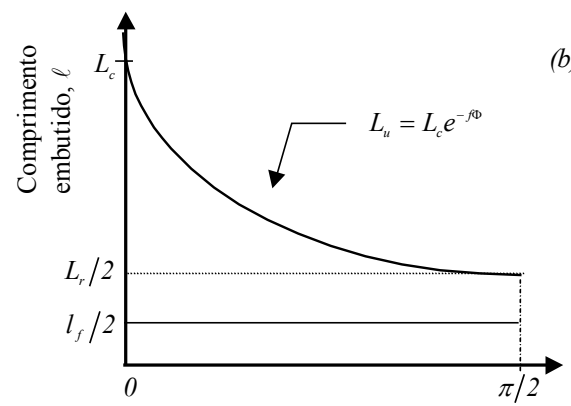

(b)

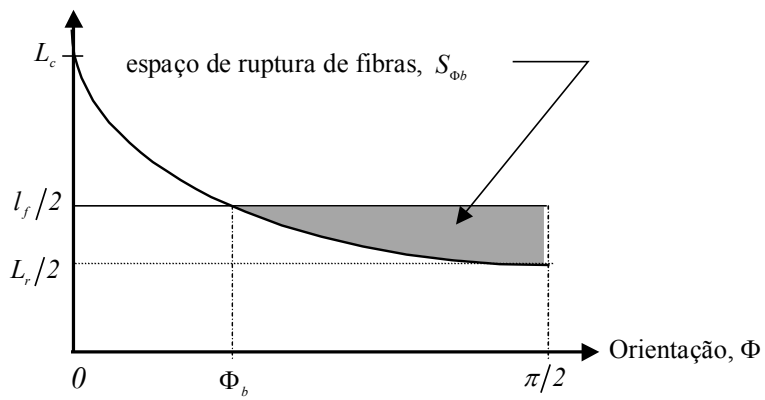

(c)

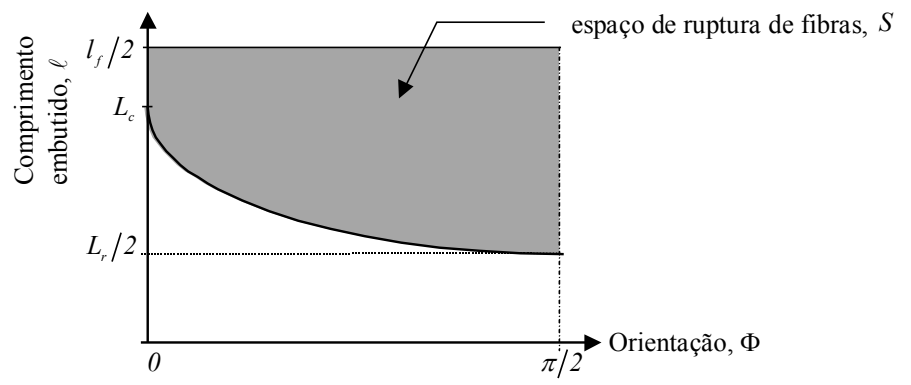

Fig. 3.10: Espaço de ruptura da fibra (Segundo MAALEJ ET AL., 1995)

A figura 3.10 ilustra esquematicamente os vários espaços de ruptura possíveis. Segundo a figura, se o comprimento da fibra $l_{f}$ for menor que $L_{r}$, o espaço de ruptura da fibra $S$ será vazio (fig. 3.10a), e todas as fibras serão arrancadas após a perda completa de aderência completa. Se ao contrário $l_{f}$ for maior que $L_{r}$, o espaço de ruptura da fibra será não-vazio e ocorrerá a ruptura da fibra. No caso particular quando o comprimento da fibra for maior que $L_{r}$ mas menor que $2 L_{c}$ (fig. 3.10b), o espaço de ruptura da fibra será dado por: 


$$
S_{\Phi b}=\left\{\ell \in\left[L_{c} e^{-f \frac{\pi}{2}}, \frac{l_{f}}{2}\right], \Phi \in\left[\Phi_{b}, \frac{\pi}{2}\right] / \ell \geq L_{c} e^{-f \Phi}\right\}
$$

onde:

$$
\Phi_{b}=-\left(\frac{1}{f}\right) \ln \left(\frac{l_{f}}{2 L_{c}}\right)
$$

Da figura 3.10b, observa-se que todas as fibras orientadas a um ângulo menor que $\Phi_{b}$ (i.e., $0 \leq \Phi \leq \Phi_{b}$ ) são arrancadas devido à perda completa de aderência completa enquanto para um comprimento de fibra maior que $2 L_{c}$, a ruptura pode ocorrer para qualquer orientação se o comprimento embutido for maior que o comprimento crítico $L_{u}$.

Quando o espaço de ruptura da fibra não é vazio, fibras de comprimento embutido $\ell$ e orientação $\Phi$, que pertencem a $S$, rompem após perda incompleta de aderência (figura 3.10c). Segundo mostra a figura 3.10c, uma fibra orientada a $90^{\circ}$ evidentemente também rompe ou escorrega segundo seu comprimento embutido. No entanto, segundo afirmam MAALEJ ET AL. (1995), na realidade uma fibra orientada a $90^{\circ}$ talvez não contribua à tensão de travejamento do compósito, pois a mesma estaria tangente ao plano da fissura. Para a simplicidade, o modelo de MAALEJ ET AL. (1995) supõe que a contribuição dessas fibras desprezível, pois apenas uma pequena proporção das fibras estará orientada a $90^{\circ}$.

É de fácil entendimento que, se ocorrer a ruptura das fibras, isto deve ser durante a perda de aderência $\left(\delta \leq \delta_{o}\right)$, porque a tensão das fibras que traveja a fissura tem uma queda durante o arrancamento (pós-pico) das fibras. Uma exceção disso, segundo LI ET AL. (1990), é quando o arrancamento das fibras manifesta o fenômeno de endurecimento no escorregamento normalmente observado durante o arrancamento de certas fibras poliméricas devido à abrasão causada pelo dano da superfície de proteção da fibra. No momento em que ocorre a ruptura da fibra, o deslocamento de abertura de fissura atinge um valor crítico, $\delta_{\text {crit }}$, que pode ser determinado fazendo a tensão de travejamento, $\sigma_{b}(\delta, \Phi, z)$, igual a $\sigma_{f u}$. Portanto temse: 


$$
\delta_{c r i t}=\delta_{c} e^{-2 f \Phi}
$$

onde:

$$
\delta_{c}=\frac{\sigma_{f u}^{2} d_{f}}{4(1+\eta) E_{f} \tau}
$$

Pode ser facilmente percebido da equação (3- 59) que, com o aumento da abertura de fissura, as fibras com grandes ângulos de orientação rompem antes às de orientações menores. Quando o espaço de ruptura da fibra é igual a $S_{\Phi b}$ (figura 3.10b), as fibras com orientação $\Phi_{b}$ são as últimas a romper. Segundo (3- 59), essas fibras rompem quando a abertura de fissura (COD) atinge um valor igual a:

$$
\delta_{c} e^{-2 f \Phi}=\delta_{c}\left(\frac{l_{f}}{2 L_{c}}\right)^{2}=\delta^{*}
$$

É interessante observar que esse COD, $\delta^{*}$, dado por (3- 60) corresponde ao estágio quando a perda de aderência está completa para aquelas fibras com o maior comprimento embutido, $\quad \ell=\frac{l_{f}}{2}$. Portanto, todas as fibras que sobrevivem a ruptura estarão num estágio de arrancamento quando o COD é maior que $\delta^{*}$. Se ao contrário, o espaço de ruptura de fibra é igual a $S$, as fibras orientadas a $0^{\circ}$, e com comprimento embutido da fibra, $\ell$, maior que $L_{u}$ são as últimas a romper. Segundo (3- 59), essas fibras rompem no COD igual a $\delta_{c}$. Portanto, todas as fibras que sobrevivem estarão no estágio de arrancamento quando o COD é maior que $\delta_{c}$.

Para o efeito de análise, a tensão de travejamento é computada considerandose todas até a ruptura, para aquelas que potencialmente rompem, acrescentado a contribuição das que são arrancadas sob o efeito de atrito. A relação tensão de travejamento-deslocamento para o grupo de fibras que eventualmente rompem é definida como uma função ressalto: 


$$
\sigma_{b}(\delta, \Phi, z)=\sigma_{d} U\left(\delta_{c} e^{-2 f \Phi}-\delta\right) e^{f \Phi}
$$

onde

$$
\begin{aligned}
& U\left(\delta_{c} e^{-2 f \Phi}-\delta\right)=1, \text { para } \delta \leq \delta_{c} e^{-2 f \Phi} \text { ou } \Phi \leq \Phi_{c} \\
& U\left(\delta_{c} e^{-2 f \Phi}-\delta\right)=0, \text { para } \delta>\delta_{c} e^{-2 f \Phi} \text { ou } \Phi>\Phi_{c}
\end{aligned}
$$

e

$$
\Phi_{c}=-\left(\frac{1}{2 f}\right) \ln \frac{\delta}{\delta_{c}}
$$

O parâmetro $\Phi_{c}\left(0 \leq \Phi_{c} \leq \frac{\pi}{2}\right)$, portanto, define a orientação das fibras que rompem quando o COD é igual a $\delta$.

\subsubsection{Modelo de travejamento do compósito}

O modelo de travejamento de fissuras por uma única fibra foi apresentado nas seções anteriores. Foi deduzida a tensão de travejamento da fibra, e como as influências da orientação e ruptura da fibra são incorporadas no modelo. Isso é representado pela equação (3-62). Agora resta determinar a tensão de travejamento devido ao arrancamento de todas as fibras.

Baseado num modelo estatístico/micro-mecânico, LI ET AL. (1991) deduziram o modelo analítico que descreve a curva tensão-abertura de fissura, $\sigma-\delta$, do compósito como a soma das contribuições das tensões nas fibras que grampeiam a fissura (fibras ativas).

Segundo LI ET AL. (1991), a tensão de travejamento do compósito é dada por: 


$$
\begin{gathered}
\sigma_{c}=\frac{F}{A_{c}}=\frac{V_{f}}{A_{f}} \int_{z=0}^{l_{f} / 2}\left[\int_{\Phi=0}^{\cos ^{-1}\left(\frac{2 z}{l_{f}}\right)} P(\ell, \Phi, \delta) p(\Phi) d \Phi\right] p(z) d z \\
\sigma_{c}=V_{f} \int_{0}^{\frac{\pi}{2}} \int_{0}^{\left(l_{f} / 2\right) \cos \Phi} \sigma_{b}(\delta, \Phi, z) p(z) p(\Phi) d z d \Phi
\end{gathered}
$$

onde $p(z)$ e $p(\Phi)$ são respectivamente as funções de densidade de probabilidade da distância do centroide da fibra e do ângulo de orientação medidas do plano da fissura. Para uma distribuição aleatória e uniforme, essas funções são definidas como:

$$
p(z)=\frac{2}{l_{f}} \text {, para } 0 \leq z \leq\left(\frac{l_{f}}{2}\right) \cos \Phi
$$

e

$$
p(\Phi)=\operatorname{sen} \Phi \text { para } 0 \leq \Phi \leq \frac{\pi}{2}
$$

Fazendo uma mudança da variável de $x$ para $z$ tal que:

$$
x=\left(\frac{\frac{l_{f}}{2}-\frac{z}{\cos \Phi}}{\frac{l_{f}}{2}}\right)=\frac{l}{l_{f} / 2}=\hat{l}
$$

A equação (3- 67) pode ser escrita como:

$$
\sigma_{c}=\frac{V_{f}}{2} \int_{0}^{\frac{\pi}{2}} \int_{0}^{l} \sigma_{b}(\delta, \Phi, x) \operatorname{sen} 2 \Phi d x d \Phi
$$

Da expressão (3-71), pode-se ver que os parâmetros constituintes são:

(a) a geometria da fibra ( diâmetro $d_{f}$, e comprimento $l_{f}$ ), 
(b) as propriedades da fibra (módulo de elasticidade $E_{f}$, resistência à tração $\left.\sigma_{f u}\right)$,

(c) taxa de fibra $V_{f}, \mathrm{e}$

(d) as propriedades de interface fibra/matriz (curva $\tau-s$ ou aderência, coeficiente de restrição $f$ ).

A partir da expressão da tensão de travejamento dada em (3- 71), pode-se deduzir as expressões das contribuições das fibras na tensão de travejamento do compósito, considerando-se todos os espaços de ruptura das fibras anteriormente definidos. Baseando-se na definição do espaço de ruptura, os seguintes casos devem ser considerados

$l_{f}<L_{r}$

Este caso corresponde ao espaço definido na figura 3.10a. Para este caso particular de $l_{f}<L_{r}$, LI (1992) mostrou que a relação tensão de travejamento-COD é dada por:

$$
\sigma_{c}=\sigma_{o} g\left[2\left(\frac{\hat{\delta}}{\hat{\delta}^{*}}\right)^{\frac{1}{2}}-\left(\frac{\hat{\delta}}{\hat{\delta}^{*}}\right)\right] \text {, para } \hat{\delta} \leq \hat{\delta}^{*}
$$

e

$$
\sigma_{c}=\sigma_{o} g(1-\hat{\delta})^{2}, \text { para } \hat{\delta}^{*} \leq \hat{\delta} \leq 1
$$

onde

$$
g=\frac{2}{4+f^{2}}\left(1+e^{f \frac{\pi}{2}}\right)
$$




\subsection{Relação tensão-deslocamento pré-pico do compósito}

A relação tensão de travejamento-deslocamento pré-pico define a parte inicial da curva $\sigma_{c}-\delta$ que termina quando o processo de ruptura das fibras esta completo e todas as fibras intactas estão na face de deslizamento. Para a fase pré-pico existem dois intervalo: $L_{r} \leq l_{f} \leq 2 L_{c}$ e $l_{f} \geq 2 L_{c}$.

$L_{r} \leq l_{f} \geq 2 L_{c}$

Para o caso de $L_{r} \leq l_{f} \leq 2 L_{c}$, o espaço de ruptura da fibra é igual a $S_{\Phi b}$ (figura 3.10b), e todas as fibras intactas estão sendo arrancadas da matriz sob atrito quando o COD, $\delta$ igual a $\delta^{*}$. Das relações (3- 38) em (3- 71) tem-se (APÊNDICE 1a )

$$
\begin{aligned}
& \sigma_{c}=\sigma_{o} g\left[2\left(\frac{\hat{\delta}}{\hat{\delta}^{*}}\right)^{\frac{1}{2}}-\left(\frac{\hat{\delta}}{\hat{\delta}^{*}}\right)\right], \text { para } \hat{\delta} \leq \hat{\delta}_{c} e^{-f \pi} \\
& \sigma_{c}=\sigma_{o}\left\{g\left(\Phi_{c}\right)\left[2\left(\frac{\hat{\delta}}{\hat{\delta}^{*}}\right)^{\frac{1}{2}}-\left(\frac{\hat{\delta}}{\hat{\delta}^{*}}\right)\right]+a(-f) \hat{L}_{c}^{2}\right\}, \text { para } \hat{\delta}_{c} e^{-f \pi} \leq \hat{\delta} \leq \hat{\delta}^{*}
\end{aligned}
$$

onde

$$
g\left(\Phi_{c}\right)=\frac{1}{4+f^{2}}\left\{\left[f \operatorname{sen}\left(2 \Phi_{c}\right)-2 \cos \left(2 \Phi_{c}\right)\right] e^{f \Phi_{c}}+2\right\}
$$

e

$$
a(t)=\frac{1}{4+t^{2}}\left\{\left[2 \cos \left(2 \Phi_{c}\right)-t \operatorname{sen}\left(2 \Phi_{c}\right)\right] e^{t \Phi_{c}}+2 e^{t \frac{\pi}{2}}\right\}
$$


$l_{f} \geq 2 L_{c}$

No caso de $l_{f} \geq 2 L_{c}$ o espaço de ruptura da fibra é igual a $S$ [figura 3.10(c)] e todas as fibras intactas estão na face de escorregamento quando o COD $\delta$ igual a $\delta_{c}$. Segue-se portanto que (APÊNDICE 1b)

$$
\sigma_{c}=\sigma_{o} g\left[2\left(\frac{\hat{\delta}}{\hat{\delta}^{*}}\right)^{\frac{1}{2}}-\left(\frac{\hat{\delta}}{\hat{\delta}^{*}}\right)\right], \text { para } \hat{\delta} \leq \hat{\delta}_{c} e^{-f \pi}
$$

e

$$
\sigma_{c}=\sigma_{o}\left\{g\left(\Phi_{c}\right)\left[2\left(\frac{\hat{\delta}}{\hat{\delta}^{*}}\right)^{\frac{1}{2}}-\left(\frac{\hat{\delta}}{\hat{\delta}^{*}}\right)\right]+a(-f) \hat{L}_{c}^{2}\right\} \text {, para } \hat{\delta}_{c} e^{-f \pi} \leq \hat{\delta} \leq \hat{\delta}^{*}
$$

Determinada a relação tensão-abertura de fissura pré-pico, segue-se o mesmo princípio para deduzir as contribuições das fibras na fase pós-pico. A relação tensão de travejamento-deslocamento pós-pico do compósito define a parte inicial da curva $\sigma_{c}-\delta$ que corresponde ao estágio de deslizamento de todas as fibras que sobreviveram a ruptura. Considera-se os mesmos intervalos como no caso pré-pico.

\subsection{Relação tensão-deslocamento pós-pico do compósito}

A relação tensão de travejamento-deslocamento pré-pico define a parte da curva $\sigma_{c}-\delta$ correspondente ao estágio de arrancamento de todas as fibras do compósito que sobreviveram a ruptura. Do mesmo modo como a fase pré-pico, existem dois intervalo: $L_{r} \leq l_{f} \leq 2 L_{c}$ e $l_{f} \geq 2 L_{c}$, para a fase pós-pico.

$L_{r} \leq l_{f} \leq 2 L_{c}$

Substituindo (3- 39) em (3- 71) tem-se (APÊNDICE 2a): 


$$
\begin{aligned}
& \sigma_{c}=\sigma_{o}\left[g\left(\Phi_{b}\right)(1-\hat{\delta})^{2}+b(-f) \hat{L}_{c}^{2}-2 b(0) \hat{L}_{c} \hat{\delta}+b(f) \hat{\delta}^{2}\right] \\
& \operatorname{para} \hat{\delta}^{*} \leq \hat{\delta} \leq \hat{L}_{c} e^{-f \frac{\pi}{2}} \\
& \sigma_{c}=\sigma_{o}\left[g\left(\Phi_{b}\right)(1-\hat{\delta})^{2}+c(-f) \hat{L}_{c}^{2}-2 c(0) \hat{L}_{c} \hat{\delta}+c(f) \hat{\delta}^{2}\right] \\
& \operatorname{para} \hat{L}_{c} e^{-f \frac{\pi}{2}} \leq \hat{\delta} \leq 1
\end{aligned}
$$

onde:

$$
\begin{aligned}
& b(t)=\frac{1}{4+t^{2}}\left\{\left[2 \cos \left(2 \Phi_{b}\right)-t \operatorname{sen}\left(2 \Phi_{b}\right)\right] e^{t \Phi_{b}}+2 e^{t \frac{\pi}{2}}\right\} \\
& c(t)=\frac{1}{4+t^{2}}\left\{\left[t \operatorname{sen}\left(2 \Phi_{a}\right)-2 \cos \left(2 \Phi_{a}\right)\right] e^{t \Phi_{a}}+\left[2 \cos \left(2 \Phi_{b}\right)-t \operatorname{sen}\left(2 \Phi_{b}\right)\right] e^{t \Phi_{b}}\right\} \\
& \Phi_{a}=-\frac{1}{f} \ln \frac{\hat{\delta}}{\hat{L}_{c}}
\end{aligned}
$$

O ângulo $\Phi_{a}$ define o grupo de fibras (fibras com orientação satisfazendo $\left.\Phi_{a} \leq \Phi \leq \frac{\pi}{2}\right)$ que já foram arrancadas até um COD $\delta$.

$l_{f}>2 L_{c}$

Nesse caso tem-se (APÊNDICE 2b):

$$
\begin{aligned}
& \sigma_{c}=\sigma_{o}\left[g_{1} \hat{L}_{c}^{2}-2 \hat{L}_{c} \hat{\delta}+g \hat{\delta}^{2}\right], \text { para } \hat{\delta}_{c} \leq \hat{\delta} \leq \hat{L}_{c} e^{-f \frac{\pi}{2}} \\
& \sigma_{c}=\sigma_{o}\left[d(-f) \hat{L}_{c}^{2}-2 d(0) \hat{L}_{c} \hat{\delta}+d(f) \hat{\delta}^{2}\right], \text { para } \hat{L}_{c} e^{-f \frac{\pi}{2}} \leq \hat{\delta} \leq \hat{L}_{c},
\end{aligned}
$$


onde

$$
\begin{aligned}
& d(t)=\frac{1}{4+t^{2}}\left\{\left[t \operatorname{sen}\left(2 \Phi_{a}\right)-2 \cos \left(2 \Phi_{a}\right)\right] e^{t \Phi_{a}}+2\right\} \\
& g_{1}=\frac{2}{4+f^{2}}\left(1+e^{-f \frac{\pi}{2}}\right)
\end{aligned}
$$

Deve-se notar que o máximo $\mathrm{COD}, \delta=L_{c}$, correspondente ao comprimento crítico das fibras com orientação normal ao plano da fissura $(\Phi=0)$.

\subsubsection{Interação Fibra-Matriz}

A eficácia das fibras no melhoramento das propriedades de matrizes cimentícias frágeis é controlado por dois processos importantes:

1. o efeito de travejamento das fibras nas fissuras, processo este que ocorre nos estágios mais avançados de carregamento.

2. os processos pelas quais o carregamento é transferido da matriz para as fibras, definidos pelas tensões na interface fibra/matriz; e

Na primeira parte deste capítulo até então, o esforço tem sido direcionado na modelagem do efeito de travejamento das fibras, apresentando-se um estudo aprofundado sobre a modelagem micro-mecânica do efeito de travejamento das fibras. Neste item, o esforço será direcionado ao segundo aspecto. Os aspecto principais da modelagem da interação matriz/compósito serão abordados.

De fato a interação fibra/matriz é um dos mecanismos pelos quais o carregamento é transferidos para as fibras num compósito armado com fibras. $\mathrm{O}$ estudo da interação fibra/matriz é de importância fundamental na engenharia de compósitos de alto desempenho. Devido à engenharia de interface, hoje é possível se falar de compósitos como ECC (Engineered Cimentitious Composites) ou HPFRCC (High Performance Fiber Reinforced Cement Composites), nas quais o desempenho do compósito é previamente fixado dependendo do fim ao qual será destinado, e a 
interface fibra/matriz engenhado para que o compósito atinja tal desempenho, quase sempre o compósito demonstrando propriedades de pseudo-endurecimento. Entretanto, não se pretende discutir no presente trabalho o problema de engenharia de interface fibra/matriz em compósitos armados com fibras. O seu estudo será limitado apenas na modelagem analítico da tensão tangencial de interface fibra/matriz como um parâmetro nos modelos de travejamento discutidos até então.

Vários modelos têm sido propostos para descrever a relação força-deslocamento num ensaio de arrancamento. Para compósitos de fibras flexíveis aleatoriamente orientadas, LI (1992), baseando-se no modelo de LI ET AL. (1991) deduziu um modelo da tensão de travejamento das fibras considerando atrito constante na interface fibra/matriz (o chamado "modelo de $\tau$ constante). Este modelo simples pode prever a relação de tensão-deslocamento pós-fissuração e a energia de fratura no arrancamento determinadas experimentalmente, para compósitos de fibras de aço e fibras sintéticas, e para uma grande gama de parâmetros micro-mecânicos. Contudo, segundo LIN E LI (1997), existem discrepâncias no emprego do modelo $\tau$ constante para sistemas com comportamento de interfaces que dependem do escorregamento, especialmente para a previsão de aberturas de fissura na tensão máxima de travejamento.

Segundo LEUNG E NUMER (1997), o comportamento não-linear pós-pico exibido em ensaios de tração para fibras alinhadas na direção do carregamento implica que $o$ atrito interfacial $\tau$ não é constante. A forma convexa da curva atrito-escorregamento, $\tau-s$, indica que $\mathrm{O}$ atrito interfacial aumenta com $\mathrm{O}$ deslocamento por escorregamento da fibra durante o arrancamento (GENG E LEUNG, 1996), que faz com que o diâmetro efetivo aumente.

LIN E LI (1997) atribuem a dependência da tensão do deslocamento por escorregamento à abrasão, aspereza devida ao desgaste, e fragmentação do revestimento da fibra na interface onde ocorre a perda de aderência. Segundo os mesmos pesquisadores, para o caso particular de compósitos de fibras sintéticas (usualmente fibras poliméricas)/matriz de cimento, a abrasão é o mecanismo preponderante por trás do fenômeno de endurecimento no escorregamento. 
Para levar em conta a dependência do atrito de escorregamento, LIN E LI (1997) deduziram um modelo para a tensão de cisalhamento interfacial. No modelo o endurecimento de escorregamento foi levado em conta baseando-se numa relação constitutiva de interface. O modelo assim deduzido por LIN E LI (1997) pode ser incorporado num modelo micro-mecânico para o arrancamento de uma única fibra, e posteriormente incorporada no modelo da tensão de travejamento da fissura do compósito, como o proposto por LI ET AL., (1991).

O modelo constitutivo proposto por LIN E LI (1997) considera a tensão de interface fibra/matriz, $\tau$, como uma função do deslocamento por escorregamento relativo entre a fibra e a matriz, $s$. Segundo LIN E LI, (1997) o atrito fibra/matriz é dado por:

$$
\tau=\tau(s)
$$

A dependência do atrito do escorregamento previsto em (3- 90) tem sido modelada por vários pesquisadores. Partindo de um modelo fenomenológico simples de dois parâmetros, BAO E SONG (1993) propuseram três modelos para a expressão (3- 90) que levam em conta os fenômenos de endurecimento de deslocamento observado no arrancamento de fibras sintéticas, e amolecimento de deslocamento observado no arrancamento de fibras metálicas. Os seguintes modelos foram considerados por BAO E SONG, (1993):

a. um modelo linear de endurecimento de deslocamento que descreve a dependência entre $\tau$ e $s$ dada por:

$$
\tau(s)=\tau_{o}\left(1+\frac{\beta}{d_{f}} s\right)
$$

b. um modelo linear de amolecimento de deslocamento dado por:

$$
\tau(s)=\tau_{o}\left(1-\frac{\beta}{d_{f}} s\right)
$$

c. um modelo exponencial de amolecimento de deslocamento dado por: 


$$
\tau(s)=\tau_{o} \exp \left(\frac{\beta}{d_{f}} s\right)
$$

onde $\tau_{o}$ e $\beta$ são empiricamente determinados pelo ajuste da curva $P-\delta$ de arrancamento de uma única fibra (WANG ET AL., 1988)

WANG ET AL. (1988), no entanto, tinham anteriormente afirmado que, embora o atrito dependa do escorregamento, qualquer modelo, como o proposto na (3-91) por LIN E LI (1997), pode necessitar termos de ordens superiores para descrever completamente a curva de arrancamento de uma fibra com precisão. A modelagem da tensão de interface pode ser feita empregando-se várias funções para ajustar os resultados obtidos em ensaios de arrancamento. Separadamente, WANG ET AL. (1988), AARRE, (1992), GLAVIND (1992), LI ET AL (1993) (1993), e STANG ET AL. (1995) obtiveram bons ajustes dos resultados experimentais considerando um polinômio de segunda ordem da seguinte forma:

$$
\tau\left(\delta^{\prime}\right)=\tau_{o}+a_{1} \delta^{\prime}+a_{2} \delta^{\prime 2}
$$

onde $\tau_{o}, a_{1}$, e $a_{2}$ são determinados experimentalmente para cada combinação especifica do tipo de fibra, matriz, e condições de moldagem do compósito.

Segundo LI ET AL (1993), pode-se supor que o deslocamento localizado, $\delta^{\prime}$, igual ao deslocamento por escorregamento da extremidade da fibra, $\delta$, que ocorre após a perda completa de aderência. Isso, segundo LI ET AL (1993), é devido ao fato de que o deslocamento localizado é desprezível antes da perda completa de aderência. Com essas considerações LI ET AL (1993) propuseram um modelo de atrito-escorregamento dado por: 


$$
\begin{aligned}
& \tau(\delta)=\tau_{o}, \text { para } \delta \leq \delta^{*} \\
& \tau(\delta)=\tau_{o}+a_{1} \delta+a_{2} \delta^{2}, \text { para } \delta>\delta^{*}
\end{aligned}
$$

Da mesma forma como LI ET AL (1993), LEUNG E NUMER (1997) deduziram um modelo polinomial da tensão interfacial, $\tau$, baseado no ajuste de resultados experimentais. No entanto, além da dependência do atrito do escorregamento modelado por LI ET AL (1993), no modelo de LEUNG E NUMER (1997), foi levado em conta o dano efetivo da fibra após a perda completa de aderência.

Baseado no dano da fibra após a perda completa de aderência, o modelo de LEUNG E NUMER (1997) propõe que na equação (3- 91), $\tau$ pode ser considerado como constante $\tau_{o}$, como na equação (3- 95). Uma vez que inicia-se o escorregamento da fibra, i.e., quando se aplica a equação (3- 52), a variação de $\tau$, do valor inicial $\tau_{o}$ é descrita por uma expressão empírica;

$$
\frac{d \tau}{d s}=c_{1}+c_{2} s+c_{3} s^{2}
$$

onde:

$s$ escorregamento da fibra após a perda completa de aderência; e $c_{1}, c_{2}$, e $c_{3}$ são determinado experimentalmente.

Segundo LEUNG E NUMER (1997), a ordem dois é escolhida para a equação (3- 96) pois um polinômio de segundo grau é o polinômio de menor ordem necessário para se conseguir um bom ajuste dos resultados experimentais.

A mudança da forma da curva de arrancamento (convexidade) observada com o aumento de orientação foi modelada por LEUNG E NUMER (1997) considerando o coeficiente de restrição como uma função crescente com respeito ao escorregamento. Segundo os mesmos, há duas razões físicas para se supor tal relação: 
a. com o aumento de escorregamento (i.e., aumento da distância de arrancamento), a deformação da fibra no ponto onde a mesma sai da matriz aproxima-se a um nó. Portanto, o efeito da restrição se torna mais significante;

b. como foi mencionado, há um dano da superfície da fibra devido ao escorregamento.

Supondo-se que o dano superficial das fibras é o mecanismo mais preponderante, pode-se considerar o coeficiente de restrição, $f$, crescente de um valor inicial, $f_{o}$, segundo a função:

$$
\frac{d f}{d s}=c_{4} R
$$

onde:

$R$ - força na matriz no ponto onde a fibra intersecta o plano de fissura; e $c_{4}$ - constante a ser determinada experimentalmente.

A força $R$ pode ser facilmente calculada da figura 3.9 como:

$$
R^{2}=P(0)^{2}+P_{f}^{2}-2 P(0) P_{f} \cos \varphi
$$

Da mesma forma a componente normal $R_{l}$ de $R$, que governa o esmagamento da matriz pode ser determinada da figura 3.9 como:

$$
R_{1}=P_{f} \operatorname{sen} \varphi
$$

onde

$\varphi$ é a orientação do comprimento livre da fibra após o esmagamento da matriz (figura 3.9).

Supondo a força $R_{l}$ distribuída ao longo de um comprimento da matriz $L_{r}$ no ponto onde a fibra intersecta o plano da fissura, LEUNG E NUMER (1997) modelaram o esmagamento da matriz considerando-se que o esmagamento ocorre se $R_{l}$ for 
maior que a força de esmagamento, $F_{s}$, obtida por elementos finitos pelo modelo de LEUNG E LI (1992), considerando a fibra como uma viga sobre uma fundação elástica.

\subsubsection{Efeito Cook-Gordon}

Em matrizes reais, as micro-estruturas especiais da interface fibra/matriz na vizinhança de uma fibra, e a geometria complexa de arrancamento de alguns tipos de fibras, como fibras de aço, pode resultar em um modo de perda de aderência e arrancamento totalmente diferente do previsto pelos modelos baseados na geometria simples de arrancamento apresentado na seção 3.3.3.1, caracterizado pelo arrancamento e perda de aderência simétricos na interface fibra/matriz. De fato, as fibras comercialmente empregadas possuem geometria muito complexas, e portanto, é evidente que a ligação fibra/matriz seja, além de aderência fibra/matriz, resultado de ancoragem mecânica, efeito este que não pode ser interpretado em termos de tensões tangenciais na interface fibra/matriz. Ademais, um volume de matriz muito maior que suposto pelos modelos de arrancamento da seção 3.3.3.1 (figura 3.3a) é mobilizado.

Além dos fatores acima expostos, um outro fenômeno de grande importância na interação fibra/matriz é o desvio do caminho da fissura quando a mesma atravessa uma fibra. Este fenômeno tem sido observado em muitos sistemas de fibras monofilamentos ou fibras empoladas, e resulta na separação da matriz em várias micro-fissuras ou a fissuração múltipla do compósito (BENTUR E MINDESS, 1990). Como foi visto no capítulo 2 (seção 2.3.2), o desvio do caminho da fissura é um mecanismo de tenacidade, e portanto, deve ser previsto no modelo analítico. Segundo BENTUR E MINDESS (1990), esta observação pode ser explicada pela fraca interface na zona de transição, e o mecanismo limitador de Cook-Gordon.

Segundo Cook e Gordon apud BENTUR E MINDESS (1990), uma fissura com uma raiz de raio finita em um sólido elástico sob uma tração remota criará um campo de tensão na extremidade da fissura composto de uma concentração de tensão na direção da tensão de tração externa, e um campo de tensão de tração na direção perpendicular, paralela ao plano de fissuração. O campo de tensões perpendicular à direção de tração atinge seu máximo não na extremidade da fissura como se espera, mas sim numa distância da sua extremidade, igual ao raio da extremidade da fissura. Na figura 3.11, estão ilustrados esquematicamente as duas família de tensões: direção 
y (curva em cor marrom) na direção da tração externa, e direção x (curva em cor azul) perpendicular à tração externa (figura 3.11).

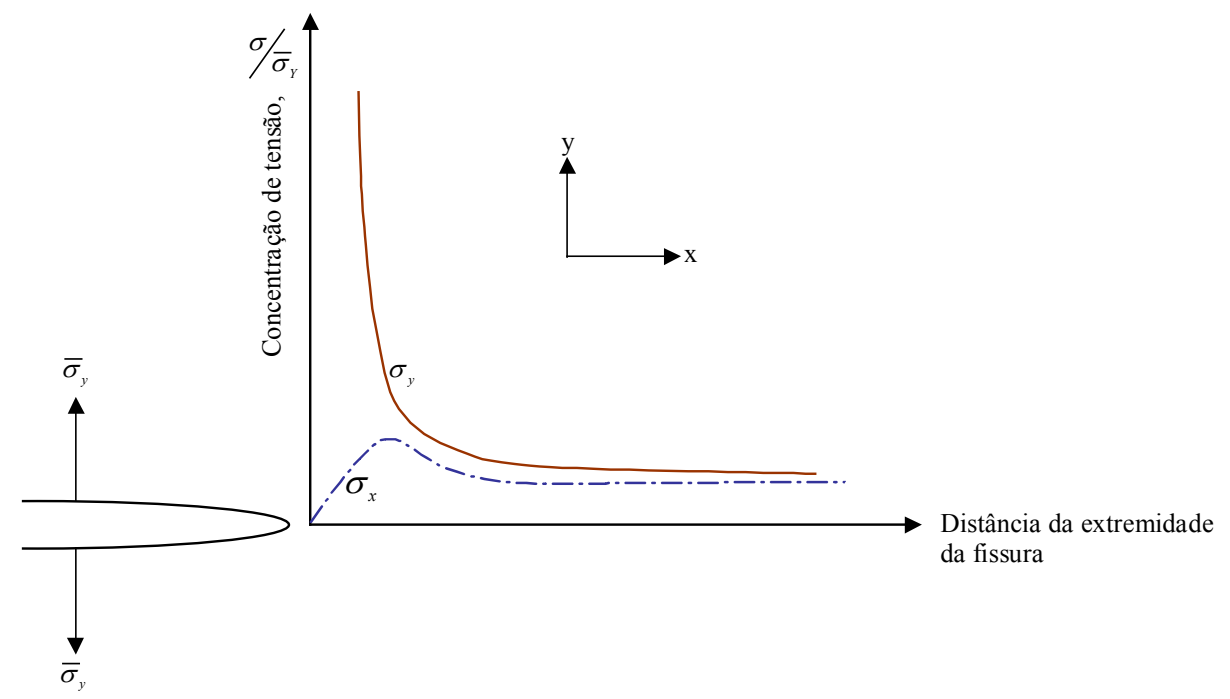

Fig. 3.11: O mecanismo de Cook-Gordon num compósito com interface fraca: o campo de tensão a frente da ponta de uma fissura (Segundo BENTUR E MINDESS 1990 apud COOK E GORDON, 1964)

Portanto, deve ao efeito Cook-Gordon acima discutido, segue-se que em uma matriz, uma fissura que aproxima uma fibra isolada pode causar uma perda de aderência, antes mesmo da extremidade da fissura ter atingida a interface fibra/matriz, se a interface for suficientemente fraca. Este efeito está ilustrado na figura 3.12, onde mostra-se o avanço de uma fissura e a perda precoce de aderência na interface fibra/matriz (figura 3.12a) antes mesmo que a fissura atinja a interface, e o aumento de abertura de fissura devido ao efeito Cook-Gordon (figura 3.12b). 

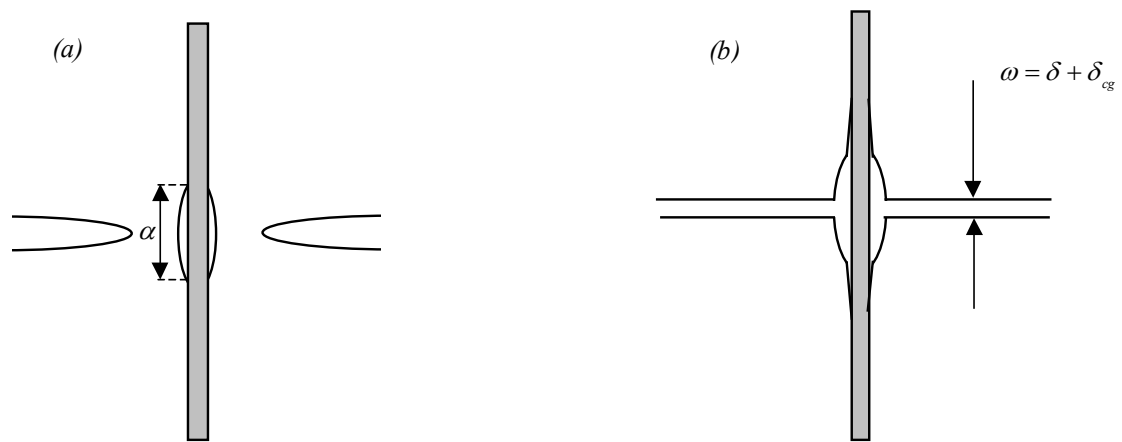

Fig. 3.12: $O$ efeito Cook-Gordon (a) induz a separação da fibra-matriz devido a tensão de tração na direção horizontal associada com o campo elástico da ponta de fissura de uma fissura que se aproxima, $e$ (b) resulta em uma abertura adicional $\delta_{c g}$ devido à deformação elástica de um Segmento da fibra $\alpha$ mais $\delta$ associado à perda de aderência na interface (Segundo LI ET AL., 1993)

Segundo LI ET AL. (1993), para se modelar completamente a interação fibra/matriz, deve-se considerar a tendência adicional de travejamento devida ao efeito Cook-Gordon. Como conseqüência desse efeito, é de se esperar que haja um deslocamento adicional, $\delta_{c g}$, relativo ao estiramento elástico de um trecho da fibra de comprimento $\alpha$, com perda de aderência. O parâmetro $\alpha$ é denominado o parâmetro de Cook-Gordon. Baseado em um comportamento elástico linear, LI ET AL. (1993) propuseram um modelo simplificado para a abertura de fissura devido ao efeito Cook-Gordon como apresentado a seguir:

$$
P_{f}=\sigma_{f} A_{f}=\varepsilon_{f} E_{f} A_{f}
$$

fazendo

$$
\varepsilon_{f}=\frac{\delta_{c g}}{\alpha}
$$

Conseqüentemente, a força de travejamento é dada por:

$$
P_{f}=\frac{\delta_{c g}}{\alpha} E_{f} A_{f} \Rightarrow \delta_{c g}=\frac{\alpha P_{f}}{E_{f} A_{f}}
$$


onde:

$\alpha$-parâmetro Cook-Gordon;

$A_{f}$-área da seção transversal da fibra.

Portanto de (3-102) tem-se:

$$
\Rightarrow \delta_{c g}=\frac{4 \alpha P_{f}}{\pi E_{f} d_{f}^{2}}
$$

A relação $P-\delta$ dada por (3-104) pode portanto, ser substituída na equação da tensão de travejamento do compósito (equação (3-67) resultando em:

$$
\delta_{c g}=\frac{4 \alpha}{V_{f} E_{f}} \sigma_{f}
$$

e a abertura total da fissura e dada aproximadamente por:

$$
w=\delta+\delta_{c g}
$$

onde $\delta$ é calculada considerando as tensões de travejamento das fibras (ou a abertura de fissura sem o efeito Cook-Gordon)

\subsubsection{Efeito da Pré-tração}

Fundamentalmente, deve-se considerar o mecanismo de pré-tração devido ao fato de que, na formação da fissura, e bem antes da sua abertura, a fibra esta sob um estado de tensão (LI ET AL., 1993). O nível de "protensão", $\sigma_{p s}$, pode ser estimado da distribuição de carregamento entre a fibra e a matriz na deformação correspondente à fissuração da matriz. Pela teoria de material compósito, esta tensão é dada por (BENTUR E MINDESS, 1990): 


$$
\sigma_{p s}=\eta_{\Phi} \eta_{\ell} \varepsilon_{m u} E_{f} V_{f}
$$

onde:

$\varepsilon_{m u}$ - deformação da matriz na primeira fissura; e

$\eta_{\Phi}$ e $\eta_{\ell}$-fatores de eficiência de orientação e de comprimento respectivamente.

Além da sua dependência de no comprimento, a eficiência de orientação depende da relação entre o comprimento da fibra e as dimensões transversais do elemento (LIM ET AL., 1987; SOROUSHIAN E LEE, 1990). SOROUSHIAN E LEE (1990) mostraram que a eficiência de orientação, $\eta_{\Phi}$, depende da relação das dimensões transversais do elemento, e o comprimento da fibra com respeito ao numero de bordas com restrição. Os mesmos afirmaram também a dependência da eficiência de orientação do tipo da adensamento.

Como simplificação, LI ET AL. (1993) adotaram um valor de $\eta_{\Phi}=1$ para a contribuição das fibras na fase pós-fissuração, considerando-se que nessa fase de carregamento, todas as fibras que travejam a fissura estarão orientadas na direção de carregamento. Para o fator de eficiência de comprimento, LI ET AL. (1993) adotam o modelo proposto por LAWS (1971) apud BENTUR E MINDESS (1990), supondo uma ligação elástica entre fibra e matriz. Segundo LAWS (1971) apud BENTUR E MINDESS (1990), o fator de eficiência de comprimento é dado por:

$$
\eta_{\ell}=1-\frac{\varepsilon_{m u} E_{f} d_{f}}{4 l_{f} \tau_{o}}
$$

LI ET AL. (1993) e STANG ET AL. (1995),afirmam que, a pré-tração da fibra é reduzida devido ao processo de perda de aderência na interface até que a mesma seja totalmente eliminada com a perda completa de aderência (quando a abertura de fissura, $\delta$, atinge um valor $\delta^{*}$ ). Baseado nessa hipótese, LI ET AL. (1993) e posteriormente STANG ET AL. (1995) supuseram uma variação linear do nível da pré-tração com a abertura de fissura de forma:

$$
\sigma_{p s}(w)=\sigma_{p s}^{o} \frac{w^{*}-w}{w^{*}}, \text { para } w \leq w^{*}
$$




$$
\sigma_{p s}(w)=0, \text { para } w>w^{*}
$$

com

$$
\sigma_{p s}^{o}=\eta \varepsilon_{m u} E_{f} V_{f}
$$

onde

$\eta$ fator de eficiência combinado devido à orientação e comprimento.

Segundo LI ET AL. (1993) e STANG E AL. (1995) a eficiência composta de orientação e comprimento da fibra pode ser simplificada como:

$$
\eta=\eta_{\Phi} \eta_{\ell}
$$

Nas expressões acima tem-se:

$$
\begin{aligned}
& w^{*}=w\left(\delta^{*}\right)=\delta^{*}+\delta_{c g}\left(\sigma_{f}=\sigma_{o}\right) \\
& \varepsilon_{m u}=\frac{\sigma_{m u}}{E_{m}}
\end{aligned}
$$




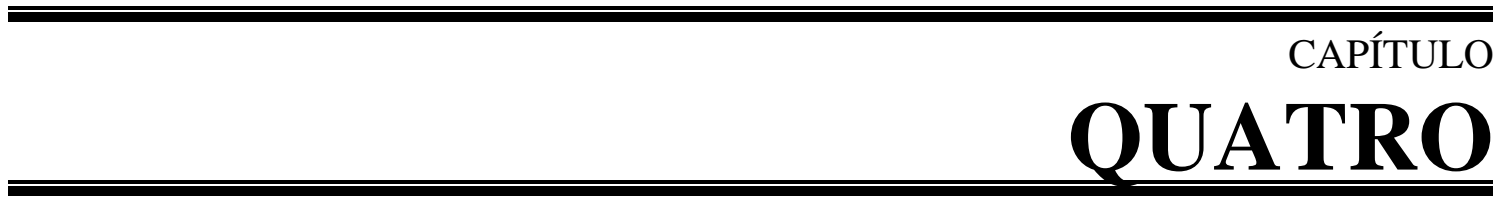

\section{PREVISÃO DE ABERTURA E ESPAÇAMENTO DE FISSURA EM CONCRETO ARMADO COM FIBRAS E ARMADURA CONVENCIONAL}

\subsection{PRELIMINARES}

Existem dois aspectos básicos do problema de fissuração: a definição de um critério adequado, e a formulação de métodos de cálculo adequados, para garantir que os critérios estejam satisfeitos. Como foi anteriormente apontado no capítulo 1 , existe uma grande discrepância entre as várias expressões para a previsão de abertura e espaçamento de fissura no concreto e seus compósitos, devido principalmente ao fato de que, as teorias que levam a essas formulações são apenas descrições parciais do fenômeno de fissuração.

No presente capítulo, antes do tratamento do problema de fissurração no contexto dessa pesquisa, será feito em primeiro lugar, um embasamento teóricoconceitual da teoria clássica da fissuração de Saliger. Esse tratamento permitirá entender os conceitos, e principalmente as modificações e simplificações que constam 
nos códigos de dimensionamento de estruturas de concreto. Em particular, os procedimentos da Norma Brasileira serão abordados.

Finalmente, dentro do contexto da pesquisa aqui desenvolvida, apresentam-se dois modelos para a previsão de abertura de fissura: o primeiro é um modelo simples proposto por AL-TAAN E AL-FEEL (1989), e baseado no trabalho de CHI E KIRSTEIN (1958), fundamentado na teoria clássica de fissuração de Saliger. O segundo modelo, normalmente conhecido como modelo de defasagem de cisalhamento foi proposto por STANG E AARRE (1992) para sistemas de um tipo de fibra, e posteriormente modificado por STANG ET AL. (1995) para sistemas híbridos, incorporando-se a possibilidade de otimização do compósito.

\subsection{TEORIA CLÁSSICA DE FISSURAÇÃO}

O desenvolvimento aqui apresentado segue o curso da teoria clássica de fissuração de Saliger até o presente momento. Para propiciar uma compreensão do desenvolvimento da teoria de fissuração, tenta-se seguir uma progressão natural, dando um retrato completo do fenômeno com a obtenção de dados mais atualizados.

Deve-se esclarecer, em primeiro lugar que, todas as teorias apenas tratam da fissuração de concreto endurecido; a fissuração plástica, por exemplo, está fora da amplitude da abordagem. Uma condição a mais da teoria clássica é que a seção deve ser suficientemente armada, tal que a armadura tenha ainda um comportamento elástico após a fissuração do elemento.

\subsubsection{Considerações Básicas da Teoria de Fissuração}

Todas as teoria de fissuração partem das seguintes suposições abordadas a seguir.

1. Em primeiro lugar, considere uma situação quando aparece a primeira fissura num elemento estrutural sob tração, como ilustra a figura 4.1. $\mathrm{Na}$ superfície do elemento, a tensão deve ser nula no concreto na região da fissura. No entanto, conforme se distancia da fissura, a tensão na superfície do concreto aumenta até, numa distância $s_{o}$ da 
fissura, a distribuição delas é uniforme. Isso implica que a tensão não é afetada pela fissura, ou seja, a fissura apenas afeta a distribuição de tensões apenas dentro de uma distância $\pm s_{o}$ dela (fig. 4.1a). Visto que a fissura afeta a distribuição da tensão superficial do concreto à níveis abaixo da resistência à tração do concreto apenas dentro de $\pm s_{o}$ da fissura, é evidente que a próxima fissura deve se formar fora dessa região. Portanto, a distância mínima entre fissuras é $s_{o}$. Se duas fissuras se formam numa distância maior que $2 s_{o}$, haverá portanto uma região entre as fissuras onde a tensão não afeta nenhuma das duas, e portanto uma outra fissura poderá se formar (figura 4.1b). Ao contrário, se o espaçamento entre fissuras for menor que $2 s_{o}$, a tensão no concreto entre a duas fissuras consecutivas será reduzida a níveis abaixo da resistência à tração (figura 4.1c) e nenhuma outra fissura poderá se formar entre as duas. Diante disso, pode-se dizer que, quando a fissuração se estabiliza, o espaçamento máximo possível entre as mesmas é portanto $2 s_{o}$, e a configuração final deverá consistir de fissuras com uma distribuição de espaçamentos entre fissuras no intervalo:

$$
s_{o} \leq s \leq 2 s_{o}
$$

A figura 4.1 ilustra esquematicamente $o$ argumento acima. 


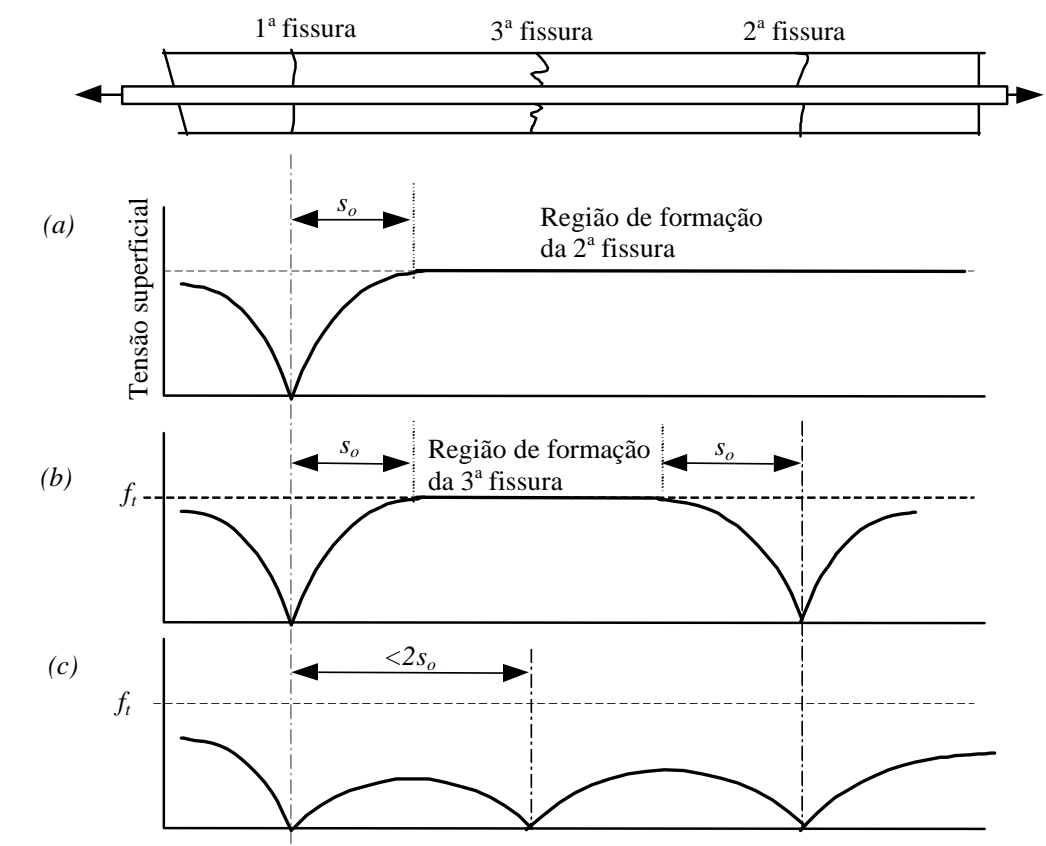

Fig. 4.1: As condições na superfície de um elemento de concreto armado tracionado durante o desenvolvimento da fissuração (Segundo BEEBY, 1979)

2. A segunda consideração é que, a abertura média de fissura é dada pelo espaçamento médio entre fissuras multiplicado pela diferença entre a deformação média na armadura e a deformação média residual do concreto entre as fissuras. A abertura média das fissura é dada por:

$$
w_{m}=s_{m}\left(\varepsilon_{s m}-\varepsilon_{c m}\right)
$$

onde:

$$
\begin{aligned}
& s_{m} \text { —espaçamento médio entre fissuras; } \\
& \varepsilon_{s m} \text { —deformação média da armadura; } \\
& \varepsilon_{c m} \text { - deformação média do concreto. }
\end{aligned}
$$

É mais comum desprezar a deformação no concreto, $\varepsilon_{c m}$, entre as fissuras. Baseando-se nesta suposição a equação (4- 2) pode ser escrita como: 


$$
w_{m}=s_{m} \varepsilon_{s m}
$$

Segundo BEEBY (1979), o espaçamento médio final das fissura, $s_{m}$, é normalmente suposto igual a $1,5 s_{o}$. No entanto, o mesmo pesquisador afirma que há base teórica suficiente para se pensar que o valor de $1,33 s_{o}$ para o espaçamento médio entre as fissuras seja mais adequado. Porem, do ponto de vista da modelagem analítica, o problema mais difícil enfrentado pelos teóricos é desenvolver modelos para prever $s_{o}$.

Além das duas considerações acima citadas, a teoria clássica de Saliger para a previsão do espaçamento de fissuras em elementos submetidos à tração direta está baseada na condição adicional de que, as seções planas permanecem planas. Isto implica que, em um elemento de concreto submetido à uma tração direta, a tensão no concreto é uniforme na seção do concreto. No entanto, a compatibilidade de deformações entre o aço e concreto não é mantida, e para validar está hipótese, supõe-se que há um deslocamento relativo entre os dois. Isso leva evidentemente a se supõe que ocorrerá uma falha da aderência na interface armadura/concreto na região de cada fissura. No restante da seção, a transferência de força será entre o aço e o concreto será efetuada através de tensões de aderência na interface armadura-concreto. Uma suposição adicional é feita que, com a suposição de falha de aderência em cada fissura, a distribuição de tensão ao longo da barra entre as fissuras pode ser considerada uma função da aderência última. Estas suposições portanto levam à seguinte expressão de $s_{o}$ :

$$
s_{o}=k_{I} \frac{\phi}{\rho_{r}} \frac{\sigma_{c t}}{\tau_{u l l t}}
$$

onde:

$$
\begin{aligned}
& \phi \text { — diâmetro da barra; } \\
& \rho_{r} \text { — taxa de armadura; } \\
& \sigma_{c t} \text { — resistência à tração do concreto; }
\end{aligned}
$$


$k_{1}$ - um constante que depende da distribuição da tensão de aderência.

No entanto, resultados experimentais mostram que para uma dado tipo de armadura, aderência última, $\tau_{u l t}$, é diretamente proporcional à resistência do concreto, $\sigma_{c t}$. Portanto, substituindo (4- 5) na equação (4- 3), a abertura de fissura pode ser escrita como:

$$
w_{m}=K \frac{\phi}{\rho_{r}} \varepsilon_{s m}
$$

onde $K$ pode ser determinado experimentalmente.

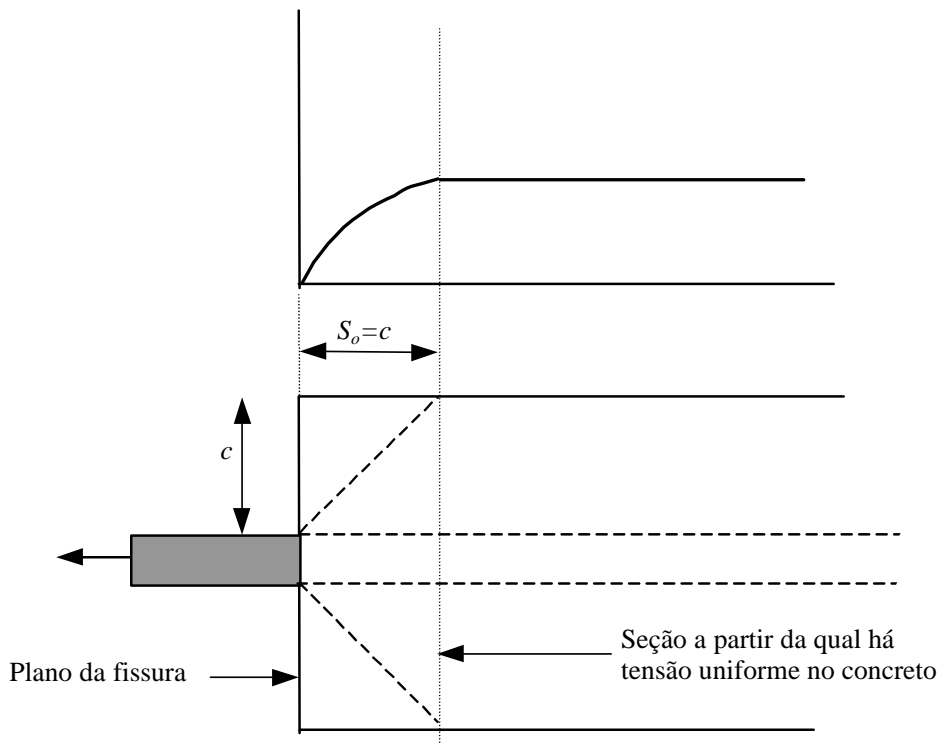

Fig. 4.2: Mecanismo de fissuração, "sem escorregamento": relação entre o cobrimento c e so (Segundo $B E E B Y, 1979)$

Tendo discutido a abordagem de escorregamento da armadura devido à falha de aderência, a próxima abordagem teórica pode ser deduzida de uma suposição exatamente oposta à de Saliger. Neste caso, supõe-se que as seções planas não permanecem planas e que, no momento da formação das fissuras, não há falha de aderência, e portanto nenhum deslocamento relativo (ou escorregamento da barra) entre a barra e o concreto. Pode-se perceber que uma estimativa das tensões nesse 
caso não é tão fácil quanto na abordagem de Saliger. Segundo BEEBY (1979), podese mostrar que a distância $s_{o}$, entre as fissuras e o ponto onde as tensões se permanecem não perturbadas pela fissura, é grosseiramente igual ao cobrimento considerando-se uma regra de $45^{\circ}$. A figura 4.2 mostra a distribuição das tensões ao se afastar da fissura, considerando a hipótese de seções não planas. Isso resulta na seguinte equação para a abertura de fissura:

$$
w_{m}=K c \varepsilon_{s m}
$$

De fato, é justo pensar que as abordagens de 'escorregamento da barra' e 'sem escorregamento' fornecem componentes diferentes do problema. o deslocamento do tipo suposto na abordagem de 'sem escorregamento da barra' deve ocorrer pois, localmente à fissura, as seções planas não permanecem planas. Isso deve portanto causar uma redução das tensões na superfície do concreto na região da fissura. A falha de aderência ou escorregamento de armadura causará uma outra redução das tensões na superfície do concreto, consequentemente aumentando $s_{o}$. Portanto, podese considerar que $s_{o}$ é composto de dois componentes: um componente, $s_{o, 1}$, que é o valor de $s_{o}$ deduzido da abordagem de 'sem escorregamento', e outro , $s_{o, 2}$, deduzido da abordagem clássica de falha de aderência. Segundo Ferry-Borges (1966) apud BEEBY (1979), os dois componentes podem ser somados para se obter a expressão do espaçamento de fissura, mais conhecida como a equação de Ferry-Borges, dada por:

$$
s_{m}=K_{1} c+K_{2} \frac{\phi}{\rho_{r}}
$$

Até este ponto a teoria clássica de Saliger foi embasada. Uma modificação adicional considerando a hipótese de seções não planas foi incluída. No entanto, é preciso fazer uma consideração mais profunda para justificar o conceito de falha de aderência, e o escorregamento que resultaram na dedução de $\frac{\phi}{\rho_{r}}$ como variável 
primária na equação (4- 7) acima. A figura 4.3 é um retrato ilustrativo completo do fenômeno de falha de aderência acima discutido. De fato, não há dificuldade em aceitar que a figura 4.3a é representativa do comportamento que ocorre em barras lisas. Entretanto, é evidente que não é dessa maneira que seções armadas com barras deformadas devem se comportar.

(a)

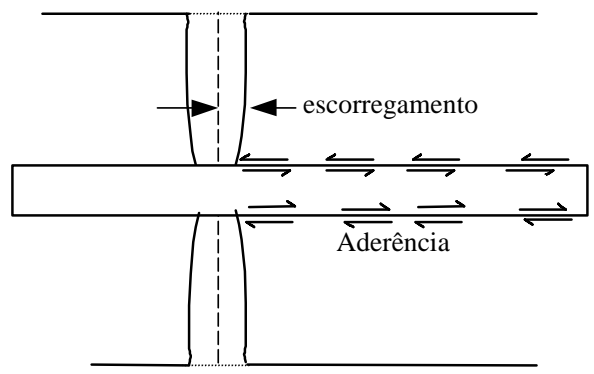

Escorregamento e deslocamento do concreto (b)

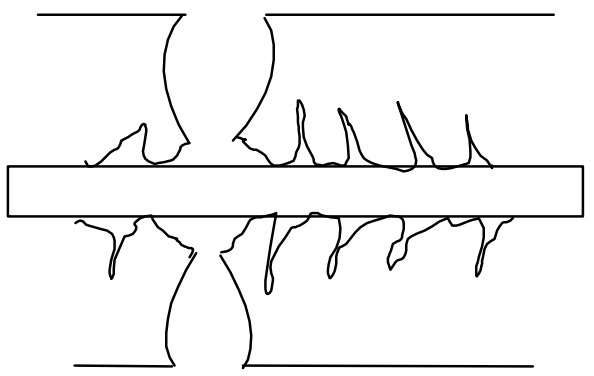

Fissuração interna e deslocamento do concreto

Fig. 4.3: Componentes de abertura de fissura (Segundo BEEBY, 1979).

Em vez de ocorrer a falha de aderência na interface barra-concreto, a distorção do concreto é acomodada por uma série de fissuras internas (figura 4.3b) É claro que para esse tipo de comportamento, a matemática da abordagem de 'sem escorregamento' de Saliger não é aplicável, e uma descrição de fenômeno é necessária.

O estudo da fissuração em volta de barras deformadas tem sido realizado por vários pesquisadores, e sugere que o desenvolvimento de uma fissura em torno de uma barra deformada é composto dos seguintes estágios:

(a) Supõe-se primeiramente que, uma fissura se forma inicialmente com abertura mínima na superfície da barra;

(b) Um carregamento adicional ocasiona a perda de aderência entre barra e concreto adjacente à fissura, e como conseqüência, transferindo a carga às mossas da barra;

(c) Fissuras internas são formadas próximo à fissura principal;

(d) Um carregamento posterior causa a formação de mais fissuras internas, a distâncias sucessivamente maiores da fissura principal. 
No estágio (a), as condições são como descritas pela teoria de 'sem escorregamento' e a tensão na superfície do concreto é afetada apenas pela fissura dentro da região \pm cobrimento, c. O efeito de quaisquer eventos; (b), (c), e (d), é reduzir o grau de transferência da força da armadura para o concreto, e portanto aumentar a distância da fissura dentro da qual as tensões na superfície são reduzidas (ou seja, $s_{o}$ aumenta sucessivamente acima do valor mínimo $c$, com o aumento de carregamento, resultando na mobilização dos eventos (b), (c), e (d)). As próximas fissuras principais podem se formar em qualquer ponto do elemento salvo dentro do intervalo $\pm s_{o}$ das fissuras já existentes, lembrando-se que fissuras intermediárias não podem se formar quando o espaçamento entre duas fissuras for menor que $2 s_{o}$.

Se ao aumentar o carregamento após ter formado uma fissura, a segunda fissura adjacente se desenvolve antes da ocorrência de uma falha interna substancial (eventos (b), (c), e (d)), a mesma será capaz de se formar próximo a anterior, mantendo um espaçamento mínimo próximo ao valor do cobrimento. Entretanto, uma falha interna substancial ocorre antes da formação da fissura adjacente. Portanto, $s_{o}$ será substancialmente maior que o cobrimento, e segundo BEEBY (1979), o espaçamento mínimo possível será aumentado. Segundo BEEBY (1979), o espaçamento médio será igual a uma constante multiplicada pelo cobrimento, mais o acréscimo médio de $s_{o}$ resultante da média da falha interna que ocorre antes da formação da fissura adjacente. Portanto tem-se:

$$
s_{m}=K_{1} c+(\text { influência média da falha interna })
$$

Neste ponto, resta apenas investigar os parâmetros que provavelmente controlam o grau de desenvolvimento da falha interna. Quantitativamente, segundo BEEBY (1979), isso pode ser feito da seguinte forma. A força máxima a ser transferida entre o aço e concreto é $A_{c} \sigma_{c t}$, onde $A_{c}$ é a área da seção transversal do elemento tracionado. Esta força deve ser transmitida através do concreto na interface barra/concreto. A resistência desse concreto depende do diâmetro da barra; quanto menor o diâmetro, menor a área através da qual a força deve ser transmitida. Portanto, a tensão transmitida é provavelmente proporcional a $A_{c} \sigma_{c t} / \phi$. Esta tensão é 
proporcional a $\phi / \rho_{r}$. Supondo que o grau de desenvolvimento da falha interna é proporcional a tensão desenvolvida, o espaçamento portanto pode ser dado por:

$$
s_{m}=K_{1} c+K_{2} \frac{\phi}{\rho_{r}}
$$

A tabela 4.1 fornece os valores das constantes $K_{l}$ e $K_{2}$.

Tabela 4.1: Valores de $K_{1}$ e $K_{2}$ (Segundo BEEBY, 1979)

\begin{tabular}{|c|c|c|}
\hline \multirow{2}{*}{$\begin{array}{c}\text { Probabilidade de } \\
\text { não exceder } \\
\text { espaçamento } \\
\text { fissura(\%) }\end{array}$} & \multicolumn{2}{|c|}{ Tração direta } \\
\cline { 2 - 3 } Média & 1,33 & $\boldsymbol{K}_{\boldsymbol{I}}$ \\
\hline $\mathbf{2 0}$ & 1,59 & 0,08 \\
\hline $\mathbf{5}$ & 1,86 & 0,12 \\
\hline $\mathbf{2}$ & 1,94 & 0,20 \\
\hline
\end{tabular}

Pode-se notar que a expressão (4- 9) é idêntica à equação de Ferry-Borges, (47). Segundo BEEBY (1979), isso implica que a dedução baseada nas considerações de 'sem escorregamento' é apenas um caso particular da proposição geral acima discutido, e além do mais, a equação (4- 7) é geral e independente da forma da falha interna envolvida. BEEBY (1979) ainda afirma que, o parâmetro $\frac{\phi}{\rho_{r}}$ pode em geral, ser considerado como o parâmetro que define o estado de tensão no concreto imediatamente em volta da barra, em vez de tensão da aderência especificamente. 


\subsubsection{Previsão das Deformações}

Até este ponto, foi discutido apenas a previsão do espaçamento de fissuras, ignorando os problemas associados com a previsão da deformação média, $\varepsilon_{m}$. É óbvio que a precisão na determinação das aberturas de fissura depende muito da precisão da determinação da deformação média, pois isso reflete na precisão da abertura final da fissura. Para a previsão da deformação, o problema pode ser abordado de diversas maneiras. Pode-se determinar uma deformação máxima supondo uma seção fissurada (estágio II), e várias normas seguem essa abordagem. Entretanto, segundo afirma BEEBY (1979), esta abordagem superestima as deformações, pois o concreto entre as fissuras sustenta uma tensão considerável, aumentando a rigidez efetiva. Esse efeito, normalmente conhecido como "tension stiffening" pode ser convenientemente manipulado, estimando-se a deformação calculada na base de seção fissurada, e depois subtraindo-se uma parcela referente ao "tension stiffening". Várias expressões empíricas têm sido propostas para levar em conta a colaboração do concreto. Uma expressão sugerida por BEEBY (1979) é da forma:

$$
\Delta \varepsilon=K \frac{\sigma_{c t} \sigma_{s, c r}}{E_{s} \rho_{r} \sigma_{s}}
$$

onde:

$\Delta \varepsilon$ - uma correção da deformação devido "tension stiffening no nível da armadura;

$\sigma_{c t}$-resistência do concreto;

$\sigma_{s}$ - a tensão na armadura sob o carregamento dado, considerando seção fissurada;

$\sigma_{s, c r}$ - tensão na armadura no momento da fissuração, calculada na base de seção fissurada;

$\rho_{r}$ - taxa geométrica de armadura;

$E_{s}$ —módulo de elasticidade de aço; 
$K$ - uma constante que depende do tipo de armadura, e a maneira de calcular a taxa geométrica de armadura, $\rho_{r}$.

\subsubsection{Desenvolvimento dos Procedimentos da Norma Brasileira}

Os procedimentos de cálculo empregados pela Norma Brasileira para a previsão de abertura e espaçamento de fissura, em estruturas de concreto são um pouco mais amplos que os fornecidos pela teoria clássica de Saliger. De fato, a Norma Brasileira fornece dois procedimentos; a formação sistemática de fissura e a formação não sistemática de fissura. Todavia, como foi anteriormente apontado, essas abordagens não deixam de ser simplificações da teoria clássica.

O procedimento baseado na formação sistemática de fissuras é fundamentado na teoria clássica de fissura de Saliger, equação (4- 2) ou (4- 3). No entanto, as simplificações adotadas pela Norma Brasileira, como muitas outras normas, está justamente na dedução das parcelas desta equação. A abordagem proposta pela Norma Brasileira para a previsão do espaçamento de fissuras segue as mesmas linhas como da teoria clássica. Na realidade, é importante salientar que, a Norma Brasileira apresenta apenas duas expressões para a verificação do estado limite de fissuração inaceitável. O que é discutido nesta seção são as formulações que fundamentaram as expressões fornecidas pela Norma Brasileira. A expressão proposta pela norma dada por:

$$
s=\xi_{1} \cdot c+\xi_{2} \cdot \frac{\phi}{\rho_{r}}
$$

onde:

$s$-espaçamento de fissura;

$\xi_{1}$-valor experimental igual a 1,5 ;

$c$-cobrimento;

$\xi_{2}-$ valor experimental igual a 0,16 ;

$\phi$-diâmetro da barra de armadura;

$\rho_{r}$-taxa de armadura. 
De fato é fácil perceber que a expressão (4- 11) é matematicamente equivalente a (4- 9) proposta pela teoria clássica. A única diferença está nos valores das constantes $\xi_{1}$ e $\xi_{2}$ propostas pela formulação da Norma Brasileira, e as constantes $K_{1}$, e $K_{2}$ fornecidas pela teoria clássica (ver tabela 4.1). Uma implicação de grande importância da equação (4- 11) é que, a Norma Brasileira considera as duas teorias; "escorregamento da barra" e "sem escorregamento da barra". Isso implica que a fissuração interna devido ao dano causado por barras deformadas está considerado. A expressão da Norma Brasileira pode portanto ser considerada exata, se os efeitos das constantes experimentais sobre a precisão foram desprezados. A grande dificuldade na previsão da abertura de fissuras parece ser a previsão das deformações. A formulação na qual está fundamentada a Norma Brasileira fornece a seguinte expressão para a previsão das deformações médias:

$$
\varepsilon_{m}=\frac{\sigma_{s}}{E_{s}}-\frac{1}{2} \frac{\sigma_{c t}}{E_{s} \rho_{r}}
$$

onde:

$\sigma_{s}$ — tensão na armadura proveniente do carregamento dado;

$E_{s}$-módulo de elasticidade;

$\sigma_{c t}$ resistência à tração do concreto;

$\rho_{r}$ - taxa geométrica de armadura.

Embora a Norma Brasileira não discuta explicitamente o endurecimento de tensão (tension stiffening), a segunda parcela da expressão (4- 12), subtraída da deformação da armadura na seção de fissura, representa justamente a colaboração do concreto na rigidez do elemento após a fissuração. Além do mais, a Norma Brasileira propõe uma expressão simplificada sem levar em conta a resistência do concreto, dada por:

$$
\varepsilon_{m}=\frac{2}{3} \sigma_{s}
$$


A equação (4- 13) implica que a contribuição do concreto (ou tension stiffening) é igual a um terço da deformação da armadura na seção fissura. No entanto, essa norma não fornece nenhuma base da fundamentação dessa simplificação adotada. Diante do exposto, pode-se concluir que a primeira expressão proposta pela Norma Brasileira para a previsão da abertura de fissura, baseada na teoria clássica, considerando apenas as equações (4- 11) e (4- 12), até certos limites, representa uma expressão exata da teoria clássica.

O segundo procedimento proposto pela Norma Brasileira tem como premissa básica, o chamada teoria de "dupla ancoragem". A formulação básica, entretanto não se diferencia da proposta pela teoria clássica. Essa expressão é dada por:

$$
w_{m}=2 s^{\prime}\left(\varepsilon_{s m}-\varepsilon_{c m}\right)
$$

ou

$$
w_{m} \cong 2 s^{\prime} \varepsilon_{s m}
$$

onde:

s'-distância a partir da primeira fissura necessária para a aderência aço-concreto entregar toda sua força ao concreto.

As expressões acima são parecidas com às da teoria clássica. Pode-se dizer portanto que, a teoria de dupla ancoragem é apenas uma derivada da teoria clássica. No entanto, a dedução das parcelas de espaçamento de fissura e deformação são abordadas de forma muito simplificada pela Norma Brasileira. O principal parâmetro que afeta a precisão das expressões propostas parece ser a aderência entre o concreto e aço. A Norma Brasileira considera uma variação linear da aderência, embora sabe-se que isso está longe de ser a distribuição da aderência concreto-amadura. Diante dessas simplificações, a Norma Brasileira propõe a seguinte expressão para a previsão do espaçamento de fissura e a deformação média:

$$
s^{\prime}=\frac{\phi}{4} \frac{\sigma_{s}}{\tau_{b}}
$$


onde:

$\tau_{b}$-aderência aço-concreto

\subsection{MODELO DE AL-TAAN E AL-FEEL}

O modelo proposto por AL-TAAN E AL-FEEL (1989) é basicamente um método macro-mecânico baseado na teoria clássica de fissuração de Saliger. Em princípio, é um método fundamentado na análise estática de duas seções do elemento fissurado. O método, portanto, tem a grande vantagem da sua simplicidade e o fato de se identificar com os principais modelos propostos em normas, o que o torna versátil e fácil de aplicar.

Embora aqui chamado de método de Al-Taan e Al-Feel, o método na forma apresentado aqui é uma modificação da formulação original, primeiramente proposto por CHI E KIRSTEIN (1958), e posteriormente adaptado para aplicação em concreto armado com fibras por AL-TAAN E AL-FEEL (1989). As modificações principais estão na forma de considerar a contribuição das fibras no comportamento global do compósito. Para isto, aproveitou-se o modelo micro-mecânico anteriormente abordado no capítulo 3, como entrada no modelo macro-mecânico, sem entretanto, abandonar o conceito básico do problema.

\subsubsection{Modelo Geométrico}

Visto que o modelo de AL-TAAN E AL-FEEL (1989) é baseado na teoria clássica, o cálculo da abertura de fissura segue o mesmo procedimento utilizado no concreto convencional. Admite-se que após ter atingido a tensão de fissuração, o elemento tracionado desenvolve fissuras discretas, até que o espaçamento entre as mesmas atinge um valor mínimo, $s_{a}$. A figura 4.4 ilustra um modelo geométrico no estágio fissurado do elemento tracionado. 


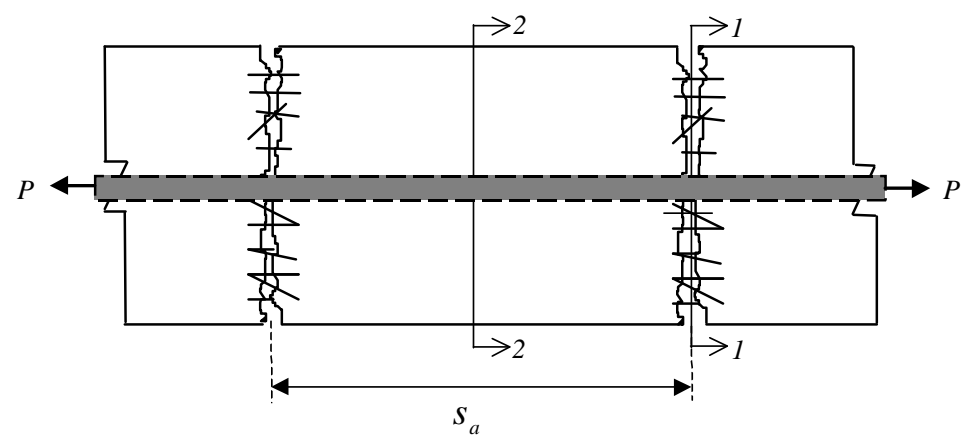

Fig. 4.4: Elemento de compósito sob tração (Segundo AL-TAAN E AL-FEEL, 1989)

Para o cálculo dos parâmetros de fissuração, faz-se um análise estático considerando o equilíbrio do corpo rígido contido entre um plano passando pela seção fissurada 2-2, e outro passando entre duas fissuras consecutivas, 1-1.

As equações de equilíbrio do corpo rígido entre as seções 1-1 e 2-2 da figura 4.4 são dadas por:

$$
\begin{aligned}
& \sigma_{s, 1} A_{s}=\sigma(x) A_{s}+\int_{0}^{x} u(x) s_{a} d x \\
& \sigma_{s, 1} A_{s}+A_{c} \sigma_{c, 1}=\sigma(x) A_{s}+A_{c} \sigma_{c, 2}
\end{aligned}
$$

onde:

$\sigma_{s}$ e $\sigma_{c}$ —tensão na armadura e compósito respectivamente;

$A_{s}$ e $A_{c}$ - seção transversal da armadura e compósito respectivamente;

$u(x)$ e $s_{a}$-aderência na seção $x$ e o espaçamento de fissuras respectivamente; e os índices 1 e 2 representam as seções 1-1 e 2-2. 
As equações constitutivas essenciais para a análise do problema são:

- Compatibilidade de deformações

$$
w=\int_{x}^{s_{s} / 2}\left(\varepsilon_{s}-\varepsilon_{c}\right) d x
$$

onde:

$w$-abertura de fissura;

$\varepsilon_{s}$ e $\varepsilon_{c}$ —são respectivamente as deformações da armadura e compósito.

- Relação tensão-deformação:

$$
\sigma_{s}=f\left(\varepsilon_{s}\right) \text { e } \sigma_{c}=f\left(\varepsilon_{c}\right)
$$

substituindo (4- 17) em (4- 18) tem-se:

$$
s_{a}=\frac{A_{c}\left(\sigma_{c, 2}-\sigma_{c, 1}\right)}{\int_{0}^{x} u(x) d x}
$$

Da equação (4- 21), pode-se calcular facilmente a distância entre fissuras se a distribuição da tensão de aderência for conhecida. No entanto é preciso um modelo da aderência entre a armadura e o CAF.

A distribuição da aderência ao do comprimento embutido é analiticamente de difícil formulação. De fato, pouco tem sido feito com respeito ao arrancamento de barras em concreto com fibras. Quando existir tal pesquisa, o interesse tem sido voltado no campo da determinação da aderência última de barras em CAF. Alguns resultados experimentais (KRSTULOVIC-OPALA ET AL., 1994; EZELDIN E BALAGURU, 1989; HOTA E NAAMAN, 1997) mostram que a aderência última depende de vários parâmetros como, a resistência da matriz, a tenacidade do compósito, e as características geométricas e propriedades mecânicas da armadura e o efeito de escala (BAZANT E SENER, 1987). Na determinação da aderência última, 
tem sido suposto uma distribuição linear de aderência (KRSTULOVIC-OPALA ET AL., 1994; EZELDIN E BALAGURU, 1989; HOTA E NAAMAN, 1997) como em concreto convencional (CHI ET KIRSTEIN, 1958) embora sabe se que esta distribuição, como em concreto convencional, esta longe de ser linear (MIANOWSKI, 1991; UIJL E BIGAJ, 1996; HUANG ET AL., 1997; JIANG ET AL., 1982).

\subsubsection{Modelo Mecânico}

Modelando-se as várias parcelas da expressão (4- 21); tensões no compósito nas seções 1-1 e 2-2, e a aderência armadura compósito, pode-se facilmente determinar a abertura de fissura pode-se deduzir a um modelo analítico simples considerando o equilíbrio do corpo rígido entre as seções 1-1 e 2-2 da figura 4.4 supondo-se uma variação linear da aderência. A figura 4.5 mostra o modelo mecânico obtido pela retirando o corpo rígido 1-1 e 2-2.

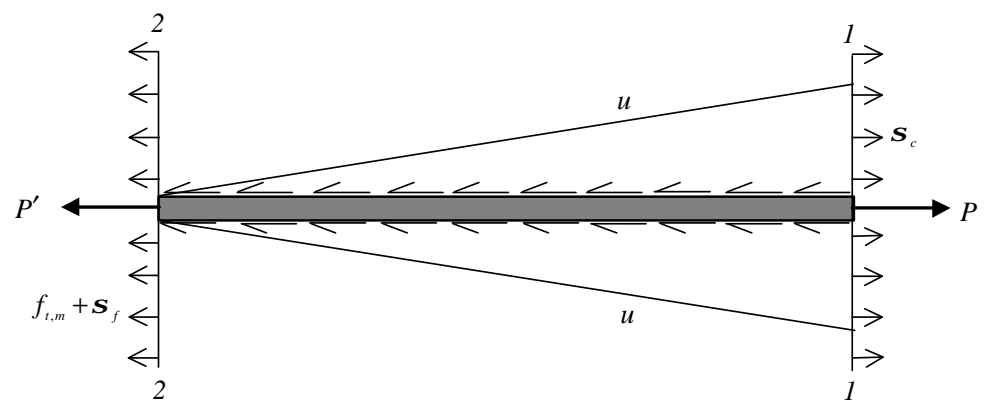

Fig. 4.5: Modelo geométrico mostrando as tensões nas seções 1-1 e 2-2 e a distribuição de aderência (Segundo AL-TAAN E AL-FEEL, 1989).

Um análise estática mostra que pelo equilíbrio das forças internas tem-se:

$$
P-P^{\prime}=\left(\frac{U_{f}}{2}\right)\left(\frac{s_{a}}{2}\right) \sum \phi
$$

onde:

$\phi$-perímetro da barra de armadura, 
$U_{f}$ — tensão de aderência entre a armadura e CAF, e

Da mesma forma, considerando o equilíbrio das forças externas tem-se:

$$
P-P^{\prime}=A_{c, e f}\left(\sigma_{c, 1}-\sigma_{c, 2}\right)
$$

Resolvendo as equações (4- 22) e (4- 23) acima, obtêm-se uma expressão do espaçamento de fissuras como:

$$
s_{a}=\frac{4 A_{c, e f}}{U_{f} \sum \phi}\left[\sigma_{m, 2}+\sigma_{f, 2}-\sigma_{c, 1}\right]
$$

Lembrado-se que a tensão nas fibras na seção fissurada é a tensão de travejamento das fibras, $\sigma_{c}$, modelada no capítulo 3 , os termos na expressão acima são dadas respectivamente por:

$$
\sigma_{c, l}=\sigma_{f, 1}=\sigma_{c}
$$

e

$$
\sigma_{c, 2}=\sigma_{m, 2}+\sigma_{f, 2}
$$

onde:

$\sigma_{c, 1}, \sigma_{f, 1}, \sigma_{c}$ são respectivamente a tensão do compósito na seção 1-1, a contribuição das fibras e a tensão pós-fissuração do compósito; $\sigma_{c, 2}, \sigma_{m, 2}, \sigma_{f, 2}$ são respectivamente a tensão do compósito na seção 2-2, a contribuição da matriz na seção 2-2, e a contribuição das fibras na seção 2-2; e $A_{c, e f}$ é área efetiva tracionada da matriz.

As contribuições da matriz e das fibras na tensão de travejamento do compósito podem ser calculadas pela lei de material compósito como visto no capítulo 3. Na seção 2-2 as contribuições são dadas por: 


$$
\sigma_{m, 2}=V_{m} f_{m, t}
$$

$$
\sigma_{f, 2}=\eta_{\ell} \eta_{\Phi} V_{f} \sigma_{f}
$$

onde:

$$
\begin{aligned}
& V_{m} \text { - taxa volumétrica da matriz; } \\
& f_{m, t} \text {-resistência à tração da matriz. } \\
& \sigma_{f} \text {-tensão numa fibra; } \\
& \eta_{\ell} \text { - fator de eficiência de comprimento pré-fissuração; } \\
& \eta_{\Phi} \text { - fator de eficiência de orientação; e } \\
& V_{f} \text {-taxa de fibra. }
\end{aligned}
$$

Considerando-se a compatibilidade de deformação entre as fibras e a matriz tem-se:

$$
\sigma_{f}=\frac{E_{f}}{E_{m}} f_{m, t}
$$

onde:

$E_{f}$ e $E_{m}$ são os módulos de elasticidade da fibra e matriz respectivamente.

É evidente que na seção 1-1, a tensão do compósito $\sigma_{c, 1}$, é devido somente à contribuição de todas fibras. Essa contribuição pode ser determinada pela lei de matrial compósito, desconsiderando a contribuição pós-fissuração da matriz. Pela lei de material compósito tem-se:

$$
\sigma_{c, l}=\eta_{\ell} \eta_{\Phi} V_{f} \sigma_{f}
$$

onde $\sigma_{f}$ é a tensão em cada fibra dada por:

$$
\sigma_{f}=\pi \tau \frac{l_{f}}{d_{f}}
$$


Substituindo as expressões (4- 27) a (4- 31) acima em (4- 24) obtêm-se a expressão analítica da abertura de fissura como:

$$
s_{a}=\frac{4 A_{c, e f}}{U_{f} \sum \phi}\left[V_{m} f_{m, t}+V_{f} \eta_{l} \eta_{\Phi}\left(\frac{E_{f}}{E_{m}}\right) f_{m, t}-\eta_{l} \eta_{\Phi}^{\prime} V_{f} \pi \tau \frac{l_{f}}{d_{f}}\right]
$$

onde $V_{m}=1-V_{f}$

$\mathrm{Na}$ equação (4- 32), o fator de eficiência de comprimento é dado segundo LI ET AL. (1993) por:

$$
\eta_{l}=1-\frac{\varepsilon_{m u} E_{f} d_{f}}{4 \tau_{o} l_{f}}
$$

onde:

$\varepsilon_{m u}$ e $\tau_{o}$ são respectivamente a deformação última e aderência máxima fibra/matriz.

Entretanto, pode-se perceber da equação (4- 32) que há uma necessidade de modelar alguns parâmetros essenciais para determinar a abertura de fissura.

\subsubsection{Aderência CAF/armadura}

Um parâmetro de extrema importância nas expressão (4- 32) acima é a aderência compósito/armadura. No entanto, como foi mencionado anteriormente, existem poucos sobre o arrancamento de barras em concreto com fibras. Em geral os resultados de ensaios de arrancamento em CAF fornecem apenas relações entre a aderência última em CAF e o concreto convencional para dadas taxas de fibras, sem entretanto estipular valores absolutos. Os resultados, muitas vezes, podem ser até conflitantes. Recentes resultados experimentais indicam que a tensão última de aderência depende da resistência à compressão da matriz (EZELDIN E BALAGURU, 
1989; KRSTULOVIC-OPALA E WATSON 1994; HOTA E NAAMAN, 1997), e o diâmetro da barra de armadura (EZELDIN E BALAGURU, 1989; KRSTULOVIC-OPALA E WATSON, 1994). E também, enquanto EZELDIN E BALAGURU (1989) apontam uma dependência desprezível da aderência última da taxa de fibra, HOTA E NAAMAN (1997) e KRSTULOVIC-OPALA E WATSON (1994) indicam uma dependência apreciável. Não é de difícil aceitação portanto que, a incorporação dos fatores citados acima num modelo de aderência CAF/armadura é extremamente complexa.

Segundo SWAMY E AL-NOOR apud AL-TAAN E AL-FEEL (1989) a aderência entre a armadura e o concreto com fibras é cerca de 35 a 40\% maior que no concreto convencional. KRSTULOVIC-OPALA E WATSON (1994) também apontam um aumento de até $40 \%$ de aderência em concreto com fibra com relação ao concreto sem fibra para $1 \%$ de fibra, comprovando portanto os resultado de SWAMY E AL-NOOR apud AL-TAAN E AL-FEEL (1989).

Diante do acima exposto, pode-se empregar a expressão proposta por SWAMY E AL-NOOR apud AL-TAAN E AL-FEEL (1989) para a previsão da aderência em CAF. Segundo os mesmos, a aderência armadura/CAF por ser expressa como:

$$
U_{f}=\gamma U_{o}
$$

onde:

$U_{o}$ é a tensão de aderência armadura/concreto convencional, $U_{o}=0,28 \sqrt{f_{c k, j}}($ Eurocode 2, 1991)

$f_{c k, j}$ é a resistência característica à compressão da matriz na idade $j$, $\gamma$ é um fator calculado por interpolação linear dado por:

$\gamma=\left(1+20 V_{f}\right) \leq 1,4$ para fibras redondas e retas, e $\gamma=\left(1+40 V_{f}\right) \leq 1,4$ para fibras com forma qualquer.

\subsubsection{Interação fibra/matriz}

A importância da interação fibra/matriz foi enfatizada no capítulo 2. No entanto, a modelagem desse parâmetro é muito difícil, exigindo um ensaio de arrancamento das 
fibras. Além do mais, resultados dos ensaios de arrancamento de fibras não pode ser generalizados. Estes depende principalmente do tipo da matriz e o seu processamento, exigindo portanto, a realização de tais ensaios para cada mistura da mesma matriz. Para o cálculo da aderência fibra/matriz, AL-TAAN E AL-FEEL (1989), adotou uma expressão proposta por Swamy e Magat (1976) para fibras de aço, dada por:

$$
\tau=3,57+0,58 \frac{\sigma_{s}-\sigma_{s, c r}}{\sigma_{y}-\sigma_{s, c r}}
$$

onde $\sigma_{s}$ e $\sigma_{s, c r}$ são a tensão na armadura e a tensão na armadura na fissuração respectivamente.

\subsubsection{Deformação do concreto}

Pela teoria clássica da fissuração a abertura média da fissura é dada por:

$$
w_{m}=s_{a}\left(\varepsilon_{s m}-\varepsilon_{c m}\right)
$$

Como no caso do concreto convencional, pode-se desprezar a deformação do concreto levando-se em conta, entretanto, o efeito de endurecimento de tensão e a deformação das fibras. Portanto, $\varepsilon_{s}$ na equação (4- 36) é a deformação correspondente da armadura e as fibras e o efeito de endurecimento de tensão.

Portanto considerando-se $\varepsilon_{c} \ll<\varepsilon_{s}$ tem-se:

$$
w_{m}=s_{a} \varepsilon_{s m}
$$

Tendo calculado o espaçamento de fissuras, resta apenas modelar da deformação média da armadura. Existem vários modelos empíricos e semi-empíricos para determinar a deformação na armadura, alguns abaixo citados. 
- CEB-90: (CEB-FIP, 1993)

$$
\varepsilon_{s m}=\varepsilon_{s 2}-\beta \varepsilon_{s, c r 2}
$$

com

$$
\begin{aligned}
& \varepsilon_{s 2}=\frac{\sigma_{s}}{E_{s}} \\
& \varepsilon_{s, c r 2}=\frac{\sigma_{c t}}{\rho_{r} E_{s}}\left(1+\alpha_{e} \rho_{r}\right)
\end{aligned}
$$

onde $\beta=0,6$, e $\alpha_{e}=\frac{E_{c t}}{E_{c}}$

$\varepsilon_{s 2}$ e $\varepsilon_{s, c r 2}$ — são respectivamente a deformação do aço na seção fissurada em qualquer instante e na seção fissurada sob forças que causam $\sigma_{c t}(t)$ na seção $A_{c, e f}$;

$\sigma_{c t}$ e $E_{c}$ - são respectivamente a resistência à tração e módulo de elasticidade do concreto;

$E_{s}$ e $E_{c t}$-são respectivamente o módulo de elasticidade do aço e compósito $\varepsilon_{s m}$ e $\sigma_{s}$-são a deformação média e tensão da armadura;

$A_{c, e f}$-área da seção do elemento tracionado.

\section{- EUROCODE 2 (1991):}

$$
\varepsilon_{s m}=\frac{\sigma_{s}}{E_{s}}\left[1-\beta_{1} \beta_{2}\left(\frac{\sigma_{s, c r}}{\sigma_{s}}\right)^{2}\right]
$$

onde $\beta_{1}=0,5$ e $\beta_{2}=1$ 
- GÜNTER (Günter apud BALÁZS ET AL., 1997)

$$
\varepsilon_{s m}=\frac{\sigma_{s}}{E_{s}}\left[1-\left(\frac{\sigma_{s, c r}}{\sigma_{s}}\right)^{2}\right]^{\frac{1}{2}}
$$

- $\quad$ BS 8110(ALLEN, 1995)

$$
\varepsilon_{s m}=\frac{\sigma_{s}}{E_{s}}-\frac{2 b_{t} h}{3 E_{s} A_{s}}
$$

onde:

$b_{1}$ e $h$-são dimensões do elemento tracionado.

- BEEBY(BEEBY, 1979):

$$
\varepsilon_{s m}=\frac{\sigma_{s}}{E_{s}}-K \frac{\sigma_{c t} \sigma_{s, c r}}{E_{s} \rho_{r} f_{l}}
$$

- CEB-FIP (1990)

$$
\varepsilon_{s m}=\frac{\sigma_{s}}{E_{s}}\left[1-\beta\left(\frac{\sigma_{s, c r}}{\sigma_{s}}\right)^{2}\right]
$$

onde $\beta=0,6$

$$
\begin{aligned}
& \sigma_{s} \text {-tensão na armadura no momento de fissuração } \\
& \sigma_{s, c r} \text {-tensão de fissuração }
\end{aligned}
$$

A previsão da tensão na armadura referente ao instante de fissuração, e em qualquer instante após a fissuração pode ser feita considerando-se a figura 4.6 abaixo. 


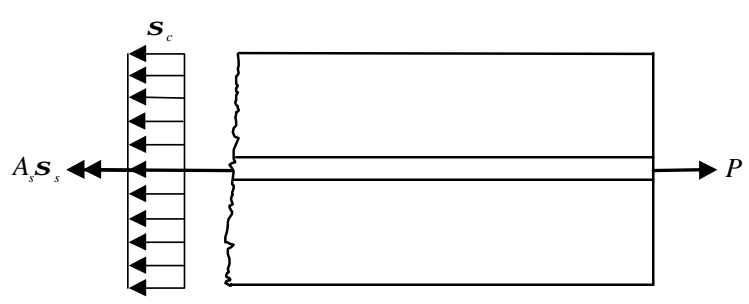

Fig. 4.6: Suposta distribuição de tensão para um elemento tracionado (Segundo AL-TAAN E AL-FEEL, 1989).

Considerando o equilíbrio da seção e empregando a força de fissura é dada, segundo LIM ET AL., (1989) por:

$$
P_{c r}=A E_{c t} \varepsilon_{c r}=\left\lfloor A_{c, e f}+\left(\alpha_{e}-1\right) A_{s}\right\rfloor E_{c t}\left\lfloor\eta_{\ell} \eta_{\Phi}^{\prime} V_{f}\left(\varepsilon_{f p}-\varepsilon_{m p}\right)+\varepsilon_{m p}\right\rfloor
$$

onde:

$$
\begin{aligned}
& \alpha_{e}=E_{s} / E_{c t} \\
& A \text { e } A_{c, e f} \text { - são respectivamente área da seção transversal do elemento e efetiva } \\
& \text { de CAF; } \\
& \varepsilon_{f p} \text { e } \varepsilon_{f p} \text {-são respectivamente a deformação da fibra e matriz no seus } \\
& \text { respectivos limites de proporcionalidade. }
\end{aligned}
$$

Entretanto, pode-se desprezar a contribuição das fibras na capacidade de carga. A equação (4- 46) portanto, pode ser escrita como:

$$
P_{c r}=A E_{c t} \varepsilon_{c r} \cong\left\lfloor A_{c, e f}+\left(\alpha_{e}-1\right) A_{s}\right\rfloor E_{c t} \varepsilon_{m p}
$$

Além da fissuração, a carga aplicada é resistida somente pela armadura e as fibras que travejam a fissura. Portanto de (4- 47) tem-se:

$$
P=\left(A_{c, e f}-A_{s}\right) \sigma_{c}+A_{s} \sigma_{s}
$$

onde $\sigma_{c}$ é dado pelas expressões de $\sigma_{c}$ no item 3.1.1.2.6 


\subsubsection{Abertura Máxima de Fissura}

A abertura de fissura na superfície da armadura é dada por $w_{a}=s_{a} \varepsilon_{s}$. Para qualquer ponto distante $a_{c r}$ da armadura mais próxima, a abertura de fissura é dada por:

$$
w_{\max }=w_{a} \frac{a_{c r}}{c}
$$

onde $c$ - cobrimento da armadura.

\subsection{MODELO DE STANG}

O modelo de Stang enquadra-se nos chamados, modelos de defasagem de cisalhamento, e tem como ponto de partida, o cálculo dos deslocamento em uma seção da armadura ou CAF empregando a teoria de desafagem de cisalhamento. Essencialmente, o modelo está fundamentado na mecânica do dano. Na forma apresentado, este modelo tem a grande vantagem da sua generalidade geométrica i.e., é possível aplicar o modelo à uma grande gama de estruturas pela caracterização da mesma através da taxa efetiva e o diâmetro da armadura. Além do mais, o modelo permite a otimização do compósito, um aspecto muito importante em sistemas híbridos.

\subsubsection{Modelo Geométrico}

Um modelo geométrico para análise da fissuração em CAF com armadura convencional está ilustrado na figura 4.7. Essencialmente, o modelo consiste de um elemento plano composto de uma barra de aço (armadura) de espessura $2 t$, e comprimento $L$. Em volta da armadura, são duas camadas da matriz de concreto com fibras de espessura $2 b$ em cada lado. Além do mais, supõe-se que após a fissuração, formam-se um total de $N$ fissuras livres de tensão que se abrem e são acompanhadas de uma perda de aderência (efeito Cook-Gordon) na interface matriz/armadura 
Admite-se o CAF não fissurada demostra um comportamento elástico-linear com módulo de elasticidade, $E_{c a f}$ e coeficiente de Poisson $v_{c a f}$. Um modelo plano como descrito acima é denominado elemento de volume representativo (EVR).

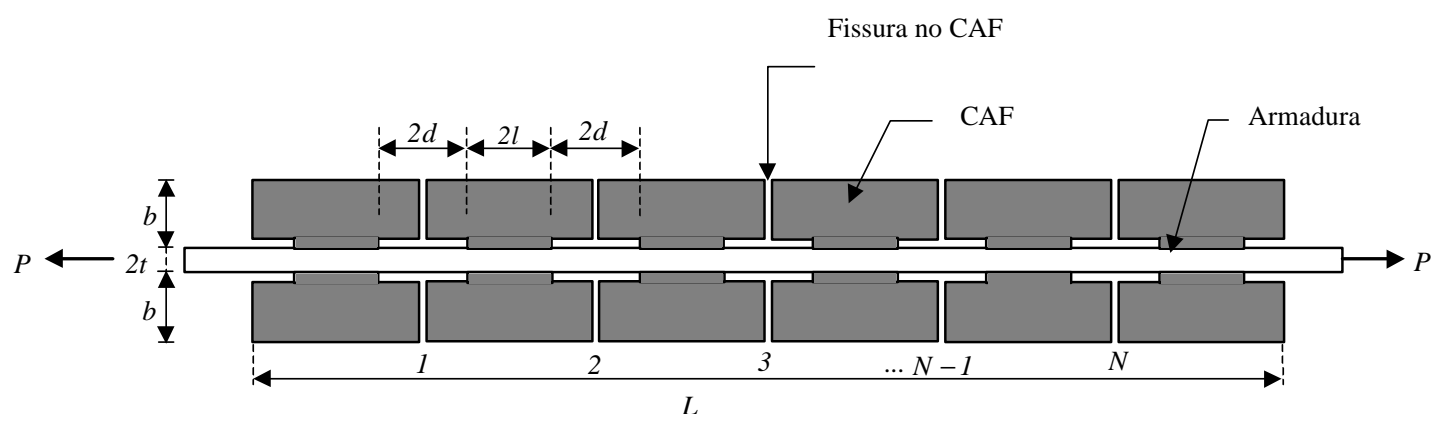

Fig. 4.7: Modelo geométrico empregado no modelo de fissura estrutural (Segundo STANG ET AL., 1995)

Os principais parâmetros do EVR são calculados baseados sobre a mecânica de dano de continuo ( MDC) em conjunto com a teoria de defasagem de cisalhamento (TDC). Inicialmente considera-se o EVR da figura $4.7 \mathrm{com}$ a armadura sujeita a uma forca $P$ por comprimento e fazendo uma analise de defasagem de cisalhamento para determinar os deslocamentos, pode-se calcular o "compliance" do EVR.

Pela lei da evolução de dano em um meio continuo tem-se:

$$
\varepsilon=M \sigma
$$

onde $\varepsilon=\frac{u}{L}$, e $\sigma=\frac{P}{2(b+t)}$

$M \multimap$ "compliance" que corresponde à flexibilidade do elemento com dado.

Baseado na mecânica do dano do continuo, STANG E AARRE (1992) obtiveram uma expressão analítica do "compliance" dado por:

$$
M=\left\{\left(1-\Omega_{1} \Omega_{2}\right)\left[\frac{1-V_{s}}{V_{s}} \frac{E_{c a f}}{E_{s}} \frac{\operatorname{tah} \lambda \ell}{\lambda \ell}+1\right] \frac{V_{s}}{E}+\Omega_{1} \Omega_{2} \frac{1}{E_{s}}\right\}
$$


com

$$
(\lambda \ell)^{2}=\frac{3}{2}\left(\frac{1}{\Omega_{1}}-\Omega_{2}\right)^{2} \frac{V_{s}}{\left(1-V_{s}\right)}\left[\left(1-V_{s}\right) E_{s}\left(1+v_{c a f}\right)+V_{s} E_{c a f}\left(1+v_{s}\right)\right]
$$

Onde $E, V_{s}, \Omega_{1}$, e $\Omega_{2}$ são parâmetros definidos a seguir.

\section{Parâmetro mecânico}

- Módulo de elasticidade efetivo

$$
E=V_{s} E_{s}+\left(1-V_{s}\right) E_{c a f}
$$

\section{Parâmetro geométricos}

- Taxa geométrica efetiva de armadura

$$
V_{s}=\frac{t}{t+b}
$$

\section{Parâmetros de dano}

- Parâmetro de fissura específica estrutural.

$$
\Omega_{1}=2 n t=2 \frac{N}{L} t
$$

e

$$
\Omega_{2}=\frac{d}{t}
$$




\subsubsection{Modelo Analítico}

Basicamente, o modelo analítico proposto por Stang tem como ponto de partida a definição do EVR acima apresentado. Para o efeito de análise, considere-se um elemento retirado do EVR entre duas seções definidas pelos planos de macro fissuras discretas, e como um sistema de coordenadas como mostra a figura 4.8. Neste caso particular $N=1$ na equação.(4- 55). Agora supõe-se uma continuidade de deslocamento na interface CAF/armadura para $-\ell<x<\ell$ enquanto a interface CAF/armadura é livre de tensões para $x<-\ell$ e $\ell<x$, permitindo assim, a modelagem de perda de aderência entre o CAF e a armadura.

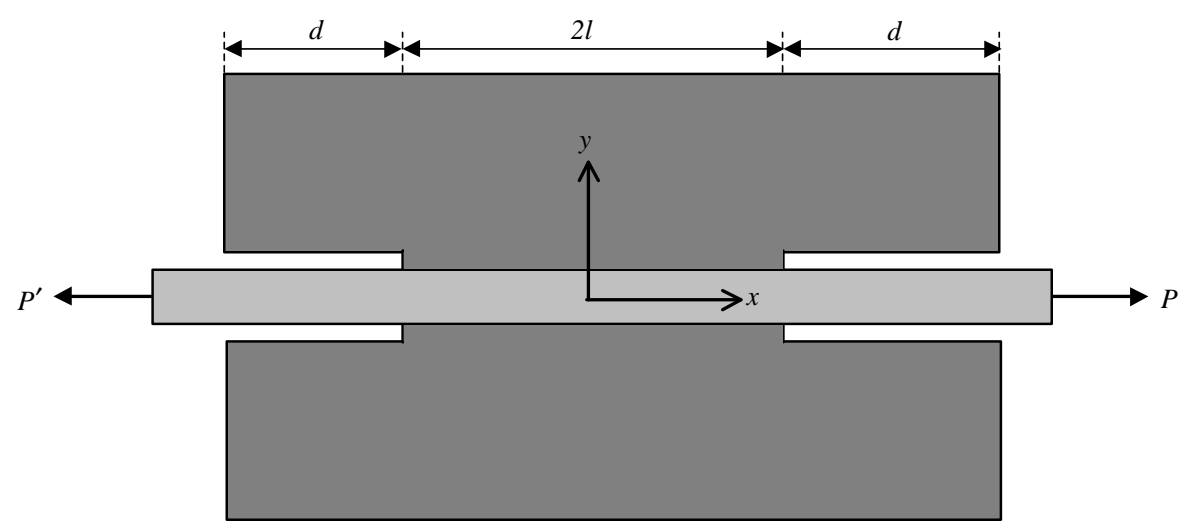

Fig. 4.8: Elemento de Volume Representativo (EVR)

Se o campo de deslocamento na direção $x$ é dado por $u$, então 0 deslocamento na direção y pode ser definido como:

$$
\frac{\Delta y}{t}=\frac{\Delta u}{u}
$$

onde os deslocamentos médios no CAF, $u_{c a f}$ e na armadura $u_{s}$ são dados respectivamente por:

$$
u_{s}=\frac{1}{t} \int_{0}^{t} u d y
$$


e

$$
u_{c a f}=\frac{1}{b} \int_{t}^{t+b} u d y
$$

Definindo $P_{c a f}$ como a força por espessura do elemento e $P_{s}$ como a força por diâmetro da armadura, a tensão no CAF e armadura podem ser escritas como:

$$
\begin{aligned}
& \sigma_{c a f}=\frac{P_{c a f}}{2 b}=E_{c a f} \frac{d u_{c a f}}{d x} \\
& \sigma_{s}=\frac{P_{c a f}}{2 t}=E_{s} \frac{d u_{s}}{d x}
\end{aligned}
$$

onde:

$E_{c a f}$, e $E_{s} \longrightarrow$ módulo de elasticidade do CAF e armadura respectivamente.

Introduzindo-se a tensão de cisalhamento na interface armadura/CAF nas equações (4- 60) e (4- 61) acima, tem-se pelo equilíbrio do elemento da figura 4.8 as seguintes expressões:

$$
\begin{aligned}
& \frac{d P_{c a f}}{d x}-2 \tau_{i}=0 \\
& \frac{d P_{s}}{d x}+2 \tau_{i}=0
\end{aligned}
$$

onde:

$\tau_{i}$ — cisalhamento na interface armadura/CAF.

Pela teoria de defasagem de cisalhamento (TDC) a tensão de cisalhamento é definida como:

$$
\tau_{i}=\Theta\left(u_{c a f}-u_{s}\right), \text { para }-\ell<x<\ell
$$




$$
\tau_{i}=0 \text {, para } x<-\ell \text { e } \ell<x
$$

onde:

$\Theta$ é um parâmetro do material com dano

Segundo STANG E AARRE (1992), se uma variação de segunda ordem na direção y é suposta na direção $x$, pode-se demostrar pela TDC que:

$$
\Theta=\frac{3}{2}\left[\frac{E_{c a f} E_{s}}{\left.b E_{s}\left(1+v_{c a f}\right)+t E_{c a f}\left(1+v_{S}\right)\right]},\right.
$$

Derivando (4- 62) e (4- 63) e fazendo as substituições necessárias, as expressões o campo de deslocamento média no CAF e na armadura pode ser escritos como:

$$
\begin{aligned}
& \frac{d^{2} u_{c a f}}{d x^{2}}-\frac{\Theta}{b E_{c a f}}\left(u_{c a f}-u_{s}\right)=0 \\
& \frac{d^{2} u_{s}}{d x^{2}}+\frac{\Theta}{t E_{s}}\left(u_{c a f}-u_{s}\right)=0
\end{aligned}
$$

\subsubsection{Soluções}

A solução das equações diferenciais acima leva à duas soluções de deslocamento para o CAF $\left(u_{c a f}^{I}, u_{c a f}^{I I}\right)$ e armadura $\left(u_{s}^{I}, u_{s}^{I I}\right)$ a partir dos quais pode-se determinar as deformações, e consequentemente, a abertura de fissura e as tensões máximas no compósito e armadura em cada instante de carregamento. Em princípio, as soluções finais da abertura de fissura e tensões são obtidas por superposição de efeitos. Primeiramente, considera-se que sob o carregamento, o deslocamento é restrito apenas à armadura, mantendo o deslocamento do CAF fixo. Para essa situação, a solução obtida pela solução das equações diferenciais (4- 67) e (4- 68) 
fornece os deslocamentos $u_{c a f}^{I}$ do CAF e $u_{s}^{I}$ da armadura. A parti dos deslocamentos e condições apropriadas de contorno, pode-se determinar a deformação total do elemento, $\varepsilon^{I}$ das quais pode-se determinar a aberturas de fissura, $w^{I}$. Da mesma maneira, fixa-se o deslocamento EVR, encontrando-se as soluções de deformação, $\varepsilon^{I I}$ e abertura de fissura, $w^{I I}$. Finalmente, superpõe-se os resultados obtidos.

Para resolver as equações o seguinte parâmetro essencial será definido:

Parâmetro mecânico de dano

$$
\lambda^{2}=\Theta\left(\frac{1}{b E_{c a f}}+\frac{1}{t E_{s}}\right)
$$

\subsection{Primeira solução (deslocamento elástico)}

A primeira solução corresponde à uma dada tensão média na armadura no ponto $x=\ell+d$. Para essa situação, as condições de contorno são as seguintes:

$$
\begin{aligned}
& u_{s}^{\mathrm{I}}(x=0)=u_{c a f}^{\mathrm{I}}(x=0) \\
& \frac{d u_{c a f}^{\mathrm{I}}(x=\ell)}{d x}=0 \\
& \frac{d u_{s(x=\ell)}^{\mathrm{I}}}{d x}=\frac{\sigma_{s(x=\ell)}^{\mathrm{I}}}{E_{s}}=\frac{\sigma_{s(x=\ell+d)}^{\mathrm{I}}}{E_{s}}
\end{aligned}
$$

definindo-se $\varepsilon=\frac{u_{s(x=\ell+d)}}{\ell+d}$, tem-se após resolvendo as equações (4- 67) e (4- 68) que:

$$
\varepsilon^{\mathrm{I}}=\sigma_{s(x=\ell+d)}^{\mathrm{I}}\left\{\left(1-\beta_{1} \beta_{2}\right)\left[\frac{(1-c)}{c} \frac{E_{c a f}}{E_{s}} \cdot \frac{\tanh \lambda \ell}{\lambda \ell}+1\right] \frac{c}{E}+\beta_{1} \beta_{2} \frac{1}{E_{s}}\right\}
$$




$$
\begin{aligned}
& \sigma_{c a f}^{\max \mathrm{I}}=\sigma_{s(x=\ell+d)}^{\mathrm{I}}\left[1-\frac{1}{\cosh \lambda \ell}\right] \frac{E_{c a f}}{E} \\
& w^{\mathrm{I}}=\sigma_{s(x=\ell+d)}^{\mathrm{I}}\left[\left(\frac{1}{\beta_{1}}-\beta_{2}\right) \frac{\tanh \lambda \ell}{\lambda \ell}+\beta_{2}\right] \frac{2 t}{E_{s}}
\end{aligned}
$$

As condições de contorno em (4- 70) e (4- 71) garantem que:

$$
\sigma_{c a f}^{\mathrm{I}(x=\ell)}=\sigma_{c a f}^{\mathrm{I}}(x=\ell+d)=0
$$

\subsection{Segunda solução (deslocamento inelástico)}

A segunda solução corresponde à uma dada tensão média no CAF nas fissuras sem permitir qualquer deslocamento na armadura no ponto $x=\ell+d$. Para essa Segunda situação as condições de contorno são:

$$
\begin{aligned}
& u_{s(x=0)}^{\mathrm{II}}=u_{c a f}^{\mathrm{II}}(x=0)=u_{s(x=\ell+d)}^{\mathrm{II}}=0 \\
& \frac{d u_{c a f}^{\mathrm{II}}(x=\ell)}{d x}=\frac{\sigma_{c a f}^{\mathrm{II}}(x=\ell)}{E_{c a f}}=\frac{\sigma_{c a f}^{\mathrm{II}}(x=\ell+d)}{E_{c a f}}
\end{aligned}
$$

Supondo $d$ muito pequeno a situação de contorno (4- 76) pode ser simplificada como:

$$
u_{s(x=0)}^{\mathrm{II}}=u_{c a f}^{\mathrm{II}(x=0)}=u_{s(x=\ell)}^{\mathrm{II}}=0
$$

Essas condições devem garantir que:

$$
\varepsilon^{\mathrm{II}}=0
$$


A tensão máxima total deve corresponder à máxima das duas soluções em um único ponto. Portanto, a segunda solução deve ser encontra no mesmo ponto onde a tensão máxima na primeira solução foi encontrada. Resolvendo as equações diferenciais, a tensão média no CAF é dada por:

$$
\sigma_{c a f}^{\text {max II }}=\sigma_{c a f}^{\mathrm{II}(x=\ell+d)} \frac{c E_{s} \lambda \ell+(1-c) E_{c a f} \operatorname{senh} \lambda \ell}{c E_{s} \lambda \ell \cosh \lambda \ell+(1-c) E_{c a f} \operatorname{senh} \lambda \ell}
$$

A solução, tanto para a abertura de fissura como a solução para a tensão média na barra de armadura no nível da macro fissura discreta é dada por:

$$
\begin{aligned}
& w^{\mathrm{II}}=-\sigma_{c a f}^{\mathrm{II}(x=\ell+d)} \cdot\left[\frac{\left(\frac{1}{\beta_{1}}-\beta_{2}\right) \operatorname{senh} \lambda \ell}{\left(c E_{s} \lambda \ell \cosh \lambda \ell+(1-c) E_{c a f} \operatorname{senh} \lambda \ell\right)} E+\beta_{2}\right] \frac{2 t}{E_{c a f}} \\
& \sigma_{s(x=\ell)}^{\mathrm{II}}=\sigma_{s(x=\ell+d)}^{\mathrm{II}}=\sigma_{c a f}^{\mathrm{II}}(x=\ell+d) \frac{(1-c) E_{s}(\operatorname{senh} \lambda \ell-\lambda \ell \cosh \lambda \ell)}{c E_{s} \lambda \ell \cosh \lambda \ell+(1-c) E_{c a f} \operatorname{senh} \lambda \ell}
\end{aligned}
$$

\subsection{Superposição dos efeitos}

A idéia básica da superposição é obter uma solução tal que a função $\sigma-w$ descrito pela equação (3-27) seja satisfeita. Portanto, uma vez caracterizado um CAF, basta resolver as equações (4- 67) e (4- 68) e verificar se a equação (3- 27) está satisfeita. Essa verificação pode ser feito por uma iteração convergente.

Suponha-se por exemplo que a deformação total, $\varepsilon_{o}$, do EVR tenha sido prescrita. Essa suposição implica portanto que a primeira solução está completamente determinada pois a deformação, $\varepsilon$ é dada por:

$$
\varepsilon=\varepsilon^{\mathrm{I}}=\varepsilon_{o}
$$


Em seguida, a tensão na segunda solução, $\sigma_{c a f}^{I I}(x=\ell+d)$ pode ser determinado resolvendo -se a equação:

$$
\sigma_{c a f}^{f i s s}=\sigma_{c a f}(x=\ell+d)=\sigma_{c a f}^{\mathrm{II}}(x=\ell+d)=f\left[w^{\mathrm{I}}+w^{\mathrm{II}}\left(\sigma_{c a f}^{\mathrm{II}}(x=\ell+d)\right)\right]
$$

Com $\sigma_{c a f}^{\mathrm{II}}(x=\ell+d)$ determinada, a segunda solução é completamente determinada, e a máxima tensão, abertura de fissura e tensão na armadura de fissura, e tensão na armadura podem ser calculadas de como

$$
\begin{aligned}
& \sigma_{c a f}^{\max }=\sigma_{c a f}^{\max \mathrm{I}}+\sigma_{c a f}^{\max \mathrm{II}} \\
& w=w^{\mathrm{I}}+w^{\mathrm{II}} \\
& \sigma_{s(x=\ell+d)}=\sigma_{s(x=\ell+d)}^{\mathrm{II}}+\sigma_{s(x=\ell+d)}^{\mathrm{II}}
\end{aligned}
$$

\subsubsection{Calibração do Modelo}

Segundo STANG E AARRE (1992), a resistência do CAF obtida experimentalmente não pode ser usada diretamente no modelo, requerendo, portanto, uma calibração do modelo analítico com relação ao resultados experimentais. Uma relação de calibragem proposta por OSLEN apud STANG E AARRE (1992) é dada por:

$$
\sigma_{c a f}^{u}=\mu \sigma_{\text {exp }}^{u}+\beta_{1} \sigma_{\beta}
$$

onde $\mu$ é um fator menor que 1

$\sigma_{\beta}$ é a medida da variação estatística da resistência à tração de um prisma de CAF (Segundo Stang e Aarre; 1993, $\sigma_{\beta}=1,0 \mathrm{MPa}$ ) 
Segundo STANG E AARRE;1993, $\mu=0,5$ portanto de (4- 88) tem-se:

$$
\sigma_{c a f}^{u}=0,5 \sigma_{\exp }^{u}+1,0 \beta_{1}
$$

\subsubsection{Otimização do Modelo}

Existem vários aplicações interessantes onde, por razões de desempenho, há uma necessidade do emprego de um tipo de fibra. Isso é de importância particular quando se deseja uma melhoria tanto na resistência quanto na tenacidade do compósito. No entanto, a mecânica de compósitos cimentíceos mostra que esses dois parâmetro são extremamente conflitantes, sendo que, existe um ponto a partir do qual o aumento da resistência é acompanhado por uma queda da tenacidade. Nessas situações o emprego de mais de um tipo de fibra (sistema híbrido), um com a função principal de aumentar a resistência, enquanto o outro desempenha a função de aumentar a tenacidade, é aconselhável.

Para o efeito de otimização do compósito, como no caso de sistemas híbridos, o modelo da relação tensão-abertura de fissura proposto na seção 3.3.1.1, pela equação (3- 28) deve ser relacionado ao presente modelo de abertura de fissura. Segundo KRENCHEL apud STANG ET AL. (1993), o modelo de abertura de fissura para sistemas híbridos está relacionado ao modelo de tensão-abertura de fissura para um tipo de fibra, e os parâmetros micro-mecânicos, através do módulo de elasticidade do CAF. Está relação é dado pela seguinte expressão:

$$
E_{\text {caf }}=\left(1-\sum_{i=1}^{F} V_{f}^{i}\right) E_{m}+\sum_{i=1}^{F} \eta_{\ell}^{i} \eta_{\Phi}^{i} V_{f}^{i} E_{f}^{i}
$$

onde:

$\eta_{\Phi}^{i}$ e $\eta_{\ell}^{i}$ são respectivamente os fatores de eficiência de orientação e comprimento finito para o sistema de fibra I . 


\subsubsection{Implementação do Modelo de Stang e Aarre}

No emprego do modelo de Stang, o cálculo da abertura de fissura sob carregamentos externos é feito conforme o algoritmo apresentado a seguir:

1. Inicia-se com uma deformação global igual a zero e um espaçamento de fissuras muito grande.

2. Aumenta as deformações em pequenas etapas. Para cada etapa, a solução completa do problema é determinada, conforme descrito na seção 4.4.2.1, empregando-se um método de iteração para resolver a equação não-linear (484).

3. Da a solução obtida, calcula-se a tensão máxima no CAF, e verifica-se se essa tensão máxima, dada por (4- 85), é maior que a resistência à tração do compósito, dada por (4- 89).

4. Se a resistência à tração do CAF for atingida, ajusta-se o comprimento do prisma $(E V R)$ tal que $\sigma_{c a f f}^{m a ́ x}=\sigma_{c a f}^{u}$. Isso corresponde à formação de novas fissuras discretas. Este ajuste corresponde a resolver uma equação não-linear. Isto é feito empregando-se a mesmo método de iteração, mas, ao contrário, são dados a deformação e comprimento do prisma.

5. A saída da análise é: deformação global, tensão máxima na armadura, tensão no CAF nas fissuras, abertura de fissuras, e espaçamento de fissuras.

Do ponto de vista computacional, o algoritmo acima apresentado é de fácil manipulação. No entanto, o modelo de STANG E AARRE (1992) apresentou certas dificuldades vis-à-vis a elaboração da presente pesquisa. Umas das principais dificuldades enfrentadas foi a falta de dados de entrada no modelo. De fato, o "software" originalmente utilizado por Stang e Aarre é um "software" específico, capaz de simular automaticamente, o dano do material e efeito Cook-Gordon, com o aumento do carregamento. Os autores não propõem dados sobre esses parâmetros, e por serem os pioneiros do modelo, os parâmetros essenciais estão fora do alcance de quem pretende empregar esse modelo, que não foram encontrado na literatura pesquisada. 
Além do mais, embora o algoritmo acima é exeqüível empregando-se os métodos de elementos finitos ou discretos, os vários "softwares" disponíveis são incapazes de simular o avanço de um dano, e a sua propagação considerando automaticamente, o efeito Cook-Gordon em um material cimentíceo. Para executar este algoritmo portanto, exigiria um ajuste dos "softwares" disponíveis, que levaria a presente pesquisa além da sua amplitude prevista, devido ao esforço computacional.

Finalmente, o conceito básico do método de Stang e Aarre, é a determinação da rigidez equivalente de um elemento de volume representativo. No entanto, a teoria do elemento de volume representativo é, por si, muito complexo, exigindo uma pesquisa fora da amplitude pretendida no presente trabalho. Portanto, diante dessas dificuldades, o método de STANG E AARRE (1992) não será abordado numericamente, deixando-o para uma futura pesquisa. 


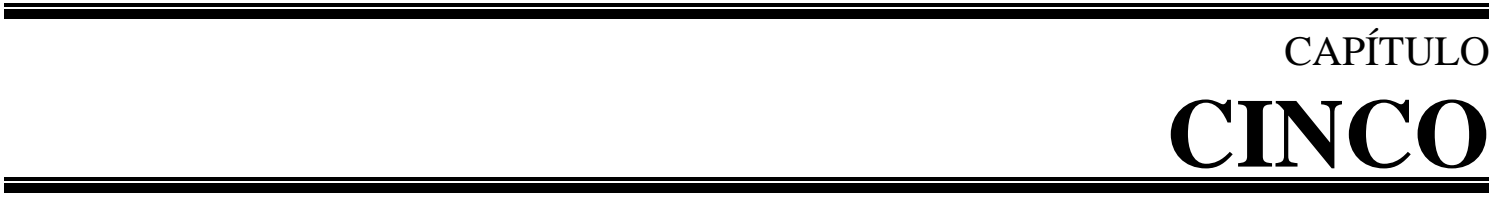

\section{PROGRAMA EXPERIMENTAL E RESULTADOS OBTIDOS}

\subsection{PRELIMINARES}

Neste capítulo apresentam-se alguns resultados obtidos baseados nos modelos apresentados. Em particular serão apresentados os resultados experimentais e analíticos baseados no método de Al-Taan e Al-Feel. Como foi mencionado anteriormente, o modelo de Stang e Aarre não será abordado numericamente, devido a uma série fatores apresentados na seção 4.4.2.2. Em princípio, a verificação da validade do modelo aqui empregado, será feita por comparação com resultados obtidos em laboratório.

Para o efeito de comparação com o modelo, um amplo estudo qualitativo baseado numa série de ensaios de tração de elemento foi realizado. Nesses ensaios, foram empregados elementos de placas delgadas de argamassa armada com fibras poliméricas, discretas e aleatoriamente dispostas e armadura convencional de tela e fio. Vale lembrar que essa abordagem e esquema adotado para o programa experimental é um dos métodos diretos para a determinação da relação 
tensão-abertura de fissura conforme foi discutido no capítulo 2. A seguir está apresentado o programa experimental e os resultados dele obtidos.

\subsection{PROGRAMA EXPERIMENTAL}

\subsubsection{Variáveis Experimentais}

EL DEBS E NAAMAN (1995) já realizaram um amplo estudo experimental sobre o comportamento de placas delgadas submetidos à tração. No estudo realizado por esses pesquisadores foram empregadas fibras poliméricas monofilamento, e tela de grande abertura. Baseando-se nesses estudos experimentais, o programa experimental desenvolvido na presente pesquisa foi realizado como uma continuação do estudo de EL DEBS E NAAMAN (1995). Portanto, no programa experimental, procurou-se aproximar quanto mais possível às variáveis experimentais empregadas em EL DEBS E NAAMAN (1995), fazendo-se algumas adaptações.

No entanto, os modelos deduzidos são apenas válidos para a previsão de espaçamento e abertura de fissura supondo armadura contínua de fios ou barras. Para aplicar esses modelos, foi realizado um primeiro estudo para verificar o efeito de adição de fibras na abertura de telas. Se confirmasse-se a viabilidade do emprego de fibras em argamassa armada com armadura contínua de fio ou barra, os modelos, assim poderão ser aplicados normalmente, caso contrário, deveriam ser modificados para o caso de armadura de tela.

Portanto, baseando-se nos programa experimental anterior realizado por EL DEBS E NAAMAN (1995), no presente programa experimental as seguintes variáveis foram empregadas:

- tipo de fibras: Polivinylálcool (PVA) e Polipropileno (PP);

- tipo de armadura convencional: tela e fio; e

- taxa de fibra - 1\% e $2 \%$ para fibras de PVA e $0,5 \%$ e $1 \%$ para fibras de PP.

Para cada taxa de fibra duas placas foram moldadas, e a abertura da malha da tela, de $50 \mathrm{~mm}$ por $50 \mathrm{~mm}$ foi mantida constante durante todo programa experimental. 
Também foi verificado o efeito da taxa de fibra sobre a abertura da malha da tela. Para isto, um arranjo especial composto de apenas armadura longitudinal de fios foi empregado. Relacionada à abertura de malha, os fios longitudinal foram considerados como um tela de abertura de malha igual a infinito. A tabela 5.1 é um resumo das variáveis experimentais.

Tabela 5.1: Variáveis Experimentais

\begin{tabular}{|c|c|c|c|c|}
\hline Tipo de fibra & $\begin{array}{c}\text { Taxa de fibras } \\
(\%)\end{array}$ & Tipo de armadura & $\begin{array}{c}\text { Espaçamento de fio } \\
\text { transversa }(\%)\end{array}$ & $\begin{array}{c}\text { ID de corpo de } \\
\text { prova }\end{array}$ \\
\hline Sem fibras & 0 & Tela & 50 & $\mathrm{~N}-\mathrm{T}$ \\
\hline \multirow{2}{*}{ PVA } & 1 & Tela & 50 & $\mathrm{~A} 1-\mathrm{T}$ \\
\hline & 2 & Tela & 50 & $\mathrm{~A} 2-\mathrm{T}$ \\
\hline \multirow[b]{2}{*}{$\mathbf{P P}$} & 0.5 & Tela & 50 & $\mathrm{P} 0.5-\mathrm{T}$ \\
\hline & 1 & Tela & 50 & $\mathrm{P} 1-\mathrm{T}$ \\
\hline \multicolumn{5}{|c|}{ Peça especiais } \\
\hline PVA & 2 & Fios & Infinito & $\mathrm{A} 2-\mathrm{I}$ \\
\hline
\end{tabular}

\subsubsection{Geometria de Corpo de Prova}

A geometria adotada no programa experimental de EL DEBS E NAAMAN (1995), 125mm de largura por $12.7 \mathrm{~mm}$ de espessura foi mantida neste programa experimental. Entretanto, algumas modificações foram feitas no presente programa devido ao método de ensaio. As cabeças das placas foram alargadas para fornecer agarramento eficiente no pórtico de reação durante o ensaio (figura 5.1), e um comprimento constante de $810 \mathrm{~mm}$ entre as cabeças foi adotado, dando à peça uma esbeltez suficiente para minimizar o efeito tensões iniciais antes da aplicação da força. As armaduras foram colocadas no plano médio da peça.

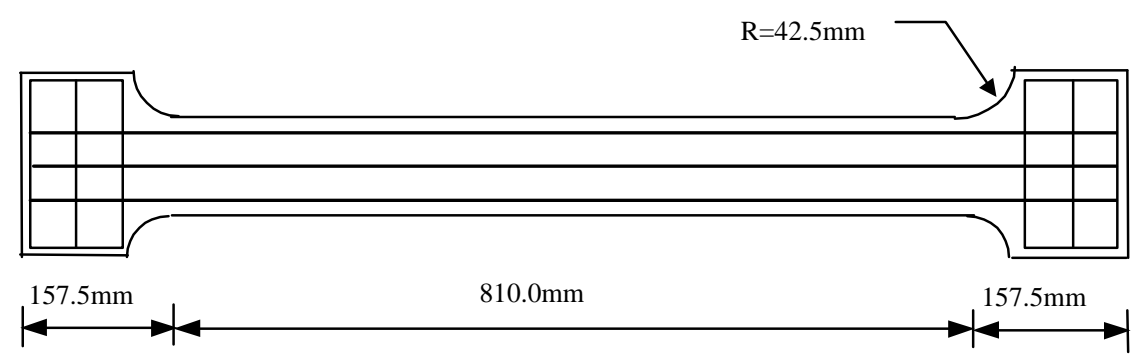

Fig. 5.1: Geometria do corpo de prova e disposição da armadura. 


\subsubsection{Materiais}

As armaduras contínuas de tela e fios usados no presente programa experimental são de aço de alta resistência normalmente empregado na fabricação de elementos de argamassa armada. As principais características são relacionadas na tabela 5.2 abaixo.

Tabela 5.2: Características geométricas e mecânicas das armaduras

\begin{tabular}{|c|c|c|c|}
\cline { 2 - 4 } \multicolumn{1}{c|}{} & $\begin{array}{c}\text { Abertura de malha } \\
(\mathbf{m m} \times \mathbf{~ m m})\end{array}$ & $\begin{array}{c}\text { Diâmetro do fio } \\
(\mathbf{m m})\end{array}$ & $\begin{array}{c}\text { Resistência nominal } \\
(\mathbf{M P a})\end{array}$ \\
\hline Tela & $50 \times 50$ & 2.67 & 600 \\
\hline Fios & - & 3.4 & 600 \\
\hline
\end{tabular}

Como previamente mencionado, as fibras usadas no presente programa experimental também são as mesmas usadas no programa de EL DEBS E NAAMAN (1995); PVA e PP. Entretanto, as fibras de PP empregadas no presente programa são do tipo multifilamento, ao contrário de monofilamento usadas no programa de EL DEBS E NAAMAN (1995). As principais propriedades físicas e mecânicas das fibras são resumidas na tabela 5.3 abaixo.

Tabela 5.3: Propriedades físicas e mecânicas das fibras

\begin{tabular}{|c|c|c|c|c|c|}
\cline { 2 - 6 } \multicolumn{1}{c|}{} & $\begin{array}{c}\text { Massa específica } \\
\left(\mathbf{k g} / \mathbf{m}^{\mathbf{3}}\right)\end{array}$ & $\begin{array}{c}\text { Comprimento } \\
(\mathbf{m m})\end{array}$ & $\begin{array}{c}\text { Diâmetro } \\
(\mathbf{m m})\end{array}$ & $\begin{array}{c}\text { Resistência à } \\
\text { tração }(\mathbf{M P a})\end{array}$ & $\begin{array}{c}\text { Módulo de } \\
\text { elasticidade (GPa) }\end{array}$ \\
\hline PVA & 1.3 & 12.0 & 0.2 & 900 & 29 \\
\hline PP & 0.9 & $35.0-45.0$ & NA & $320-400$ & $3.5-3.6$ \\
\hline
\end{tabular}

\subsection{PREPARO DAS PLACAS}

\subsubsection{Preparo e Montagem das Armaduras}

A moldagem das placas foi feita em formas metálicos nos quais foram colocados insetos de madeira para se obter a geometria desejada (figura 5.3). No preparo e montagem das armaduras, cuidados especiais foram tomadas com respeito à geometria adotado, pontos da sua fixação na forma para evitar a sua flambagem que 
causaria o desvio da mesma fora do plano médio do elemento. No que diz respeito à geometria, as armaduras foram confeccionadas de tal modo que seguisse a geometria do corpo de prova.

Antes da montagem da armaduras, uma camada de óleo foi passada na forma. As mesmas foram montadas na forma por meio de fios de arrame colocados em cada umas dos três longitudinais. Os pontos de fixação das armadura na forma foram escolhido de tal forma que minimizasses a esbeltez do fio, e o arrame de fixação com diâmetro suficientemente menor que o tamanho do agregado, para evitar a formação de um macrodefeito a partir do qual propagaria uma fissura preferencial. Também o comprimento do arrame de fixação foi fixado igual ao corrimento para não necessitar qualquer acabamento posterior. A figura 5.2 mostram o detalhamento das armaduras de fio. Note que os pontos de fixação dos fios foram ligeiramente defasadas entre si. $A$ figura 5,3 mostra a montagem das armadura de fio e tela respectivamente na forma.

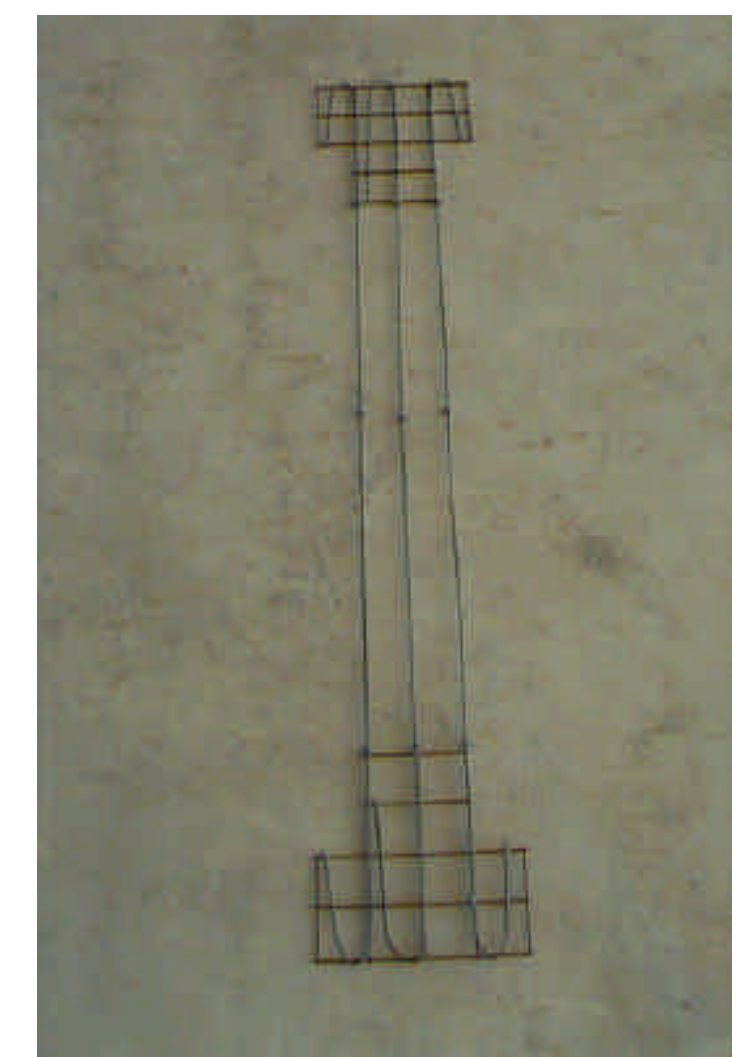

(a)

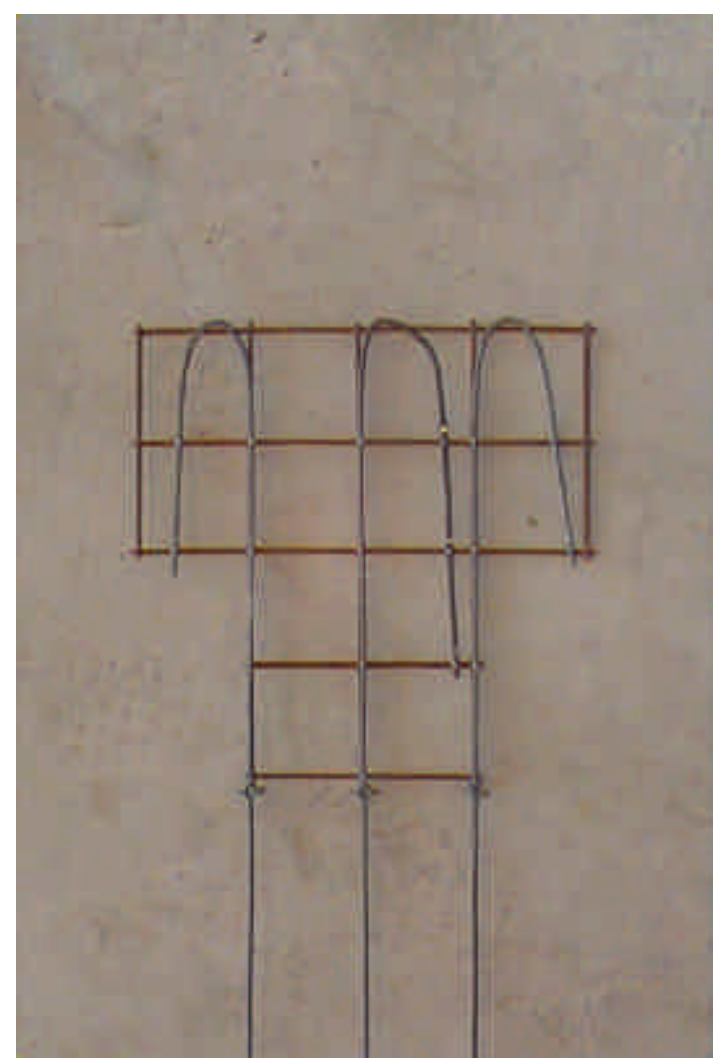

(b)

Fig. 5.2: Esquema da geometria e preparo da armadura de fio (a) visão geral note que os pontos de fixação foram defasadas entre si para evitar um plano preferencial de fissuração, e $(b)$ detalhamento da extremidade alargada. 


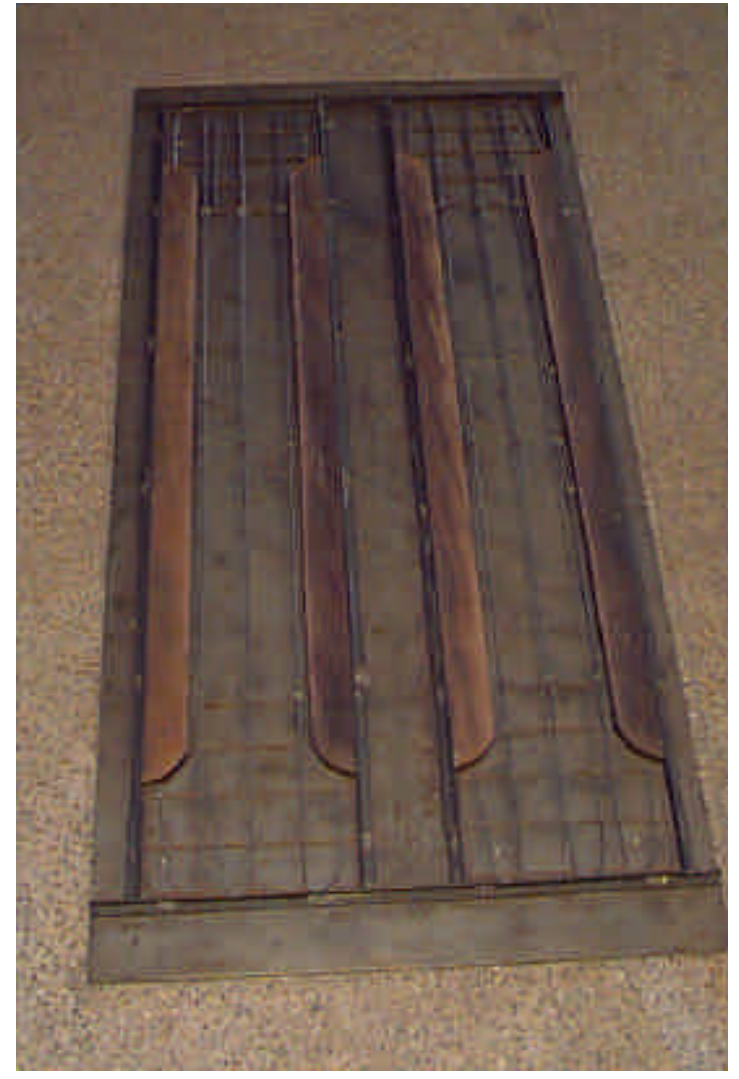

(a)

Fig 5.3. Esquema da montagem das armaduras na forma forma com armadura de tela soldada.

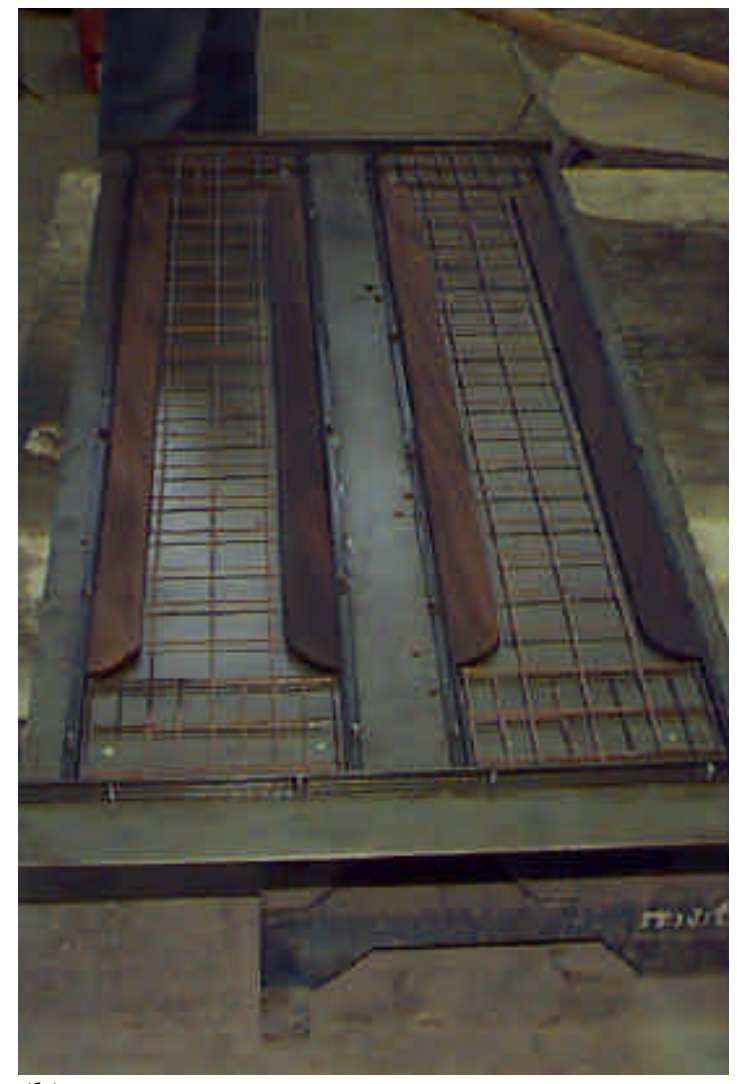

(b)

\subsubsection{Mistura}

Como foi apontado anteriormente, foi adotado o programa experimental realizado por EL DEBS E NAAMAN (1995) como base do presente programa. No entanto, algumas adaptações foram necessárias. Primeiro, vários traços, sempre próximos ao empregado por EL DEBS E NAAMAN (1995), foram adotados para verificação. No entanto, baseando-se na melhor trabalhabilidade da argamassa, chegou-se a um traço diferente no presente programa experimental. Nesse programa experimental, o traço da matriz foi mantido constante em $1: 2: 0.51$ em peso de cimento de alta resistência inicial, areia natural de diâmetro característica de $2,4 \mathrm{~mm}$, e água. Com esse traço, obteve-se um abatimento de $35 \mathrm{~cm}$ com o cone invertido.

A adição de fibras em concreto impõe várias exigências, do ponto de vista tecnológica, sobre o método de processamento do material, e confecção do corpos de prova. Um aspecto de grande importância quando se trabalha com compósitos 
armados com fibras é a trabalhabilidade da mistura. Portanto, para obter uma razoável trabalhabilidade da argamassa com fibra compatível à obtida com a matriz sem fibras, um aditivo, superplastificante (F-1000) foi empregado.

A mistura foi realizada de na forma convencional. Primeiramente, uma mistura seca do agregado, cimento, e fibras foi feita. As fibras foram despejadas na matriz manualmente (figura 5.4) e cuidadosamente para evitar ou reduzir ao mínimo, o fenômeno de "balling" ou "bundling". Em seguida uma fração da água (entorno de 70\%) foi adicionada, e a mistura realizada para verificar a consistência (figura 5.4b). $\mathrm{O}$ restante da água e uma quantidade de superplastificante foi adicionado para atingir uma trabalhabilidade desejada. Após a mistura, o abatimento foi medido pelo método de cone invertido.

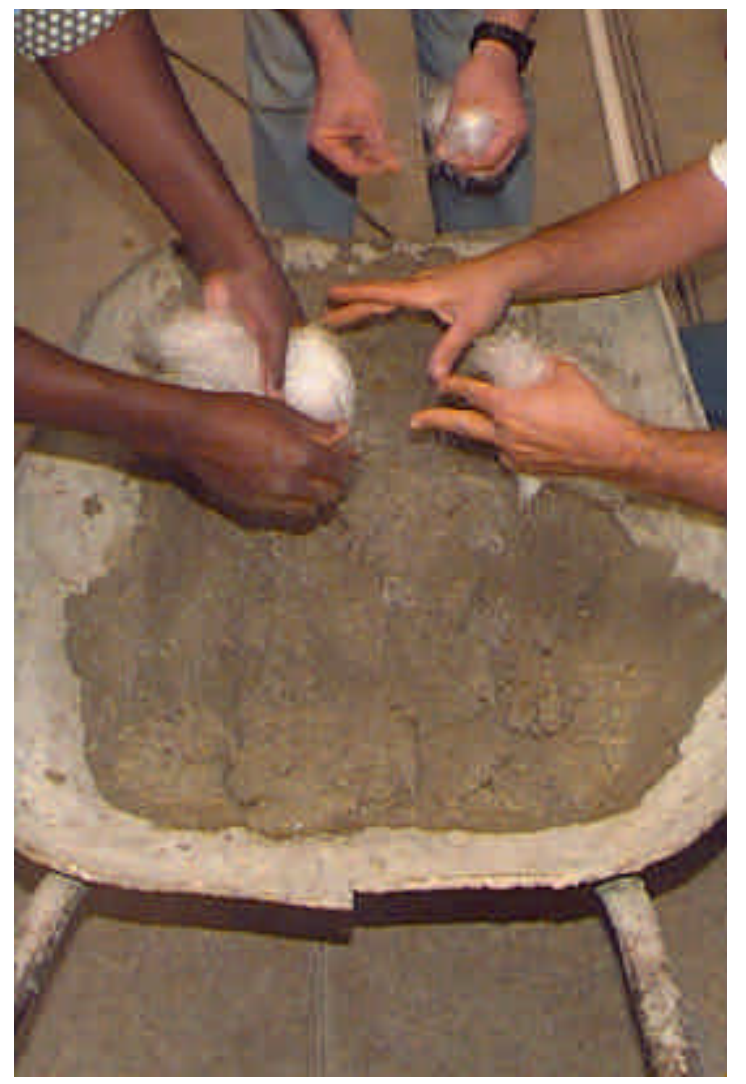

(a)

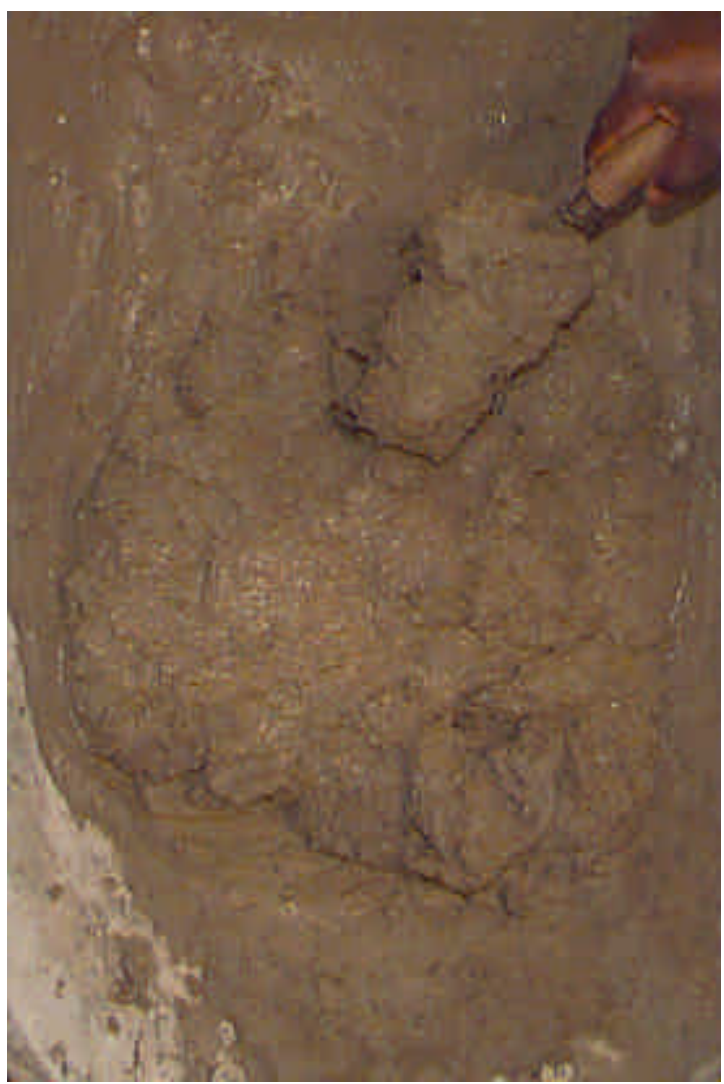

(b)

Fig. 5.4: Processo de mistura: (a) mistura de fibras na argamassa, (b) verificação da consistência da mistura. 


\subsubsection{Moldagem, Adensamento e Cura}

A moldagem das placas foi feita em formas metálicos previamente montadas com insetos de madeira para se obter a geometria desejada, fixação da armadura, e após ter passado uma camada de óleo para facilitar a desforma. Em seguida, já com a forma sobre uma mesa vibratória, a forma foi preenchida. O preenchimento da forma foi feito na posição horizontal, portanto facilitando a moldagem. Finalmente, o adensamento foi realizado na mesa vibratória conforme mostra a figura 5.5. A tabela 5.4 mostra as composições e consumo dos materiais.

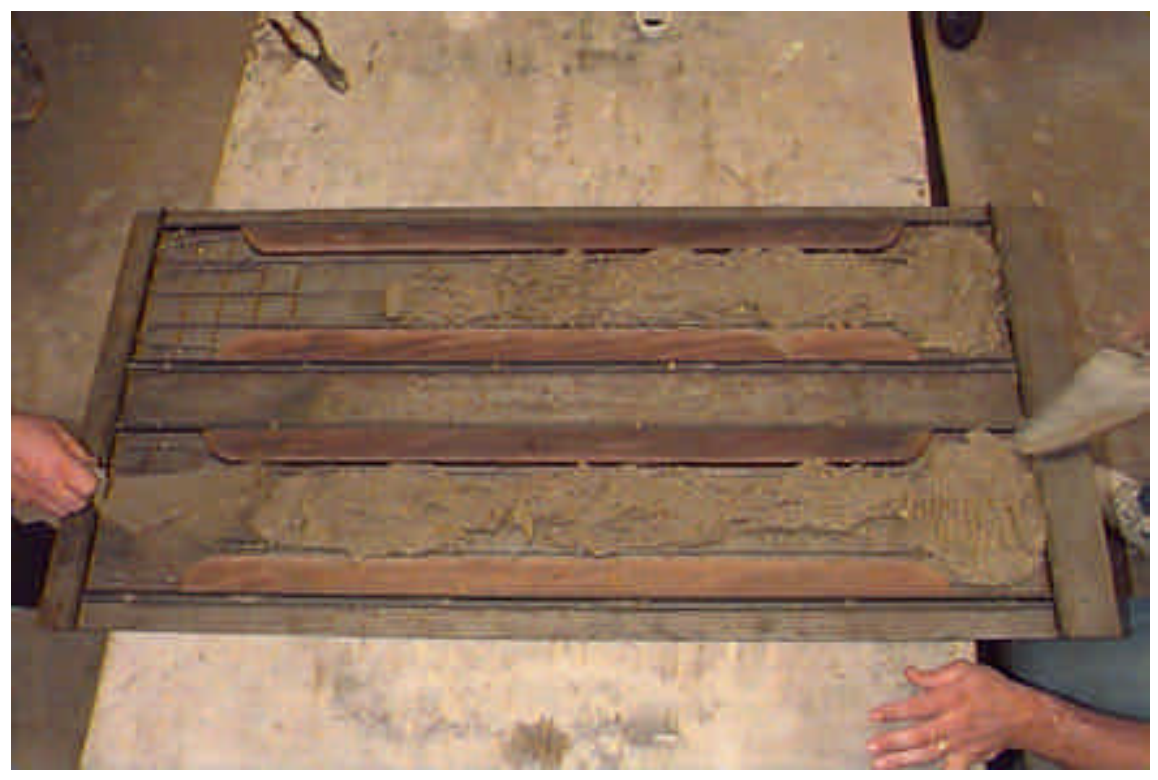

Fig. 5.5: Preenchimento e vibração da forma

Tabela 5.4: Composição das misturas

\begin{tabular}{|c|c|c|c|c|c|c|c|c|c|}
\hline \multirow{2}{*}{ Tipo de fibra } & \multirow{2}{*}{$\begin{array}{r}\text { Taxa de } \\
\text { fibra }(\%)\end{array}$} & \multirow{2}{*}{ Armadura } & \multirow{2}{*}{ Traço } & \multirow[b]{2}{*}{$\begin{array}{l}\text { Slump } \\
\text { (cm) }\end{array}$} & \multicolumn{5}{|c|}{ Consumo de materiais } \\
\hline & & & & & $\begin{array}{c}\text { Cimento } \\
\text { (g) }\end{array}$ & $\begin{array}{c}\text { Areia } \\
\text { (g) }\end{array}$ & $\begin{array}{l}\text { Água } \\
\text { (g) }\end{array}$ & $\begin{array}{c}\text { Fibra } \\
\text { (g) }\end{array}$ & $\begin{array}{c}\text { Superp. (F-1000) } \\
\text { (g) }\end{array}$ \\
\hline Sem fibras & 0 & Tela & 1: $0,50: 2,0$ & 35 & 5000 & 11200 & 2250 & 0 & 55 \\
\hline \multirow[b]{2}{*}{ Polipropileno } & 0,5 & Tela & $1: 0,50: 2,0$ & 33 & 4445 & 8890 & 2267 & 32 & 7 \\
\hline & 1,0 & Tela & 1: $0,50: 2,0$ & 33 & 4445 & 8890 & 2267 & 64 & 15 \\
\hline \multirow[b]{3}{*}{ PVA } & 1,0 & Tela & $1: 0,50: 2,0$ & 36,7 & 4445 & 8890 & 2267 & 90 & 20 \\
\hline & 2,0 & Tela & 1: $0,50: 2,0$ & 36,7 & 4445 & 8890 & 2267 & 180 & 44 \\
\hline & 2,0 & Fio & 1: $0,50: 2,0$ & 38 & 44660 & 9320 & 2377 & 189 & 40 \\
\hline
\end{tabular}


Após a moldagem das placas, as mesmas foram cobertas com panos úmidos para controlar a perda de água de amassamento, e evitar a fissuração precoce por retração. Vinte quatro horas após a moldagem, as placas foram retirados das formas e curados por submersão total em tanques de cura por 5 dias. Após esse período, as mesmas foram deixados para secar em ambiente de laboratório por outros 24 horas, e finalmente ensaiados no sétimo dia.

Para cada dosagem, foram preparados seis corpos de prova cilíndricos de dimensões $5 \mathrm{~cm}$ de diâmetro, e $10 \mathrm{~cm}$ de comprimento para o ensaio de resistência à compressão simples. A moldagem dos corpos de prova foi feita segundo as prescrições da norma da ABNT (NBR-12821). O preenchimento foi feito em quatro camadas, cada uma compactada com 30 golpes de pistão padrão segundo a norma. Os mesmos foram dados a mesma cura como as placas, e ensaiados no mesmo dia do ensaio das placas. As figuras 5.6 e 5.7 mostram os procedimentos de moldagem dos corpos de prova.

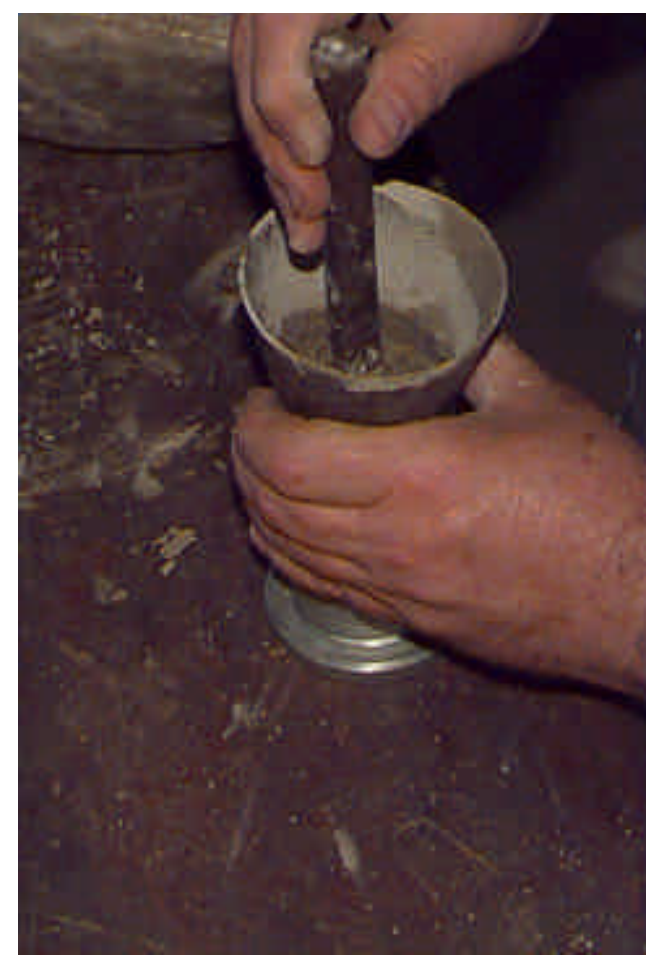

(a)

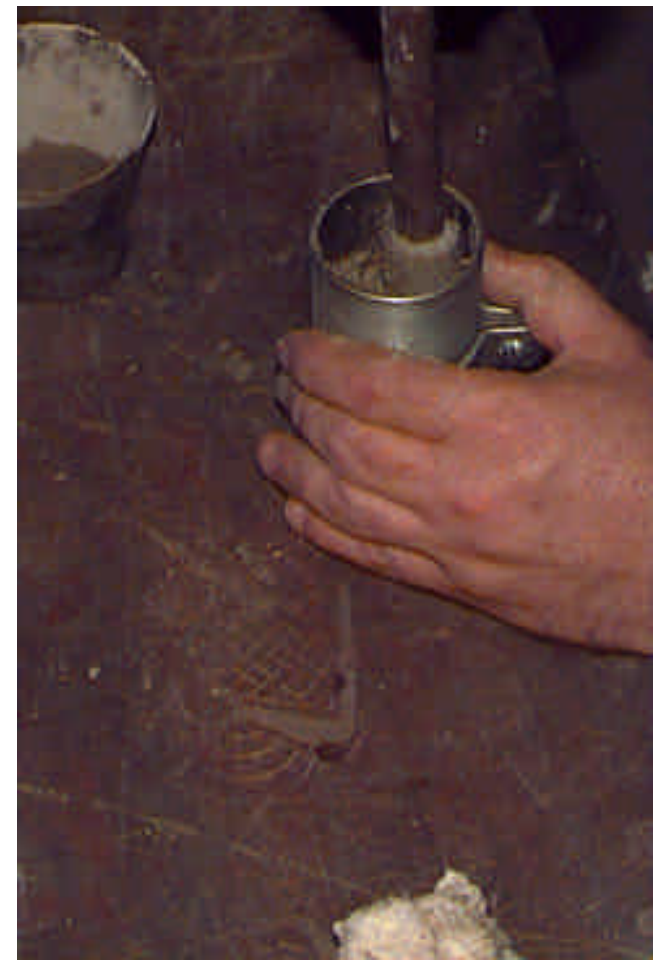

(b)

Fig. 5.6: Moldagem dos corpos de prova: (a) preenchimento da forma, e (b) compactação 


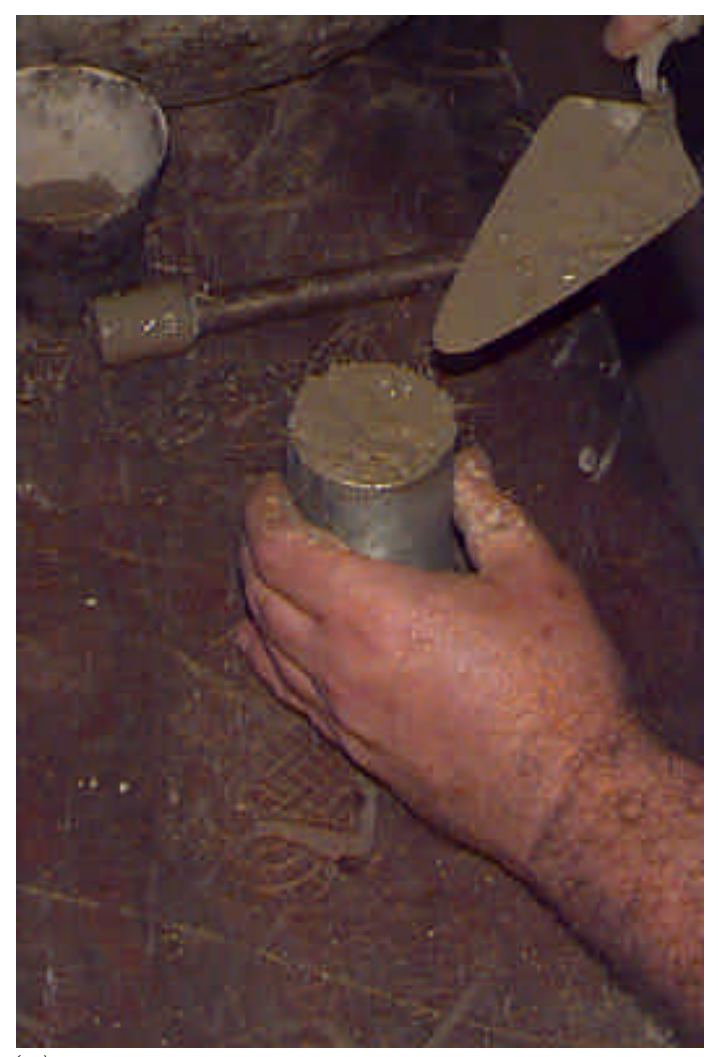

(a)

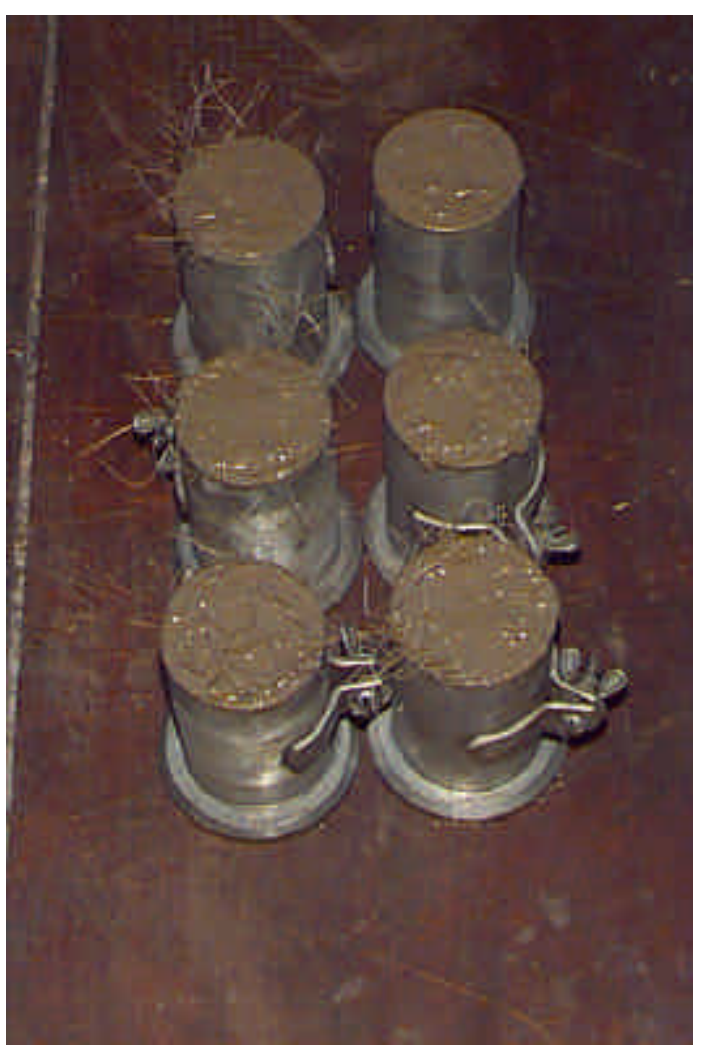

(b)

Fig. 5.7: Moldagem dos corpos de prova: (a) acabamento do corpo de prova, e (b) visão geral dos corpos de prova moldados

Embora a composição da matriz do presente programa ser diferente do programa experimental de EL DEBS E NAAMAN (1995) : (1:2:0,6), foram tomados, entretanto, cuidados para obter uma matriz com a mesma resistência na idade do ensaio como no programa de El Debs e Naaman. As resistências à compressão simples após sete dias são dadas na tabela 5.5 abaixo.

Tabela 5.5: Resistência à compressão simples do compósito

\begin{tabular}{|c|c|c|c|c|c|c|c|c|c|c|}
\hline Matriz & \multicolumn{2}{|c|}{ N } & \multicolumn{2}{c|}{ A1-T (PVA) } & \multicolumn{2}{c|}{ A2-T (PVA) } & \multicolumn{2}{c|}{ P0.5-T (PP) } & \multicolumn{2}{c|}{ P1-T (PP) } \\
\hline & ED/N & P & ED/N & P & ED/N & P & ED/N & P & ED/N & P \\
\hline Taxa de fibra (\%) & \multicolumn{2}{|c|}{0,0} & \multicolumn{2}{|c|}{1,0} & \multicolumn{2}{|c|}{2,0} & \multicolumn{2}{c|}{0,5} & & 1,0 \\
\hline Resistência (MPa) & 43 & 46 & 41 & 43 & 35 & 43 & 39 & 38 & 41 & 34 \\
\hline
\end{tabular}

ED/N= El Debs e Naaman, 1995; $\mathrm{P}=$ Presente pesquisa 


\subsubsection{Ensaio das Placas}

Em primeiro lugar, a garras do sistema de aplicação de carga foram montadas na placa sobre uma mesa. Isso foi feita principalmente para alinhar o ponto de aplicação do carregamento com o eixo da peça o melhor possível. Para a caracterização das fissuras, cada lado da placa foi dividido em três regiões. Uma linha central ao longo do comprimento foi traçada em cada lado para permitir o alinhamento do haste do relógio comparador no eixo da placa, e posteriormente, a placa foi entalhada. A figura 5.8 mostra a seqüência da montagem da placa na garra.

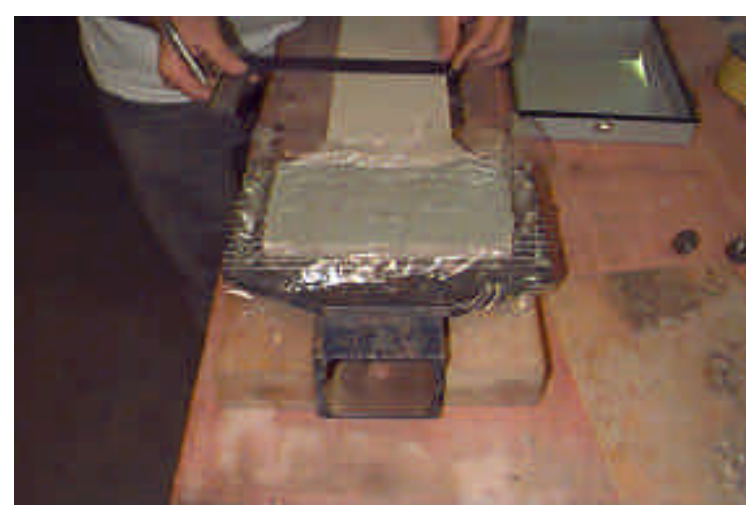

(a)

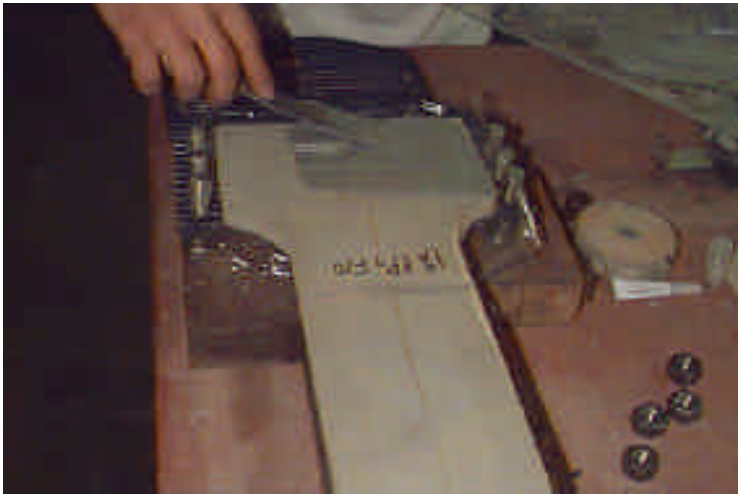

(b)

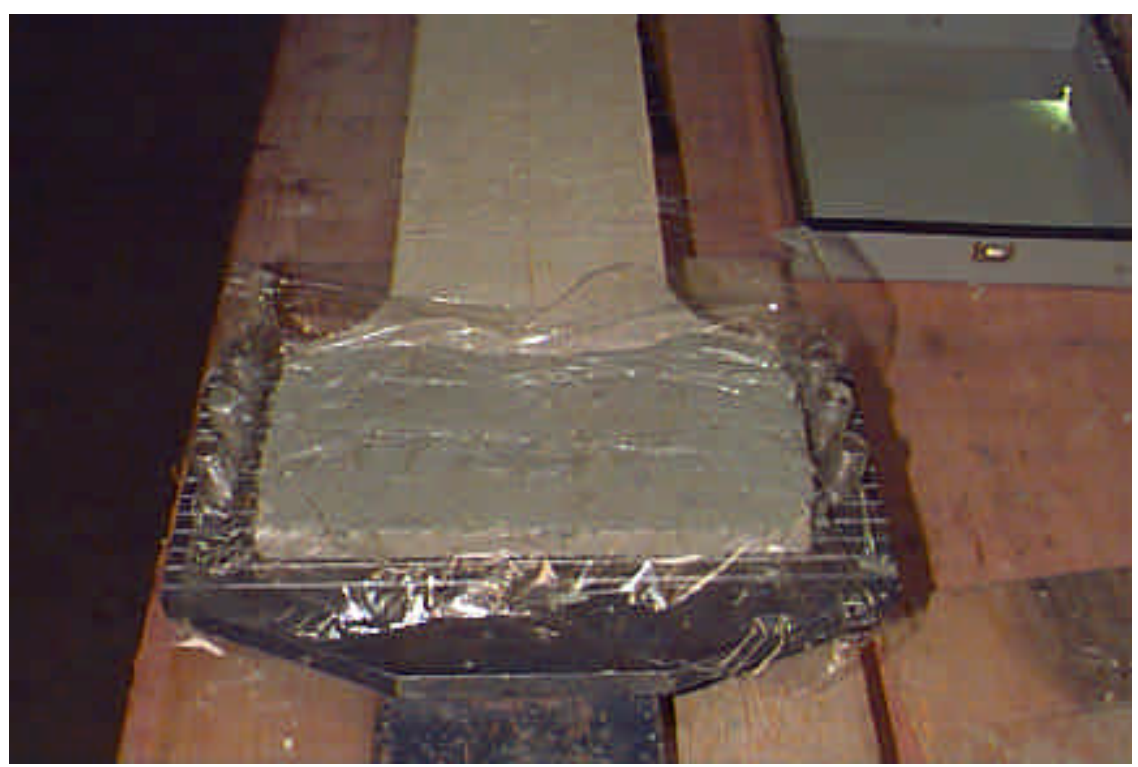

(c)

Fig. 5.8: Montagem do sistema garra/placa: (a) divisão da placa em regiões e colocação de entalhe, (b) colocação de massa colante de epóxi, e (c) montagem da garra 
Após a montagem da placa nas garras, o sistema garras/placa foi montado no pórtico de reação, tomando o cuidado de evitar ou minimizar quaisquer excentricidades iniciais do elemento.

Colocado em posição no pórtico, o corpo de prova foi instrumentado com relógios comparadores colocados em ambos os lados do mesmo. O esquema básico do ensaio de tração era composto de um pórtico de reação equipado de garras metálicos. A aplicação do carregamento foi feita por um sistema de pórtico de reação. O carregamento foi controlado em etapas de $0,25 \mathrm{KN}$ em todo o ensaio, aplicado por cilindro hidráulico e medido por células de carga (figura 5.9b), sem entretanto, nenhum controle da velocidade de carregamento. Durante o ensaio as deformações entre dois pontos foram medidas por relógios comparadores de sensibilidade da ordem de 1/1000mm. A figura 5.6a mostra o esquema básico do ensaio.

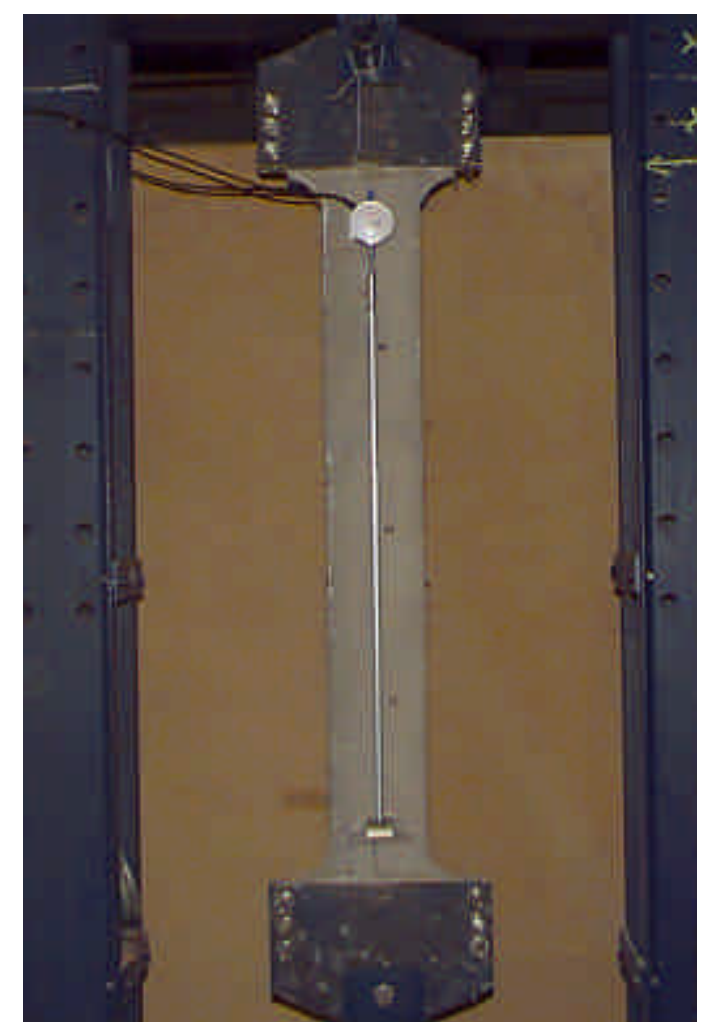

(a)

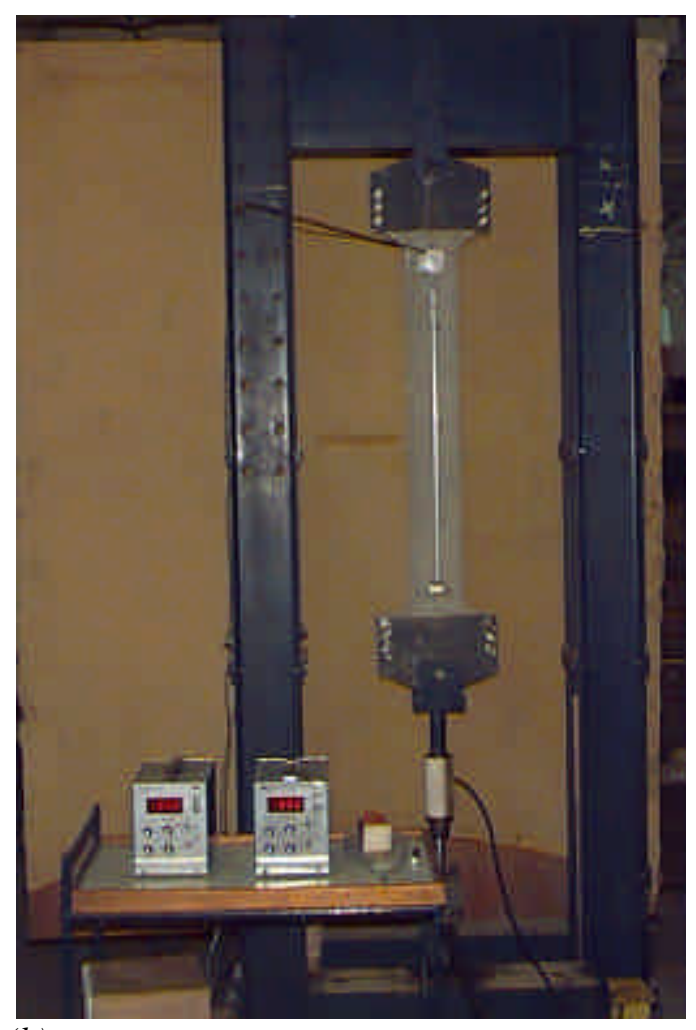

(b)

Fig. 5.9: Esquema de ensaio: (a) montagem do sistema garras/placa no pórtico e instrumentação , e (b) ensaio da placa, mostrando sistema hidráulica. 
Para acompanhar a evolução da fissuração, uma fissura característica foi escolhida em cada uma das três regiões em ambos os lados, e sempre marcada com um X. A abertura de fissura foi medida com uma lupa ótica. A evolução completa da fissuração foi depois marcada com tinta preta como mostra a figura 5.10.

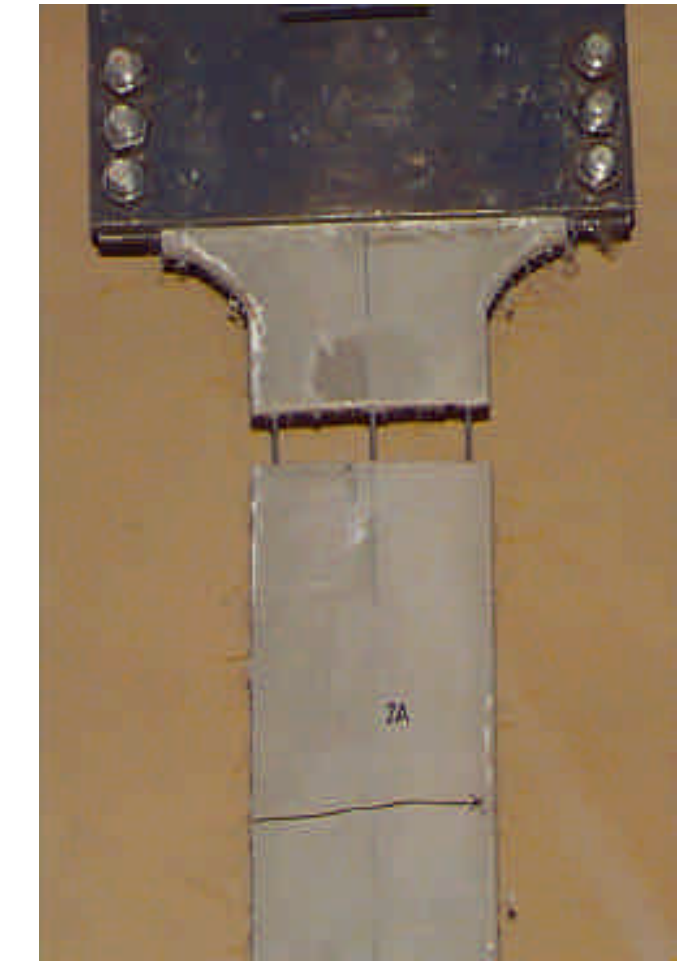

(a).

Fig. 5.10: Esquema de acompanhamento da fissuração: (a) Detalhe de uma fissura característica marcada X em tinta preta na região designada $2 A$. O número 2 representa o lado 2, e a letra A, região. Note que ocorreu uma ruptura no entalhe, e (b) Visão geral de uma peça rompida mostrando as fissuras características e as três regiões.

\subsubsection{Resultados Obtidos}

Conforme foi discutido na capítulo 2, uma das maneiras de obter a relação $\sigma-w$ é pelos ensaios de tração em elementos esbeltos. Porem, sabe-se que o esquema de ensaio, e principalmente a rigidez do equipamento e sistema equipamento/corpo de prova tem uma grande influência sobre os resultados. Esses fatores são os principais fatores responsáveis para a instabilidade durante os ensaios de tração. De importância particular, é o fato de que, essa instabilidade afeta o comportamento da parte pós-pico da curva tensão-deslocamento. 
Porem, no presente programa experimental, os problemas relacionados à instabilidade não foram levados em consideração no que diz respeito à rigidez. Apenas alguns cuidados foram tomados para evitar grandes excentricidades.

No capítulo 3 foi mostrado que o comportamento de concreto armado com fibras depende de um grande numero de variáveis. Uma série de modelos analíticos foi discutida. Um enorme espaço foi consumido e um grande esforço desempenhado no desenvolvimento desses modelos. Isso foi devido principalmente às diretrizes do desenvolvimento proposto nesta pesquisa, na qual se pretende apenas abordar modelos analíticos para o estudo da fissuração em CAF. Portanto, é importante ter em mente que no programa experimental aqui desenvolvido, não se aprofundou no estudo do efeito de determinadas varáveis sobre o comportamento do material, pois estes estudo teve o único objetivo de aferir o modelo analítico. Porem, os resultados dos ensaios mostram alguns fatos muito importantes que merecem comentário.

\subsubsection{Efeitos de taxa de fibra sobre abertura de fissura}

Um estudo do efeito da taxa de fibras sobre a abertura de fissura foi realizado para ter um retrato qualitativo da melhoria proveniente do aumento das fibras. De fato, é evidente que o aumento de fibras além de certas taxas pode prejudicar as propriedades mecânicas do material, devido às dificuldades de processamento e incorporação de ar. Portanto este estudo serviu para definir um teto da taxa de fibras. Além do mais, sabe-se que a melhoria no comportamento proveniente do emprego de fibras pode ser medida da curva $\sigma-w$. Portanto, deste estudo foi também possível descrever o desempenho das fibras. A figura 5.11 mostra as curvas tensão-abertura de fissura, $\sigma-w$, obtidas experimentalmente para várias combinações de armadura contínua e taxa de fibra. Dois aspectos merecem uma análise minuciosa: a melhoria no desempenho devido ao aumento da taxa de fibra para um dado tipo de fibra, e a melhoria proveniente do tipo de fibra para uma dada taxa de fibra. 


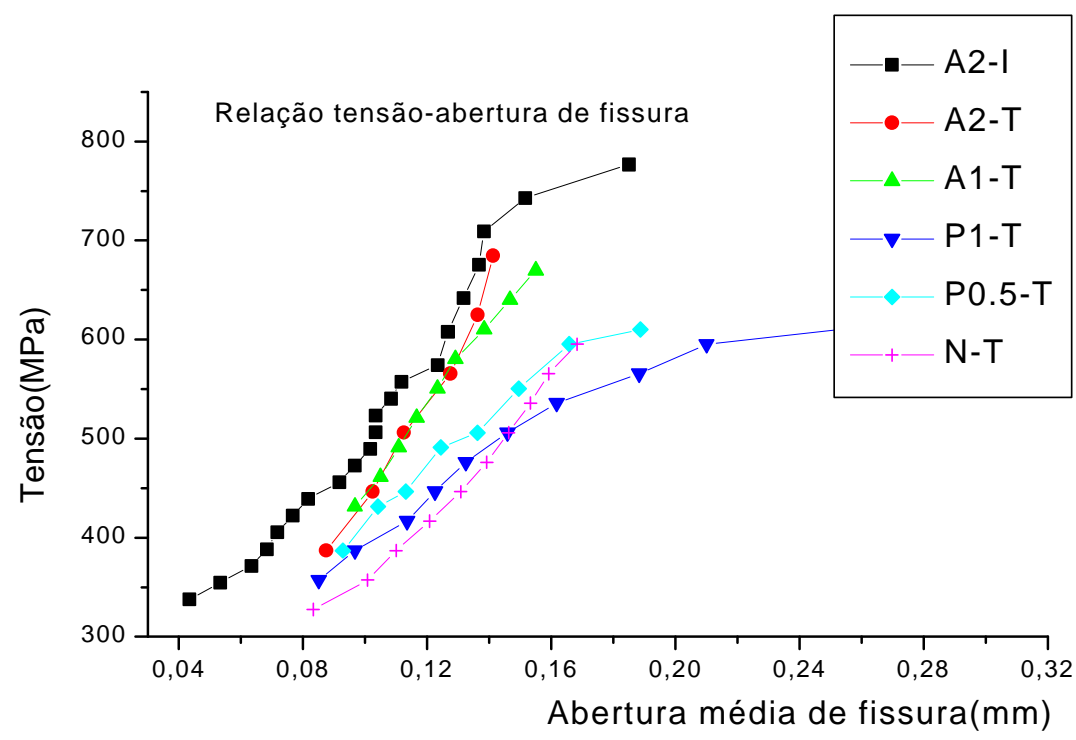

Fig. 5.11: Curvas de tensão-abertura média de fissura

Da figura 5.11 é de fácil aceitação que:

- A adição de fibras no concreto melhora o desempenho do material com respeito à fissuração e ductilidade.

- As fibras de PVA têm maior influência no controle de fissuração que as de PP. Uma das principais razões para essa diferença é o módulo de elasticidade. Percebe-se que as fibras com PVA confere ao CAF uma maior capacidade de deformação. Porém, há também um aspecto muito importante a ser analisado antes de fazer qualquer conclusão. Isso diz respeito ao comprimento da fibra. É fácil perceber da figura 5.11 que, embora as placas com PVA (alto módulo de elasticidade) possuem maior capacidade, a extensão das curvas tensão-abertura de fissura das peças com PP é maior. Isso pode ser atribuído ao comprimento da fibra, e pode ter grandes implicações no desempenho, especialmente a energia.

- Além disso, a taxa de fibras de PP não tem influência significativa sobre o controle da fissuração.

- A adição de fibras de PP praticamente não afeta a abertura de fissura. Veja que a curva referente à PP praticamente coincide com as peças sem fibras. 


\subsubsection{Efeito de fibras sobre o tipo de armadura}

Para a aplicação efetiva dos modelos desenvolvidos no capítulo 3, foi estudado o efeito da taxa de fibra sobre o tipo de armadura contínua. O objetivo aqui foi encontrar a taxa de fibra a partir da qual a aplicação de fios é viável, e portanto os modelos são aplicáveis. Isso foi feto mantendo fixo o tipo de fibra, e variando apenas o tipo de armadura contínua.

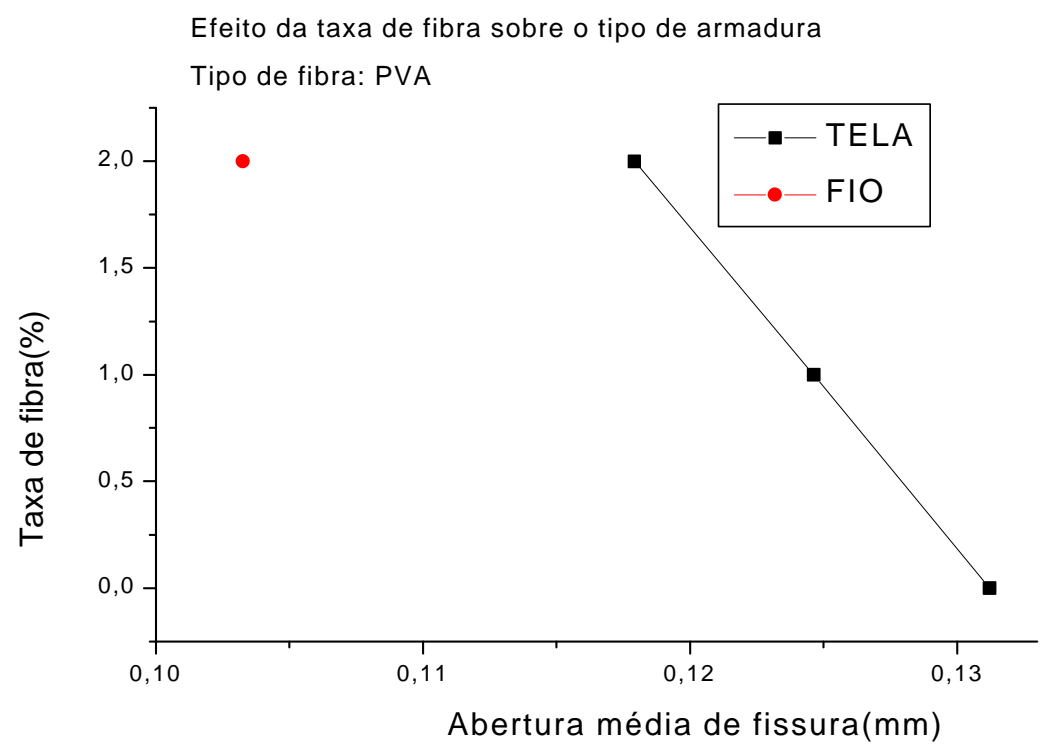

Fig. 5.12: Curva de taxa de fibra-abertura média de fissura

Da figura 5.11, percebe-se que as curvas referentes às peças com armadura de fio e tela para a fibra de PVA intersectam se quase a uma taxa de $2 \%$, o que permite concluir que, a partir dessa taxa de fibra, o emprego de fios, em vez de tela é viável, e os modelos analíticos discutidos no capítulo 3 são aplicáveis. A figura 5.12 mostra o mesmo efeito discutido acima. 


\subsubsection{Modo de Fissuração}

A seguir são mostrados alguns os modos de fissuração obtidos nos ensaios experimentais para várias combinações de armadura contínua, taxa, e tipo de fibra. $A$ figuras 5.13 e 5.14 mostram os modo de fissuração obtidos para placas armadas com fibras de polipropileno e PVA respectivamente. Comparando visualmente o modo de fissuração dos elementos sem (N-T) e com fibras (restantes) nas figura 5.13 e 5.14, não é difícil aceitar que a adição das fibras melhora o comportamento do material na fissuração. Outro conclusão a que se pode chegar após a comparação dos modos de fissuração na figura 13 é que, no caso de fibras de PP, o aumento de taxa de fibras não tem forte influência no comportamento do material. Note que entre o elemento com $0,5 \%$ e $1 \%$ de fibra de PP, a diferença no modo de fissuração é mínima, confirmando portanto os resultados mostrados na figura 5.11 .

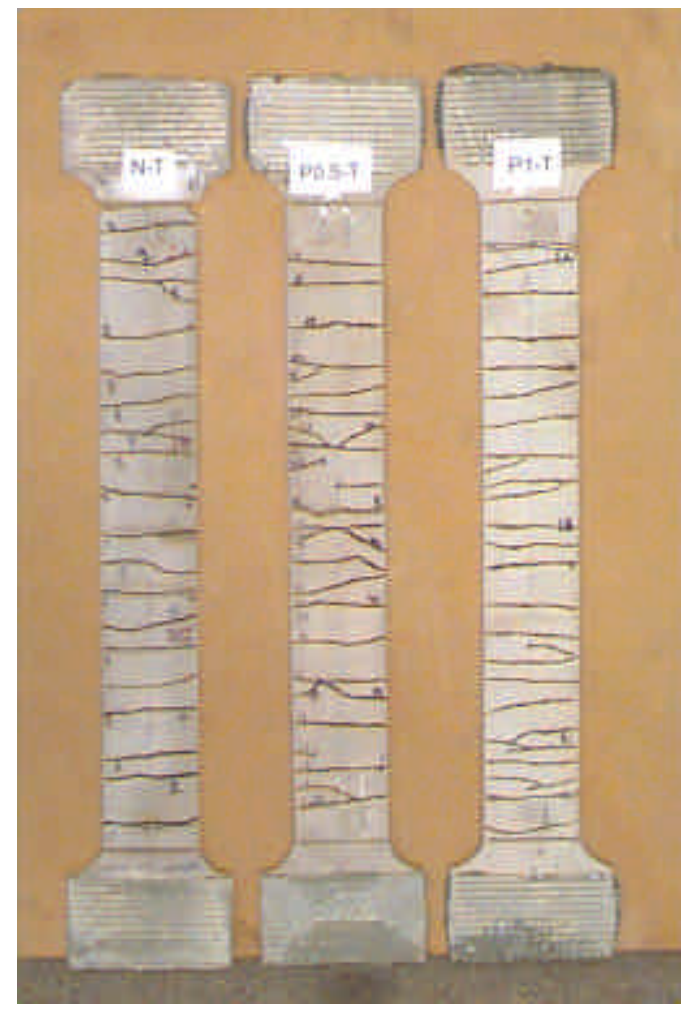

Fig. 5.13: Modo de fissuração da série $N-T$; P0,5-T; e P1-T

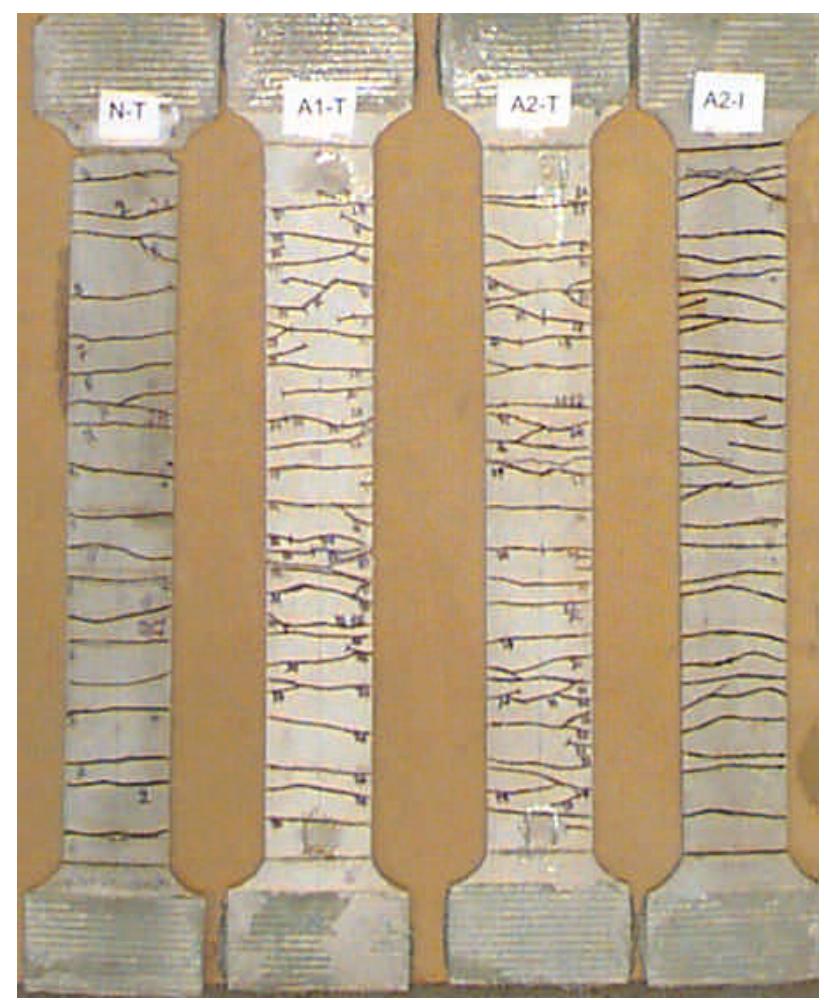

Fig. 5.14: Modo de fissuração da Série N-T; Al-T; A2-T; e A2-I 
Pode-se chegar à outra conclusão interessante comparando-se visualmente as duas figuras acima (figuras 5.13 e 5.14). É fácil concluir após a comparação entre, por exemplo do elemento com $1 \%$ de PP (na figura 5.13) e o com 1\% de PVA (na figura 5.14), que as fibras de PVA são mais efetivas no controle da fissuração. Esse quadro é mostrado de forma mais claro na figura 5.15. Um outro modo de fissuração interessante foi observado em uma das séries compostas de placas armadas com fio. Nessas placas em particular, foram empregados fios novos. O modo de ruptura foi por perda de aderência, o que não foi o esperado. Num estudo cuidadoso, chegou-se à conclusão de que, a perda de aderência foi devido ao óleo protetor empregado pelo fabricante. Os resultados referentes às peças com esse fio foram portanto descartados, pois não são representativos. O resultado de ensaios anteriores realizados com um fio velho foram mantidos. Esse resultado é o que consta no resultado experimental da figura 5.12. A peça referente a esse fio (velho) é designada (A2-I) na figura 5.14.

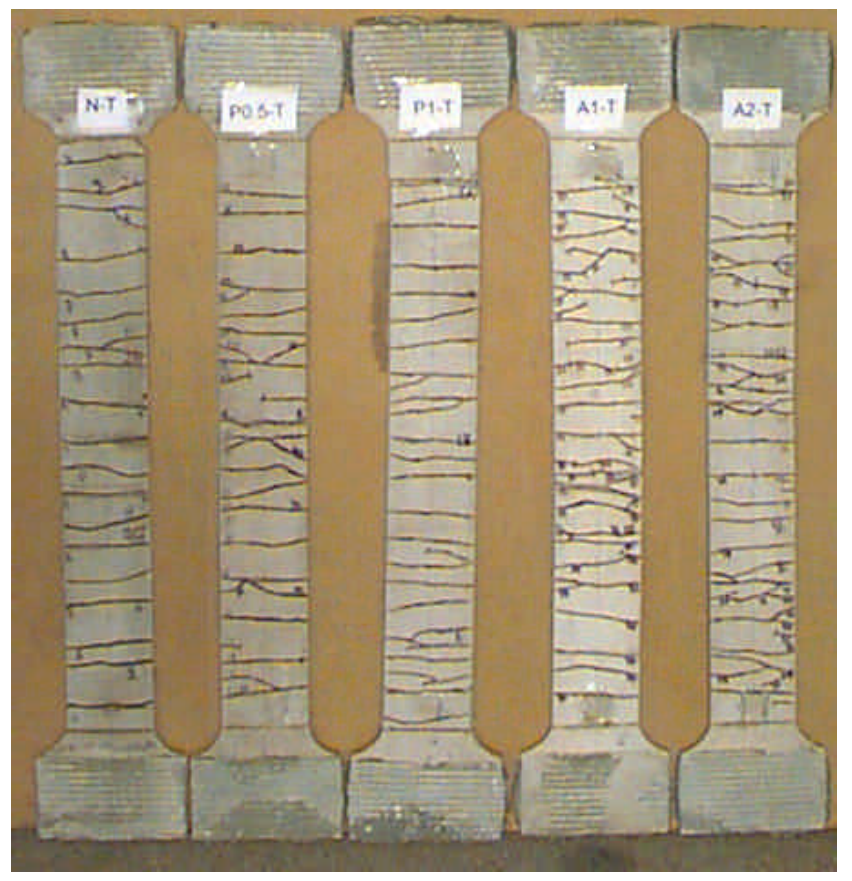

Fig. 5.15: Modo de fissuração da série N-T; P0.5-T; P1-T; A1-T; e A2-T 


\subsection{ANÁlISE TEÓRICA DOS RESULTADOS}

Embora os resultados experimentais acima comprovam a viabilidade do emprego de fibras e fios em vez de telas, para o efeito da comparação do modelo apresentado com os resultados experimentais, será considerado apenas os resultados referentes às peças A1-T e A2-T. Isto é devido ao fato de que, não foi possível obter resultados teóricos para os casos de elementos armados com fibras de polipropileno, por falta dos parâmetros geométricos e micro-mecânicos, essenciais das fibras. De fato, esses parâmetros não foram fornecidos pelo fabricante. Além disso, como anteriormente mencionado os resultados referentes ao elementos armados com fios também não foram aproveitados. Isso foi devido ao fato de que, os fios fornecidos na época do programa experimental foram dadas um tratamento superficial de óleo. Isso resultou em um modo de ruptura não representativo da situação real. De fato, todos os elementos da série com esses fios atingiram a sua capacidade por perda de aderência resultando no escorregamento do fio.

Os cálculos de abertura de fissuras foram baseados nas indicações da norma Brasileira para o uso de tela soldada. É importante lembrar que a Norma Brasileira não fornece nenhuma indicação para os procedimentos de cálculo de elementos armados com tela soldada. No entanto, várias expressões foram deduzidas, partindo-se das premissas da teoria clássica de fissuração. As indicações, aqui utilizadas são as fornecidas no manual do Instituto Brasileira de Tela Soldada (IBTS). Os resultados analíticos foram gerados automaticamente utilizando-se o Software: MATHEMATICA versão 3.0, capaz de manipular expressões analíticas complexas. Para o cálculo analítico, os seguintes parâmetros foram usados:

\section{Parâmetros geométricos e macromecânicos}

Os parâmetros essenciais do materiais para a determinação dos parâmetros micromecânicos das fibras são dados nas tabelas 5.2, 5.3, e 5.5. 


\section{Parâmetros micromecânicos}

A tabela 5.6 mostra os parâmetros micro-mecânicos essenciais calculados. A taxa crítica e comprimento crítico da fibra foram calculados das expressões (3- 17) e (3- 55) vistas no capítulo 3, e o fator de eficiência do comprimento determinado da expressão (4- 33) na seção 4.3.2 no capítulo 4. Os outros parâmetros, fatores de eficiência pré-fissuração e pós-fissuração são dados em BENTUR E MINDESS (1990). O coeficiente de restrição foi adotado de (LEUNG E NUMER, 1997). Percebese da tabela 5.3 e 5.6 que, o comprimento da fibra (PVA) é menor que o comprimento crítico necessário para provocar a ruptura das fibras. O comportamento será portanto, descrito pelo espaço de ruptura 3.10a. As relações tensão-abertura de fissura pré e pós-pico são portanto dada por (3- 72) e (3- 73).

Tabela 5.6: Parâmetros micromecâmicos

\begin{tabular}{|c|c|c|c|c|c|c|c|}
\hline $\mathbf{V}_{\mathbf{f}, \text { crit }}(\%)$ & $\mathbf{L}_{\mathbf{c}}(\mathbf{m m})$ & $\mathbf{f}$ & $\left(\tau / \mathbf{E}_{\mathbf{f}}\right)^{*}$ & $\tau \operatorname{adotado}(\mathbf{M P a})$ & $\eta_{\Phi}$ & $\eta_{\Phi}^{\prime}$ & $\eta_{\ell}$ \\
\hline $3,6 \%$ & 22,5 & 0.7213 & $10^{-4}$ & 2,00 & 0,14 & 0,405 & 0,995597 \\
\hline
\end{tabular}

w segundo Lin e Li (1997)

\subsubsection{Espaçamento de Fissura}

O cálculo do espaçamento de fissura foi feito empregando-se a expressão (432) do modelo analítico desenvolvido na seção 4.3 .2 do capítulo 4 . Os valores experimentais representam os valores médios. Os espaçamentos de fissuras obtidos nos ensaios e previstos pelo modelo são mostrados na tabela 5.7 abaixo.

Tabela 5.7: Espaçamento de fissura prevista pelo modelo e resultados experimentais (em $\mathrm{cm}$ )

\begin{tabular}{|c|c|c|}
\cline { 2 - 3 } \multicolumn{1}{c|}{} & Experimental $^{1}$ & Modelo \\
\hline A1-T & 4.45 & 5.00 \\
\hline A2-T & 3.00 & 3.06 \\
\hline
\end{tabular}

Observação: (1) valores médios 


\subsubsection{Carga de Fissuração}

A carga de fissuração foi determinada pela expressão (4- 47). A tabela 5.8 abaixo mostra a forças de fissuração experimentalmente obtidas e previstas pelo modelo.

Tabela 5.8: Carga de fissuração prevista pelo modelo e resultados experimentais (em KN)

\begin{tabular}{|c|c|c|}
\cline { 2 - 3 } \multicolumn{1}{c|}{} & Experimental $^{1}$ & Modelo \\
\hline A1-T & 5.75 & 5.37 \\
\hline A2-T & 6.00 & 5.45 \\
\hline
\end{tabular}

\subsubsection{Curvas Força-Abertura de Fissura}

Calculado o espaçamento de fissura, resta determinar a deformação para que a abertura de fissura seja especificada. No entanto, a manipulação do modelo apresentado no capítulo 3 não é fácil. As expressões da deformação dadas na seção 4.3.2.3 dependem da tensão do compósito. Essa tensão por si está intimamente ligada à abertura de fissura através da relação $\sigma-w$. Isso resulta em uma expressão muito complexa a ser manipulada. Além do mais, os valores devem ser determinados para duas situações: pré-pico e pós-pico. Para amenizar o trabalho, foi empregado um programa "MATEMÁTICA, versão 3" capaz de manipular expressões complexas.

$\mathrm{Na}$ figura 5.16, estão mostradas as curvas força-abertura de fissura para a serie de placas com fibras de PVA e tela. Na análise teórica, duas situações foram consideradas para cada taxa de fibra: (a) a contribuição de concreto (efeito de endurecimento de tensão e (b) sem o efeito de endurecimento de tensão. Esse efeito foi simulado variando-se o valor do parâmetro $\beta$, que determinar o efeito de endurecimento de tensão. Os valores considerados, $(\beta=0,5)$ e $(\beta=0)$, foram baseados em observações experimentais. 


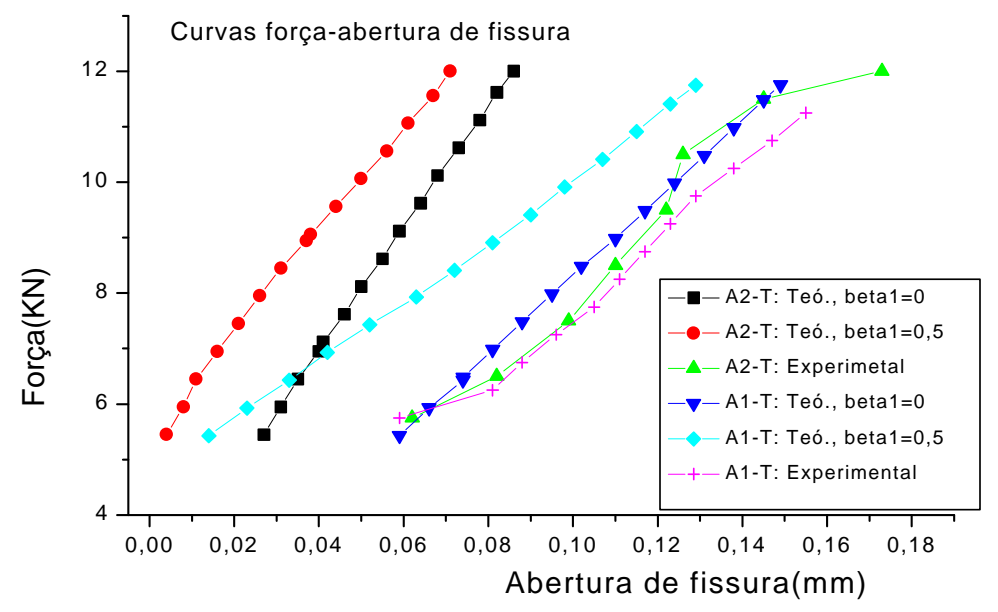

Fig 5.16: Curvas de força-abertura de fissura teóricas e experimentais 


\section{CONSIDERAÇÕES FINAIS E CONCLUSÕES}

O objetivo primário dessa dissertação é fornecer diretrizes para o dimensionamento de estruturas de concreto armado com fibras sob condições de serviço.

As características do material sob tração direta são de suma importância considerando a formação de fissuras discreta no elemento estrutural. Existem fortes razões portanto, para que o comportamento do CAF na tração direta seja dados uma grande ênfase nesta pesquisa. As discussões básicas com respeito ao comportamento do CAF, controlado pela zona de processo são dados no capítulo 2.

Os resultados de um ensaio de tração direta são considerados uma propriedade do material. Não obstante, os resultados de tais ensaios não podem ser aplicados sem restrições. Há vários fatores que podem afetar a resposta da relação tensão-abertura de fissura medida num ensaio de tração direta (seção 2.4.5). Esses fatores incluem:

- A não uniformidade da abertura de fissura na parte de amolecimento causada por, por exemplo, a insuficiência de rigidez do equipamento de ensaio. 
- O comprimento do corpo de prova e do instrumento de medida de deslocamento.

- Tensões iniciais ou residuais, como as proveniente do efeito de retração por secagem, gradientes de umidade e temperatura.

- A geometria do corpo de prova (presença ou não, de entalhe)

Dois modelos matemáticos/micro-mecânicos para prever o comportamento mecânico de concreto armado com fibras foram apresentados no capítulo 3. Um dos modelos incorpora muitos dos parâmetro chaves que influenciam o comportamento pós-fissuração levando em conta a contribuição das fibras. Os parâmetros incluem: a aderência fibra/matriz, a taxa de fibras, a geometria e parâmetros do material da fibra, orientação das fibras, efeito Cook-Gordon, o esmagamento da matriz, e a resistência à tração da matriz.

No capítulo 4, dois modelos macro-mecânicos aplicáveis para a previsão da fissuração em estruturas de CAF são apresentados. É mostrado que os modelos micro-mecânicos propostos no capítulo 2 se encaixam perfeitamente nos modelos macro-mecânicos.

Os resultados do programa experimental são apresentados no capítulo 5. Em conjunto com esses resultados experimentais, os resultados teóricos previstos pelo modelo de AL-TAAN E AL-FEEL (1989) são apresentados, e comparados com valores experimentais deduzidos dos programa experimental. De fato, uma comparação do resultados experimentais e teóricos das aberturas e espaçamento de fissuras mostra que o modelo apresentado é válido. Isso é comprovado particularmente pelos resultados dos espaçamentos de fissuras que mostra claramente uma concordância entre o modelo teórico apresentado e os resultados experimentais. Também o modelo teórico mostra uma concordância com os resultados experimentais para valores menores de efeito de endurecimento de tensão. Isso é esperado, pois a aderência compósito/fio é baixa. Essa conclusão é proveniente do fato de que, eventuais discrepâncias das aberturas e espaçamentos de fissuras são consideradas normais, devido à natureza estatística de compósitos cimentíceos. Segundo COTTERELL E MAI (1996), compósitos cimentíceos são sujeitos a uma grande dispersão de tensões, aberturas de fissura e espaçamentos de fissuras. 
Outras conclusões deduzidas particularmente dos resultados experimentais são:

- As fibras de PVA têm maior influência no controle de fissuração que as de PP. Além disso, a taxa de fibras de PP não tem influência significativa sobre o controle da fissuração (figura 5.11).

- A adição de fibras de PP praticamente não afeta a abertura de fissura (figura 5.11).

- Para uma certa taxa de fibra de PVA (aproximadamente $2 \%$ ), as telas podem ser substituídas por fios (figura 5.12)

$\mathrm{Na}$ presente pesquisa, dois critérios necessários e suficientes para 0 dimensionamento de estruturas de concreto armado com fibras foram apresentados; a necessidade de uma modelagem micro-mecânica, e um modelo macro-mecânico adequado. Futuras pesquisas serão centralizadas dentro dos seguintes contexto:

\section{Modelos micro-mecânicos aplicáveis a outros tipos de carregamentos}

Como se pode perceber, o modelo micro-mecânico proposto no capítulo 3 é válido apenas para carregamento de tração (modo I). Há portanto uma necessidade de ampliar o horizonte da modelagem micro-mecânica para outros tipos de solicitações como: compressão, flexão, e cisalhamento, sejam esses, monotônicos ou dinâmicos. Esses modelos servirão como parâmetros de entrada em um modelo macro-mecânico adequado para descrever o comportamento da estruturas sob uma dada solicitação.

\section{Otimização de concreto armado com fibras}

Como foi mencionado na seção 1.6, uma segunda importância da modelagem micro-mecânico é fornecer um guia para uma receita ótima para o dimensionamento do material. Na seção 3.3.3.6.1, as relações tensão-abertura de fissura do compósito foram deduzidas. Essas relações mostram claramente que a tensão do compósito pode ser expressa com uma função de certos parâmetros do material compósito. A tenacidade, dada pela área sob a curva $\sigma-\delta$, por exemplo, pode ser facilmente 
calculada por integração e maximizada ou minimizada, dependendo na necessidade, por métodos como o cálculo ou programação linear ou não linear. Essa maximização ou minimização de uma dada propriedade do material é conhecida como a otimização da estrutura do material.

As propriedades de compósitos cimentíceos são intimamente ligadas numa maneira complexa, à sua estrutura interna e à sua composição. Normalmente, o dimensionamento do compósito é um processo iterativo, iniciando com dados objetivos e limites. Os procedimentos são normalmente baseados na experiência prévia com o uso extensivo de uma abordagem de tentativo e erro. Além disso, o método tradicional do projeto do material (cálculo do traço) é baseado no critério de resistência à compressão em conjunto com o critério de trabalhabilidade, desprezando portanto a importância da fragilidade intrínseca (micro-mecânica) do material como fator que governa o comportamento. Esses métodos são portanto considerados vagos e não diretos, e os resultados dependem da experiência do engenheiro.

Os métodos de otimização têm como objetivo indicar parâmetros para 0 dimensionamento racional do material. O método é considerado importante, e em muitos casos, até necessário, para apoiar os métodos tradicionais pela sua abordagem objetiva. Isso é em particular, de grande valia no dimensionamento de materiais compósitos onde, devido a um grande numero de variáveis, qualquer abordagem intuitiva de dimensionamento é difícil.

A modelagem micro-mecânico portanto tem um papel muito importante na engenharia sistemática de compósitos cimentíceos, diminuindo o empirismo na engenharia de materiais, e fazendo possível o objetivo de engenhar a micro-estrutura, e consequentemente fornecendo a força motriz para a seleção crítica de adições, agregados e fibras em compósito armados com fibras. Em conjunto com o otimização pode-se obter uma receita ótima proporcionando um dimensionamento racional e baseado em objetivos, e assim suprindo as necessidades da sociedade.

O conhecimento micro-mecânico dos concretos e seus compósitos é o indicador barométrico do avanço científico na engenharia de materiais cimentíceos em geral, e os concretos armados com fibras em particular. Alimentando a técnica de otimização de material, a modelagem micro-mecânica e a otimização de compósitos são duas técnicas que, em conjunto, representam a ferramenta básica para o 
desenvolvimento de compósitos avançados a base de cimento para a engenharia civil. São portanto a força motriz no avanço tecnológico no desenvolvimento de novos concretos para a engenharia civil. Uma futura pesquisa será portanto, a partir dos modelos micro-mecânicos obtidos para vários carregamentos, otimizar a estrutura e composição de concretos armados com fibras para fins específicos.

\section{Modelagem macro-mecânica e Análise de estruturas de concreto armado com fibras}

No capítulo 4, os modelos macro-mecânicos propostos foram empregados apenas para o caso de tração, aplicável para o cálculo de espaçamento e abertura de fissura. Além do mais, o modelo de STANG E AARRE (1992), não foi abordado numericamente devido ao esforço computacional exigido. Este modelo portanto não foi empregado no cálculo de abertura e espaçamento de fissuras, por não se dispõe de ferramenta (software) capaz de manipular as expressões analíticas. Portanto, deixouse este modelo para uma futura pesquisa da macro-estrutura sob carregamento de tração. Nessa análise estrutural, o compósito seria o previamente otimizado. 


\section{CAPÍTULO}

SETE

\section{APÊNDICE}

\section{APÊNDICE I: DEDUÇÃO DA RELAÇÃO TENSÃO-ABERTURA DE FISSURA PRÉ-PICO DO COMPÓSITO}

\section{Apêndice Ia}

$L_{r} \leq l_{f} \leq 2 L_{c}$

Para o caso de $L_{r} \leq l_{f} \leq 2 L_{c}$, o espaço de ruptura da fibra é igual a $S_{\Phi b}$ (figura 3.10b), e todas as fibras intactas estão na face de deslizamento quando o COD, $\delta$ igual a $\delta^{*}$. A tensão de travejamento das fibras pré-pico do compósito é composta de três contribuições das fibras individuais. Para as fibras com comprimento embutido $\ell$ maior que $L_{c} e^{-f \Phi}$, a sua contribuição é pela perda de aderência. Cada fibra neste caso começa a perder a aderência no momento da aplicação do carregamento e rompe eventualmente quando $\circ \mathrm{COD}$ atinge $\delta_{c} e^{-2 f \Phi}$. Após a sua ruptura, a contribuição dessas fibras ao valor de $\sigma_{c}$ é descontada. A contribuição do segundo grupo também é pela perda de aderência. Entretanto, as fibras nesse grupo passam para o terceiro 
grupo com o aumento de $\delta$. São as fibras para as quais $\ell$ menor que $L_{c} e^{-f \Phi}$. A contribuição das fibras do terceiro grupo é por deslizamento das fibras.

Portanto, para o primeiro grupo $\ell \geq l_{u}$.e portanto, $x \geq \hat{l}_{u}$. Devido ao fato de as fibras do primeiro grupo estarem composta de apenas fibras que eventualmente rompem, é necessário que $\Phi \geq \Phi_{b}$. Portanto, de (3- 62) em (3-71) tem-se:

$$
\sigma_{c l}=\frac{V_{f}}{2} \int_{\Phi_{b}}^{\frac{\pi}{2}} \int_{\hat{l}_{u}}^{1} \sigma_{d} U\left(\delta_{c} e^{-2 f \Phi}-\delta\right) e^{f \Phi} \operatorname{sen} 2 \Phi d x d \Phi
$$

substituindo $U\left(\delta_{c} e^{-2 f \Phi}-\delta\right)$ em (A- 1) tem-se:

$$
\sigma_{c 1}=\frac{V_{f}}{2} \int_{\Phi_{b}}^{\Phi_{c}} \int_{\hat{l}_{u}}^{l} \sigma_{d} e^{f \Phi} \operatorname{sen} 2 \Phi d x d \Phi
$$

A contribuição das fibras do segundo grupo é composta da contribuição de todas as fibras orientadas $\left(0 \leq \Phi \leq \Phi_{b}\right)$ tal que as mesmas não rompem (qualquer que seja o seu comprimento embutido), como também outras fibras com comprimento embutido muito curto $\left(\ell<l_{u}\right)$ tal que não permite a ruptura das fibras. As fibras do segundo grupo eventualmente se deslizam. Durante a perda de aderência, é necessário que $\delta \leq \delta_{o} \Rightarrow x \geq x_{o}$, onde $x_{o}=\left(\frac{\hat{\delta}}{\hat{\delta}^{*}}\right)^{\frac{1}{2}}$ e portanto,

$$
\sigma_{c 2}=\frac{V_{f}}{2}\left\{\int_{0}^{\Phi_{b}} \int_{x_{o}}^{l} \sigma_{d} e^{f \Phi} \operatorname{sen} 2 \Phi d x d \Phi+\int_{\Phi_{b}}^{\frac{\pi}{2}} \int_{x_{o}}^{\hat{l}_{u}} \sigma_{d} e^{f \Phi} \operatorname{sen} 2 \Phi d x d \Phi\right\}
$$

O limite inferior de $x$ definido por (3- 70), em (A-3) garante que apenas as fibras que não perderam completamente a aderência são consideradas na contribuição. O limite superior de $x$ no segundo termo da direita de (A-3) garante que apenas aquelas fibras que eventualmente vão deslizar (em vez de romper) são consideradas na contribuição. Como $x_{o} \leq \hat{l}_{u}$, a equação (A-3) pode ser escrita como: 


$$
\sigma_{c 2}=\frac{V_{f}}{2}\left\{\int_{0}^{\Phi_{b}} \int_{x_{o}}^{1} \sigma_{d} e^{f \Phi} \operatorname{sen} 2 \Phi d x d \Phi+\int_{\Phi_{b}}^{\Phi_{c}} \int_{x_{o}}^{\hat{l}_{u}} \sigma_{d} e^{f \Phi} \operatorname{sen} 2 \Phi d x d \Phi\right\}
$$

As fibras no segundo grupo que perderam a aderência, passam portanto ao terceiro grupo. Durante o deslizamento, tem-se $\delta \leq l \Rightarrow x \geq \hat{\delta}$, e portanto:

$$
\sigma_{c 3}=\frac{V_{f}}{2}\left\{\int_{0}^{\Phi_{b}} \int_{\delta}^{x_{0}} \sigma_{p} e^{f \Phi} \operatorname{sen} 2 \Phi d x d \Phi+\int_{\Phi_{b}}^{\frac{\pi}{2}} \int_{\delta}^{x_{o}} \sigma_{p} e^{f^{\Phi}} \operatorname{sen} 2 \Phi d x d \Phi\right\}
$$

O limite inferior de $x$ em (A- 5) garante que apenas as fibras que não perderam completamente a aderência são consideradas na contribuição. Considerando que, para aquelas fibras orientadas a um ângulo maior que $\Phi_{b}$, o comprimento embutido deve ser menor que o comprimento mínimo crítico $l_{u}$, a equação (A- 5) pode ser escrita como:

$$
\sigma_{c 3}=\frac{V_{f}}{2}\left\{\int_{0}^{\Phi_{c}} \int_{\hat{\delta}}^{x_{o}} \sigma_{p} e^{f \Phi} \operatorname{sen} 2 \Phi d x d \Phi+\int_{\Phi_{c}}^{\frac{\pi}{2}} \int_{\hat{\delta}}^{\hat{l}_{u}} \sigma_{p} e^{f \Phi} \operatorname{sen} 2 \Phi d x d \Phi\right\}
$$

Somando todas as contribuições; $\sigma_{c 1}, \sigma_{c 2}$, e $\sigma_{c 3}$ tem-se de (A- 4), (A- 5) e (A6) , a tensão de travejamento pré-pico dada por:

para $\delta \leq \delta_{c} e^{-f \pi}$ e $\Phi \leq \frac{\pi}{2}$,

$$
\begin{aligned}
\sigma_{c} & =\frac{V_{f}}{2}\left\{\int_{0}^{\Phi_{c}} \int_{x_{o}}^{l} \sigma_{d} e^{f \Phi} \operatorname{sen} 2 \Phi d x d \Phi+\int_{0}^{\Phi_{c}} \int_{\delta}^{x_{o}} \sigma_{p} e^{f \Phi} \operatorname{sen} 2 \Phi d x d \Phi+\right. \\
& \left.+\int_{\Phi_{c}}^{\frac{\pi}{2}} \int_{\hat{\delta}}^{\hat{l}_{u}} \sigma_{p} e^{f \Phi} \operatorname{sen} 2 \Phi d x d \Phi\right\}
\end{aligned}
$$

Substituindo as equações (3- 34) e (3- 36) em (A- 7) tem-se: 


$$
\sigma_{c}=\frac{V_{f}}{2}\left\{\int_{0}^{\frac{\pi}{2}} \int_{x_{o}}^{l} \sigma_{d} e^{f \Phi} \operatorname{sen} 2 \Phi d x d \Phi+\int_{0}^{\frac{\pi}{2}} \int_{\hat{\delta}}^{x_{o}} \sigma_{p} e^{f \Phi} \operatorname{sen} 2 \Phi d x d \Phi\right\}
$$

Para $\delta \leq \delta_{c} e^{-f \pi} e \Phi \leq \frac{\pi}{2}$

$$
\sigma_{c}=\sigma_{o} g\left[2\left(\frac{\hat{\delta}}{\hat{\delta}^{*}}\right)^{\frac{1}{2}}-\left(\frac{\hat{\delta}}{\hat{\delta}^{*}}\right)-\frac{4}{3} \hat{\delta}^{*}\left(\frac{\hat{\delta}}{\hat{\delta}^{*}}\right)^{\frac{3}{2}}+\hat{\delta}^{2}-\frac{2}{3} \hat{\delta}^{*} \hat{\delta}^{3}\right]
$$

Para $\delta_{c} e^{-f \pi} \leq \delta \leq \delta^{*}$,

$$
\begin{aligned}
& \sigma_{c}=\sigma_{o}\left\{g\left(\Phi_{c}\right)\left[2\left(\frac{\hat{\delta}}{\hat{\delta}^{*}}\right)^{\frac{1}{2}}-\left(\frac{\hat{\delta}}{\hat{\delta}^{*}}\right)-\frac{4}{3} \hat{\delta}^{*}\left(\frac{\hat{\delta}}{\hat{\delta}^{*}}\right)^{\frac{3}{2}}+\hat{\delta}^{2}-\frac{2}{3} \hat{\delta}^{*} \hat{\delta}^{3}\right]+\right. \\
& \left.+a(-f) \hat{L}_{c}^{2}-2 a(0) \hat{L}_{c} \hat{\delta}+a(f)\left[1-\frac{2}{3} \hat{\delta}^{*} \hat{\delta}\right] \hat{\delta}^{2}+\frac{2}{3} a(-2 f) \hat{L}_{c}^{3} \hat{\delta}^{*}\right\}
\end{aligned}
$$

Segundo MAALEJ ET AL. (1995), geralmente tem-se $\hat{\delta}^{*}<<1$. Neste caso, a relação $\sigma_{c}-\delta$ pré-pico se deduze uma forma simplificada dada por (3- 75) e (3- 76)

\section{Apêndice Ib}

$l_{f} \geq 2 L_{c}$

No caso de $l_{f} \geq 2 L_{c}$, o ângulo $\Phi_{b}$ igual a zero. O espaço de ruptura da fibra é $S$ e todas as fibras intactas estão na face de escorregamento quando o COD $\delta$ igual a $\delta_{c}$. Portanto, a ruptura pode ocorrer se o comprimento $\ell$ for maior que o comprimento crítico mínimo $L_{u}$. Além disso, a ruptura termina quando o COD atinge $\delta_{c}$ e não $\delta^{*}$. Fazendo $\Phi_{b}$ igual a zero as mesma expressões dadas por (A- 7) a (A- 10) são obtidas para $\sigma_{c}$. Portanto: 
Para $\delta \leq \delta_{c} e^{-f \pi} e \Phi \leq \frac{\pi}{2}$

$$
\sigma_{c}=\sigma_{o} g\left[2\left(\frac{\hat{\delta}}{\hat{\delta}^{*}}\right)^{\frac{1}{2}}-\left(\frac{\hat{\delta}}{\hat{\delta}^{*}}\right)-\frac{4}{3} \hat{\delta}^{*}\left(\frac{\hat{\delta}}{\hat{\delta}^{*}}\right)^{\frac{3}{2}}+\hat{\delta}^{2}-\frac{2}{3} \hat{\delta}^{*} \hat{\delta}^{3}\right]
$$

Para $\delta_{c} e^{-f \pi} \leq \delta \leq \delta^{*}$,

$$
\begin{aligned}
\sigma_{c} & =\sigma_{o}\left\{g\left(\Phi_{c}\right)\left[2\left(\frac{\hat{\delta}}{\hat{\delta}^{*}}\right)^{\frac{1}{2}}-\left(\frac{\hat{\delta}}{\hat{\delta}^{*}}\right)-\frac{4}{3} \hat{\delta}^{*}\left(\frac{\hat{\delta}}{\hat{\delta}^{*}}\right)^{\frac{3}{2}}+\hat{\delta}^{2}-\frac{2}{3} \hat{\delta}^{*} \hat{\delta}^{3}\right]\right. \\
& \left.+a(-f) \hat{L}_{c}^{2}-2 a(0) \hat{L}_{c} \hat{\delta}+a(f)\left[1-\frac{2}{3} \hat{\delta}^{*} \hat{\delta}\right] \hat{\delta}^{2}+\frac{2}{3} a(-2 f) \hat{L}_{c}^{3} \hat{\delta}^{*}\right\}
\end{aligned}
$$

Como anteriormente mencionado, geralmente $\delta^{*}<<1$. Portanto (3- 79) e (3- 80)

\section{APÊNDICE II: DEDUÇÃO DA RELAÇÃO TENSÃO-ABERTURA DE FISSURA Pós-PICO DO COMPÓsITO}

\section{Apêndice IIa}

$L_{r} \leq l_{f} \leq 2 L_{c}$

Determinada a relação tensão-abertura de fissura pré-pico, segue-se o mesmo princípio para deduzir as contribuições das fibras na fase pós-pico. A relação tensão de travejamento-deslocamento pós-pico do compósito define a parte inicial da curva $\sigma_{c}-\delta$ que corresponde ao estágio de deslizamento de todas as fibras que sobreviveram a ruptura. Considera-se os mesmos intervalos como no caso pré-pico.

Considerando o caso de $L_{r} \leq l_{f} \leq 2 L_{c}$, para $\delta \geq \delta^{*}$, todas as fibras estariam se deslizando. Entretanto, a contribuição das fibras que romperam na face pré-pico deve ser descontadas no cálculo da tensão de travejamento do compósito. A tensão de 
travejamento pós-pico do compósito é composta da contribuição das fibras do terceiro grupo das face pré-pico. Da equação (A-6) e usando os limites apropriados, tem-se:

$$
\sigma_{c 3}=\frac{V_{f}}{2}\left\{\int_{0}^{\Phi_{b}} \int_{\hat{\delta}}^{1} \sigma_{p} e^{f \Phi} \operatorname{sen} 2 \Phi d x d \Phi+\int_{\Phi_{b}}^{\frac{\pi}{2}} \int_{\hat{\delta}}^{\hat{l}_{u}} \sigma_{p} e^{f \Phi} \operatorname{sen} 2 \Phi d x d \Phi\right\}
$$

$\mathrm{Na}$ equação (A-13), o limite inferior de $x$ garante que apenas aquelas fibras que não forem totalmente arrancadas são consideradas contribuindo para $\sigma_{c}$. O limite superior do segundo membro da direita na equação garante que apenas as fibras que não romperam são consideradas contribuindo para $\sigma_{c}$. Considerando-se que, para aquelas fibras orientadas com um ângulo maior que $\Phi_{b}$, o comprimento embutido deve ser menor que o comprimento mínimo crítico $l_{u}$, a equação $(\mathbf{A}-7)$ pode ser escrita como:

$$
\sigma_{c 3}=\frac{V_{f}}{2}\left\{\int_{0}^{\Phi_{b}} \int_{\hat{\delta}}^{1} \sigma_{p} e^{f \Phi} \operatorname{sen} 2 \Phi d x d \Phi+\int_{\Phi_{b}}^{\Phi_{a}} \int_{\hat{\delta}}^{\hat{l}_{u}} \sigma_{p} e^{f \Phi} \operatorname{sen} 2 \Phi d x d \Phi\right\}
$$

Fazendo $\Phi=\frac{\pi}{2}$ em (A-14) tem-se:

Para $\delta^{*} \leq \delta \leq L_{c} e^{-f \frac{\pi}{2}}$

$$
\begin{aligned}
\sigma_{c}= & \sigma_{o}\left\{g\left(\Phi_{b}\right)\left[(1-\hat{\delta})^{2}+\frac{2}{3} \hat{\delta}^{*}\left(1-\hat{\delta}^{3}\right)\right]+b(-f) \hat{L}_{c}^{2}-2 b(0) \hat{L}_{c} \hat{\delta}+\right. \\
& \left.+b(f)\left(1-\frac{2}{3} \hat{\delta}^{*} \hat{\delta}\right) \hat{\delta}^{2}+\frac{2}{3} b(-2 f) \hat{L}_{c}^{3} \hat{\delta}^{*}\right\}
\end{aligned}
$$


Para $L_{c} e^{-f \frac{\pi}{2}} \leq \delta \leq \frac{l_{f}}{2}$,

$$
\begin{aligned}
\sigma_{c}= & \sigma_{o}\left\{g\left(\Phi_{b}\right)\left[(1-\hat{\delta})^{2}+\frac{2}{3} \hat{\delta}^{*}\left(1-\hat{\delta}^{3}\right)\right]+c(-f) \hat{L}_{c}^{2}-2 c(0) \hat{L}_{c} \hat{\boldsymbol{\delta}}\right. \\
& \left.+c(f)\left(1-\frac{2}{3} \hat{\delta}^{*} \hat{\delta}\right) \hat{\delta}^{2}+\frac{2}{3} c(-2 f) \hat{L}_{c}^{3} \hat{\delta}^{*}\right\}
\end{aligned}
$$

Considerando-se novamente que, geralmente $\hat{\delta}^{*}<<1$, as equações (A- 15) e (A-16) podem ser escritas como (3- 81) e (3-82)

\section{Apêndice IIb}

$l_{f}>2 L_{c}$

Analisando-se o intervalo $l_{f}>2 L_{c}$, a relação tensão-abertura de fissura, $\sigma-\delta$, pós-pico pode ser obtida fazendo $\Phi_{a}=0$ nas equações (A-15) e (A- 16).

Para $\delta_{c} \leq \delta \leq L_{c} e^{-f \frac{\pi}{2}} \Rightarrow \hat{\delta}_{c} \leq \hat{\delta} \leq \hat{L}_{c} e^{-f \frac{\pi}{2}}$

$$
\sigma_{c}=\sigma_{o}\left[g_{1} \hat{L}_{c}^{2}-2 \hat{L_{c}} \hat{\delta}+g\left(1-\frac{2}{3} \hat{\delta}^{*} \hat{\delta}\right) \hat{\delta}^{2}+\frac{2}{3} g_{2} \hat{L}_{c}^{3} \hat{\boldsymbol{\delta}}^{*}\right]
$$

Para $L_{c} e^{-f \frac{\pi}{2}} \leq \delta \leq L_{c} \Rightarrow \hat{L}_{c} e^{-f \frac{\pi}{2}} \leq \hat{\delta} \leq \hat{L}_{c}$

$$
\sigma_{c}=\sigma_{o}\left[d(-f) \hat{L}_{c}^{2}-2 d(0) \hat{L}_{c} \hat{\delta}+d(f)\left(1-\frac{2}{3} \hat{\delta}^{*} \hat{\delta}\right) \hat{\delta}^{2}+\frac{2}{3} d(-2 f) \hat{L}_{c}^{3} \hat{\delta}^{3}\right]
$$

Observa-se da equação (A- 18) que ${\lim \delta \rightarrow L_{c}}_{c} \sigma_{c}=0$. Para $\hat{\delta}^{*}<<1$, a relações $\sigma_{c}-\delta$ pós-pico dadas por (A-17) e (A-18) se reduzem para (3- 86) e (3- 87) 


\section{APÊNDICE III: RELAÇÃO TENSÃO-ABERTURA DE FISSURA SEM CONSIDERAÇÃO DA RUPTURA DAS FIBRAS}

As vezes, por motivos de simplificação, pode ser interessante desprezar a contribuição das fibras que potencialmente rompem. Isso implica a consideração de apenas a contribuição das fibras na fase pré-pico. Para descontar a contribuição dessas fibras da tensão de travejamento do compósito, subtrai-se $\sigma_{c}$, definida pela equação (3- 75) de (3- 83) para $\delta \leq \delta_{c} e^{-f \pi}$ e de (3- 84) para $\delta_{c} e^{-f \pi} \leq \delta \leq \delta_{p}$ (onde $\delta_{p}=\delta^{*}$ para $L_{r} \leq L_{f} \leq 2 L_{c}$ e $\delta_{p}=\delta_{c}$ para $\left.l_{f} \geq 2 L_{c}\right)$.

$L_{r} \leq l_{f} \leq 2 L_{c}$

Considerando-se o intervalo $L_{r} \leq l_{f} \leq 2 L_{c}$, a tensão de travejamento é calculada de (3-76). Portanto tem-se:

$>$ Para $\delta \leq \delta_{c} e^{-f \pi} ;$ ou $\left(\hat{\delta} \leq \hat{\delta}_{c} e^{-f \pi}\right) \Rightarrow \Phi_{c}=\frac{\pi}{2}$,

$$
\sigma_{c l}=2 \sigma_{o}\left(\frac{\hat{\delta}}{\hat{\delta}^{*}}\right)^{\frac{1}{2}}\left\{\left[\left(\frac{1+\cos \left(2 \Phi_{b}\right)}{2}\right) \hat{L}_{c}\right]-k\left(\Phi_{b}, \frac{\pi}{2}\right)\right\}
$$

onde;

$$
k(u, v)=\frac{1}{4+f^{2}}\left\{[f \operatorname{sen}(2 u)-2 \cos (2 u)] e^{f u}+[2 \cos (2 v)-f \operatorname{sen}(2 v)] e^{f v}\right\}
$$

$>\operatorname{Para} \delta_{c} e^{-f \pi} \leq \delta \leq \delta^{*} ;$ ou $\left(\hat{\delta}_{c} e^{-f \pi} \leq \hat{\delta} \leq \hat{\delta}^{*}\right)$,

$$
\sigma_{c l}=2 \sigma_{o}\left(\frac{\hat{\delta}}{\hat{\delta}^{*}}\right)^{\frac{1}{2}}\left\{\left[\left(\frac{\cos \left(2 \Phi_{c}\right)-\cos \left(2 \Phi_{b}\right)}{2}\right) \hat{L}_{c}\right]-k\left(\Phi_{b}, \Phi_{c}\right)\right\}
$$


$l_{f} \geq 2 L_{c}$

Para o intervalo $l_{f} \geq 2 L_{c}$, calcula-se a tensão de travejamento fazendo $\Phi_{b}=0$ na equação (3-76). Isso resulta:

$>$ Para $\delta \leq \delta_{c} e^{-f \pi} ;$ ou $\left(\hat{\delta} \leq \hat{\delta}_{c} e^{-f \pi}\right) \Rightarrow \Phi_{c}=\frac{\pi}{2}$

$$
\sigma_{c 1}=2 \sigma_{o}\left(\frac{\hat{\delta}}{\hat{\delta}^{*}}\right)^{\frac{1}{2}}\left[g-\hat{L}_{c}\right]
$$

$>\operatorname{Para} \delta_{c} e^{-f \pi} \leq \delta \leq \delta_{c}\left(\hat{\delta}_{c} e^{-f \pi} \leq \hat{\delta} \leq \hat{\delta}_{c}\right)$,

$$
\sigma_{c 1}=2 \sigma_{o}\left(\frac{\hat{\delta}}{\hat{\delta}^{*}}\right)^{\frac{1}{2}}\left\{\left[\left(\frac{\cos \left(2 \Phi_{c}\right)-1}{2}\right) \hat{L}_{c}\right]-k\left(0, \Phi_{c}\right)\right\}
$$




\section{CAPÍTULO}

OITO

\section{REFERÊNCIA BIBLIOGRÁFICA}

AARRE, TINE; (1992). Tensile Characteristics of FRC with Special Emphasis on its applicability in a Continuous Pavement, PhD Theses, Technical University of Denmark.

ABNT - Projeto e Execução de Obras de Concreto Armado -,NB-1 (NBR 6118); 1978, Rio de Janeiro, JR

ABNT - Projeto e Execução de Estrururas de Concreto Pré-moldado - Procedimentos; NBR-9062.

ABRISHAMI, HOMAYOUN H.; MITCHEL, DENIS; (1997). Influence of Steel Fibers on Tension Stiffening, ACl Structural Journal, v. 94, n. 6, p. 769-776, Nov.-Dec.

ACI COMMITTEE 224R-90. Controle of Cracking in Concrete Structures; Manual of Concrete Practice Part 3; 1994, American Concrete Institute.

ACI COMMITTEE 544 (1988). Design Considerations for Steel Fiber Reinforced Concrete, ACl Structural Journal, v. 85, n. 5, p. 563-580, Set-Out.

ALLEN, A. H.; (1995) Reinforced Concrete Design to BS-8110 Simply Explained; Apendice. E \$ FN Spon. p. 224-229.

AL-TAAN, S. A; AL-FEEL, J. R; (1989). Prediction of Crack Width in Fibrous Reinforced Concrete Members, In: SWAMY, R. N; BARR, B, ed. Fibre Reinforced Cements and Concretes: Recent Developments. London / New York, Elsevier Applied Science. $p$. 209-218 
BALAGURU, P. N.; SHAH, S. P.; (1992). Fiber Reinforced cement Composites. New York. McGraw-Hill Book CO., Inc.

BALÁZS, GYÖRGY L.; (1993). Cracking Analysis Based on Slip and Bond Stresses, ACI Material Journal, v. 90, n. 4, p. 340-348, Julho-Agosto.

BALÁZS, GYÖRGY I.; JACCOUD, JEAN-PAUL; NÜRNBERGEROVÁ, TERESIA; HÁJEK, JAN; PITONAK, ANDREJ; SEIBEL, PETRA; LENKEI, PÉTER; DEÁK, GYÖRGY; HANZA, ISTVÁN; (1997). Bond Behaviour. In: Serviceability Models: Behaviour and Modelling in Serviceability Limit States Including Repeated and Sustained Loads. CEB Bulletin d'Information, n.235, cap. 1, p.1-46 .avril.

BALÁZS, GYÖRGY L; KOCH; RAINER; (1997). Bond Behaviour. In: Serviceability Models: Behaviour and Modelling in Serviceability Limit States Including Repeated and Sustained Loads. CEB Bulletin d'Information, n.235, cap. 2, p.86-104 .avril.

BAO, G.; SONG, Y.; (1993). Crack Bridging for Fiber Composites with Slip-Dependent Interfaces. Journal of Mechanics and Physics of Solids, v. 41, n. 9, p. 1425-1444.

BARENBLATT, G. I.; (1995). The Scaling Laws and Renormalization Group in the Mechanics and Micromechanics of Fracture. In BACKER, G.; KARIHALOO, B. L., ed., Fracture of Brittle Disordered materials: Concrete, Rock and Ceramics.. London/Glasow. E \& FN SPON

BARR, B.; GETTU, R.; AL-ORQIMI, S. K. A. (1996) Toughness Measurment - the Need to Think Again, Cement and Concrete Composites, v. 18, p. 281-297.

BAYASI, ZIAD; ZENG, A. K; (1993). Properties of Polypropylene Fiber-Reinforced Concrete, ACI Material Journal, v. 90, n. 6, p. 605-610, Novembro-Dezembro.

BAZANT, ZDENEK P.; SENER, SIDDIK; (1987). Size Effect in Pullout Tests, ACI Material Journal, v. 85, n. 5, p. 347-351, Set.-Out.

BEEBY, A W.; (1972) A Study of Cracking in Members Subjected to Pur Tension, Cement and Concrete Association, Technical Report 42.468, London.

BEEBY, A W.; KEYDER, E.; TAYLOR,H. P. J.; (1972) Cracking and Deformation of Partially Prestressed Concrete Beams. Cement and Concrete Association. Technical Report 42.465, London.

BEEBY, A. W.; (1979). The Prediction of Crack Widths in Hardened Concrete, The Structural Engineer, v. 57 A, n. 1, Janeiro.

BENAICHE, F.; BARR, B.; (1989). Fracture Characteristics of High Strength Concrete and FRC Materials, p. 411-433. In SWAMY, R. N.; BARR, B, ed. Fibre Reinforced Cements and Concretes: Recent Developments. London/New York, Elservier Applied Science 
BENTUR, ARNON; DIAMOND, SIDNEY; MINDESS, SIDNEY; (1985). Cracking Processes in Steel Fiber Reinforced Cement Paste, Cement and Concrete Research, v. 15, p. 331-342.

BENTUR, ARNON; MINDESS, SIDNEY; (1990). Fibre Reinforced Cementitious Composites, Cap. 1, 2, 3, 4, 5, 6, 7, 10, 12. London / New York, Elsevier Applied Science.

BOLANDER JR., J. E.; SAITO, S.; (1997). Discrete Modeling of Short-Fiber Reinforcement in Cementitious Composites, Advanced Cement Basesd Materials, v. 6, p. 76-86.

CHI, MICHAEL; KIRSTEIN, ARTHUR F.; (1957). Flexural Cracks in Reinforced Concrete Beams, ACI Proceedings, v. 29, n. 10, p. 865-878, Abril.

CEB-FIP (1993). Verification of Serviceability Limit States. In: Thomas Telford, ed. CEB-FIP Model Code 1990: Design Code, CEB Bulletin d'Information, n.213/214, Cap. 7, pg. 241-263. London.

CHI, MICHAEL; KIRSTEIN, ARTHUR F., (1953). Flexural Cracks i Reinforced Concrete Beams, Journal of American Concrete Institute, v. 29, n. 1, p. 865-879.

CLYNE, T, W.; WITHERS, P. J; (1993). An Introduction to Metal Matrix Composites, Cap. 2. Cambridge University Press.

COTTERELL, B; MAI, Y. W.; (1996). Fracture Mechanics of Cementitious Materials. London/Glasgow/Weinheim/New York/Tokyo/Melbourne/Madras.Blackie Academic \& Professional.

DESAYI PRAKASH; EL-KHOLY, SAID A.; (1991). Lightweight Fibre-Reinforced Ferrocement in Tension, Cement \& Concrete Composites, v 13, p. 37-48.

DU, JIAJI; HAWKINS, N. M.; KOBAYASHI, A. S.; (1989). A Hybrid Analysis of Fracture Process Zone in Concrete. In: SHAH, S. P.; SWARTZ, S. E.; BARR, B., ed. Fracture of Concrete and Rock: Recent Developments. London/New York, Elservier Applied Science. p. 297-305.

DUDA, H.; KÖNIG, G.; (1992). Stress-Crack Opening Relation and Size Effect in Concrete. In: CARPINTERI, ALBERTO, ed. Application of Fracture Mechanics to Reinforced Concrete. London/New York, Elsevier Applied Science. Cap. 3, p. 45-61.

EI DEBS, M. K.; EKANE, B. E,; (1998) Tension Tests of Mortar Reinforcad with Steel Meshes and Polymeric Fibers, Proceedings of the Sixth International Symposium on Ferrociment - Lambot Symposium, v. 6, p. 403-414.

EL DEBS, M. K.; NAAMAN, A. E.; (1995). Bending Behaviour of Mortar Reinforced with Steel Meshes and Polymeric Fibers, Cement \& Concrete Composites, v. 17, n. 4, p. 327-338. 
EL DEBS, M. K; NAAMAN, A. E; (1995). Bending Behaviour of Mortar Reinforced With Steel Meshes and Polymeric Fibers. Report N. UMCEE 95-04.Michigan.

EUROPEAN STANDARD (EUROCODE-2) Basis of Design and Actions on Structures; European Committee for Standardization, 1993.

EUROCOD-2; (1991). The Design of Concrete Structures, Part 1: General Rules and Rules for Buildings, Revised Final Draft approved bu EC2 Editoral Groop.

EZELDIN, SAMEN; BALAGURU, P. N.; (1989). Bond Behaviour of Normal and HighStrength Fiber Reinforced Concrete, ACl Material Journal, v. 86, n. 5, p. 515-524, Set.-Out.

GAO, JIANMING; SUN, WEI; MORINO, KEIJI; (1997) Mechanical Properties of Steel Fiber-Reinforced, High-strength, Lightweight Concrete, Cement and Concrete Composites, v. 19, p. 307-313.

GENG, Y.; LEUNG, C. K. Y.; (1996). A Micromechanical Study of Fibre/Mortar Interfaces During Fibre Debonding and Pullout, Journal of Materials Science, v. 31, p. $1285-1294$.

HANAI, J.B (1996). Argamassa Armada, Volume 2: Projeto Estrutural e Dimensionamento com Telas Soldadas.

HANNANT, D. J.;(1972). The Tensile Strength of Concrete: A Review Paper, The Structural Engineer, v. 50, n. 7, p. 253-258.

HILLERBORG, A; (1989). Stability Problems in Fractue Mechanics Testing, In: SHAH, S. P.; SWARTZ, S. E.; BARR, B., ed. Fracture of Concrete and Rock: Recent Developments. London/New York, Elservier Applied Science. p. 369-378.

HILLERBORG, A; MODÉER, M.; PETERSSON, P. -E.; (1976). Analysis of Crack Formation and Crack growth by Means of fracture mechanics and Finite Elements, Cement and Concrete Research, v. 6 n. 6 p. 773-782.

HOTA, SIVA; NAAMAN ANTOINE E.; (1997). Bond Stress-Slip Response of Reinforcing Bars Embedded in FRC Matrices under Monotonic and Cyclic Loading. ACl Structural Journal, v. 94, n. 5, p. 525-537, Set.-Out.

JACCOUD, JEAN-PAUL; (1997). Cracking Under Long Term Loads or Imposed Deformation, In: Serviceability Models: Behaviour and Modelling in Serviceability Limit States Including Repeated and Sustained Loads. CEB Bulletin d'Information, n.235, cap. 2, p. 86-104, avril.

JOHNSTON, COLIN D.; (1993). Effects of Testing Rate and Age on ASTM C 1018 Toughness Parameters and their Precision for Steel Fiber-Reinforced, Concrete, Cement, Concrete, and Aggregates, v. 15, n. 1, p. 50-58. 
KARIHALOO, BHUSHAN L.; (1995). Fracture Mechanics \& Structural Concrete. Concrete Design \& Construction Series. Longman

KATZ, A; (1996). Effect of Fiber Modulus of Elasticity on the Long Term Properties of Micro-Fiber Reinforced Cementitious Composites, Cement and Concrete Composites, v. 18, p. 389-399.

KATZ, AMNON; LI, VICTOR C.; (1995). Inclination Angle of Carbon Fibers in Cementiotious Composites, Journal of Engineering Mechanics, v. 121, n. 12, $p$. 1340-1348, Dec.

LANGE-KORNABAK, D.; KARIHALOO, B.L.; (1997). Tension Softening of FibreReinforced Cementitious Composites. Cement and Concrete Composites, v. 19, p. 315-328.

LANGE-KORNABAK, D.; KARIHALOO, B.L.; (1996). Design of Concrete Mixes for Minimum britleness, Advanced Cement Based materials, v. 3, p. 124-132.

LEUNG, C. K. Y.; LI, V. C.; (1990). Strength-Based and Fracture-Base Approaches in the Analysis of Fibre Debonding, Journal of Materials Science Letters, v. 9, p. 11401142.

LEUNG, C. K. Y.; LI, V. C.; (1991). New Strength-Based Model for the Debonding of Discontinuous Fibres in an Elastic Matrix, Journal of Materials Science, v. 26, $p$. 5996-6010.

LEUNG, CHRISTOPHER K. Y.; CHI, JEFFREY; (1995). Crack-Bridging Force in Random Ductile Fiber Brittle Matrix Composites, Journal of Engineering Mechanics, v. 121, n. 12, p. 1315-1324, Dec.

LEUNG, CHRISTOPHER K. Y.; LI, VICTOR C.; (1992). Effect of Fiber Inclination on Crack Bridging Stress in Brittle Fiber Reinforced Brittle Matrix Composites, v. 40, $n$. 6, p. 1333-1362.

LEUNG, CHRISTOPHER K. Y.; YBANEZ, NUMER; (1997). Pullout of Inclined Flexible Fiber in Cementitious Composite, Journal of Engineering Mechanics, v. 123, n. 3, p. 239-246, Março.

LI, V. C.; HASHIDA, T.; (1993). Engineering Ductile Fracture in Brittle-Matrix Composites, Journal of Materials Science Letters, v. 12, p. 898-901.

LI, V.C.; MAALEJ, M.; HASHIDA, T.; (1994). Experimental Determination of the StressCrack Opening Relation in Fibre Cementitious Composites with a Crack-Tip Singularity. Journal of Materials Science, v. 29, p. 2719-24.

LI, V. C.; STANG, H.; KRENCHEL, H.; (1993). Micromechanics of Crack Bridging in Fibre-Reinforced Concrete, Materials and Structures, v. 26. P. 486-494. 
LI, V. C.; WU, H. -C. ( 1991). Pseudo Strain-Hardening in Cementitious Composites, $p$. 371-387. In: REINHARDT, H. W.; NAAMAN, A. E., ed., High Performance Fibre Reinforced Cement Composites: Proceedings of the International RILEM / ACI Workshop London. E \& F. N. Spon.

LI, V. C.; (1992). A Simplified Micromechanical Model of Compressive Strength of Fiber-Reinforced Cementitious Composites, Cement \& Concrete Composites, v. 14, p. 131-141.

LI, VICTOR C.; (1997). Applicability of J-Integral to Tension-Softening Materials, ASCE Journal of Engineering Mechanics, v. 123, n. 5, p. 531-533, Maio.

LI, VICTOR C.; (1992). Postcrack Scaling Relations for Fiber Reinforced Cementitious Composites, Journal of Materials in Civil Engineering, v. 4, n. 1, p 41-57, Fev.

LI, VICTOR C.; CHAN, CHUN-MAN; LEUNG, CHRISTOPHER K. Y.; (1987). Experimental Determination of the Tension-Softening Relation for Cementitious Composites, Cement and Concrete Research, v. 17, p. 441-452.

LI, VICTOR C.; CHAN, YIN-WEN; (1994). Determination of Interfacial Debond Mode for Fiber-Reinforced Cementitious Composites, Journal of Engineering Mechanics, $v$. 120, n. 4, p. 707-719, Abril.

LI, VICTOR C.; LEUNG, CHRISTOPHER K. Y.; (1992). Steady-State and Multiple Cracking of short Random Fiber Composites, ASCE Journal of Engineering Mechanics, v. 118, n. 11, p. 2246-2264, novembro.

LI, VICTOR C.; LIANG, ERWING; (1986). Fracture Processes in Concrete and Fiber Reinforced Cementitious Composites, Journal of Engineering Mechanics, v. 112, $n$. 6, p. 566-587, Junho.

LI, VICTOR C.; MAALEJ, MOHAMED; (1996). Toughening in Cement Based Composites. Part I: Cement, Mortar, and Concrete, Cement \$ Concrete Composites, v. 18, p. 223-237.

LI, VICTOR C.; WANG YOUJIANG; BACKER STANLEY; (1991). A Micromechanical Model of Tension- Softening and Bridging Toughening of Short Random Fiber Reinforced Brittle Matrix Composites. Journal of Mechanics and Physics of Solids, $v$. 39, n. 5, p. 607-625.

LI, VICTOR C.; WARD, ROBERT; HAMZA, ALI M.; (1992). Steel and Synthetic Fibers as Shear Reinforcement, ACl Material Journal, v. 89, n. 5, p.49-507.

LI, VICTOR C.; WU, HWAI-CHUNG; (1992). Conditions for Pseudo-Strain Hardening in Fiber Reinforced Brittle Matrix Composites, Applied mechanics Review, v.45, n. 8, $p$. 390-398.

LIM, T. Y.; PARAMASIVAM P.; LEE, S.; (1987). Analytical Model for Tensile Behaviour of Steel-Fiber Concrete, ACl material Journal, v. 84, n. 4, p. 286-298, julho/agosto. 
LIN ZHONG; LI VICTOR, C.; (1997). Crack Bridging in Fiber Reinforced Cementitious Composites with Slip-Hardening Interfaces. Journal of Mechanics and Physics of Solids, v. 45, n. 5, p. 763-787.

LUB, K. B.; PADMOES, T.; (1989). Mechanical Behaviour of Steel Fiber-Cement Motar in Tensãoand Flexure, Interpreted by Means of Statistics, ACl Material Journal, $p$. 16-28. January-Febuary.

MAALEJ, MOHAMED; LI, V. C.; (1995). Introduction of Strain-hardening Engineering Cementitious Composites in Design of Reinforced Concrete Flexural Members for Improved Durability, ACI Structural Journal, v. 92, n. 2, p. 167-176.

MAALEJ, MOHAMED; LI, VICTOR C.; HASHIDA, TOSHITUKI; (1995). Effect of Fiber Rupture on Tensile Properties of Short Fiber Composites, Journal of Engineering Mechanics, v. 121, n. 8, p. 903-913, Agosto.

MAI, YUI-WING; (1992). Modelling Crack Toughness Curves in Fibre-Reinforced Cement Composites. In: CARPINTERI, ALBERTO, ed. Application of Fracture Mechanics to Reinforced Concrete. London / New York, Elsevier Applied Science. Cap. 8, p. 201-229.

MARSHALL, DAVID B.; OLIVER, W. C.; (1987). Measurement of Interfacial Mechanical Properties in Fiber-Reinforced Ceramic Composites, Journal of the American Ceramic Society, v. 70, n. 8, p. 542-548.

MEHTA, P. KUMAR; MONTEIRO, PAULO J. M.;(1994). Concreto: Estrutura, Propriedades, e Materiais, Cap. 3. São Paulo. Pini.

MIANOWSKI, K. M.; (1991). A New Approach to Bond and Cracks Problems in Reinforced Concrete. In: BRANDT, A. M.; MARSHALL, I. H., ed. Brittle Matrix Composites 3. London / New York, Elsevier Applied Science.

MIER VAN, J. G. M.; (1992). Scaling in Tensile and Compressive Fracture of Concrete. In: CARPINTERI, ALBERTO, ed. Application of Fracture Mechanics to Reinforced Concrete. London / New York, Elsevier Applied Science. Cap. 5, p. 95-135.

MORTON, J; GROVES, G. W.; (1974). The Cracking of Composites consisting of Discontinuous Ductile Fibers Effect of Fiber Orientation, Journal of Materials Science, v. 9, p. 1436-1445.

MORTON, J; GROVES, G. W.; (1976). The Effect of Metal wires on the Fracture of a Brittle-Matrix Composite, Journal of Materials Science, v. 11, p. 617-623.

NEVILLE, ADAM M.;(1997). Propriedades do Concreto, Cap. 12. São Paulo. Pini.

NGOLLÈ, ALBERT; PÉRA, JEAN; (1997). Microstructural Based Modelling of the Elastic Modulus of Fiber Reinforced Cement Composites, Advanced Cement Based Materials, v. 6, p. 130-137. 
OBLA, KARTHIKEYAN H.; LI, VICTOR C.; (1995). A Novel Technique for Fiber-Matrix Bond Strength Determination for Rupturing Fibers, Cement \& Concrete Composites, v. 17, p. 219-227.

OHNO, SADATOSHI; HANAT, D. J.; (1994). Modelling the Stress-Strain Response of Continuous Fiber Reinforced Cement Composites, ACl Material Journal, v. 91, n. 3, p. 306-312, Maio-Junho.

OPARA-KRSTULOVIC, NEVEN; WATSON, KIMBERLY A.; LaFAVE, JAMES M; (1994). Effect of Increased Tensile Strength and Toughness on Reinforcing-Bar Bond Behaviour, Cement \& Concrete Composites, v. 16, p. 129-141.

ORTIZ, M.; (1988). Microcrack Coalescence and Macroscopic Crack Growth Initiation in Brittle Solids, International Journal of Solids and Structures, v. 24, n. 3, p. 231-250.

OUYANG, CHENGSHENG; MOBASHER, BARZIN; SHAH, SURENDRA P.;(1992). Prediction of Fracture of Concrete and Fiber Reinforced Concrete by the $R$-Curve Approach. In: CARPINTERI, ALBERTO, ed. Application of Fracture Mechanics to Reinforced Concrete. London / New York, Elsevier Applied Science. Cap. 6, p. 137168.

PARAMASIVAM, P.; TAN, KIANG-HWEE; MURUGAPPAN, K.; (1995).Finite Element Analysis of Partially Prestressed Steel Fiber Concrete Beams in Shear, Advanced Cement Based Materials, v. 2. P. 231-239.

SÉRGIO, M.J . O Uso de Tela Soldada no combate à Fissuração.

SHAH, SURENDRA; OUYANG, CHENGSHENG; (1991). Mechanical Behavior of FiberReinforced Cement-Based Composites, Journal of American Ceramic Society, v. 74, n. 11, p. 2727-2738, 2947-2953.

SHAH. SURENDER P.; SWARTZ, STUART E.; OUYANG, CHENGSHENG, ed. (1995). Fracture Mechanics of Concrete: Applications of Fracture Mechanics to Concrete, Rock and other Quasi-Brittle Materials. Cap. 1,2, 3, 4, 5, 11, 12. New York / Chicheter / Brisane / Toronto / Singapore, Wiley-Interscience.

SOROUSHIAN, PARVIZ; KHAN, ATAULAH; HSU, JER-WEN; (1992). Mechanical Properties of Concrete Materials Reinforced with Polypropylene or Polyethylene Fibers, ACI Material Journal, v. 89, n. 6, p. 535-540, Novembro- Dezembro.

SOROUSHIAN, PARVIZ; LEE, CHA-DON; (1990). Distribution and Orientation of Fibers in Steel Fiber Reinforced Concrete, v. 87, n. 5, p. 433-439, Set.-Oct.

SPADEA, C. D. ET AL.; (1995). Fiber Reinforced Concrete Testing for Practical Application. In: STEVENS, D. J.; ET AL., ed. Testing of Fiber Reinforced Concrete: ACI Publication SP-155. 
STANG, H.; (1995). Micromechanical Parameters, Fracture Processes and Application of Fiber Reinforced Concrete, p. 131-148. In BACKER, G.; KARIHALOO, B. L., ed., Fracture of Brittle Disordered materials: Concrete, Rock and Ceramics.. London/Glasow. E \& FN SPON

STANG, H.; (1991) a . Evaluation of Properties of Cementitious Fiber Composite Materials, p. 388-403. In: REINHARDT, H. W.; NAAMAN, A. E., ed., High Performance Fibre Reinforced Cement Composites: Proceedings of the International RILEM / ACI Workshop. London. E \& F. N. Spon.

STANG, H.; LI, Z.; SHAH, S. P.; (1990). Pullout Problem: Stress versus Fracture Mechanical Approach, Journal of Engineering Mechanics, v. 116, n. 10, p. 2136 2150, outubro.

STANG, H.; SHAH, S. P.; (1986). Failure of Fibre-Reinforced Composites by Pull-Out Fracture, Journal of Materials Science, v. 21, p. 953-957.

STANG, HENRIK; (1991) ${ }^{\mathrm{b}}$. Prediction of Crack Width in Conventionally Reinforced FRC, p. 193-203. In: BRANDT, A. M.; MARSHALL, I. H.ed., Brittle Matrix Composites. London/New York. Elsevier Applied Science.

STANG, HENRIK; AARRE, TINE; (1992). Evaluation of Crack Width in FRC with Conventional Reinforcement, Cement \& Concrete Composites, v. 14, p. 143-154.

STANG, HENRIK; LI, VICTOR C.; KRENCHEL, HERBERT; (1995). Design and Structural Applications of Stress-Crack Relations in Fibre Reinforced Concrete, Materials and Structures, v. 28. P. 210-219.

STANG, HENRIK; SHAH, S. P.; (1989). Damage Evolution in FRC Materials Modelling and Experimental Observations, In: SWAMY, R. N; BARR, B, ed. Fibre Reinforced Cements and Concretes: Recent Developments. London/New York, Elsevier Applied Science. p. 378-387.

TAERWE, L.; VAN GYSEL, A.; (1996). Influence of Steel Fibers on Design StressStrain curves for High-Strength Concrete, Journal of Engineering Mechanics, v. 122, n. 8, p. 695-704, agosto.

TAN, K. H.; MURUGAPPAN, K.; PARAMASIVAM, P.; (1994). Constitutive Relation for Steel Fibre Concrete Under Biaxial Compression, Cement \& Concrete Composites, v. 16, p. 9-14.

TAN, K. H.; MURUGAPPAN, K.; PARAMASIVAM, P.; (1995). Shear Behavior of Fiber Reinforced Concrete Beams, ACI Structural Journal, v. 89, n. 6, p. 3-11.

TAN, KIANG-HWEE; PARAMASIVAM, P. TAN, KAH-CHAI; (1995). Cracking Characteristics of Reinforced steel Fiber Concrete Beam under Short- and LongTerm Loading, Advanced Cement Based Materials, v. 2, n. 4, p. 127-137, julho. 
TJIPTOBROTO, PRIJATADI; HANSEN, WILL; (1993). Model for Predicting the Elastic Strain of Fiber Reinforced Composites Containing High volume Fractions of Discontinuous Fibers, ACl material Journal, v. 90, n. 2, p. 134-142, Maço-Abril.

den UIJL, JOOP A.; BIGAJ, AGNIESZKA J; (1996). A Bond Model for Ribbed Bars Based on concrete Confinement, HERON, v. 41, n. 3, p. 201-226.

VAN MIER, J. G. M.; SCHLANGEN, E.;(1989). On the Stability of Softening Systems, In: SHAH, S. P.; SWARTZ, S. E.; BARR, B., ed. Fracture of Concrete and Rock: Recent Developments. London/New York, Elservier Applied Science. p. 387-396.

VISALVANICH, KITISAK; NAAMAN, ANTOINE E.; (1983). Fracture Model for Fiber Reinforced Concrete, ACl Journal, Title n. 80-14, Março-Abril.

WANG, YOUJIANG; LI, VICTOR C.; BACKER, STANLEY; (1990) Tensile Properties of Synthetic Fiber Reinforced Mortar, Cement and Concrete Composites, v. 12, p. 2940.

WANG YOUJIANG; LI, V.C.; BACKER, S.; (1991). Tensile Failure Mechanisms in Synthetic Fibre-Reinforced Mortar. Journal of Materials Science, v. 26, p. 6565-6575.

WARD, R. D.; LI, V. C.; (1989). Simple Dependence of Structural behavior on Material Fracture, p. 645-660. In SHAH, S. P.; SWARTZ, S. E.; BARR, B, ed. Fracture of Concrete and Rock: Recent Developments. London/New York, Elsevier Applied Science

WU, HWAI-CHUG; LI, VICTOR C.; (1994). Trade-off Between Strength and Ductility of Random Discontinuous Fiber Reinforced Cementitious Composites, Cement \& Concrete Composites, v. 16, p. 23-29.

WU, HWAI-CHUNG; MATSUMOTO, TAKASHI; LI, V. C; (1994). Buckling of Bridging Fibres in Composites, Journal of Materials Science Letters, v. 13, p. 1800-1803.

YUAN, F. G.; PAGANO, N. J.; CAI, X.; (1997). Elastic Moduli of Brittle Matrix Composites with Interfacial Bebonding, International Journal of Solids and Structures, v. 34, n. 2, p. 177-202.

YEIH, W.; HUANG, R.; CHANG, J. J.; YANG, C. C.; (1997). A Pullout Test for Determining Interface Properties between Rebar and Concrete, Advanced Cement Based Materials , v. 5, n. 2, p. 57-65.

YUAN, F. G.; PAGANO, N. J.; CAI, X.; (1997). Elastic Moduli of Brittle Matrix Composites with Interfacial Bebonding, International Journal of Solids and Structures, v. 34, n. 2, p. 177-202. 